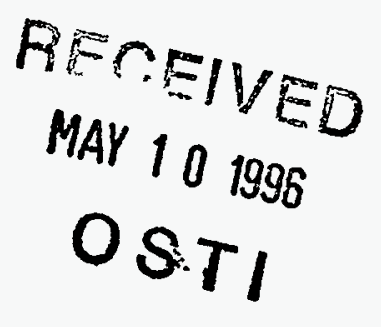

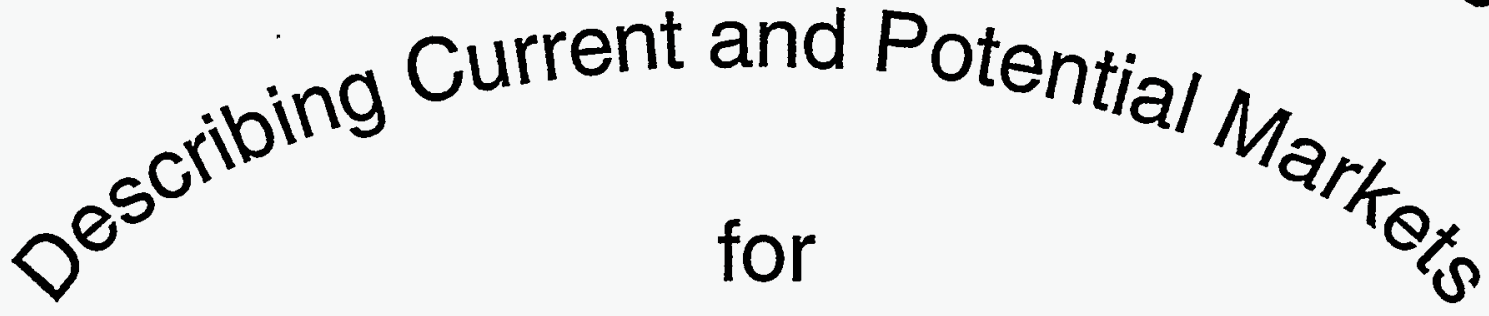

\title{
Alternative-Fuel Vehicles
}
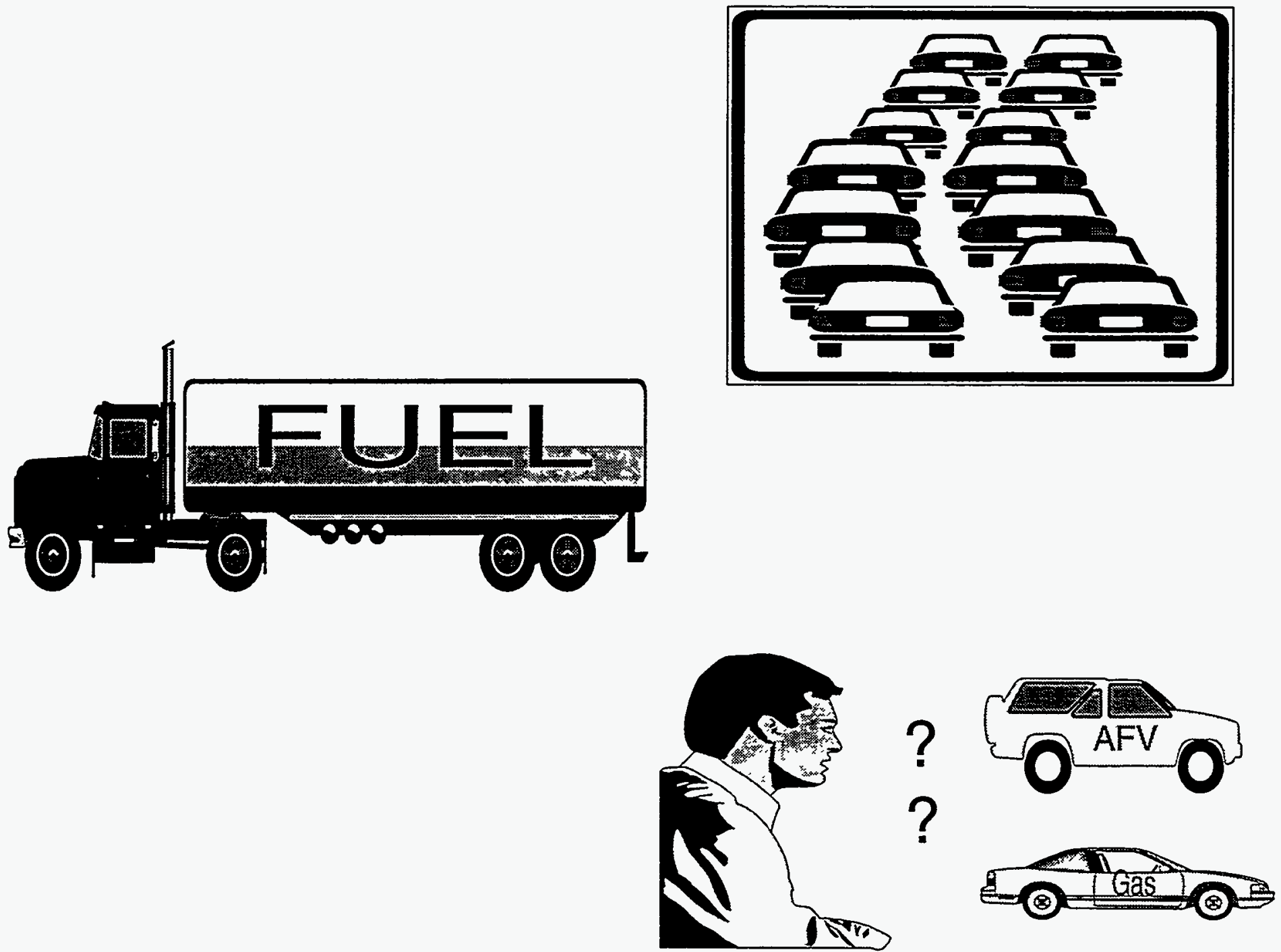
Released for Printing: March 26, 1996 
DOE/EIA-0604

Distribution Category UC-950

\title{
Describing Current and Potential Markets for Alternative-Fuel Vehicles
}

\author{
March 1996
}

\author{
Energy Information Administration \\ Office of Energy Markets and End Use \\ U.S. Department of Energy \\ Washington, D.C. 20585
}

This report was prepared by the Energy Information Administration, the independent analytical agency within the Department of Energy. The information contained herein should not be construed as advocating or reflecting any policy position of the Department of Energy or any other organization. 


\section{Contacts}

General information about Energy Information Administration (EIA) data on energy consumption can be obtained from Lynda T. Carlson, Director of the Energy End Use and Integrated Statistics Division (EEUISD) (202-586-1112). General information regarding the contents of this publication can be obtained from Dwight K. French, Chief of the Transportation and Industrial Branch (202-586-1126, Internet DFRENCH@EIA.DOE.GOV). Jennifer Reichert (202586-5736, Internet JREICHER @EIA.DOE.GOV) is the contact for the "Fleets of Alternative Fuel Providers" section of this report. Christy Hall (202-586-1068, Internet CHALL@EIA.DOE.GOV) is the contact for the "Composition of the U.S. Vehicle Stock" and "Consumer Vehicle Preferences". sections of this report. The FAX number for all EEUISD personnel is 202-586-0018.

The questionnaires administered in the alternative fuel provider fleet surveys and the consumer preference study have not been included in this report. For information regarding the alternative fuel provider fleet questionnaire, contact Jennifer Reichert. Contact Christy Hall for information concerning the consumer preference questionnaire.

EIA maintains a file transfer protocol (ftp) site on the Internet (ftp://ftp.eia.doe.gov) to allow the general public to access electronically the tables found in this report and in many of EIA's statistical reports. In addition to the tables presented in this report, there are additional tables from the alternative fuel provider fleet surveys available. For the Electric Utility Fleet Survey and the Natural Gas Supplier Fleet Survey, State-level data tables are available on the ftp site. All data tables can be found in the pub/consumption directory within the ftp site. EIA also maintains a Home Page (http://www.eia.doe.gov) on the Internet.

Special thanks are given to Ken Brown, Margaret Natof, Sylvia Norris, Linda Bromley, Mike Griffey, and Paula Weir of EIA for their patience and cooperation in the preparation and fielding of the alternative fuel provider fleet surveys. Appreciation is expressed to Dr. Stanley Presser of the University of Maryland and his students enrolled in the Joint Program in Survey Methodology for conducting the Consumer Preference Survey. Thanks are also provided to Margaret Beckham for editorial assistance.

If you have any data or report-related requirements or suggestions for any of the other EIA consumption surveys, please contact the appropriate survey manager directly or use the address below.

Commercial Buildings Energy Consumption Survey (CBECS): Martha Johnson, Survey Manager, at 202-586-1135 (Internet: MJOHNSON@EIA.DOE.GOV).

Manufacturing Energy Consumption Survey (MECS): Mark A. Schipper, Survey Manager, at 202586-1136 (Internet: MSCHIPPE@EIA.DOE.GOV).

Residential Energy Consumption Survey (RECS): Wendel Thompson, Survey Manager, at 202-5861119 (Internet: WTHOMPSO@EIA.DOE.GOV).

Residential Transportation Energy Consumption Survey (RTECS): Ron Lambrecht, Survey Manager, at 202-586-4962 (Internet: RLAMBREC@EIA.DOE.GOV).

You are encouraged to provide your comments to the survey managers. Your feedback is important to us.

EI-63, Mail Stop 2G-090

1000 Independence Avenue, SW

Washington, DC 20585

FAX: 202-586-0018 


\section{Contents}

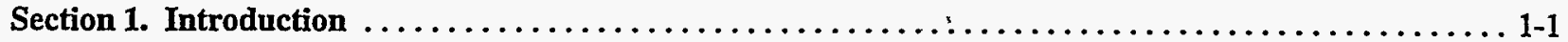

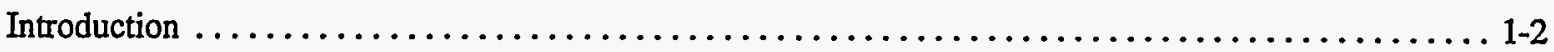

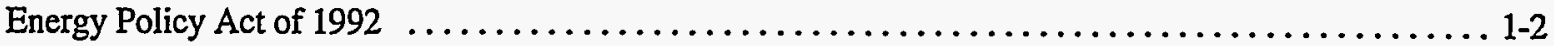

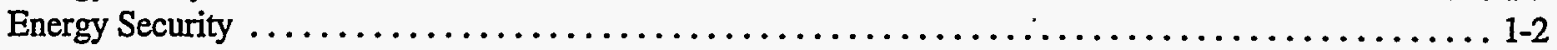

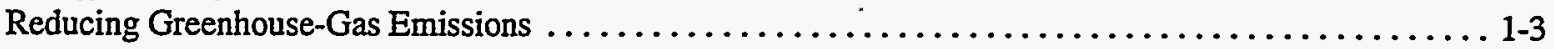

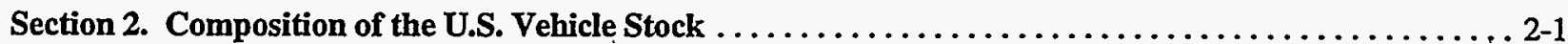

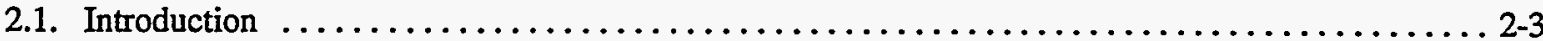

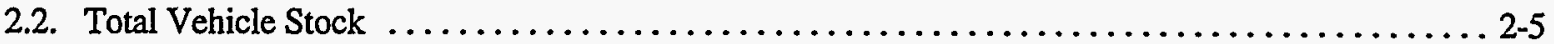

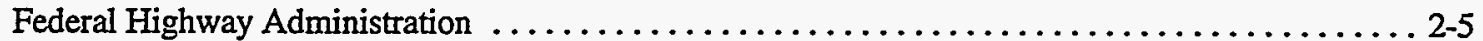

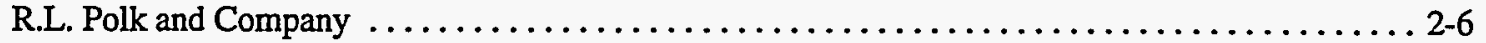

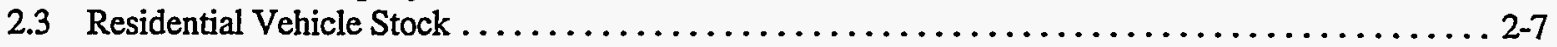

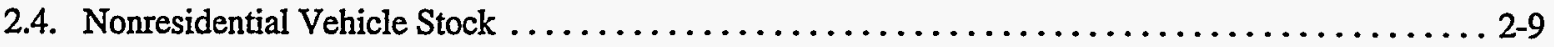

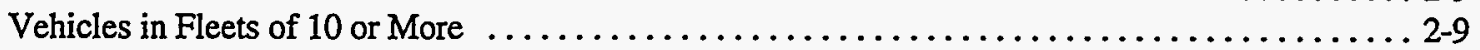

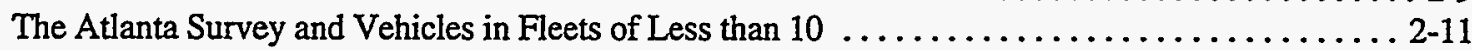

All Types of Nonresidential Vehicles .................................... 2-11

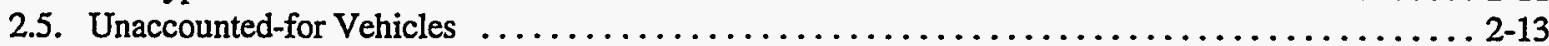

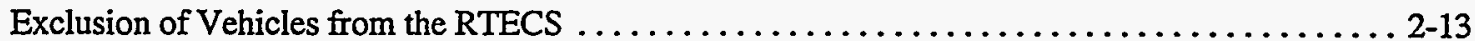

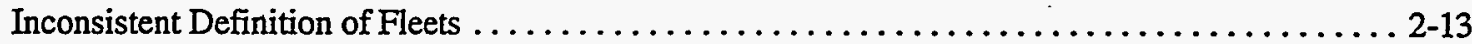

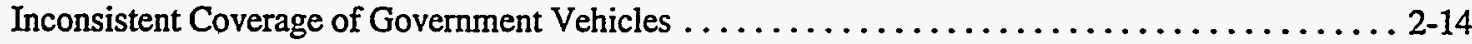

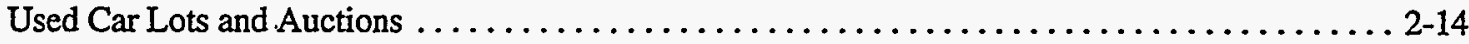

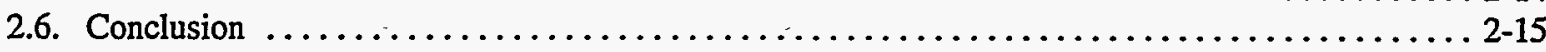

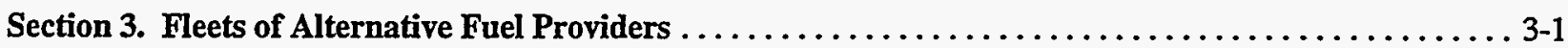

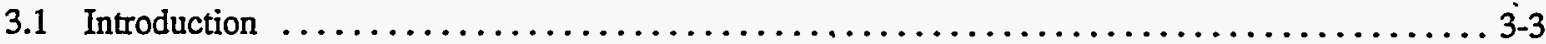

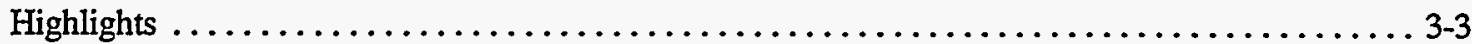

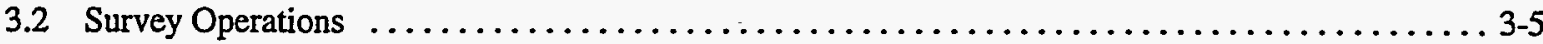

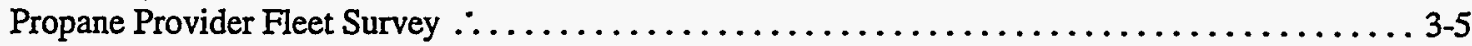

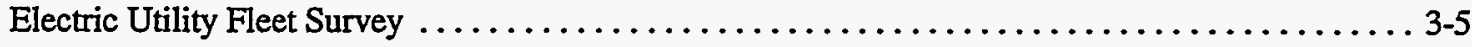

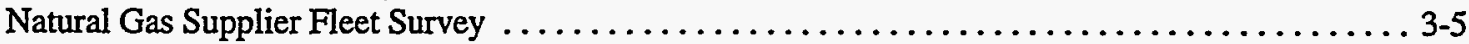

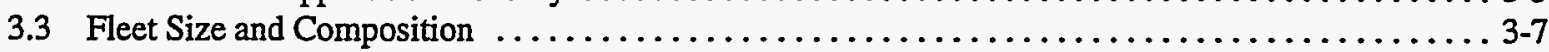

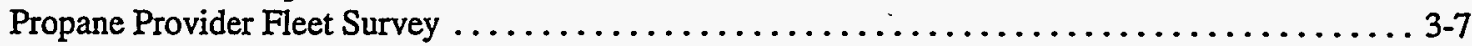

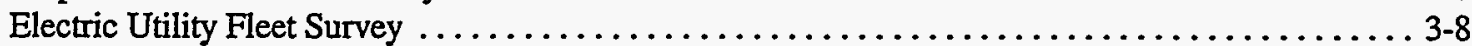

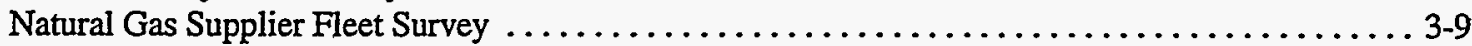

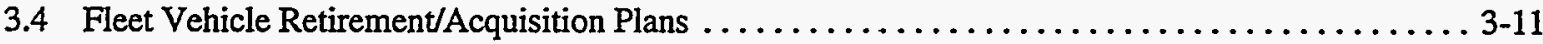

Propane Provider Fleet Survey $\ldots \ldots \ldots \ldots \ldots \ldots \ldots \ldots \ldots \ldots \ldots \ldots \ldots \ldots \ldots \ldots \ldots \ldots \ldots \ldots \ldots \ldots, 11$

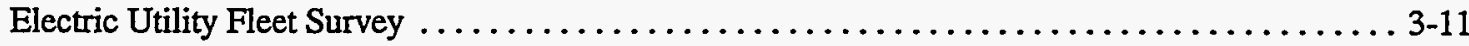

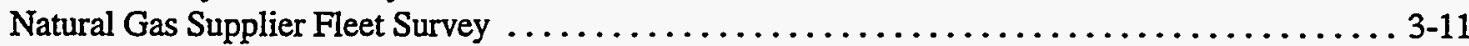

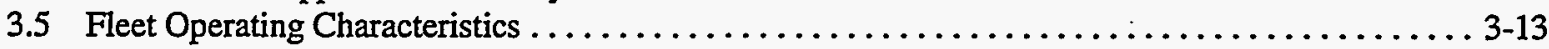

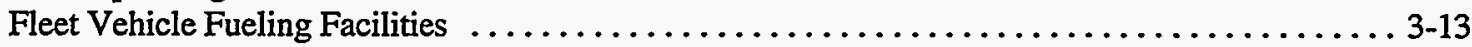

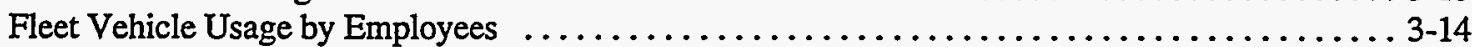

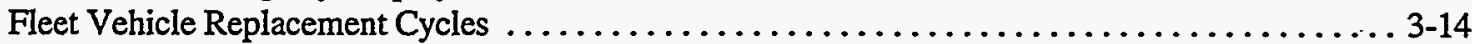

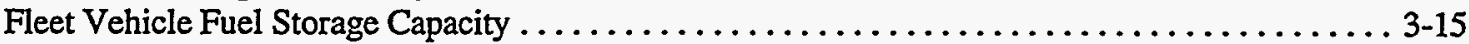

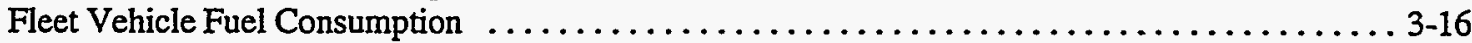

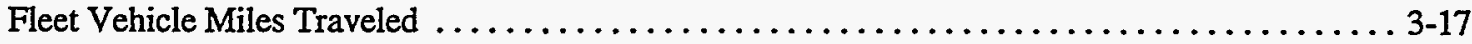

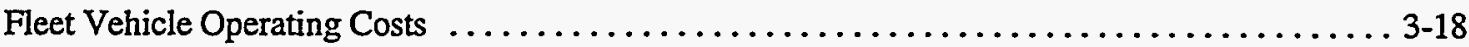

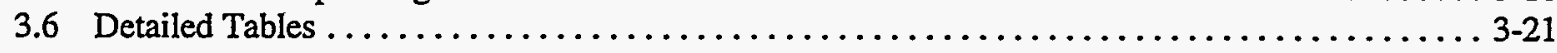




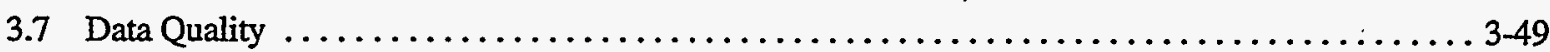

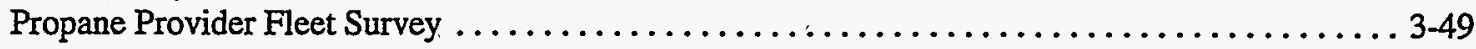

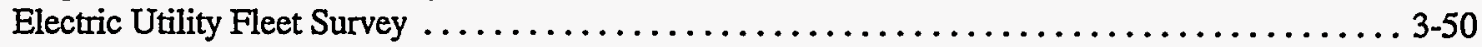

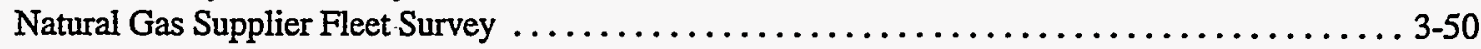

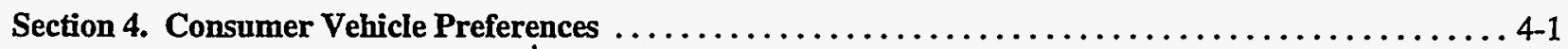

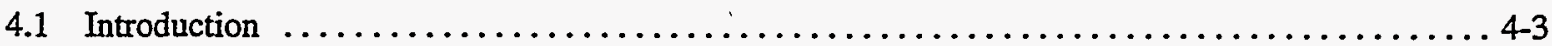

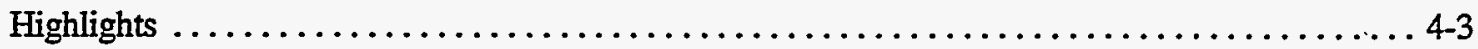

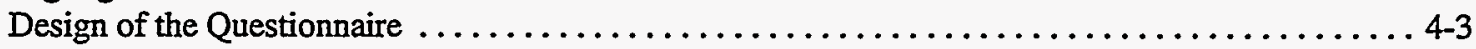

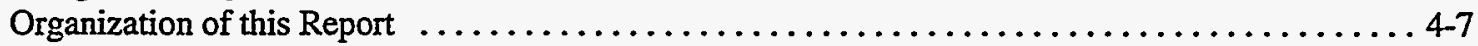

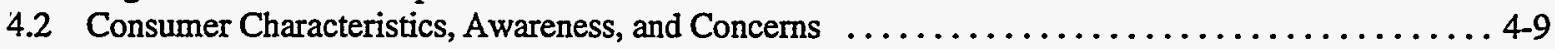

Consumer Characteristics ......................................

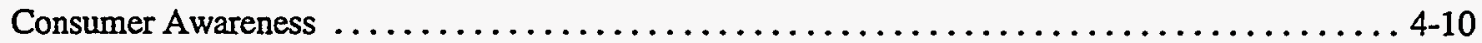

Consumer Concern ....................................... 4-11

4.3 Consumer Receptiveness to Behavioral Changes and Price Differentials $\ldots \ldots \ldots \ldots \ldots \ldots \ldots$. 43

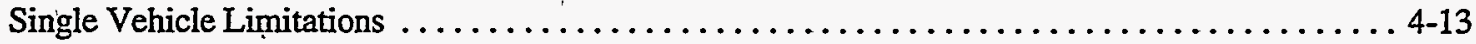

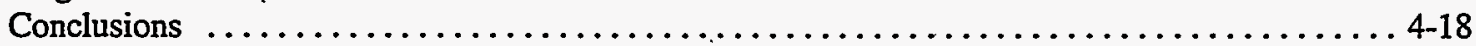

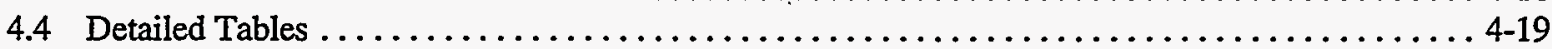

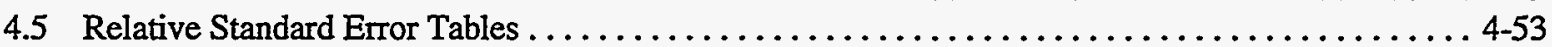

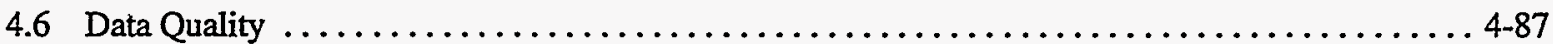

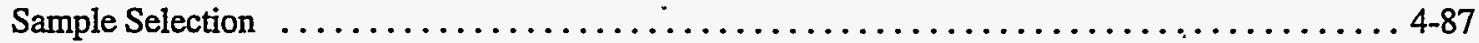

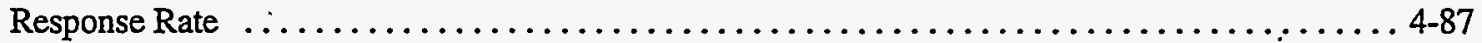

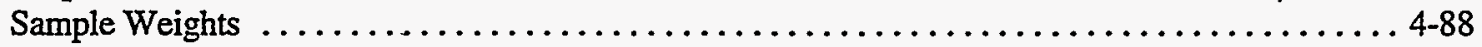

Nonsampling and Sampling Error $\ldots \ldots \ldots \ldots \ldots \ldots \ldots \ldots \ldots \ldots \ldots \ldots \ldots \ldots \ldots \ldots \ldots \ldots \ldots, 4.88$

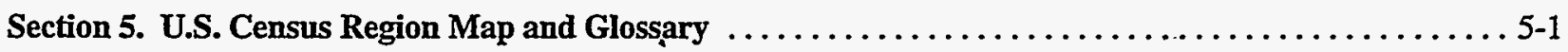

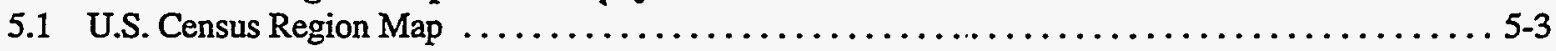

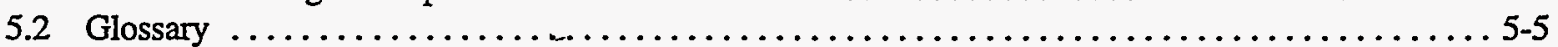




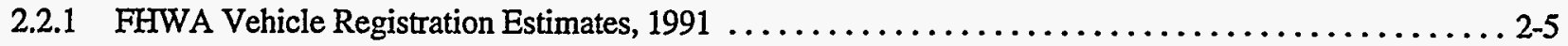

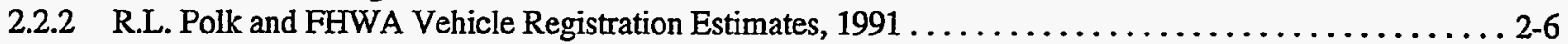

2.3.1 Number of Residential Vehicles by Vehicle Type and Survey Year $\ldots \ldots \ldots \ldots \ldots \ldots \ldots \ldots \ldots \ldots .7 \ldots \ldots \ldots$

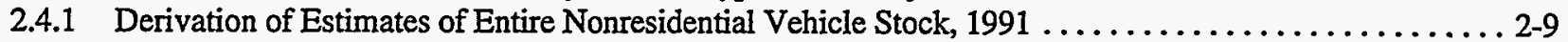

3.3.1 Propane Provider Fleet Vehicles by Provider Category, $1993 \ldots \ldots \ldots \ldots \ldots \ldots \ldots \ldots \ldots \ldots \ldots . . .6 \ldots$

3.6.1 Fleet Vehicles Operated by Propane Providers as of December 31, $1993 \ldots \ldots \ldots \ldots \ldots \ldots \ldots \ldots .22$

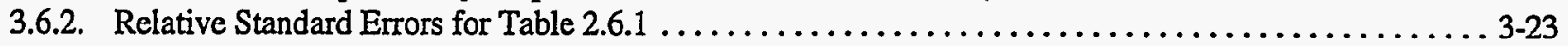

3.6.3. Alternative-Fuel Vehicles in Propane Provider Fleets by Source, $1993 \ldots \ldots \ldots \ldots \ldots \ldots \ldots \ldots \ldots$. . . . . . . .

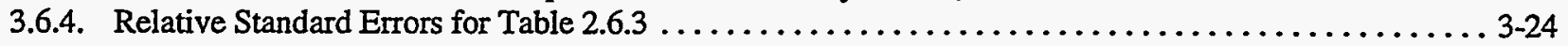

3.6.5. Propane Provider Fleet Vehicle Retirement/Acquisition Plans - $1994 \ldots \ldots \ldots \ldots \ldots \ldots \ldots \ldots \ldots$. . . . . . . . .

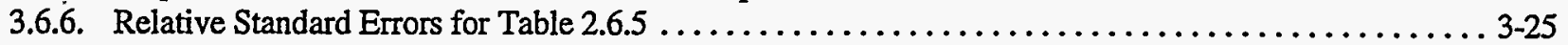

3.6.7. "New" Propane Provider Fleet Vehicles Planned for Service in $1994 \ldots \ldots \ldots \ldots \ldots \ldots \ldots \ldots \ldots$. . . . . . . . .

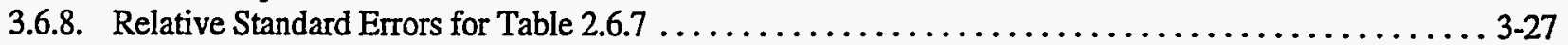

3.6.9. Propane Provider Fleet Vehicle Fueling Locations, $1993 \ldots \ldots \ldots \ldots \ldots \ldots \ldots \ldots \ldots \ldots \ldots .28$

3.6.10. Propane Provider Fleet Vehicle Usage for Vehicles Assigned to Employees, 1993 . . . . . . . . . . . 3-29

3.6.11. Propane Provider Fleet Vehicle Replacement Cycles, 1993 . . . . . . . . . . . . . . . . . . . . . 3-30

3.6.12. Propane Provider Fleet Vehicle Costs, 1993 . . . . . . . . . . . . . . . . . . . . . . . . 3-31

3.6.13. Alternative-Fuel Vehicle Maintenance Costs Relative to Conventional-Fuel Vehicles in

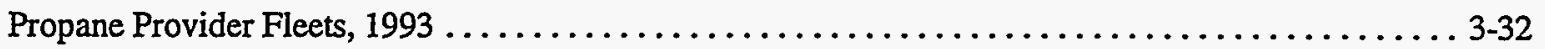

3.6.14. Fuel Storage Capacity in Propane Provider Fleet Vehicles, 1993 ..................... 3-33

3.6.15. Annual Consumption by Fuel and Vehicle Technology for Propane Provider Fleet Vehicles, 1993 . . . 3-34

3.6.16. Annual Miles Travelled by Fuel and Vehicle Technology for Propane Provider Fleet Vehicles, 1993 . . 3-35

3.6.17. Fleet Vehicles Operated by Electric Utilities as of December 31, $1993 \ldots \ldots \ldots \ldots \ldots \ldots \ldots \ldots$. 36

3.6.18. 1994 Electric Utility Fleet Vehicle Retirement/Acquisition Plans . . . . . . . . . . . . . . . . 3-37

3.6.19. "New" Electric Utility Fleet Vehicles Planned for Service in 1994 . . . . . . . . . . . . . . . . . . 3-38

3.6.20. Fleet Vehicles Operated by Natural Gas Suppliers as of December 31, $1993 \ldots \ldots \ldots \ldots \ldots \ldots \ldots .3 .39$

3.6.21. Alternative-Fuel Fleet Vehicles in Natural Gas Supplier Fleets by Source, 1993 . . . . . . . . . . . 3-40

3.6.22. 1994 Natural Gas Supplier Fleet Vehicle Retirement/Acquisition Plans . . . . . . . . . . . . . . . 3-41

3.6.23. "New" Natural Gas Supplier Fleet Vehicles Planned for Service in 1994 . . . . . . . . . . . . . . . . . . 3-42

3.6.24. Natural Gas Supplier Fleet Vehicle Fueling Locations, 1993 . . . . . . . . . . . . . . . . . 3-43

3.6.25. Natural Gas Supplier Fleet Vehicle Usage for Vehicles Assigned to Employees, 1993 . . . . . . . . . 3-44

3.6.26. Natural Gas Supplier Fleet Vehicle Daily Miles Traveled Range, 1993 . . . . . . . . . . . . . . . 3-45

3.6.27. Natural Gas Supplier Fleet Vehicle Replacement Cycles, 1993 . . . . . . . . . . . . . . . . . . 3-46

3.6.28. Annual Consumption per Vehicle by Fuel and Vehicle Technology for Natural Gas Supplier Fleet

Vehicles, 1993 ............................................. 347

4.3.1 Overview of Vehicle Preference by Modified Vehicle Limitations, $1994 \ldots \ldots \ldots \ldots \ldots \ldots \ldots \ldots$. . . . 13

4.3.2. Vehicle Preference Regarding Loss of One-Half Trunk Space, by Size of Current

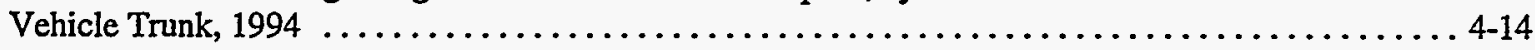

4.3.3. Vehicle Preference Incorporating Price Differential Based on Original Vehicle Choice, 1994 . . . . . 4-15

4.3.4. Willingness to Drive 15 Minutes Out of the Way to Refuel by Frequency of

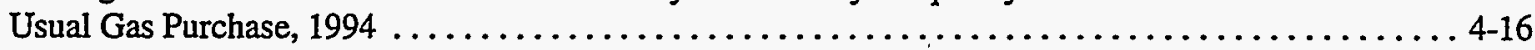

4.3.5. Vehicle Preference Incorporating Price Differential Based on Original Vehicle Choice, 1994 ...... 4-16

4.3.6. Willingness to Refuel Twice as Often by Frequency of Usual Gas Purchase, 1994 . . . . . . . . . . 4 4 17

4.3.7. Vehicle Preference Incorporating Price Differential Based on Original Vehicle Choice, 1994 . . . . . 4-17

4.3.8. Overview of Vehicle Preference by Combinations of Modified Vehicle Limitations for

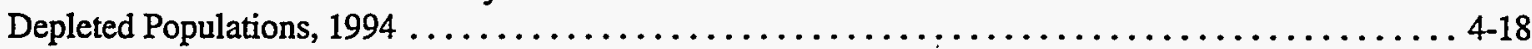

4.4.1 Consumer Characteristics by Level of Concern for the Environment, $1994 \ldots \ldots \ldots \ldots \ldots \ldots \ldots \ldots$. . . . . . . . .

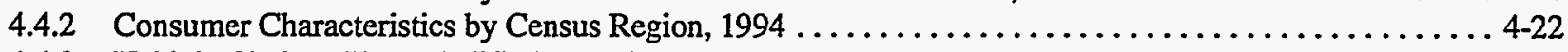

4.4.3 Vehicle Choice When Modified Vehicle Has Half the Trunk/Cargo Space of a

Regular Vehicle, 1994 ........................................... 4-24

4.4.4 Vehicle Choice When Modified Vehicle Has Half the Trunk/Cargo Space of a Regular Vehicle

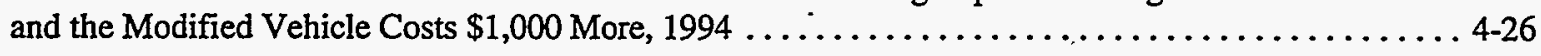


4.4.5 Vehicle Choice When Modified Vehicle Has Half the Trunk/Cargo Space of a Regular Vehicle

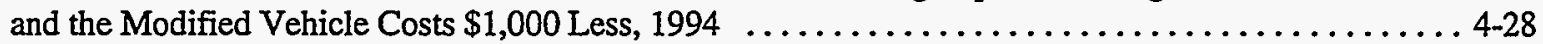

4.4.6 Vehicle Choice. When Consumer Must Drive 15 Minutes Out of the Way to Refuel

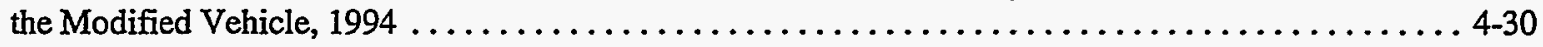

4.4.7 Vehicle Choice When Consumer Must Drive 15 Minutes Out of the Way to Refuel the Modified Vehicle and the Modified Vehicle Costs $\$ 1,000$ More, 1994 ............... 4-32

4.4.8 Vehicle Choice When Consumer Must Drive 15 Minutes Out of the Way to Refuel the Modified Vehicle and the Modified Vehicle Costs $\$ 1,000$ Less, 1994 ................ 4-34

4.4.9 Vehicle Choice When Consumer Must Refuel the Modified Vehicle Twice as Often

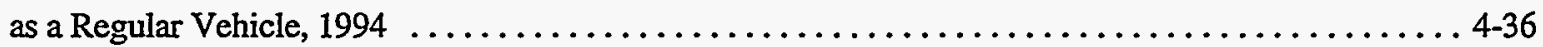

4.4.10. Vehicle Choice When Consumer Must Refuel the Modified Vehicle Twice as Often as a Regular Vehicle and the Modified Vehicle Costs $\$ 1,000$ More, $1994 \ldots \ldots \ldots \ldots \ldots \ldots \ldots .4 .38$

4.4.11 Vehicle Choice When Consumer Must Refuel the Modified Vehicle Twice as Often as a Regular.Vehicle and the Modified Vehicle Costs $\$ 1,000$ Less, $1994 \ldots \ldots \ldots \ldots \ldots \ldots \ldots .440$

4.4.12 Vehicle Choice When Consumer Must Drive 15 Minutes Out of the Way to Refuel the Modified Vehicle and the Modified Vehicle Has Half the Trunk/Cargo Space

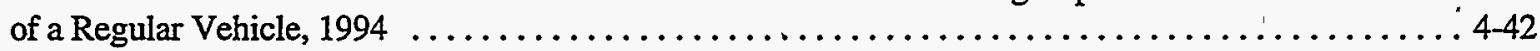

4.4.13 Vehicle Choice When Consumer Must Refuel the Modified Vehicle Twice as Often as a Regular Vehicle and the Modified Vehicle Has Half the Trunk/Cargo Space of a Regular Vehicle, 1994

4.4.14 Vehicle Choice When Consumer Must Drive 15 Minutes Out of the Way to Refuel the Modified Vehicle and the Modified Vehicle Must be Refueled Twice as Often

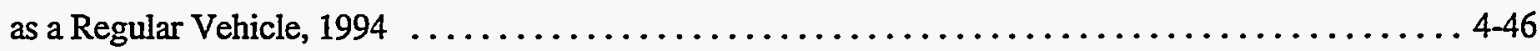

4.4.15 Vehicle Choice When Consumer Must Drive 15 Minutes Out of the Way to Refuel the Modified Vehicle, the Modified Vehicle Must be Refueled Twice as Often as a Regular Vehicle, and the Modified Vehicle Costs $\$ 1,000$ Less, $1994 \ldots \ldots \ldots \ldots \ldots \ldots \ldots .448$

4.4.16 Vehicle Choice When Consumer Must Drive 15 Minutes Out of the Way to Refuel the Modified Vehicle, the Modified Vehicle Must be Refueled Twice as Often as a Regular Vehicle, and the Modified Vehicle Has Half the Trunk/Cargo Space

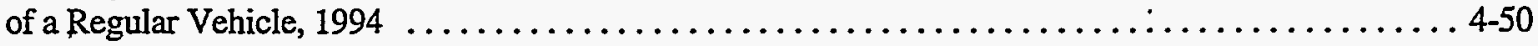

4.5.1 Relative Standard Errors for Consumer Characteristics by Level of Concern

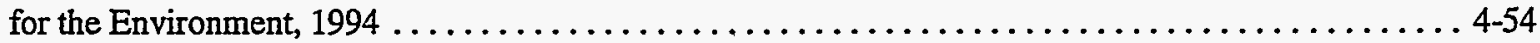

4.5.2 Relative Standard Errors for Consumer Characteristics by Census Region, $1994 \ldots \ldots \ldots \ldots \ldots$. . . . 4-56

4.5.3 Relative Standard Errors for Vehicle Choice When Modified Vehicle Has Half

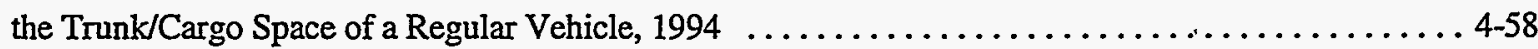

4.5.4 Relative Standard Errors for Vehicle Choice When Modified Vehicle Has Half the Trunk/Cargo Space of a Regular Vehicle and the Modified Vehicle Costs $\$ 1,000$ More, 1994 . . . . 4-60

4.5.5 Relative Standard Errors for Vehicle Choice When Modified Vehicle Has Half the Trunk/Cargo Space of a Regular Vehicle and the Modified Vehicle Costs $\$ 1,000$ Less, 1994 . . . . 4-62

4.5.6 Relative Standard Errors for Vehicle Choice When Consumer Must Drive 15 Minutes

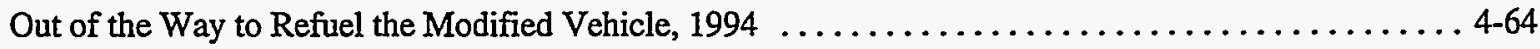

4.5.7 Relative Standard Errors for Vehicle Choice When Consumer Must Drive 15 Minutes Out of the Way to Refuel the Modified Vehicle and the Modified Vehicle Costs $\$ 1,000$ More, 1994 . . 4-66

4.5.8 Relative Standard Errors for Vehicle Choice When Consumer Must Drive 15 Minutes Out of the Way to Refuel the Modified Vehicle and the Modified Vehicle Costs $\$ 1,000$ Less, 1994 . . . 4-68

4.5.9 Relative Standard Errors for Vehicle Choice When Consumer Must Refuel the Modified Vehicle Twice as Often as a Regular Vehicle, 1994 4-70 


\section{Tables (Continued)}

4.5.10 Relative Standard Errors for Vehicle Choice When Consumer Must Refuel the Modified Vehicle Twice as Often as a Regular Vehicle and the Modified Vehicle

Costs $\$ 1,000$ More, 1994

4.5.11 Relative Standard Errors for Vehicle Choice When Consumer Must Refuel the Modified Vehicle Twice as Often as a Regular Vehicle and the Modified Vehicle Costs $\$ 1,000$ Less, 1994

4.5.12 Relative Standard Errors for Vehicle Choice When Consumer Must Drive 15 Minutes Out of the Way to Refuel the Modified Vehicle and the Modified Vehicle Has Half the Trunk/Cargo Space of a Regular Vehicle, 1994 ...

4.5.13 Relative Standard Errors for Vehicle Choice When Consumer Must Refuel the Modified Vehicle Twice as Often as a Regular Vehicle and the Modified Vehicle Has Half the Trunk/Cargo Space of a Regular Vehicle, 1994

4.5.14 Relative Standard Errors for Vehicle Choice When Consumer Must Drive 15 Minutes Out of the Way to Refuel the Modified Vehicle and the Modified Vehicle Must be Refueled Twice as Often as a Regular Vehicle, 1994

4.5.15 Relative Standard Errors for Vehicle Choice When Consumer Must Drive 15 Minutes Out of the Way to Refuel the Modified Vehicle, the Modified Vehicle Must be Refueled Twice as Often as a Regular Vehicle, and the Modified Vehicle Costs \$1,000 Less, 1994

4.5.16 Relative Standard Errors for Vehicle Choice When Consumer Must Drive 15 Minutes Out of the Way to Refuel the Modified Vehicle, the Modified Vehicle Must be Refueled Twice as Often as a Regular Vehicle, and the Modified Vehicle Has Half the Trunk/Cargo Space

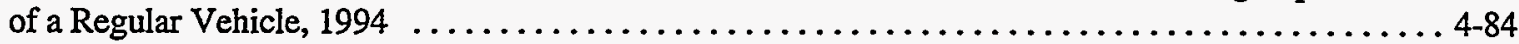

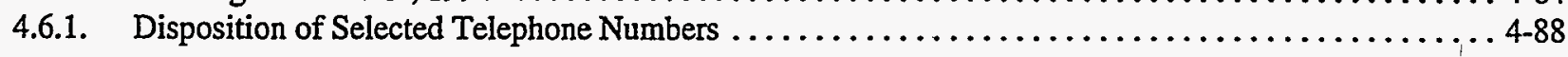

\section{Figures}

Page

1.1 Percent Growth in Alternative and Traditional Fuels Consumption Relative to $1992 \ldots \ldots \ldots \ldots \ldots \ldots$. $\ldots \ldots$

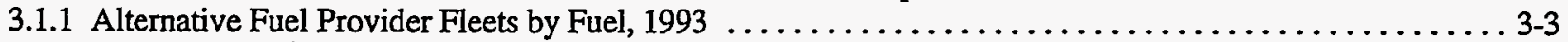

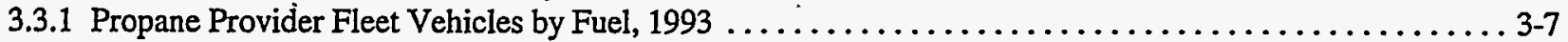

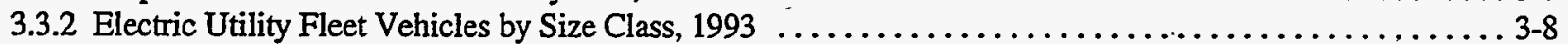

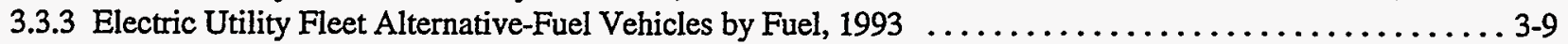

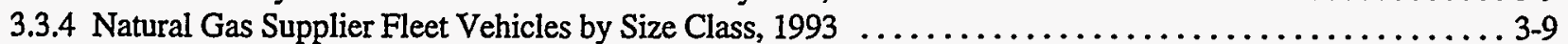

3.3.5 Natural Gas Supplier Alternative-Fuel Vehicles by Technology and Source, 1993 . . . . . . . . . . . . . . 3-10

3.5.1 Types of Fueling Facilities Used by Natural Gas Supplier Fleets, $1993 \ldots \ldots \ldots \ldots \ldots \ldots \ldots \ldots \ldots$. . . . . . . . . .

3.5.2 Months-Based Replacement Cycles for Propane Provider Fleet Vehicles, 1993 . . . . . . . . . . . . . . 3-14

3.5.3 Miles-Based Replacement Cycles for Propane Provider Fleet Vehicles, 1993 . . . . . . . . . . . . . . . 3-15

3.5.4 Annual Propane Consumption per Vehicle by Vehicle Size Class for Propane Provider

Fleet Vehicles, 1993 ........................................... 3 16

3.5.5 Percent of Natural Gas Supplier CNG and Propane Fleet Vehicles and Consumption

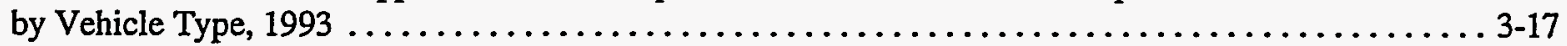

3.5.6 Annual Vehicle Miles Traveled per Vehicle on Gasoline, Diesel, and Propane by Vehicle Technology

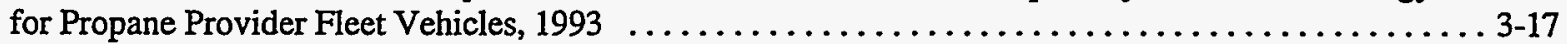

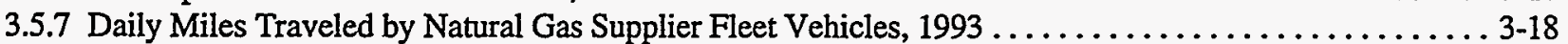

3.5.8 Propane Provider Fleet Vehicle Acquisition and Conversion Costs, 1993 . . . . . . . . . . . . . . . . . 3-19

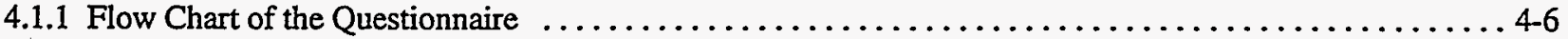

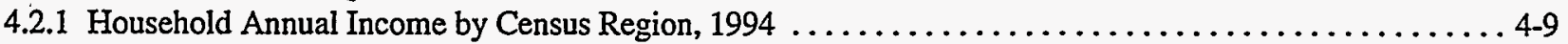


4.2.2 Number of Vehicles by Census Region, 1994

4.2.3 Household Annual Income by Number of Vehicles, 1994

4-10

4.2.4 Level of Concern for the Environment by Census Region, 1994

4-11

4.3.1 Consumers Willing to Drive 15 Minutes Out of the Way to Refuel by Census Region, 1994

4-15 
Section 1.

\section{Introduction}





\section{Introduction}

Motor vehicles are an integral part of the American way of life. Private motor vehicles give us personal freedom and nearly unfettered mobility; and trucks, both large and small, bring goods to even the smallest towns throughout the country. Today, record numbers of vehicles are on the road and are being driven record numbers of miles.

Our reliance on motor vehicles has major implications for both international trade policy and environmental policy. Dependence on foreign oil reached its highest level in 17 years in 1994, with net imports amounting to 45 percent of consumption. Motor gasoline represented the greatest consumption of all oil products, 43 percent of all petroleum products supplied in 1994. ${ }^{1}$ Both foreign imports of petroleum and consumption of motor gasoline are on the rise; and consequently, the United States remains as vulnerable as ever to oil embargoes abroad.

Concern that highway-vehicle combustion of gasoline produces by-products that could lead to global warming has heightened awareness of the so-called "greenhouse gases." Motor vehicles are a major source of greenhouse gases, and the trends of rising numbers of motor vehicles and miles driven could lead to more harmful emissions that may ultimately affect the world's climate. One approach to curtailing such emissions is to use, instead of gasoline, alternative fuels: liquefied petroleum gas (usually propane), compressed natural gas, electricity, or alcohol fuels.

In addition to the concerns over greenhouse-gas emissions, there is also increasing concern over pollutants which are harmful to human health. The major examples of these pollutants are atmospheric ozone and carbon monoxide. Ozone is not only directly harmful to humans, acting as a powerful irritant to the human respiratory system, but also indirectly because it absorbs ultraviolet light, which can cause skin cancer. Carbon monoxide is also harmful to human health by reducing the flow of oxygen to the body's organs and tissues. The Clean Air Act Amendments of 1990 authorized the U.S. Environmental Protection Agency to set National Ambient Air Quality Standards (NAAQS). These standards were set in order to address air pollution and designate standards to mediate carbon monoxide and ozone levels.

\section{Energy Policy Act of 1992}

The Energy Policy Act of 1992 (EPACT), which was adopted after the Persian Gulf conflict of 1990-1991, was the first new law to emphasize strengthened energy security and decreased reliance on foreign oil since the oil shortages of the 1970's. The EPACT emphasized increasing the number of alternative-fuel vehicles (AFV's) by mandating that Federal, State, and alternative fuel provider fleets incrementally increase the proportion of AFV's in their vehicle fleets over the next few years. It was concluded that targeting fleets was the most practical approach to increasing the number of.AFV's on the road. One major drawback of alternative fuel use is the lack of a refueling infrastructure. Generally, commercial fleets are centrally refueled, so establishing a widespread refueling infrastructure would not be necessary.

\section{Energy Security}

The United States obtains 53 percent of its net imports of petroleum products from the Organization of Petroleum Exporting Countries (OPEC), mostly from Saudi Arabia and Venezuela. Canada is another major source of net imports, but is not a member of OPEC. The transportation sector consumes 65 percent of the total petroleum products supplied, and, by far, the largest share of product supplied to the transportation sector is motor gasoline. ${ }^{2}$

Growth in gasoline consumption has occurred in spite of significant advances in fuel economy. In 1973, the year of the Arab oil embargo, average miles per gallon for passenger vehicles was 13.3; in 1992, the average miles per gallon was 21.6. ${ }^{3}$ Automobile manufacturers instituted several engineering refinements to improve fuel economy, such as the use of lighter materials to decrease weight, aerodynamic body design to reduce drag, and the near universal use of radial tires

1 Energy Information Administration (EIA), Annual Energy Review 1994, Juiy 1995, Tables 5.1 and 5.11.

2 EIA, Annual Energy Review 1994, July 1995, Table 5.12b.

3 EIA, Annual Energy Review 1994, July 1995, Table 2.15. 
instead of bias-ply tires. These refinements were encouraged by the Federal Corporate Average Fuel Economy (CAFE) standards, which set fuel efficiency standards for different types of vehicles. However, the number of motor vehicles on the road and the number of miles driven have continued to grow, and motor gasoline consumption has continued to increase. The energy security provisions of EPACT represent a new approach to decreasing U.S. vulnerability to oil price shocks abroad and call for practical approaches to promoting domestic energy sources.

The EPACT set a national goal to replace 30 percent of the petroleum content of fuels for light-duty vehicles with nonpetroleum-derived fuels by the year 2010. To help meet this goal, the legislation also provided the possibility for future requirements for private fleets to acquire AFV's. Tax incentives for the purchase of AFV's and the development of retail service stations are also a requirement in the EPACT, as is encouragement to States to develop their own programs.

The goals set by the EPACT are far from Figure 1.1. Percent Growth in Alternative and Traditional being met. Alternative fuels' share of total vehicle fuel consumption remains trivial (approximately 0.3 percent). There was, however, about 28 percent growth in alternative fuel consumption between 1992 and 1993 and 61 percent growth between 1992 and 1995. Growth in consumption of traditional fuels was not as substantial--1.2 percent between 1992 and 1993 and 4.4 percent between 1992 and 1995 (Figure $1)^{4}$ The Energy Information Administration (EIA) is monitoring the consumption of alternative fuels, the numbers of fleet vehicles, and the overall motor vehicle market. It is also taking a particularly detailed look at fleets in the Department of Energy (DOE)-designated "Clean Cities." These cities have DOEFuels Consumption Relative to 1992

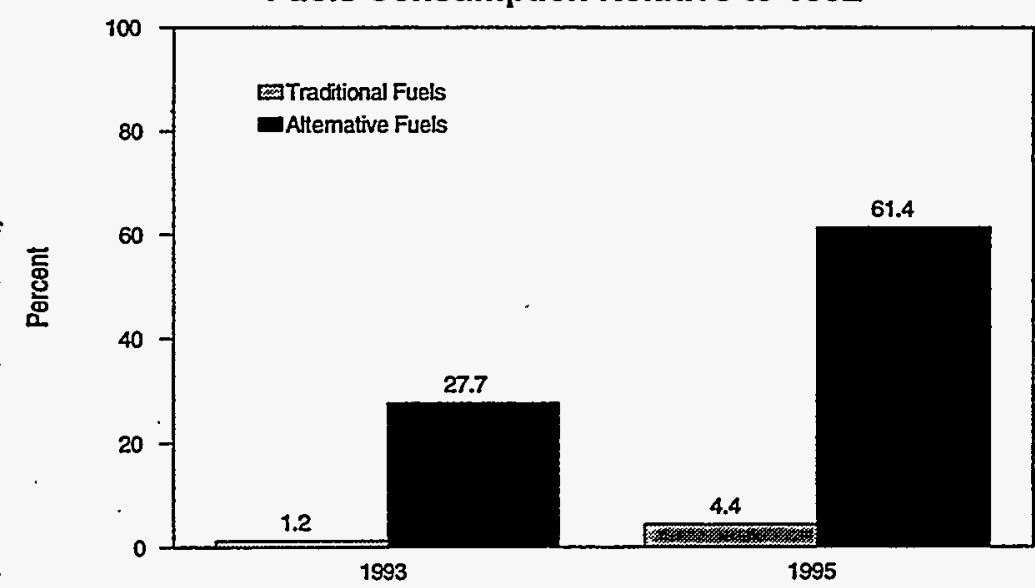

Source: Energy Information Administration, Altematives to Traditional Transportation Fuels, 1993, DOEIEIA-0585(93), January 1995.

accepted approaches for promoting the penetration of AFV's and development of the associated infrastructure needed for AFV acceptance. They are located in climatically and geographically diverse parts of the country.

\section{Reducing Greenhouse-Gas Emissions}

Reducing greenhouse-gas emissions is another priority of the EPACT. Transportation, through the burning of petroleum products, accounts for about 30 percent of all anthropogenic greenhouse gases in the United States. Greenhouse gases are gases that absorb heat or prevent its release into the stratosphere, thus warming the Earth (the "greenhouse effect"); or that reflect sunlight, preventing its entry into the troposphere and striking the Earth's surface, thus cooling the Earth. The major gases--carbon dioxide, methane, and nitrous oxide--are found in combustion of hydrocarbons like motor gasoline and diesel fuel. Other gases, including carbon monoxide, nitrogen oxides, and nonmethane volatile organic compounds, are not greenhouse gases, however, they contribute indirectly to the greenhouse effect and are found in vehicle emissions.

4 EIA, Alternatives to Traditional Transportation Fuels 1993, January 1995, p. 18.

5 The EIA has conducted fleet surveys in Atlanta, GA and Denver, CO, which are two of the designated Clean Cities. Currently, there are a total of 41 Clean Cities-39 additional Clean Cities are as follows: Philadelphia, PA; Wilmington, DE; Las Vegas, NV; Washington, DC; Boston, MA; Austin, TX; Florida Gold Coast; Chicago, IL; Albuquerque, NM; Wisconsin - SE Area; Colorado Springs, CO; Long Beach, CA; Lancaster, CA; Salt Lake City, UT; White Plains, NY; Baltimore, MD; State of West Virginia; Louisville, KY; Rogue Valley, OR; San Francisco, CA; Sacramento, CA; South Bay (San Jose), CA; Oakland, CA; San Joaquin Valley, CA; Westem New York; Portland, OR; St. Louis, MO; Waterbury, CT; Norwalk, CT; Norwich, CT; New London, CT; Peoria, IL; Kansas - Southwest Area; Central New York; Dallas/Ft. Worth, TX; Honolulu, HI; Missoula, MT; New Haven, CT; and Central Arkansas. 
In the United States, the transportation sector contributes:

- about one-third of carbon dioxide emissions

- about one-third of nitrous oxide emissions

- less than 1 percent of anthropogenic methane emissions

- 77 percent of carbon monoxide emissions

- 45 percent of nitrogen oxide emissions

- more than one-third of nonmethane volatile organic compounds ${ }^{6}$

Alternative-fuel vehicles have the potential to reduce the emissions of many greenhouse gases, but they present a number of drawbacks for the consumer--including shorter driving ranges, less cargo space (because of extra fuel tanks or batteries), and fewer refueling outlets. Only electricity has a suitable fueling infrastructure in place; however, in many respects, electricity is the alternative fuel most in need of technological improvements in order to be a practical transportation fuel.

Fuel distributors are reluctant to build the necessary infrastructures for AFV's until these vehicles are more prevalent on the road; and, at the same time, automobile manufacturers fear the market for AFV's will be very limited until the refueling infrastructure is in place. The EPACT purchase mandates are designed to increase the market for AFV's, but the purchase mandates apply to entities-government and commercial fleets-that are least likely to use retail fuel outlets. Fleet vehicles are much more likely to refuel in a centralized location, often owned by the fleet operator.

In addition to the aforementioned requirements set forth by the EPACT, the Act directed the EIA to establish several new data collection programs. In particular, Section 407 of EPACT required information useful to those entering the markets related to AFV's and the associated infrastructure. As with any emerging market, the core information includes the makeup of the market in which new products would have to compete and the nature of the products that new technology might replace. The text box below gives overviews of the EIA programs required by EPACT Sections 407 and 503 . The box first summarizes EIA's data acquisition programs required by Section 407, and then addresses those programs designed to comply with EPACT Section 503, which relates to AFV's in particular rather than to the vehicle market in general. Section 503 required EIA to identify AFV's already in use, AFV's likely to be in use in the following year, and AFV's being made available to the market each year.

This report describes current and potential markets for AFV's. It begins by assessing the total vehicle stock. Then it focuses on the current use of AFV's in alternative fuel provider fleets and the potential for use of AFV's in U.S. households. These topics are covered in the following three sections:

\section{Section 2. Composition of the U.S. Vehicle Stock}

Section 407 required information about the total U.S. vehicle market, and the EIA determined that the composition of the U.S. vehicle stock should be assessed. Using existing data sources and the new data collection systems designed to comply with EPACT, a speculative attempt was made to detect where and in what capacity vehicles are being operated within the United States. Results of this effort are presented in this section.

\section{Section 3. Fleets of Alternative Fuel Providers}

In addition to the various data collection systems, EPACT implemented programs designed to encourage governments and private companies to purchase AFV's for their fleets. These programs require that a certain percentage of new vehicle acquisitions be AFV's. These purchase mandates, which go into effect at different times for the various fleet subpopulations, increase incrementally over several years. The fleets operated by the Federal government were the first to be affected, with purchase requirements going into effect in 1993. Beginning with model year 1997 (approximately September 1996), alternative fuel providers--sellers and distributors of propane, electricity, and natural gas--may fall under AFV purchase mandates.

${ }^{6}$ EIA, Emissions of Greenhouse Gases in the United States 1987-1994, October 1995, pp. 12, 25, 45, 63-65. 
The EIA established three fleet-level surveys to collect data concerning fleets and fleet vehicles operated by alternative fuel providers. The results of the three surveys: the Propane Provider Fleet Survey, the Electric Utility Fleet Survey, and the Natural Gas Supplier Fleet Survey are presented in this section. The EIA surveyed only providers of propane, natural gas, and electricity because there were existing EIA databases that made the population of those providers easily accessible. At the time the surveys were conducted, there was no database in existence for easy access to the methanol and ethanol providers, and it was still uncertain (due to pending Rules) whether the oil providers/refiners would be covered under the EPACT as alternative fuel providers.

\section{Section 4. Consumer Vehicle Preferences}

Section 407 of the EPACT also called for data on consumer preferences relating to vehicle operation to assess consumer acceptance of AFV's. To comply, EIA obtained data from a national consumer vehicle preference survey that was designed and conducted by a practicum class in the Joint Program in Survey Methodology sponsored by the University of Maryland, the University of Michigan, and Westat, Inc. This survey collected data concerning consumer vehicle preferences and attitudes toward AFV's and the possible limitations commonly associated with them. Analysis of these data is presented in this section. 


\section{Energy Policy Act}

\section{Section 407 Data Acquisition Program}

- Section 407 (a) and (a)(1) direct the Energy Information Administration (EIA) to collect data that would be useful to marketers of alternative-fuel vehicles, and to identify "the number and types of motor-vehicle trips made daily and miles driven per trip." EIA has responded to these requirements with surveys that collected data on the "Stock of Motor Vehicles in Fleets." These included national surveys of electric, natural gas, and propane fuel provider fleets; and surveys of private-company and municipal fleets in Atlanta (Profile of Motor-Vehicle Fleets in Atlanta 1994, November 1995 (DOE/EIA-0601)), and Denver. For data from the survey in Denver, refer to EIA's home page on the Intemet at http://www.eia.doe.gov or contact Leigh Carleton (202-586-1132); Contact Jennifer Reichert (202-586-5736) for details on the fuel provider fleet surveys.

- Section 407 (a)(2) calls for "Projections of Alternative-Fuel Vehicles." These forecasts are being conducted as part of EIA's basic National Energy Modeling System. The forecasts are driven by a consumer vehicie choice model and by estimates of the sales impact of EPACT and the California LEV program. Please refer to The Supplement to the Annual Energy Outlook (February 1995, DOE/EIA-0554(95)) or contact David Chien (202-586-3994).

- Section 407 (a)(3) covers “Cost, Environmental, Energy, and Safety Data" on alternative fuels and alternative-fuel vehicles. No specific projects are currently underway. Some related data may be developed as part of the EPACT Section 503 Program. Contact Fred Mayes (202-426-1166) for details.

- Section 407 (a)(4) calls for data on "Consumer Preferences." An EIA analysis and summary of the results of a national telephone survey of consumer vehicle preferences and attitudes toward alternative-fuel vehicles was conducted in response to this requirement. These data are not available by fuel type. The survey was conducted by students in a joint survey methodology program of the University of Maryland, the University of Michigan, and Westat, Inc. Contact Christy Hall (202-586-1068) for dètails.

\section{Section 503-Replacement Fuel Demand Estimates and Supply Information}

- Section 503 directs the Energy Information Administration to estimate annually for the following calendar year: (1) the number of each type of alternative-fuel vehicle (AFV) likely to be in use in the United States, (2) the probable geographic distribution of the vehicles, (3) the amount and distribution of each type of replacement fuel, and (4) the greenhouse-gas emissions likely to result from replacement fuel use. Alternatives to Traditional Transportation Fuels 1994 (DOE/EIA$0585(94)$ ) is the second in a series of annual reports designed to provide such information. In June 1994, EIA provided background information on alternative and replacement fuels and the use of AFV's and alternative transportation fuels in the publication Alternatives to Traditional Transportation Fuels: An Overview (DOE/EIA-0585/O).

- Section 503 also requires that suppliers of AFV's report annually, to the Department of Energy, the number and type of AFV's "made available" in the previous calendar year and those that the supplier plans to make available in the following calendar year. In 1995, the EIA conducted the first survey of AFV suppliers using Form EIA-886, "Altemative Fuel Vehicle Suppliers' Annual Report." Survey respondents include vehicle manufacturers and companies that perform conversions. Preliminary survey results are presented in Alternatives to Traditional Transportation Fuels 1994. Contact Fred Mayes (202-426-1166) or Mary Joyce (202-426-1168) for details of these data programs. 



\section{Section 2}

Composition of the U.S. Vehicle Stock 


\subsection{Introduction}

The Energy Policy Act of 1992 (EPACT) directed the EIA to establish a data collection program of use to those seeking to enter the market for alternative-fuel vehicles and their fueling facilities. Two critical areas of understanding concerning these emerging markets are the total U.S. vehicle market in which alternative-fuel vehicles would have to compete and the nature of the vehicles that they might replace. Therefore, ELA determined to assess the-composition of the total U.S. vehicle stock.

Many vehicle data sources exist, each of which has collected data for distinct groups with specific needs. Together, these data sources provide information that is somewhat limited and often not comparable. Measuring and dissecting the entire U.S. vehicle stock based upon analysis of the existing collections of vehicle data are complicated by the following:

- The data sources that produce definitive estimates on the vehicle stock (those data sources that use State vehicle registration data as a base for estimation) include residential vehicles in their total count, and they do not distinguish the residential vehicles from the nonresidential.

- Different data sources are generally prepared for very different purposes. Consequently, each source has its own scope, target population, relative data of interest, and methodology.

- The data sources are of varied degrees of completeness and/or have different reference periods.

- Many data sources use additional, contributing information from other sources; unclear relationships and circular logic often arise.

Perhaps the most intriguing aspect of the U.S. vehicle stock is that there are nearly fourteen to sixteen million nonresidential vehicles for which no data source can account. The estimate of the expected number of nonresidential vehicles is much larger than the number that can be identified in the major nonresidential vehicle markets. ${ }^{1}$ In other words, there exists a gap between how many nonresidential vehicles there should be and how many nonresidential vehicles have been accounted for. This study provides some plausible, but not documented, conjectures regarding the discrepancy. Additionally, some data from local areas have been extrapolated to derive estimates that represent the entire United States. Because of the uncertainty involved with some data sources and the theoretically unsupported nature of inferring by projecting or extending estimated values without sound statistical basis, this study should be viewed as a speculative attempt to quantify the U.S. vehicle stock.

\footnotetext{
residential vehicles as reported by EIA's 1991 Residential Transportation Energy Consumption Survey.

${ }^{1}$ The expected number of nonresidential vehicles is the difference between the 1991 total reported number of registered vehicles and the estimate of 



\subsection{Total Vehicle Stock}

To dissect the U.S. vehicle stock, the total number of registered vehicles must be ascertained. Two important sources for the number of vehicles in the total vehicle stock are the Federal Highway Administration (FHWA) and the R.L. Polk Company. Data year 1991 is used for stock counts and subsequent discussion in this analysis. It is the latest year for which detailed composition data are available for residential vehicles, which account for a large majority of the vehicle stock.

\section{Federal Highway Administration}

The FHWA collects U.S. vehicle registration data on a State-by-State basis. By collecting State-by-State data, the FHWA faces three general problems. First, obtaining identical forms of data for all the States is not possible because the registration practices for vehicles, and the way in which the vehicle registrations are reported to the FHWA, differ greatly among the States. For example, in some States, cars and light trucks have separate registrations; in others, light trucks are allowed to be registered as cars. Therefore, the FHWA truck category includes light trucks only to the extent that they can be identified and separated from automobiles. One would expect that this registration and reporting practice would contribute to an overcount of the number of automobiles and an undercount of light duty trucks. Second, the annual vehicle registration dates vary among States. For example: two States use the calendar year for registering all vehicle types; nine States use the calendar year for registering trucks only; fifteen States register only their automobiles on a staggered basis; and twenty-one States register all of their vehicles on a staggered basis. (The staggered system permits a distribution of the registration renewal workload throughout all the months of the year.) To complicate matters further, the FHWA data include all vehicles registered any time throughout the calendar year. Therefore, the data include vehicles retired during the year and may double-count vehicles preregistered or registered twice in different or the same States. Conceivably, a vehicle could have been retired for two years before it would be eliminated from FHWA counts. Third, although the detail of motor-vehicle data collected by States has improved in recent years, sometimes the FHWA must supplement the data supplied by the States with information obtained from other sources. For example, many States report only new registrations; in which case, $R$. L, Polk's attrition rate of 10 percent is used to adjust for vehicle retirement.

The Highway Statistics 1991 publication gives the following estimates:

Table 2.2.1. FHWA Vehicle Registration Estimates, 1991 (Thousand Vehicles)

\begin{tabular}{|c|c|c|c|c|c|c|}
\hline \multirow[b]{2}{*}{ Vehicle Ownership } & \multicolumn{4}{|c|}{ Motor Vehicles } & \multirow[b]{2}{*}{$\begin{array}{c}\text { Trailers } \\
\text { and Semi- } \\
\text { Trailers }\end{array}$} & \multirow[b]{2}{*}{ Motorcycles } \\
\hline & Automobiles & Buses & $\begin{array}{l}\text { Trucks } \\
\text { and Truck } \\
\text { Tractors }\end{array}$ & Total & & \\
\hline $\begin{array}{l}\text { Total } \ldots . \ldots \ldots \ldots \ldots \ldots \ldots \ldots \\
\text { Publicly Owned }\end{array}$ & 142,956 & 631 & 44,785 & 188,372 & 16,467 & 4,177 \\
\hline Total $\ldots \ldots \ldots$. & 1,179 & 357 & 1,771 & 188,372 & 192 & 37 \\
\hline Federal (civilian only) & 96 & 5 & 269 & 370 & 4 & $(*)$ \\
\hline State, County, and Municipal ... & 1,082 & 352 & 1,502 & 2,937 & 188 & 37 \\
\hline Private and Commercial ...... & $141,7 \pi$ & 275 & 43,014 & 185,065 & 16,275 & 4,140 \\
\hline
\end{tabular}

(")Rounds to zero.

Source: U.S. Department of Transportation, Federal Highway Administration, Highway Statistics 1991. 


\section{R.L. Polk and Company}

RI. Polk and Company, like the FHWA, reports estimates of the automobile and truck population. Although both FHWA and R.L. Polk data use the individual States' registration data, the sources' estimates are different (Table 2.2.2). Some of the more important differences are:

- Unlike the FHWA, whose data are reported by the States by major vehicle classes (i.e., automobiles, buses, trucks, and motorcycles), R.L. Polk obtains more detailed State registration data. ${ }^{2}$ Included in these data are vehicle identification numbers (VIN). Decoded, the VIN allows R.L. Polk to more precisely identify the vehicle type.

- R.L. Polk data include only those vehicles registered as of July 1 of the given year, thereby excluding vehicles retired, registered, or re-registered during the last half of the year. In this way, much, but not all, erroneous counting and double counting can be avoided.

- Since 1980, the R.L. Polk data have included passenger vans in the truck category. Passenger vans could be classified as either automobiles or trucks depending on the individual State's practice in the FHWA data.

Table 2.2.2. R.L. Polk and FHWA Vehicle Registration Estimates, 1991 (Thousand Vehicles)

\begin{tabular}{c|r|r|r}
\hline Vehicle Type & FHWA & R.L. Polk & $\begin{array}{c}\text { Differénce } \\
\text { (FHWA - R.L. Polk) }\end{array}$ \\
\hline Total ............... & 187,741 & 181,438 & 6,303 \\
Automobiles $\ldots \ldots \ldots \ldots \ldots$ & 142,956 & 123,268 & 19,688 \\
Trucks $\ldots \ldots \ldots \ldots \ldots \ldots$ & 44,785 & 58,179 & $-13,394$ \\
\hline
\end{tabular}

Source: U.S. Department of Energy, Transportation Energy Data Book: Edition 14.

R.L. Polk estimates that in 1991, there were approximately 181.4 million registered vehicles, roughly 123.3 million automobiles and 58.2 million trucks. Because R.L. Polk's point-in-time registration count does a better job than FHWA of avoiding duplicate registrations, the remainder of the discussion will use the 1991 Polk estimates as the starting point for assessing the makeup of the U.S. vehicie stock. The next issue is how to describe the composition of the stock.

\footnotetext{
${ }^{2}$ Some States are "Privacy States" and do not release these data. Information provided by any data source for these States are based on other data sources and are estimated. 


\subsection{Residential Vehicle Stock}

The large majority of vehicles in the stock are associated with households and are used in conjunction with everyday household activities. The EIA collects data on these vehicles using the Residential Transportation Energy Consumption Survey (RTECS). The RTECS provides information on the vehicle stock and its energy use from data gathered directly from the end user, the household. The RTECS is a national multistage probability sample survey conducted triennially. In order for a vehicle to be included in the RTECS, one of two criteria must be met. Vehicles must be either (1) owned or used by household members on a regular basis for personal transportation or (2) company vehicles, not owned by the household but kept at home and regularly available to household members.

The RTECS was conducted in 1983,1985, 1988, and 1991. It is a consistent, reliable information base about the residential vehicle stock. Table 2.3.1 provides RTECS estimates for total number of residential vehicles by vehicle type and survey year. ${ }^{3}$

Table 2.3.1. Number of Residential Vehicles by Vehicle Type and Survey Year (Million Vehicles)

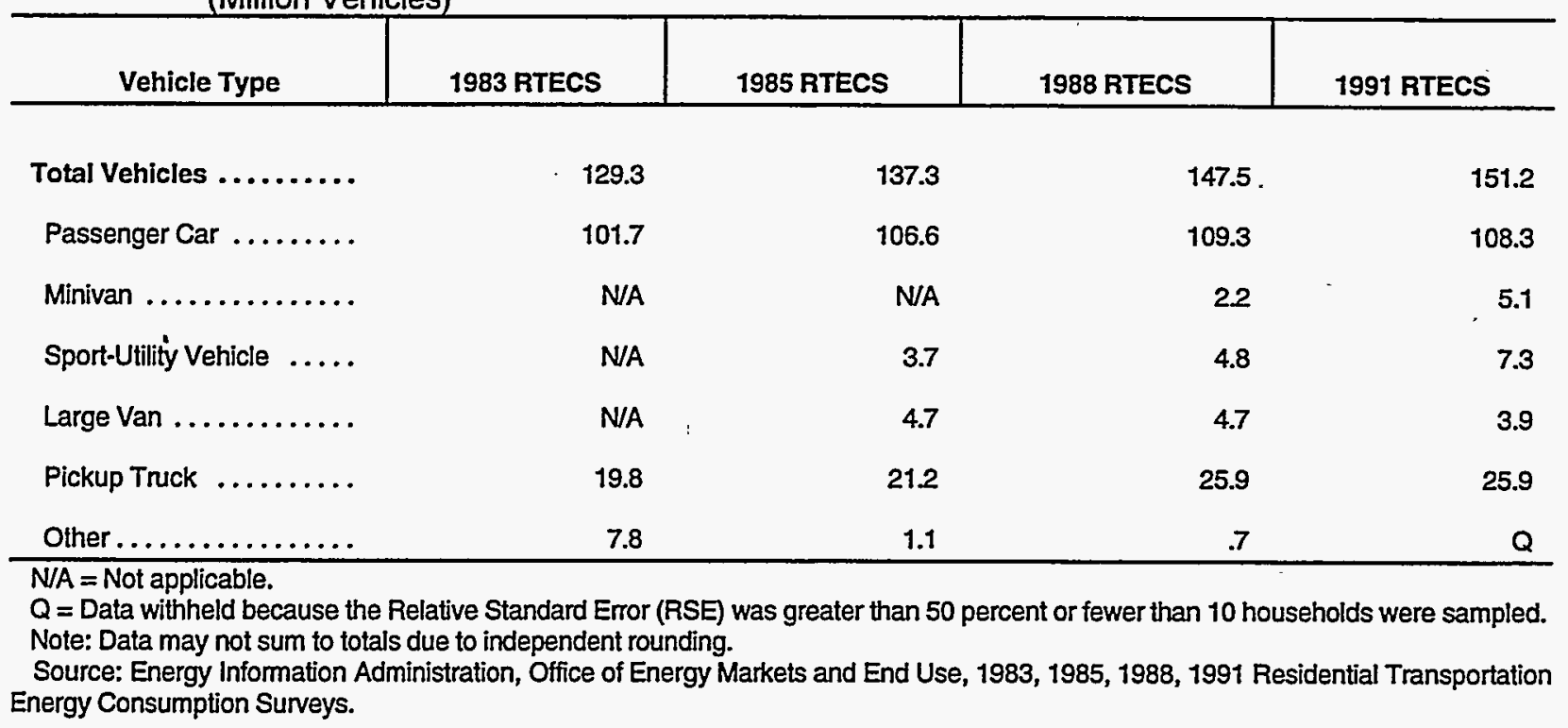

There is a difference of 30.2 million vehicles between the $1991 \mathrm{RL}$. Polk estimate of vehicle registrations and the 1991 RTECS residential stock estimate. To account for these vehicles, it is necessary to examine a much more diverse and difficult-to-assess population, the stock of nonresidential vehicles.

\footnotetext{
${ }^{3}$ For more information regarding the RTECS sample design, estimation methodologies, and data quality, see Energy Information Administration, Household Vehicles Energy Consumption 1991, Appendices A, B, and C.
} 



\subsection{Nonresidential Vehicle Stock}

Unfortunately, no comprehensive nationwide data source for the nonresidential vehicle stock is currently available. Subtracting the 1991 RTECS residential estimates from R.L. Polk registration data gives a target for the number of vehicles yet to be accounted for (Table 2.4.1). The sections to follow discuss several data sources that provide estimates for two subsets of the nonresidential vehicle stock, fleets of 10 or more vehicles and fleets of less than 10 vehicles.

Table 2.4.1. Derivation of Estimates of Entire Nonresidential Vehicle Stock, 1991 (Million Vehicles)

\begin{tabular}{|c|c|c|c|}
\hline \multirow[b]{2}{*}{ Data Source } & \multicolumn{3}{|c|}{ Motor Vehicles } \\
\hline & Autos & Trucks & Total \\
\hline Vehicle Registration Estimate Source & " & & \\
\hline 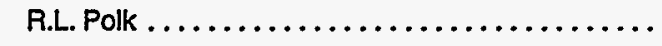 & . 123.3 & 582 & 181.4 \\
\hline 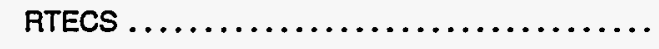 & 108.3 & 42.9 & 151.2 \\
\hline Nonresidential Vehicles ................. & 15.0 & 15.3 & 30.2 \\
\hline
\end{tabular}

\section{Vehicles in Fleets of $\mathbf{1 0}$ or More}

Many studies have explored this sector of the nonresidential fleet, each having a different focus and scope. Data have been collected for distinct groups with specific needs and interests. Because of this, estimates of the number of vehicles in fleets of 10 or more vary by as much as four million. Three data sources available are the Bobit Publishing Company, Dwights Energydata, and the Natural Gas Vehicle Fleet Market Study. The major difficulty in comparing these sources' estimates is determining whether and to what extent government vehicles are included.

\section{Government Vehicles}

According to the General Services Administration's FY 92 Federal Motor Vehicle Fleet Report, the Federal Government owned about 553 thousand vehicles and leased about 15 thousand additional vehicles as of September 30,1991 . Overall, nearly 568 thousand vehicles of the 30.2 million (about 1.9 percent) are used by the Federal Government.

The Federal Highway Administration's Highway Statistics, 1991 indicates that there were approximately 2.9 million vehicles owned by State, county, and municipal governments. These vehicles account for approximately 9.6 percent of the 30.2 million nonresidential vehicles. 
The Bobit Publishing Company publishes the Automotive Fleet which is a car and truck fleet and leasing management magazine. Bobit estimates that as of January 1, 1993 there were approximately 8.2 million non-government vehicles in fleets of 10 or more vehicles. ${ }^{4}$ The data include only those vehicles whose gross vehicle weight (GVW) is $19,500 \mathrm{lbs}$ or less. This estimate combined with the estimate of government vehicles results in approximately 11.7 million vehicles in fleets of 10 or more.

Dwights Energydata provides commercial information products, proprietary market research and analysis, and management consulting services. One product offered is the National Fleet Vehicle Database. This database provides commercial fleet data by county. According to Dwights Energydata (as cited in Bobit's Automotive Fleet 1993 Fact Book), there were approximately 124 thousand fleets of 10 or more vehicles operating in the U.S. in 1993. These fleets accounted for about 10.5 million vehicles. ${ }^{6}$ It is unclear from this source to what extent government vehicles and large trucks are included. Because of this uncertainty, Dwights estimates will serve as the lower bound for vehicles found in fleets of 10 or more vehicles.

In December of 1991, Easton Consultants, Inc., conducted a study, Natural Gas Vehicle Fleet Market Study, on behalf of the American Gas Association and the Natural Gas Vehicle Coalition (NGVC). ${ }^{7}$ This study involved secondary research, consultant field research, and a structured telephone survey of 500 fleet managers. Government vehicles were included in this study, as were all large trucks (vehicle classes I - VIII). Among the findings was that approximately 12.3 million vehicles were in fleets of 10 or more. ${ }^{8}$ This estimate will be used as the upper bound for the number of vehicles in fleets of 10 or more.

Overall, it is reasonable to postulate that there are approximately 10.5 to 12.3 million vehicles in fleets of 10 or more, roughly 34.8 to 40.7 percent of the total nonresidential vehicle stock. The next two section discuss two subgroups of vehicles which operate in fleets of 10 or more vehicles.

\section{Utility Fleet Vehicles}

Bobit estimates that as of January 1,1993 approximately 1.1 million vehicles were operating in utility fleets of 10 or more. ${ }^{9}$ This would account for approximately 8.9 to 10.5 percent of the vehicles in fleets of 10 or more and for about 3.6 percent of the entire nonresidential vehicle stock.

The Energy Policy Act of 1992 (EPACT) Sections 407(a) and 407(a1) directed EIA to collect data useful to marketers of alternative-fuel vehicles. EIA established three surveys in 1993 designed to collect information regarding the fleet's and fleet vehicles operated by alternative fuel providers. The surveys targeted providers of propane, electricity, and natural gas, all of which are alternative fuels according to EPACT definitions. These surveys are discussed in more detail in later chapters of this report. At the end of 1993, propane providers in the U.S. operated approximately 82,000 fleet vehicles, electric utilities operated nearly 202,000 fleet vehicles, and natural gas suppliers operated just over 138,000 fleet vehicles. ${ }^{10}$ Overall, these three utility fleets account for about 422 thousand vehicles (about 3.4 to 4.0 percent) in fleets of 10 or more, or around 1.4 percent of the 30.2 million nonresidential vehicles.

\footnotetext{
${ }^{4}$ Bobit Publishing Company, Automotive Fleet, 1993 Fact Book .

${ }^{5}$ Vehicles in Class IV - VIII are not included. It is unclear how many vehicles in fleets of 10 or more these classes account for.

${ }^{6}$ Bobit Publishing Company, Automotive Fleet, 1993 Fact Book

${ }^{7}$ The Natural Gas Vehicle Coalition, Natural Gas Vehicle Fleet Market Study.

${ }^{8}$ The degree to which govemment vehicles were covered is unclear; thus, the estimate of 12.3 million vehicies in fleets of 10 or more may be low.

${ }^{9}$ Bobit Publishing Company, Automotive Fleet, 1993 Fact Book.

${ }^{10}$ The Electric Utility Fleet Survey and the Natural Gas Supplier Survey was conducted only if there were 10 or more vehicles in the fleet.
} 


\section{Taxis and Rental Vehicles}

Bobit also estimates that as of January 1, 1993 there were 140 thousand taxis in operation and 1.75 million rental vehicles." Together, these types of vehicles account for around 1.89 million vehicles (15.4 to 18 percent) of the vehicles in fleets or 10 or more vehicles, or approximately 6.3 percent of the total nonresidential vehicle stock.

\section{The Atlanta Survey and Vehicles in Fleets of Less than 10}

Also as part of the EPACT Section 407 data program, EIA conducted a motor-vehicle fleet survey in Atlanta. The findings from the 1994 Survey of Motor-Vehicle Fleets in Atlanta can serve as another potential data source. ${ }^{12}$ The study found that approximately 83 thousand vehicles in private (non-government) business fleets of six or more were operating in the Atlanta nonattainment area. ${ }^{13}$ In 1990 , about 1 percent of the U.S. population resided in the Atlanta nonattainment area. If we assume that the Atlanta nonattainment area population and the number of private business fleet vehicles operating in Atlanta are related to the U.S. population and the U.S. number of vehicles in private business fleets similarly (1 percent of the total), then the resulting national estimate is about 8.3 million vehicles. Because the Atlanta study included fleets with six to nine vehicles, it is somewhat surprising that this estimate is not much larger than Bobit's non-government estimate of 8.2 million vehicles in fleets of 10 or more. However, extrapolation from a single area to the Nation is a risky, theoretically unjustified exercise, so a discrepancy of this size is not surprising.

The Atlanta results suggest that there are few fleets with six to nine vehicles. The results of Atlanta benchmark data collection reinforce this assumption. Before the actual survey was conducted, benchmark data were collected as a screening mechanism for the main fleet survey. Respondents were asked if the business had a fleet, and, if so, how many vehicles were in the fleet. Nearly 33 thousand vehicles were in fleets of one to five, while only 9 thousand were found in fleets of six to nine. If the estimate of 42 thousand vehicles in Atlanta fleets of one to nine is about 1 percent of the total U.S. number of private business vehicles in fleets with less than 10 vehicles, small fleets account for approximately 4.2 million more nonresidential vehicles (about 14 percent of the nonresidential vehicle stock).

\section{All Types of Nonresidential Vehicles}

Adding all the vehicles from each group (fleets of 10 or more vehicles and fleets of less than 10 vehicles) results in a total of 14.7 to 16.5 million vehicles, or around 48.7 to 54.6 percent of the nonresidential vehicle stock. This leaves about 45.4 to 51.3 percent of the nonresidential vehicle stock, or 13.7 to 15.5 million vehicles, unaccounted for. This gap represents about 7.6 to 8.5 percent of the U.S. vehicle stock.

\footnotetext{
"Bobit Publishing Company, Automotive Fleet, 1993 Fact Book

${ }^{12}$ For more information regarding this survey, see Energy Information Administrarion, Profile of Motor-Vehicle Fleets in Atlanta 1994: Assessing the Market for Alternative-Fuel Vehicles, DOE/EIA-0601(94).

${ }^{13}$ The 13 counties defined by the Clean Air Act Amendments of 1990 to be the nonattainment area. The 13 counties immediately surround Atlanta and roughly correspond to the Atlanta Metropolitan Statistical Area (MSA) with the exclusion of five counties on the outer edge of the MSA.
} 



\subsection{Unaccounted-for Vehicles}

One possible reason for the large number of unaccounted-for vehicles is that the estimate of the total vehicle stock is too high. R.L. Polk collects registration data at a particular day of the year; thus, vehicles registered one place at one time of the year and another place at another time of the year are counted only once. However, it is possible for a vehicle to be registered at two different places simultaneously. If this were the case, then the vehicle would be double counted. For example, after a car is sold, it must be registered; but it may still exist in State registration files under the previous owner. In some States, it is at the time of registration renewal that the State is notified of a change in vehicle ownership. The same could be true if the vehicle was retired from circulation. Nearly 11 million vehicles are retired from use every year, ${ }^{14}$ and many more are either traded in or sold privately. If any significant proportion of them shows up as duplicate registrations or registrations of nonexistent vehicles at the time R.L. Polk collects registration data, then the Polk estimate for the total vehicle stock could be too high by several million vehicles. It is possible that the opposite situation could arise: recent registrations of new vehicles that are in use but, due to lag time in data entry, are not included in the R.L. Polk counts. However, the organized registration process should get vehicles into the Polk counts much faster than the less organized deregistration process gets them out.

It is to be expected that some of the 13.7 to 15.5 million vehicles that are not accounted for by any data source are, in fact, available, properly registered vehicles. In other words, these vehicles might be the vehicles that are beyond the scope in the existing surveys and studies. Other potential sources of missing vehicles are discussed below.

\section{Exclusion of Vehicles from the RTECS}

Some vehicles are out of scope for the RTECS and would not be picked up in any of the nonresidential data sources. For example, vehicles associated with students living in group quarters at colleges would not be in the RTECS scope. The total higher education enrollment in 1990 was 13.7 million, of which 7.8 million were full-time. ${ }^{15}$ The National Center for Education Statistics estimates that in 1991, approximately 15 percent of full-time undergraduates lived on campus, 56 percent lived off campus and not with parents, and 28 percent lived with parents. Corresponding percents for graduate students were 8,84 , and 8 . The students living on campus and some part of the students living off campus but not with parents would not be covered in the RTECS. Many of these students would have vehicles, but the number of vehicles probably would not exceed one million.

\section{Inconsistent Definition of Fleets}

Within the fleet industry, the definition of a fleet is not consistent. Much of the inconsistency of the definition of a fleet lies in the distinction between what number of vehicles constitutes a fleet, whether the vehicles are purchased in bulk, and whether they are operated under one central control. The most typical number used to distinguish a fleet is ten or more vehicles, thus missing all the smaller fleets, which very well may amount to several million. Statistics published by Bobit Publishing Company on fleet vehicles are, for example, based on vehicles operated in groups of ten or more. However, this cutoff for the number of vehicles says nothing about whether the vehicles were purchased in bulk of 10 or more. In contrast, R.L. Polk and Company classifies a vehicle as a member of a fleet only if it is sold to a customer who buys ten or more vehicles within a 2-year period. ${ }^{16}$ Conceivably, many fleet vehicles could be missed because of the data source's definition of what vehicles constitute a fleet.

\footnotetext{
${ }^{14}$ U.S. Department of Commerce, Economics and Statistics Administration, Bureau of the Census, Statistical Abstract of the United States 1993.

${ }_{15}^{15}$ U.S. Department of Commerce, Economics and Statistics Administration, Bureau of the Census, Statistical Abstract of the United States 1992.

${ }^{16}$ Shonka, D.B., Characteristics of Automotive Fleets in the United States: 1966-1977, ORNL/MM-6449, Oak Ridge National Laboratory, Oak Ridge, Tennessee, 1978.
} 


\section{Inconsistent Coverage of Government Vehicles}

Generally, data sources are prepared for very different purposes. Consequently, each source has its own target population, scope, and relative data of interest. Because Dwights Energydata, the Bobit Publishing Company, and the Natural Gas Vehicle Coalition are all most interested in the private, commercial business sector of the U.S., it is conceivable that some portion of government vehicles would not be fully covered in their estimates of the number of vehicles in fleets of 10 or more. It is also reasonable to assume that many government vehicles belong to fleets of less than 10 vehicles. These vehicles are not included in the estimate of vehicles in fleets because government vehicles were out of scope in the 1994 Survey of MotorVehicle Fleets in Atlanta. Together, Federal, State, and local government vehicles account for about 3.5 million vehicles, or 11.6 percent, of the total nonresidential vehicle stock. Any significant noncoverage of these vehicles would result in a substantially lower estimate of the total number of nonresidential fleet vehicles than are actually in operation and a higher estimate of those vehicles yet to be accounted for. For example, if 2.5 million government vehicles were not covered by the data sources used to estimate the upper and lower limit for the number of nonresidential vehicles in fleets, then only 11.2 to 13.0 million vehicles, or 37.1 to 43.0 percent, would remain unaccounted for. Because of the high level of uncertainty associated with these data sources' coverage of government vehicles, no estimates of the number of government vehicles potentially excluded from these sources are provided.

\section{Used Car Lots and Auctions}

Another possible data gap that might encompass a substantial number of vehicles is the used car industry. Vehicles traded in or sold among used car dealers would likely have an ongoing registration for some time under the previous owner and thus be counted in the total vehicle stock. No data source would identify these vehicles, however, because no survey is currently conducted to obtain this information. This could account for a great many vehicles. For example, in the Washington, DC, metropolitan area telephone book, there are 194 used car establishments listed. If the average number of cars per lot is about 65 , then in the DC area alone there are 12,610 vehicles included in the total vehicle stock, yet they are not counted in the residential or nonresidential stock. ${ }^{17}$ The Washington metropolitan area contains about 1.7 percent of the total U.S. population. If we assume that population is related similarly to distribution of used car lots, then we could account for about 742,000 vehicles.

Used vehicles are also marketed through the auction industry. Although some auctions are open to the public, for the most part, auctions are a means of selling and acquiring used vehicles among vehicle dealers. It is estimated that around seven million vehicles moved through auctions in $1991 .^{18}$ Including the time it would take a dealer to transport a vehicle to an auction, the time it would take for the vehicle to be sold, and the time it would take the buyer to transport the vehicle to its destination, a vehicle could be out of use, and even away from a used car lot, for as much as three weeks. Apportioning the seven million vehicles using a turnaround time of 21 days, approximately 403,000 more vehicles could be accounted for as being at auto auctions at any given time throughout the year.

\footnotetext{
${ }^{17}$ The average number of 65 vehicles per used car lot was obtained by randomly calling nine Washington used car establishments and asking how many used vehicles were currently on their lot.

${ }^{18}$ Source: Automotive Fleet, 1993 Fact Book. 


\subsection{Conclusion}

The existing residential and nonresidential vehicle data sources, which are of some reliability, can account for 165.9 to 167.7 million vehicles, or 91.5 to 92.4 percent of the total U.S. vehicle stock, leaving 13.7 to 15.5 million vehicles, or 7.6 to 8.5 percent, unaccounted for. The speculative explanations discussed in section 2.5 include perhaps as many as one million student vehicles and perhaps slightly over one million vehicles out of active use in auctions or used car lots. These values leave 11.7 to 13.5 million vehicles still unaccounted for, with no obvious explanation other than uncertainty in fleet estimates and uncertainty about duplicate registrations in the R.L. Polk files.

In a sense, the extrapolated number of vehicles in used car lots and auctions seems surprisingly small. The vacancy rate for residential households is about 8 percent, ${ }^{19}$ and the vacancy rate for commercial floorspace is roughly comparable. ${ }^{20}$ Yet, the suggested level of vehicles in used car lots and auto auctions, potential surrogate "vacancy" measure for vehicles, is much less than 1 percent of the total U.S. vehicle stock. Perhaps this is due to the shorter lifetimes of most vehicles and quicker turnaround to new ownership, compared with the lifetimes and ownership changes of residential and commercial buildings.

The persistent gap of several million vehicles is most likely due to some combination of double counting of registrations and overlooking places where vehicles could be found. Perhaps one day there will be a means to assess this section of the vehicle stock directly, but without more complete and consistent data sources all that can be done, for now, is educated speculation.

\footnotetext{
${ }^{19}$ U.S. Department of Commerce, Economics and Statistics Administration, Bureau of the Census, Statistical Abstract of the United States 1993.
}

${ }^{20}$ Energy Information Administration, Commercial Buildings Energy Consumption Survey, Commercial Buildings Characteristics 1992. 



\section{Section 3.}

Fleets of Alternative Fuel Providers 



\subsection{Introduction}

The EPACT established vehicle purchase mandates for particular subsets of the U.S. vehicle fleet population. These mandates, which go into effect at different times for various fleet subpopulations, required that an incremental percentage of new vehicle purchases must be alternative-fuel vehicles (AFV's). The Federal government fleets were the first to be affected, with their purchase requirements going into effect with model year 1993. Beginning with model year 1996, providers of alternative fuels also will fall under AFV purchase mandates.

EIA established three surveys to collect information about the fleets operated by providers of propane, natural gas, and electricity. The reason for focusing on alternative-fuel providers is that they would likely be important early users of AFV's because they would derive publicity and public relations benefits from using their energy source as a vehicle fuel. The EIA surveyed only providers of propane, natural gas, and electricity because there were existing EIA databases that made the population of those providers easily accessible. At the time the surveys were conducted, there was no database in existence for easy access to the methanol and ethanol providers, and it was still uncertain (due to pending Rules) whether the oil providers/refiners would be covered under the EPACT as alternative fuel providers.

Survey data reveal that alternative-fuel providers are making use of alternative-fuel vehicles. The three classes of providers covered in this report operate a total of 422,127 vehicles in their fleets. Of those, approximately 60,000 vehicles (14 percent) are fueled by alternative fuels, with propane being the most common (Figure 3.1.1). Detailed tables display the complete survey results, and summary descriptions of survey methodologies and results are presented for each type of provider. Throughout this section of the report the term "multifuel" is used to refer to all AFV's that are capable of operating on more than one fuel type (i.e., bi-fuel, flex-fuel, dual-fuel, and hybrid).

Figure 3.1.1. Alternative Fuel Provider Fleets by Fuel, 1993

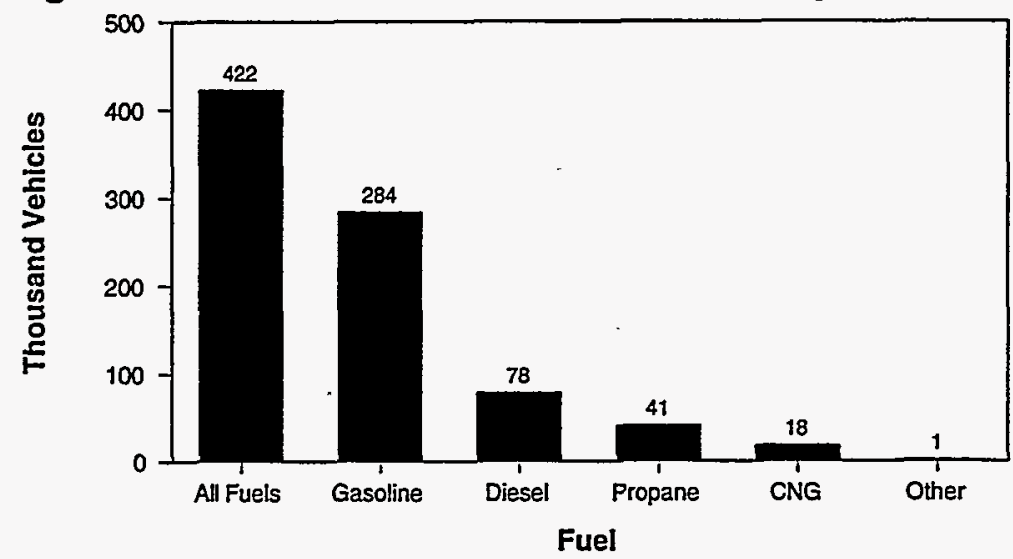

Sources: Energy Information Administration, Form ElA-885, Propane Provider Fleet Survey: Form EIA-861, Schedule VII, Electric Utility Fleet Survey; and Form ElA-176. Schedule B, Natural Gas Supplier Fleet Survey.

\section{Highlights}

\section{Propane Provider Fleet Survey}

- The top 35 propane providers (as measured by sales volume) are responsible for nearly two-thirds of the propane deliveries in the United States, but they operate only about one-third of all propane provider fleet vehicles. The smaller companies operate approximately 70 percent of the total vehicle stock. However, the top 35 companies are much more likely to operate AFV's. Overall, about 80 percent of the top 35 companies' fleet vehicles use propane, while slightly less than one-third of those of the smaller companies use propane. 
- On average, costs to acquire conventional-fuel vehicles were 42 percent higher than the costs of acquiring AFV's; however, acquisition costs varied widely over vehicles types. Respondents also reported lower maintenance costs for propane vehicles than for conventional-fuel vehicles, regardless of vehicle type.

\section{Electric Utility Fleet Survey}

- Although one may expect that electric utilities would use electric vehicles in order to promote their energy source as a transportation fuel, only 237 electric vehicles (4.2 percent of all AFV's) were reported in the Electric Utility Fleet Survey. One could speculate that this is probably because many electric utilities are opting to operate the more economical compressed natural gas (CNG) vehicles until electric vehicle technology develops further. Also, some of the utilities reporting data on the fleet survey are combined utilities, which provide natural gas as well as electricity. These utilities may be choosing to operate CNG vehicles and still are able to promote their energy source.

- After CNG, methanol/ethanol was the most common alternative fuel in electric utility fleets, followed by propane, and then electricity.

\section{Natural Gas Supplier Fleet Survey}

- Natural gas suppliers appear to be farther along than electric utilities in integrating AFV's into their fleets. Survey data indicate that nearly 12 percent of the fleet vehicles operated by natural gas suppliers are AFV's. This proportion is substantially higher than the 3 percent found in the electric utility fleets, but much lower than the 46 percent penetration realized by the propane providers.

- Vehicles fueled by CNG were predominantly multifuel vehicles--vehicles capable of using more than one type of fuel. Most AFV's were converted from the use of conventional fuels to the use of alternative fuels. 


\subsection{Survey Operations}

\section{Propane Provider Fleet Survey}

The Propane Provider Fleet Survey collected information from a sample of the approximately 7,800 propane providers in the United States. The top 35 propane providers in the United States (as determined by 1992 sales volumes ${ }^{1}$ ) were asked to provide detailed information on fleet characteristics and operating practices. These providers, who in 1992 accounted for two-thirds of total residential and commercial propane sales, were mailed a questionnaire that collected the following information:

- Distribution of fleet vehicles among size classes, fuel types, and AFV engine technologies (i.e., multifuel vs. dedicated)

- Fleet vehicle retirements, acquisitions, and conversions planned for 1994

- Source of AFV's (original equipment manufacturer vs. conversion)

- Fleet vehicle fueling practices for conventional-fuel and alternative-fuel vehicles

- Fuel consumption

- Vehicle miles traveled.

- Employee usage of fleet vehicles

- Average length of service of fleet vehicles before retirement (in months and miles)

- Fuel storage capacity in fleet vehicles

- Vehicle acquisition costs

- Vehicle conversion costs (for converted AFV's)

- Comparison of maintenance costs between AFV's and conventional-fuel vehicles.

A stratified random sample of 100 of the remaining smaller providers was selected to provide basic information about their vehicle stock and 1994 acquisition plans by means of a brief telephone interview that collected only the first three items in the above list. These smaller providers were separated into four strata corresponding to the four Census regions. The sample was then drawn using proportional allocation.

\section{Electric Utility Fleet Survey}

Approximately 1,000 electric utilities provided information on their fleets and fleet vehicles in response to the Electric Utility Fleet Survey. This survey was conducted as a supplement to the EIA survey "Annual Electric Utility Report" (Form EIA-861), a census survey of about 3,200 electric utilities in the United States. Only utilities operating a fleet of 10 vehicles or more were required to provide information on the fleet portion of the survey. The respondents to the Electric Utility Fleet Survey were asked (via a mail questionnaire) to report the following:

- Distribution of fleet vehicles among size classes, fuel types, and AFV engine technologies (i.e., multifuel vs. dedicated) and

- Fleet vehicle retirements, acquisitions, and conversions planned for 1994.

\section{Natural Gas Supplier Fleet Survey}

As with the Electric Utility Fleet Survey, the Natural Gas Supplier Fleet Survey was conducted as a supplement to an existing EIA survey, "Annual Report of Natural and Supplemental Gas Supply and Disposition" (Form EIA-176). This form is a census survey of all companies in the United States that take custody of natural gas, excluding consumers and producers. For the 1993 survey, there were approximately 2,064 respondents that completed Form EIA-176. Of those companies, only 553 which operated a fleet of 10 vehicles or more were required to complete the fleet survey.

1 "Top 35 U.S. LPG Retailers," LP-Gas Magazine, June 1993, pg. 22. 
The respondents to the Natural Gas Supplier Fleet Survey were asked to provide the following information:

- Distribution of fleet vehicles among size classes, fuel type, and AFV engine technologies (i.e., multifuel vs. dedicated)

- Fleet vehicle retirements, acquisitions, ànd conversions planned for 1994

- Fleet vehicles fueling practices for conventional-fuel and alternative-fuel vehicles

- Fuel consumption

- Daily vehicle miles traveled range

- Employee usage of fleet vehicles

- Average length of service of fleet vehicles before retirement (in months and miles)

- Source of AFV's (original equipment manufacturer vs. conversion). 


\subsection{Fleet Size and Composition}

\section{Propane Provider Fleet Survey}

At the end of 1993, propane providers in the United States operated approximately 82,000 fleet vehicles. More than two-thirds of these vehicles were medium-duty and heavy-duty trucks, i.e., trucks with a Gross Vehicle Weight (GVW) greater than 8,500 pounds. These large vehicles tended to be trucks for making deliveries of propane to households and businesses. Large pickup trucks made up the next largest share of fleet vehicles.

Nearly half ( 47 percent) of the propane provider fleet vehicles were fueled by alternative fuels, more than were fueled by either gasoline or diesel alone (Figure 3.3:1). As expected, the primary alternative fuel used by propane providers in their fleet vehicles was propane. Only a small number (less than one percent) of their AFV's were fueled by compressed natural gas (CNG).

Figure 3.3.1. Propane Provider Fleet Vehicles by Fuel, 1993

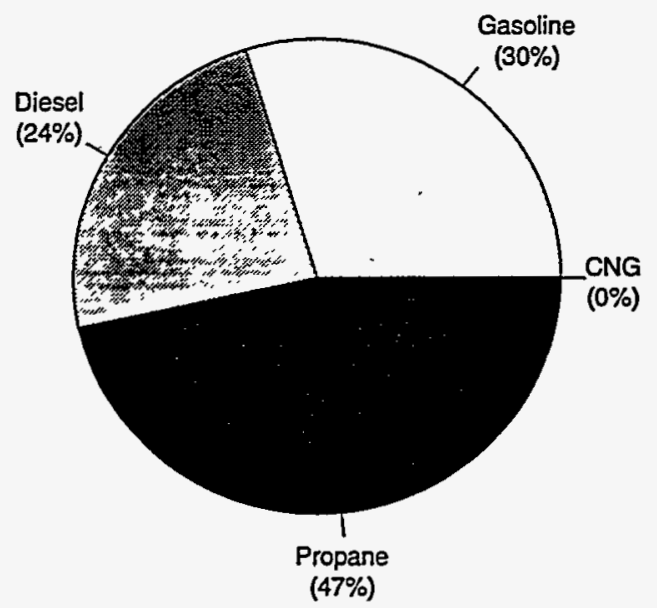

Source: Energy Intomation Administration, Office of Energy Markets and End Use, Form ElA-885, Propane Provider Fleet Survey.

Nearly all of the propane vehicles reported by the propane providers ( 89 percent) were dedicated vehicles, that is, vehicles that operate solely on one fuel--in this case, propane. Multifuel vehicles, meaning AFV's capable of operating on more than one fuel, i.e., bi-fuel, flex-fuel, dual-fuel, and electric hybrid vehicles, made up the rest of the AFV's.

Considerable disparity in the proportion of AFV's in fleets existed between the fleets operated by the top 35 providers and the smaller providers. The top 35 providers operated about three times as many light-duty vehicles fueled by propane as light-duty vehicles fueled by gasoline or diesel alone. The top 35 providers operated nearly five times as many propane vehicles as gasoline or diesel vehicles within the medium- and heavy-duty classes. In contrast, the fleets operated by the smaller providers contain twice as many conventional-fuel vehicles as propane vehicles in these classes (Table 3.3.1). 
Table 3.3.1. Propane Provider Fleet Vehicles by Provider Category, 1993 (Number of Vehicles)

\begin{tabular}{|c|c|c|c|}
\hline $\begin{array}{l}\text { Provider Category } \\
\text { and Vehicle Type }\end{array}$ & Total & Light-Duty Vehicles & $\begin{array}{c}\text { Medium-/Heavy-Duty } \\
\text { Vehicles }\end{array}$ \\
\hline Total ........................ & 81,967 & 25,648 & 56,319 \\
\hline \multicolumn{4}{|l|}{ Top 35 Providers } \\
\hline Total Vehicles ............... & 24,236 & 6,730 & 17,506 \\
\hline Conventional-Fuel Vehicles ....... & 4,694 & 1,685 & 3,010 \\
\hline Propane Vehicles ........... & 19,448 & 4,956 & 14,492 \\
\hline \multicolumn{4}{|l|}{ Remaining Providers } \\
\hline Total Vehicles .............. & 57,731 & 21,057 & 36,674 \\
\hline Conventional-Fuel Vehicles ...... & 39,005 & 14,375 & 24,631 \\
\hline Propane Vehicles . . . . . . . . . . . . & 18,726 & 6,682 & 12,044 \\
\hline
\end{tabular}

Source: Energy Information Administration, Office of Energy Markets and End Use, Form ElA-885, Propane Provider Fleet Survey.

Fleets can acquire alternative-fuel vehicles in two ways: by purchasing them from an original equipment manufacturer $(\mathrm{OEM})$ or by converting a conventional-fuel vehicle to operate on an alternative fuel. The propane providers used both methods to place AFV's in their fleets, but for the most part the propane providers tended to operate converted AFV's. Among dedicated AFV's, only 27 percent were OEM vehicles and only 17 percent of multifuel vehicles were obtained from OEM's. Overall, three-fourths of the AFV's operated by propane providers were converted from conventional-fuel vehicles.

\section{Electric Utility Fleet Survey}

As of December 31, 1993, electric Figure 3.3.2. Electric Utility Fleet Vehicles by Size Class, 1993 utilities with fleets of 10 vehicles or more operated a total of 201,836 vehicles. These vehicles were widely distributed among the different vehicle size classes, although nearly one-third of the vehicles (70,448 vehicles) were medium-duty and heavy-duty trucks. Pickup trucks were the next largest category of vehicles, followed by compact and mid-size passenger cars. Nearly 20 percent of all fleet vehicles in electric utility fleets were passenger cars, in contrast to the propane provider fleets, which had only three percent pașsenger cars (Figure 3.3.2).

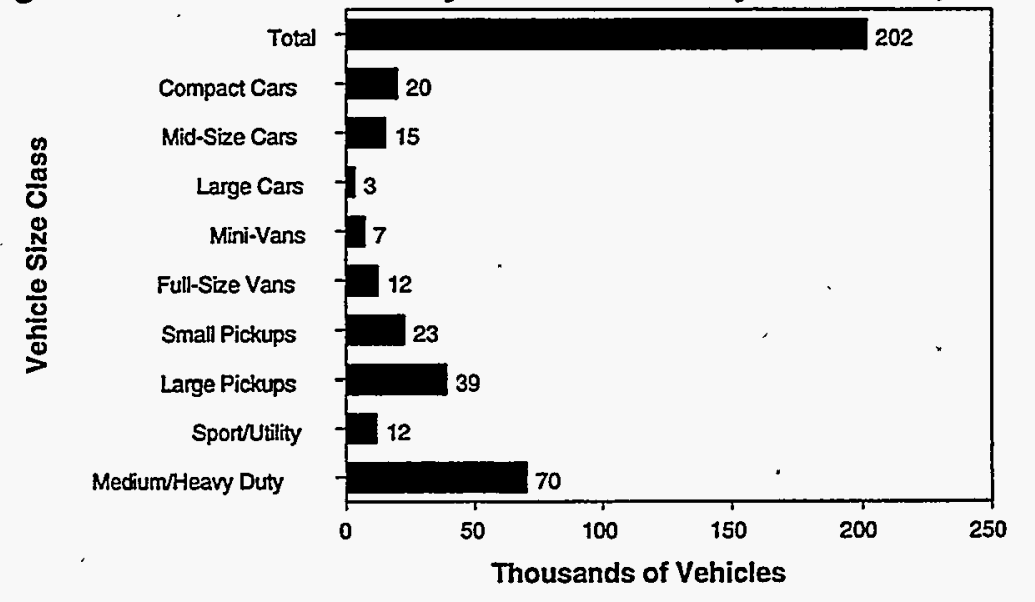

Source: Energy Information Administration, Otfice of Coal, Nuclear, Electric, and Allemative Fuets, Form ElA-861 Schedule VIl, Electric Utility Fleet Survey. 
Nearly all fleet vehicles ( 97 percent) operated Figure 3.3.3. Electric Utility Fleet Alternative-Fuel by electric utilities were conventional-fuel vehicles, with the vast majority of those being dedicated gasoline vehicles. Approximately 21 percent of the conventional-fuel vehicles in electric utility fleets were diesel vehicles. Only 3 percent of the fleet vehicles were alternative-fuel vehicles, and two-thirds of these AFV's were fueled with CNG. These CNG vehicles were mostly multifuel vehicles (78 percent), with only 821 of the 3,756 CNG vehicles being dedicated vehicles. The next most common alternative fuel used in electric utility fleets was methanol/ethanol (used in 935 vehicles), followed by propane (658 vehicles), and then electricity ( 237 vehicles). An insignificant number of alternative-fuel vehicles are fueled by other alternative fuels, mostly liquid natural gas (Figure 3.3.3).

\section{Vehicles by Fuel, 1993}

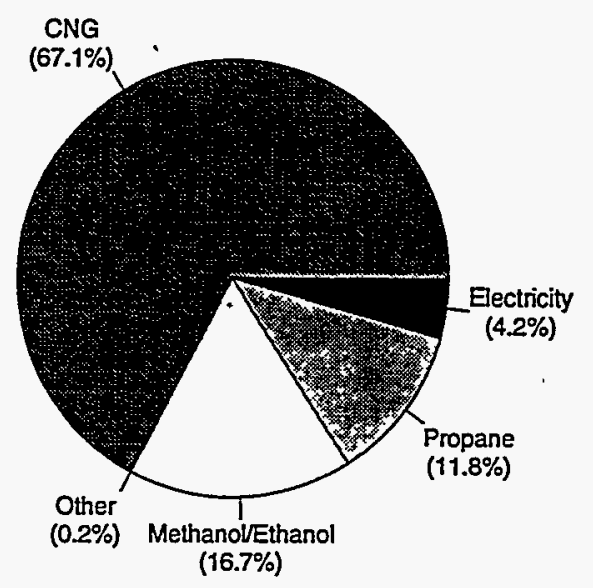

Note: Atternative-Fuel vehicles represent onty three percent of the total fieet vehicles operated by electric utilities.

Source: Energy Information Administration, Office of Coal, Nuclear, Electric, and Altemative Fuels. Form ElA-861 Schedule VII, Electric Utility Fleet Survey.

\section{Natural Gas Supplier Fleet Survey}

At the end of 1993, natural gas suppliers with fleets of 10 or more vehicles operated a total of 138,324 fleet vehicles. As with the fleets operated by electric utilities, the fleet vehicles operated by natural gas suppliers were well distributed among the various vehicle size classes. However, pickup trucks and full-sized vans made up nearly half ( 45 percent) of the fleet vehicles used by natural gas suppliers. Medium-duty and heavy-duty vehicles represented a substantial 26 percent of the fleet vehicles in use. Passenger cars made up another 20 percent (Figure 3.3.4).

Gasoline vehicles dominated the conventional-fuel vehicles with 85 percent of the total. These vehicles were mostly

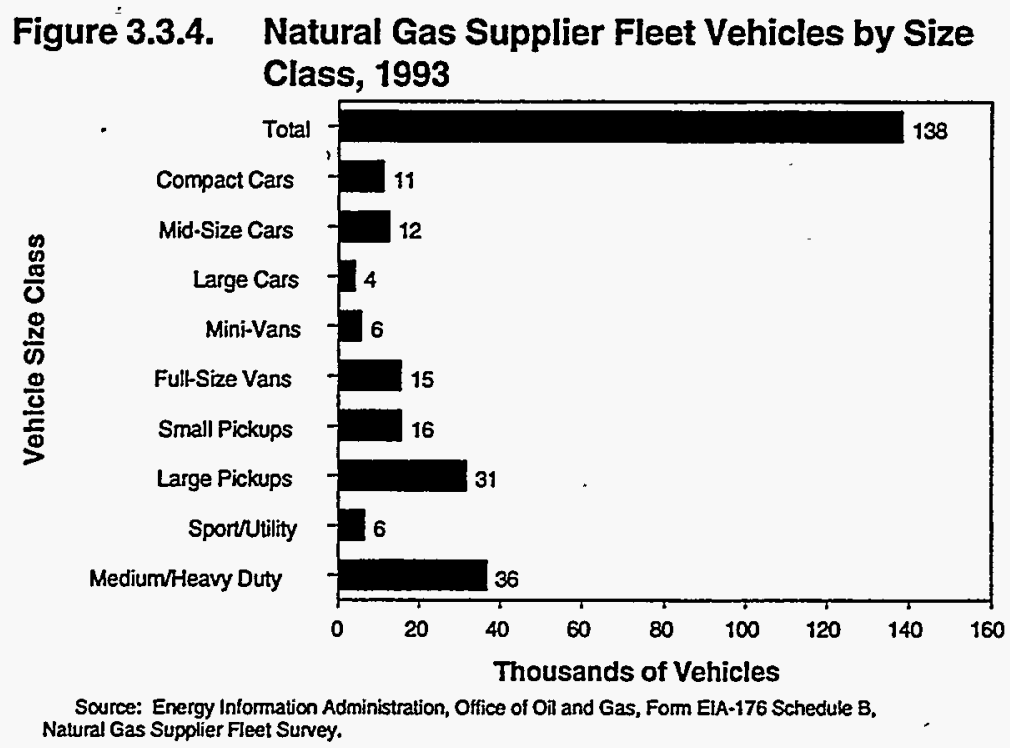

light-duty vehicles, with medium-duty and heavy-duty vehicles representing only 17 percent of the gasoline vehicles. The remaining 15 percent of the conventional-fuel vehicles were mostly medium-duty and heavy-duty diesel vehicles.

Predictably, most AFV's ( 87 percent) were fueled by CNG, but the natural gas providers did make significant use of propane as a vehicle fuel. Of the $14,032 \mathrm{CNG}$ vehicles in natural gas supplier fleets, 84 percent $(11,809$ vehicles) were 
multifuel vehicles. Conversely, dedicated propane vehicles outnumbered multifuel propane vehicles. Fewer than 1 percent were fueled by electricity and other alternative fuels.

The alternative-fuel vehicles in natural gas supplier fleets were almost all converted vehicles. The few OEM vehicles in use in natural gas supplier fleets tended to be dedicated vehicles--only 55 were reported to be OEM multifuel vehicles. The dedicated vehicles in operation were fairly evenly split between OEM and conversion vehicles: 1,582 OEM vehicles and 1,401 converted vehicles (Figure 3.3.5).

Figure 3.3.5. Natural Gas Supplier Alternative-Fuel Vehicles by Technology and Source, 1993

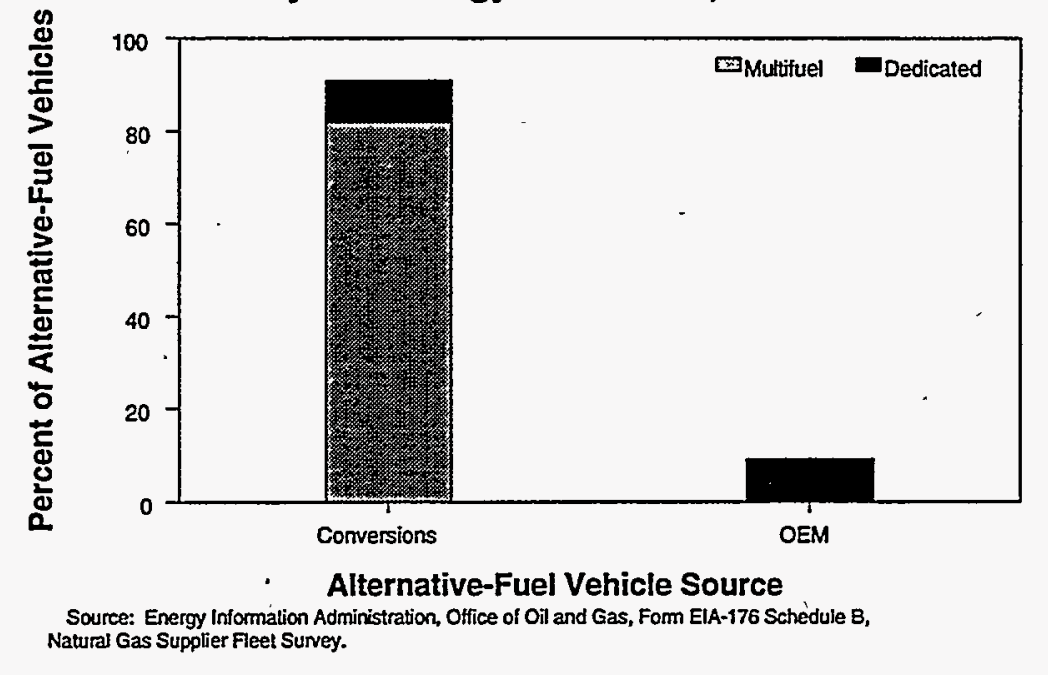




\title{
3.4. Fleet Vehicle Retirement/Acquisition Plans
}

\author{
Propane Provider Fleet Survey
}

The propane providers were asked to report their plans for vehicle retirements and acquisitions during 1994. Only 6 percent $(5,592$ vehicles) of the fleet vehicles operated by propane providers were planned for retirement, nearly half (47 percent) of which were AFV's. The planned acquisitions, 6,970 vehicles, would more than make up for the vehicles being retired.

In addition to the acquisitions, 1,475 vehicle conversions were planned for 1994. There is some double counting in the acquisitions and conversions data. Analysis of the reported data revealed that if a respondent had plans to acquire a new vehicle in 1994 and then immediately convert that vehicle to an alternative fuel, in some cases that vehicle was reported as both an acquisition and a conversion. Analyzing the data to correct the double counting shows that of the 1,475 conversions planned for 1994, 921 were conversions of newly acquired conventional-fuel vehicles and 554 were conversions of vehicles previously operated within the fleet as conventional-fuel vehicles. Overall, more new AFV's were planned for service in 1994 than conventional-fuel vehicles, including both new vehicles and old vehicles being converted to use alternative fuels.

\section{Electric Utility Fleet Survey}

Only about 9 percent of the fleet vehicles operated by electric utilities, (18,956 vehicles) were planned for retirement during 1994. Most retirements were planned for gasoline vehicles; of the total of 16,438 gasoline vehicles planned for retirement, 2,736 were medium/heavy-duty vehicles, 5,675 were pickup trucks, and 3,052 were compact passenger cars. Only 455 AFV's were planned for retirement, and most of these were large pickup trucks. The acquisitions planned for 1994 (18,182 vehicles) would not completely replace all vehicles being retired. Only 724 conversions of conventionalfuel vehicles to alternative-fuel vehicles were planned.

As with the propane survey data, there is double counting within the data regarding fleet vehicle acquisitions and conversions. A similar analysis to the one conducted with the propane provider fleet data revealed that of the 724 conversions planned for 1994, only 159 were conversions of existing fleet vehicles. The other 565 planned conversions were of vehicles newly purchased as conventional-fuel vehicles. Further, only 1,003 of the planned new vehicle acquisitions (6 percent) were AFV's. The remainder were conventional-fuel vehicles, some of which were planned for subsequent conversion.

\section{Natural Gas Supplier Fleet Survey}

The natural gas suppliers planned to retire a larger percentage of their fleet vehicles than either the propane providers or the electric utilities. About 12 percent $(17,088$ vehicles) of the fleet vehicles operated by natural gas suppliers were planned for retirement during 1994. In addition, only 14,374 vehicle acquisitions were planned, indicating that the fleets operated by natural gas suppliers tended to downsize in 1994 . Only 7 percent of the planned vehicle retirements included alternative-fuel vehicles.

A total of 4,623 newly acquired AFV's and conversions of existing vehicles to AFV's were planned for service in 1994 . Aimost 80 percent of those planned vehicles were multifuel CNG vehicles. Most CNG vehicles were light-duty vehicles, with the largest proportion (40 percent) being large pickup trucks. The Natural Gas Supplier Fleet Survey did not experience the double counting problems encountered in the Propane Provider Fleet Survey and the Electric Utility Fleet Survey, so all of the 1,623 planned conversions represent conversions planned for existing fleet vehicles. 



\subsection{Fleet Operating Characteristics}

In addition to the fleet size and composition characteristics covered above, the Propane Provider Fleet Survey (top 35 providers only) and the Natural Gas Supplier Fleet Survey also collected information regarding operating characteristics. Information collected included data concerning fleet vehicle fueling facilities, vehicle usage by employees, vehicle replacement cycles, vehicle fuel storage and consumption, and vehicle miles traveled. In addition, the top 35 propane providers responded to questions about vehicle costs.

\section{Fleet Vehicle Fueling Facilities}

A company has several ways to fuel its fleet vehicles. Large commercial fleets tend to use their own fuel tanks located on a company site to fuel their vehicles. Fleets can also fuel at public fueling stations in the same manner as personal vehicles are fueled, or at private facilities that are designed for use by fleets and are not open to the general public. Fleets sometimes enter into fuel-purchase agreements with their fueling facilities, stipulating that the fleet agrees to purchase its fuel from a specific facility. If the fleet has a credit card for use at a facility but has no commitment to purchase fuel there, then such an arrangement is not considered a fuel purchase agreement.

The EPACT purchase mandates use central fueling as a criterion for determining which fuel provider fleets would be covered by vehicle purchase requirements, so questions about fueling arrangements were asked in order to determine whether alternative-fuel providers were centrally fueled or were capable of being centrally fueled.

\section{Propane Provider Survey}

Conventional-fuel vehicles, for the most part, were fueled either at a company-owned location or at a public fueling location without any type of fuel-purchase agreement. A small number of conventional-fuel vehicles also obtained their fuel at private facilities not open to the public. The data indicate that the propane provider fleets tended not to enter into fuel-purchase agreements with the facilities that provide their fuel.

Only a very small number of the AFV's operated by propane providers fuel at facilities other than company-owned sites. This is probably because almost all of the AFV's operated by propane providers run on propane and therefore use the company's fuel. Vehicles that do obtain their fuel off-site generally purchase the fuel through a fuel-purchase agreement with private facilities.

\section{Natural Gas Supplier Survey}

Natural gas suppliers tended to fuel their fleet vehicles at a variety of types of facilities. For both the conventional-fuel vehicles and the alternative-fuel vehicles, the majority of vehicles were fueled on company-owned sites, but significant numbers of vehicles fueled at other types of facilities. More than one-quarter $(35,370$ vehicles) of the conventional-fuel vehicles operated in fleets belonging to natural gas suppliers were fueled at public fueling facilities. Nearly all of those (88 percent) were fueled without any commitments to a fuel purchase agreement.
Figure 3.5.1. Types of Fueling Facilities Used by Natural Gas Supplier Fleets, 1993

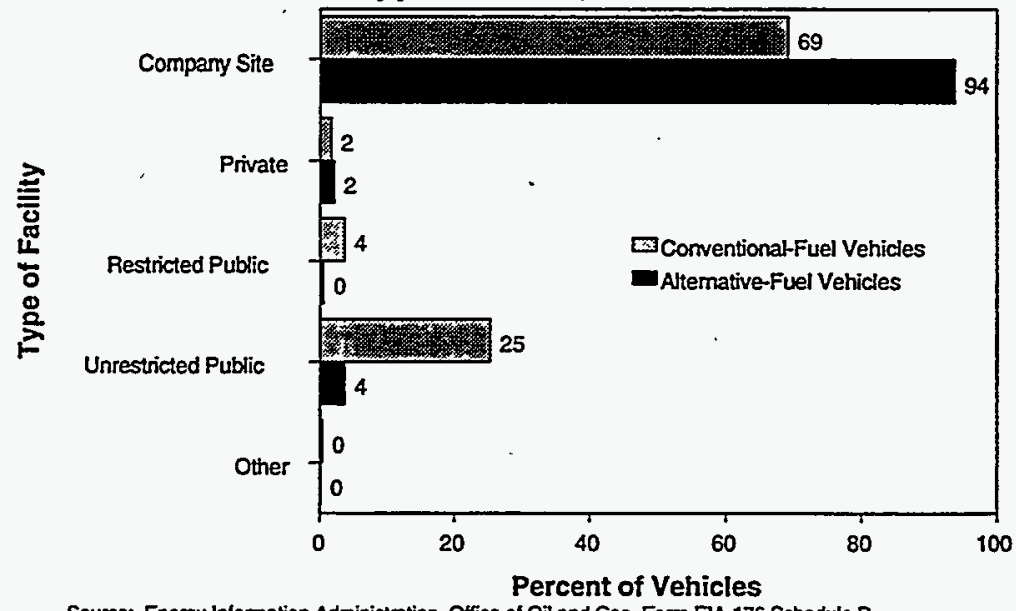

Source: Energy Information Administration, Office of Oil and Gas, Form EA-176 Schedule B, Natural Gas Supplier Fleet Suvey. 
Only 6 percent of AFV's, or 1,004 vehicles, were fueled off-site, a much lower percentage than for conventional-fuel vehicles (Figure 3.5.1).

\section{Fleet Vehicle Usage by Employees}

Company vehicles parked overnight at an employee's residence and not centrally fueled from the provider's facility are excluded from a provider's fleet for purposes of determining whether a fleet is subject to EPACT's purchase mandates. For that reason, the Propane Provider Fleet Survey (top 35 providers) and the Natural Gas Providers Survey collected information regarding the availability of fleet vehicles to company employees.

\section{Propane Provider Survey}

Nearly all vehicles ( 87 percent) operated by propane providers were available to their employees for business use only, and those vehicles were garaged overnight at a company site. The remaining vehicles were available to employees for commuting and business use or for unrestricted business and personal use, and would most likely be garaged overnight at the employees' residences. The respondents also indicated that 99 percent of employees who had the unrestricted use of company vehicles were required to keep a log to record personal and business use.

\section{Natural Gas Supplier Survey}

Fleet vehicles operated by natural gas suppliers tended not to be available to company employees for uses other than business. Three-fourths of the fleet vehicles were designated as for business use only. Employees were allowed to use another 16 percent (22,662 vehicles) for commuting to and from work in addition to using them for business. A relatively small number of vehicles were available to employees for unrestricted or other uses. These data indicate that the fleets belonging to natural gas suppliers were, for the most part, garaged at a company site.

\section{Fleet Vehicle Replacement Cycles}

Replacement cycles refer to the amount of time (or other measure) a company keeps its vehicles before retiring and/or replacing them. A company may retire or replace a vehicle after a certain number of months or after the vehicle has been driven a certain number of miles. In these surveys, respondents could provide replacement cycle data in months, miles, or both.

\section{Propane Provider Survey}

The average months-based cycle for conventional-fuel vehicles in propane provider fleets was 84 months, although propane vehicles were in service for an average of 91 months (Figure 3.5.2). The average miles-based cycle for conventional-fuel vehicles $(216,482$ miles) was higher than for propane vehicles $(179,866$ miles) (Figure 3.5.3). Analysis of the miles-based cycles for the individual vehicle types reveals that this was completely due to the miles-based cycle for the heavy-duty trucks. The miles-based replacement cycle for conventional-fuel heavy-duty vehicles
Figure 3.5.2. Months-Based Replacement Cycles for Propane Provider Fleet Vehicles

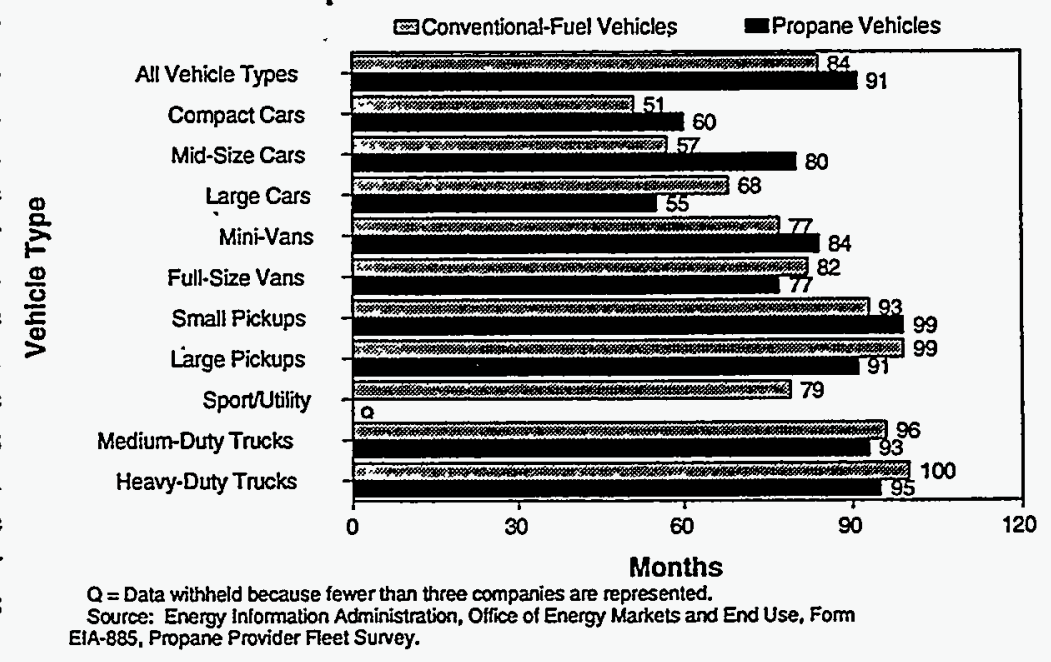


was nearly twice that of the propane heavy- Figure 3.5.3. Miles-Based Replacement Cycles for Propane duty vehicles. This is most likely because the conventional-fuel heavy-duty vehicles travel longer distances than the heavy-duty vehicles fueled by alternative fuels, but the miles traveled data (discussed below) for light-duty vehicles are much more similar.

Analysis of the replacement cycle data reported by the respondents to the Propane Provider Fleet Survey reveals that there is a discrepancy within the reported data. The propane providers reported that approximately 6 percent of their fleet vehicles were planned for retirement in 1994. If 1994 was a typical year for vehicle retirements, then about 100 percent

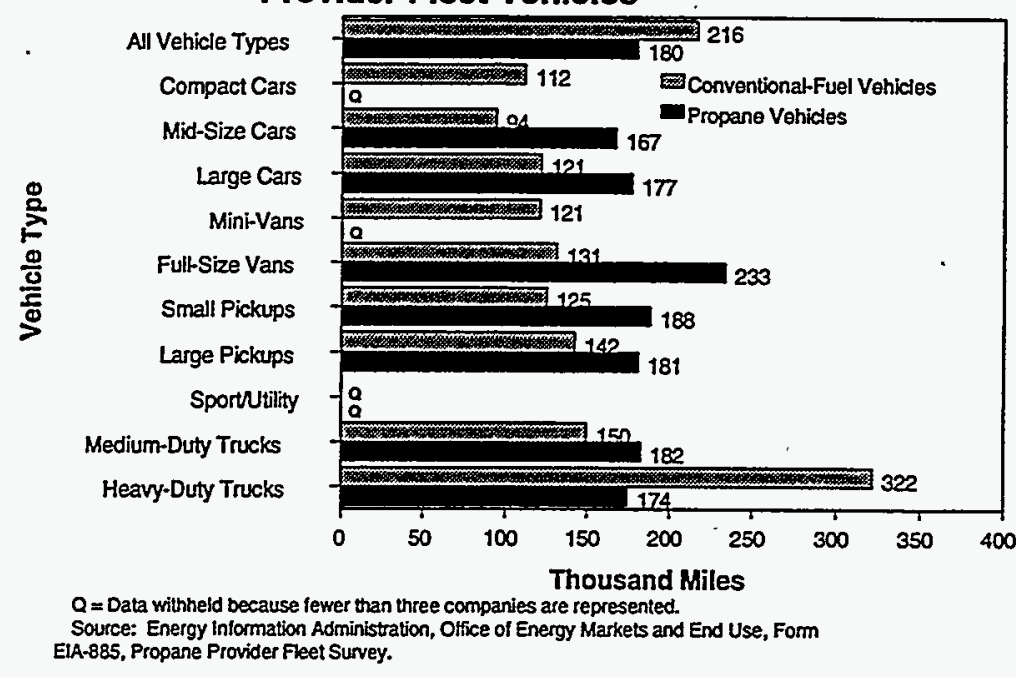
of the fleet vehicles would have been retired and replaced every 17 years. However, data indicate that the typical reported replacement cycle for vehicles is approximately every 7 years. The data collected in the survey cannot positively explain this discrepancy, but possible explanations can be offered. One explanation is that nearly half of all retirements and/or replacements are unplanned; that is, although only 6 percent of the vehicles are planned for retirement at the beginning of a given year, another 6 percent may be retired or replaced due to vehicle condition or other unforeseen circumstances. Four respondents reported that they did not retire their vehicles on a cycle, but rather they retired or replaced them when the condition of the vehicle dictated that it was necessary. Another possible explanation is that 1994 was an abnormal year for retirements, and in a normal year, twice that many vehicles tend to be retired or replaced.

\section{Natural Gas Supplier Survey}

The replacement cycles for fleet vehicles reported by the natural gas suppliers indicated that fleet vehicles tended to be replaced more often in natural gas supplier fleets than in propane provider fleets. On average, vehicles are replaced after about 6 years of use or after 94,530 miles have been traveled, slightly less than the average replacement cycles for the vehicles in propane provider fleets. A possible explanation may be that propane provider fleets contain more mediumduty and heavy-duty vehicles, which tend to be replaced less often than the light-duty vehicles that are more prominent in natural gas supplier fleets.

There also appears to be a small discrepancy between the planned vehicle retirements and the reported replacement cycles among natural gas suppliers. The natural gas suppliers reported that they planned to retire approximately 12 percent of their fleet vehicles in 1994. Using the same logic as with the propane provider fleet data, one could conclude that the entire fleet is replaced approximately every 8 years. However, the natural gas suppliers reported that the average replacement cycle for their fleet vehicles is about 6 years. In addition to the possible explanations provided with the propane provider fleet data, another reason for the discrepancy could be that the suppliers report the replacement cycles that the company would like to adhere to, but, due to budgetary or other constraints, those cycles cannot be met and fleet. vehicles are actually kept in service longer than the replacement cycles indicate. However, none of the possible explanations provided in this report can be confirmed using the data collected on the fuel provider surveys.

\section{Fleet Vehicle Fuel Storage Capacity}

One of the most prominent drawbacks of alternative-fuel vehicles is that the vehicles cannot be driven as far between refuelings as conventional-fuel vehicles. Additional fuel tanks are often placed in the vehicles in order to provide additional fuel. Information on fuel storage capacity was collected only from the propane providers. 
The survey data reveal that the propane vehicles indeed had more fuel storage capacity than the conventional-fuel vehicles. The average fuel storage capacity for dedicated vehicles in the light-duty category was approximately 91 percent higher for propane vehicles than for conventional-fuel vehicles. The difference between multifuel vehicles and conventional-fuel vehicles was much smaller. For the multifuel light-duty vehicles, the average fuel storage capacity for propane was only approximately 22 percent higher than the storage capacity for conventional fuels in conventional-fuel vehicles. This may be due to the fact that in multifuel vehicles, capacity is needed for both propane and gasoline or diesel. Meaningful comparisons between the reported propane and conventional fuel storage capacities for the mediumand heavy-duty vehicles cannot be made, because these vehicles are often fueled from the large delivery tanks they carry, which can hold thousands of gallons of propane.

\section{Fleet Vehicle Fuel Consumption}

\section{Propane Provider Survey}

Of the three fuels that are significantly represented in propane provider fleets (gasoline, diesel, and propane), the most heavily consumed per vehicle is diesel (6,512 gallons per vehicle per year). Diesel fuel is used, for the most part, in the heavy-duty trucks that tend not only to travel long distances, but also to achieve low fuel economies--even though diesel is more efficient than gasoline for similar vehicle types. Gasoline tends to be the Figure 3.5.4. Annual Propane Consumption per Vehicle by least consumed fuel, with dedicated gasoline vehicles only consuming an average of about 1,100 gallons per vehicle per year. Multifuel AFV's consume an average of another 200 gallons of gasoline per vehicle per year. Annual consumption of propane per vehicle was about 2,640 gallons in dedicated propane vehicles and 1,696 gallons in multifuel vehicles. As expected, the lairgest consumers of propane were the medium-duty and heavy-duty trucks. The dedicated medium-duty and heavy-duty propane vehicles consumed an average of 3,583 gallons of propane per vehicle per year, while the multifuel vehicles consumed 3,402 gallons per vehicle per year. Although over all vehicle types the Figure 3.5.4. Annual Propane Consumption per Vehicle by
Vehicle Size Class for Propane Provider Fleet Vehicles

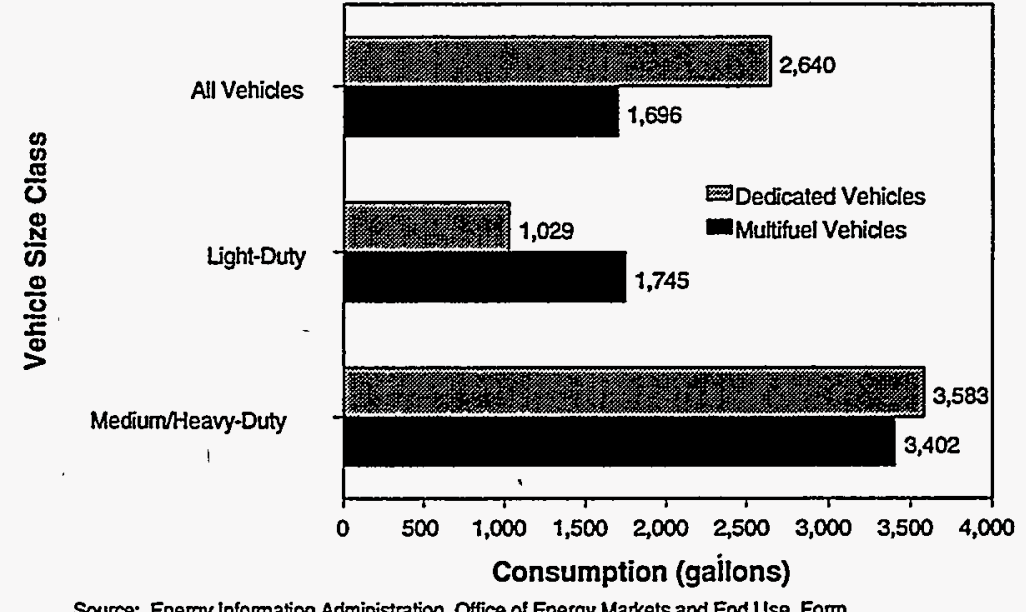

Source: Energy Information Administration, Office of Energy Markets and End Use, Form EiA-885, Propane Provider Fleet Survey.

dedicated vehicles tended to be heavier consumers per vehicle of propane than the multifuel vehicles, among just lightduty vehicles, the multifuel propane vehicles consumed about 70 percent more per vehicle per year than the dedicated - propane vehicles (Figure 3.5.4).

\section{Natural Gas Supplier Survey}

Analysis of the fuel consumption data provided by the natural gas suppliers revealed that more CNG was consumed in multifuel CNG vehicles than in dedicated CNG vehicles. ${ }^{2}$ Because there are substantially more multifuel CNG vehicles than dedicated vehicles, the data suggest that natural gas suppliers make greater use of their multifuel CNG vehicles than their dedicated CNG vehicles. This is probably because the range limitations are not as constraining for multifuel

\footnotetext{
${ }^{2}$ The natural gas consumption data for some respondents to the Natural Gas Supplier Fleet Survey required imputation. See the Data Quality section for details on the imputation.
} 
vehicles because they can operate on gasoline if no CNG is available. The reported consumption of gasoline in multifuel vehicles is 315 gallons per vehicle per year.

At first glance, that level of gasoline consumption may appear low considering it represents consumption of gasoline in CNG multifuel vehicles as well as in propane multifuel vehicles. However, examination of propane and CNG consumption indicates that the multifuel vehicles consume more propane and CNG per vehicle than the dedicated vehicles, implying that those multifuel vehicles tend to operate on the alternative fuel as opposed to gasoline (Figure 3.5.5).
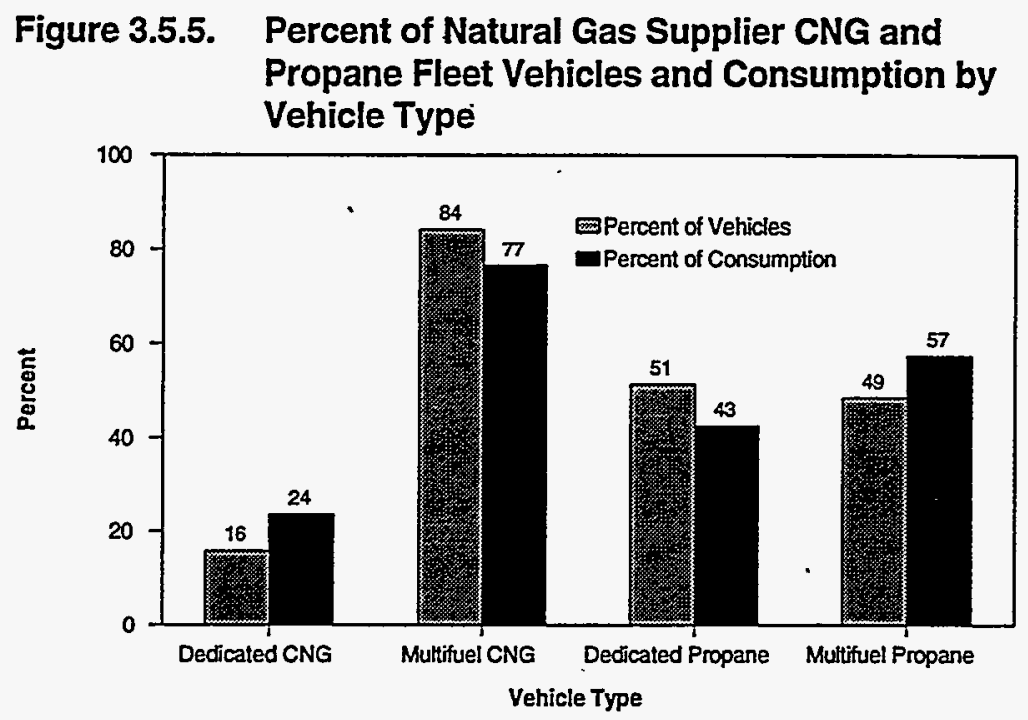

Source: Energy Information Administration, Office of Oil and Gas, Form ElA-176 Schedule B, Natural Gas Supplier Feet Survey.

\section{Fleet Vehicle Miles Traveled}

\section{Propane Provider Survey}

In the analysis of annual vehicle miles traveled, the diesel vehicles tended to stand out. On average, over all vehicle types, the diesel vehicles traveled twice as far per year than the next closest category, dedicated propane vehicles, averaging slightly less than 48,000 miles per year per vehicle. Dedicated gasoline vehicles traveled about 20,000 miles per year, and approximately 3,500 additional miles were traveled on gasoline in multifuel AFV's (Figure 3.5.6). Because little gasoline was consumed in multifuel vehicles and multifuel vehicles traveled relatively few miles on gasoline, one can conclude that the multifuel propane vehicles operated by propane providers were more likely to run on propane than gasoline. Overall, the propane vehicles traveled an average of about 21,000 miles per year per vehicle. The dedicated propane vehicles (23,997 miles per year) do tend to travel slightly more in a year than the multifuel propane vehicles $(18,768$ miles per year).
Figure 3.5.6. Annual Vehicle Miles Traveled per Vehicle on Gasoline, Diesel, and Propane by Vehicle Technology for Propane Provider Fleet Vehicles

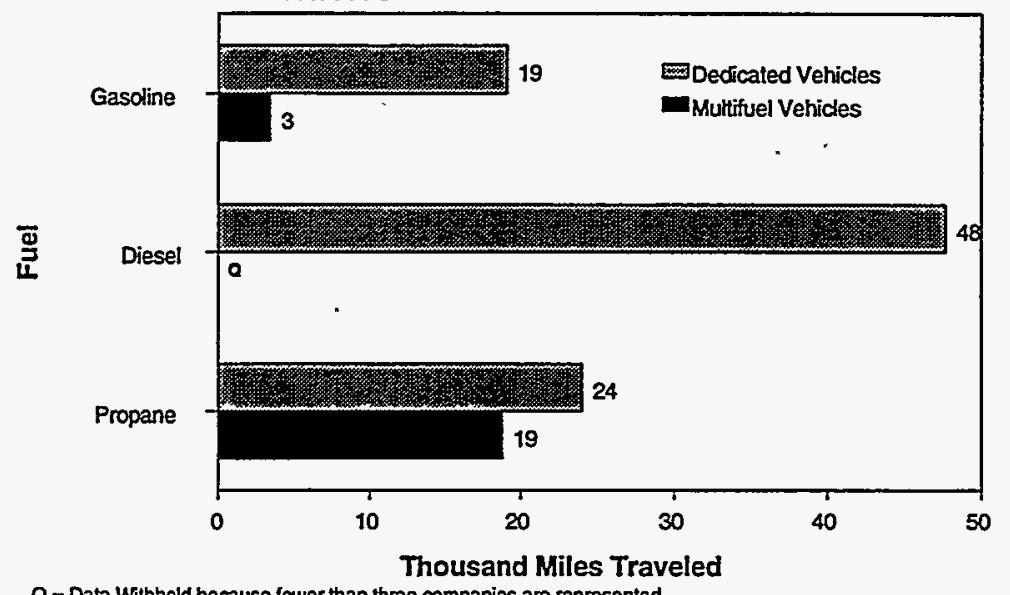

$Q=$ Data Withheld because fewer than thres companies are represented.

Source: Energy Information Administration, Otice of Energy Markets and End Use, Form ElA-885, Propane Provider Fleet Survey. 


\section{Natural Gas Supplier Survey}

Natural gas supplier fleet vehicles tended not to travel long distances on a daily basis. Miles traveled data were collected from the respondents to the Natural Gas Supplier Fleet Survey in the form of ranges of daily miles traveled. Nearly all fleet vehicles ( 92 percent) traveled between 0 and 100 miles per day on average. The vehicles that traveled more miles in a day tended to be large passenger cars and large pickup trucks (Figure 3.5.7).

Figure 3.5.7. Daily Miles Traveled by Natural Gas Supplier

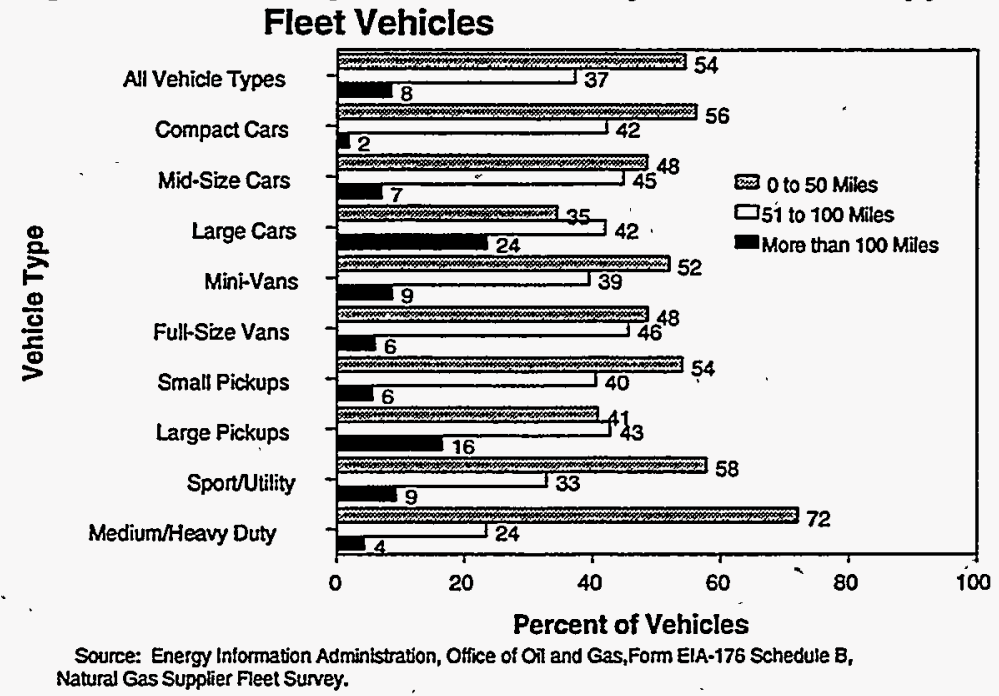

\section{Fleet Vehicle Operating Costs}

Proponents of alternative-fuel vehicles often cite lower operating costs as a benefit of these vehicles, so the Propane Provider Survey asked respondents about their vehicle operating costs. The Natural Gas Supplier Fleet Survey did not include these questions.

Operating costs were separated into three types of costs: vehicle acquisition costs, costs to convert vehicles to an alternative fuel, and maintenance costs. Data on acquisition costs and conversion costs were collected in dollars, and data on maintenance costs were collected as a comparison between conventional-fuel vehicles and alternative-fuel vehicles; that is, the respondents were asked to report if the maintenance costs for a particular alternative-fuel vehicle were more or less than a'comparable conventional-fuel vehicle and by what percentage.

No clear trend appears between conventional-fuel vehicle acquisition costs and the cost to acquire propane vehicles. For example, the costs were about equal for large pickup trucks; for medium-duty trucks (8,501 to $26,000 \mathrm{lbs}$. GVW), the conventional-fuel vehicles were acquired for less than the dedicated propane vehicles; and for heavy-duty trucks (more than $26,000 \mathrm{lbs}$. GVW), the costs to acquire conventional-fuel vehicles were significantly higher than the costs to acquire propane vehicles. On average, for all vehicle types, the acquisition costs for conventional-fuel vehicles $(\$ 35,802)$ tended to be 73 percent higher than the cost to acquire propane vehicles $(\$ 20,736)$ (Figure 3.5.8). The majority of this difference can be attributed to the difference between acquisition costs for propane vehicles and for conventional-fuel heavy-duty vehicles. The differences for the other vehicle types are not nearly that great. The large difference in the heavy-duty vehicle category cannot be explained without further information, but one possible explanation is that the heavy-duty propane vehicles tend to be just slightly more than $26,000 \mathrm{lbs}$. GVW, whereas the conventional-fuel heavyduty vehicles are very large vehicles weighing substantially more than $26,000 \mathrm{lbs}$. This explanation would be consistent with the finding that the acquisition costs for heavy-duty propane vehicles tend to be very close to the acquisition costs for medium-duty propane vehicles. 
The cost to convert vehicles from a Figure 3.5.8. Propane Provider Fleet Vehicle Acquisition conventional fuel to an alternative fuel was fairly stable over the various vehicle types, $\$ 40,000$ ranging from around $\$ 1,200$ to just under $\$ 1,800$. The most costly conversion appeared to be the conversion of a large $\$ 30,000$ passenger car $(\$ 1,783)$ to a dedicated AFV, and the least expensive conversion tended to be that of medium-duty trucks to $\$ 20,000$ multifuel vehicles $(\$ 1,150)$. Conversion to a dedicated AFV tended to cost slightly more than conversion to a multifuel vehicle, $\$ 10,000$ with the difference averaging $\$ 100$ to $\$ 150$ (Figure 3.5.8).

One of the many benefits of AFV's promoted by the industry is that they are more economical to maintain because the and Conversion Costs

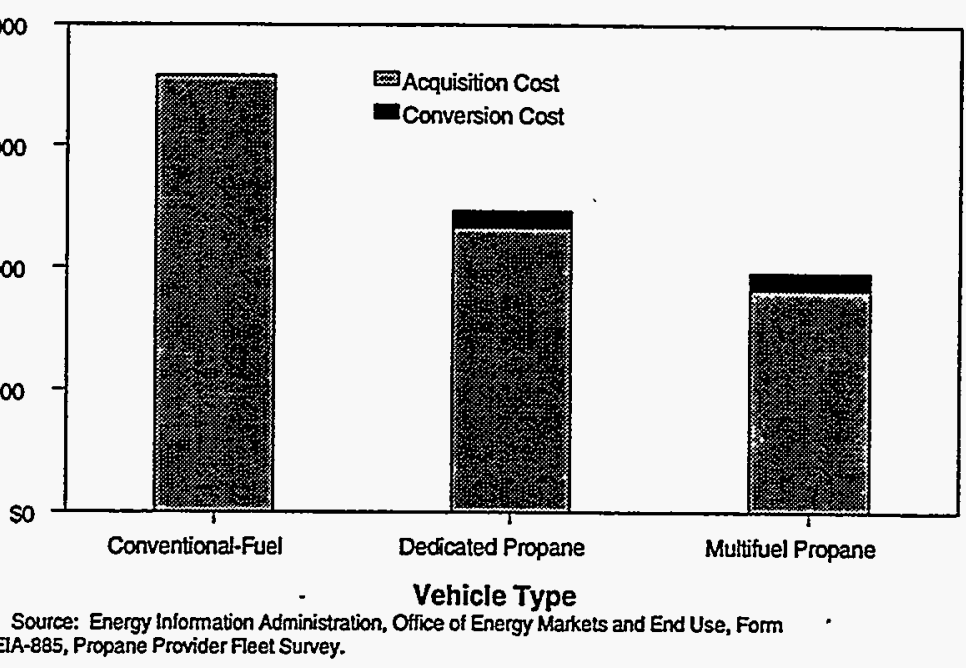
engines tend to have fewer moving parts and the fuels burn cleaner. The data from the Propane Provider Fleet Survey seem to confirm this. The respondents report that the maintenance costs for their propane vehicles are less than for their conventional-fuel vehicles across all vehicle types. The difference between the two types of vehicles is slightly greater for dedicated vehicles (5.7 percent) than for multifuel vehicles ( 4.4 percent). 



\subsection{Detailed Tables}

The tables on the following pages present all data collected on the alternative-fuel provider surveys. All numbers quoted in the preceding text and figures can be obtained using the data in the detailed tables. For those tables that include data from the sampled companies, the corresponding table of Relative Standard Errors is also provided. ${ }^{3}$ Tables 3.6.1 through 3.6.16 contain data from the Propane Provider Fleet Survey; Tables 3.6.17 through 3.6.19 contain data from the Electric Utility Fleet Survey; and Tables 3.6.20 through 3.6.28 present data from the Natural Gas Supplier Fleet Survey.

State-level data for the Electric Utility Fleet Survey and the Natural Gas Supplier Fleet Survey are available. These data can be accessed using EIA's file transfer. protocol (ftp) site on the Internet at ftp://ftp.eia.doe.gov in the pub/consumption directory. 
Table 3.6.1. Fleet Vehicles Operated by Propane Providers as of December 31, 1993 (Number of Vehicles)

\begin{tabular}{|c|c|c|c|c|c|c|c|c|c|c|c|}
\hline \multirow[b]{3}{*}{ Fuel Type } & \multirow[b]{3}{*}{ Total } & \multicolumn{10}{|c|}{ Vehicle Type } \\
\hline & & \multicolumn{3}{|c|}{ Passenger Cars } & \multicolumn{5}{|c|}{$\begin{array}{c}\text { Light-Duty Vans/Trucks } \\
(\leq 8,500 \text { lbs. GVW }\end{array}$} & \multicolumn{2}{|c|}{$\begin{array}{c}\text { Medium-/Heavy-Duty } \\
\text { Trucks }\end{array}$} \\
\hline & & $\begin{array}{c}\text { Sub- } \\
\text { compact/ } \\
\text { Compact } \\
\end{array}$ & $\begin{array}{l}\text { Mid- } \\
\text { Size }\end{array}$ & Large & $\begin{array}{l}\text { Mini- } \\
\text { Van }\end{array}$ & $\begin{array}{c}\begin{array}{c}\text { Full-Size } \\
\text { Van }\end{array} \\
\end{array}$ & $\begin{array}{l}\text { Small } \\
\text { Pickup }\end{array}$ & $\begin{array}{c}\text { Large } \\
\text { Pickup } \\
\end{array}$ & $\begin{array}{l}\text { Sport/ } \\
\text { Utility }\end{array}$ & $\begin{array}{c}8,501 \text { to } \\
26,000 \text { lbs. } \\
\text { GVW }\end{array}$ & $\begin{array}{l}>26,000 \\
\text { lbs. GVW }\end{array}$ \\
\hline $\begin{array}{l}\text { Conventional-Fuel } \\
\text { Vehicles ........... }\end{array}$ & 43,699 & 279 & 1,801 & $Q$ & $\mathbf{Q}$ & 1,571 & 585 & 8,040 & 575 & 10,128 & 17,512 \\
\hline Gasoline ......... & 24,288 & 279 & 1,801 & $\mathbf{Q}$ & $\mathbf{Q}$ & 1,545 & 584 & 6,360 & 571 & 7,686 & 2,255 \\
\hline Diesel .......... & 19,412 & NC & NC & $\mathbf{Q}$ & NC & $\mathbf{Q}$ & $\mathbf{Q}$ & $\mathbf{Q}$ & $Q$ & 2,443 & 15,257 \\
\hline $\begin{array}{l}\text { Alternative-Fuel } \\
\text { Vehicles ......... }\end{array}$ & 38,267 & 131 & 41 & 65 & 14 & $\mathbf{Q}$ & 1,282 & 9,786 & $Q$ & 15,078 & 11,462 \\
\hline $\begin{array}{l}\text { Compressed } \\
\text { Natural Gas }\end{array}$ & . & & & & & & & & & & \\
\hline Dedicated ....... & $\mathbf{Q}$ & NC & NC & NC & NC & $\mathbf{Q}$ & $\mathbf{Q}$ & $Q$ & NC & NC & NC \\
\hline Multifuel ....... & $\mathbf{Q}$ & $Q$ & NC & $\mathbf{Q}$ & NC & $\mathbf{Q}$ & $\mathbf{Q}$ & $Q$ & NC & $Q$ & NC \\
\hline Propane & & - & & & & & & & & & \\
\hline Dedicated ....... & 33,800 & 124 & 6 & $\mathbf{Q}$ & $\mathbf{Q}$ & $\mathbf{Q}$ & 1,082 & 7,080 & $Q$ & 14,383 & 10,719 \\
\hline Multifuel ........ & 4,374 & 6 & 35 & 39 & 6 & $\mathbf{Q}$ & 182 & 2,659 & NC & 691 & 743 \\
\hline Total ............. & 81,967 & 409 & 1,842 & $\mathbf{Q}$ & $\mathbf{Q}$ & 1,934 & 1,867 & 17,826 & 732 & 25,300 & 28,974 \\
\hline
\end{tabular}

NC $=$ No cases in sample.

$\mathrm{Q}=$ Data withheld because Relative Standard Errors are greater than 50 percent or fewer than three companies are represented.

Notes: - Data in this table are based on total survey sample (top 35 providers as well as 100 sampled providers). - Totals may not equal sum of components due to independent rounding. "Multifuel" refers to all AFV's capable of operating on more than one fuel (i.e.,bi-fuel, flex-fuel, hybrid, and dual-fuel vehicles).

Source: Energy Information Administration, Office of Energy Markets and End Use, Form EIA-885, "Propane Provider Fleet Survey." 
Table 3.6.2. Relative Standard Errors for Table 3.6.1

(Percent)

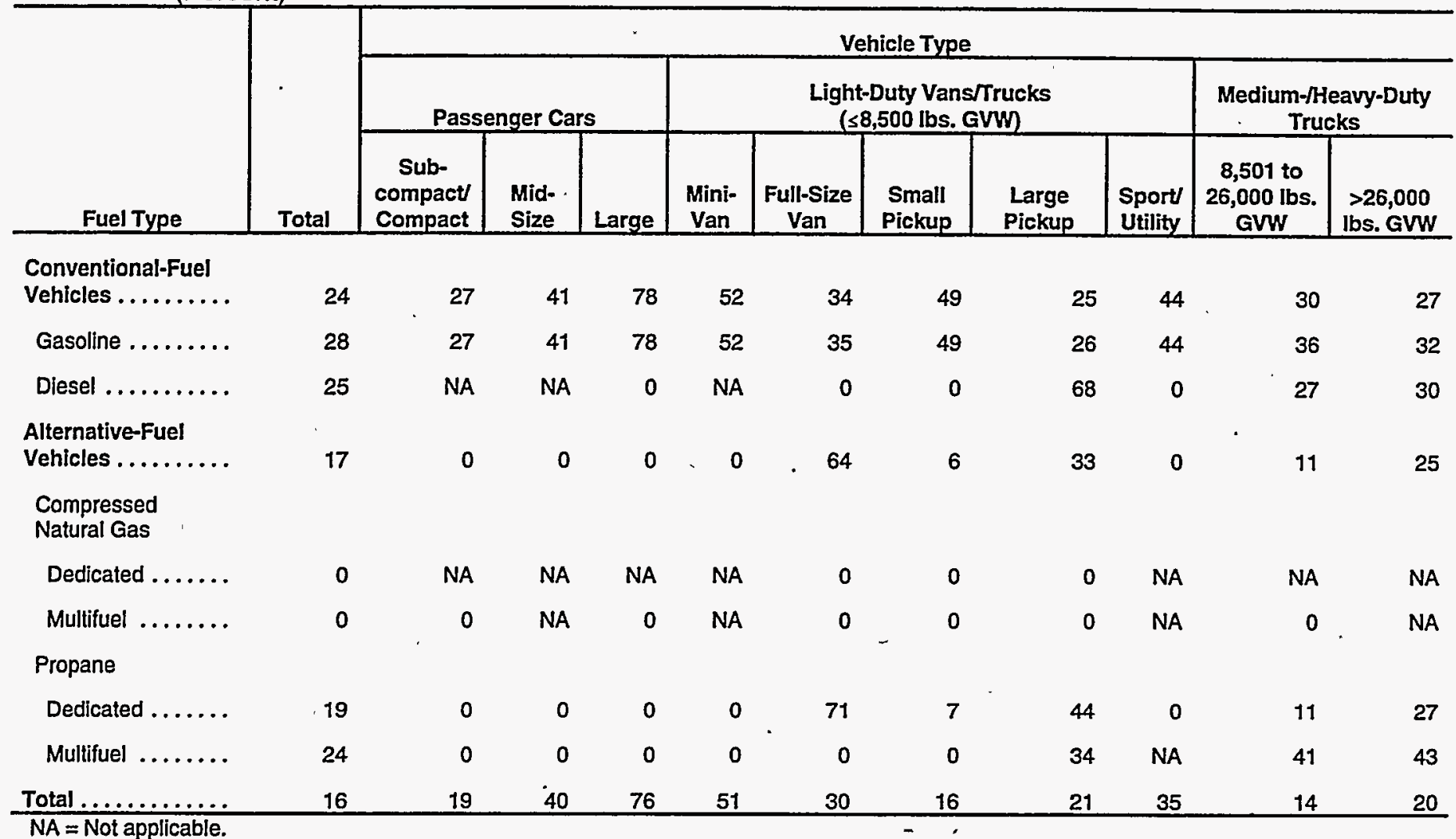

Note: "Multifuel" refers to all AFV's capable of operating on more than one fuel (i.e., bi-fuel, flex-fuel, hybrid, and dual-fuel vehicles).

Source: Energy Information Administration, Office of Energy Markets and End Use, Form ElA-885, "Propane Provider Fleet Survey." 
Table 3.6.3. Alternative-Fuel Fleet Vehicles in Propane Provider Fleets by Source, 1993 (Number of Vehicles)

\begin{tabular}{|c|c|c|c|c|c|c|c|c|c|c|c|}
\hline \multirow[b]{3}{*}{ Vehicle Source } & \multirow[b]{3}{*}{ Total } & \multicolumn{10}{|c|}{ Vehicle Type } \\
\hline & & \multicolumn{3}{|c|}{ Passenger Cars } & \multicolumn{5}{|c|}{$\begin{array}{c}\text { Light-Duty Vans/Trucks } \\
(\leq 8,500 \text { lbs. GVW })\end{array}$} & \multicolumn{2}{|c|}{$\begin{array}{c}\text { Medium-/Heavy-Duty } \\
\text { Trucks }\end{array}$} \\
\hline & & $\begin{array}{c}\text { Sub- } \\
\text { compact } \\
\text { Compact }\end{array}$ & $\begin{array}{l}\text { Mid- } \\
\text { Size }\end{array}$ & Large & $\begin{array}{l}\text { Mini- } \\
\text { Van }\end{array}$ & $\begin{array}{c}\text { Full-Size } \\
\text { Van }\end{array}$ & $\begin{array}{c}\text { Small } \\
\text { Pickup }\end{array}$ & $\begin{array}{c}\text { Large } \\
\text { Pickup } \\
\end{array}$ & $\begin{array}{l}\text { Sport/ } \\
\text { Utility }\end{array}$ & $\begin{array}{l}8,501 \text { to } \\
26,000 \\
\text { lbs. GVW }\end{array}$ & $\begin{array}{l}>26,000 \\
\text { lbs. GVW }\end{array}$ \\
\hline Total Vehicles...$\ldots \ldots$ & 38,267 & 131 & 41 & 65 & 14 & $Q$ & 1,282 & 9,786 & $\mathbf{Q}$ & 15,078 & 11,462 \\
\hline Dedicated & & & ' & $\checkmark$ & & & & & & & \\
\hline Original Equipment ..... & 9,131 & $\mathbf{Q}$ & $Q$ & NC & NC & $\mathbf{Q}$ & NC & $Q$ & $\mathbf{Q}$ & 3,742 & $Q$ \\
\hline Conversion ........... & 24,709 & $\mathbf{Q}$ & $\mathbf{Q}$ & $\mathbf{Q}$ & $\mathbf{Q}$ & $\mathbf{Q}$ & 1,088 & 6,918 & $\mathbf{Q}$ & 10,756 & 5,415 \\
\hline Multifuel & & & & & $\because$ & & & & & & \\
\hline Original Equipment $\ldots .$. & 605 & NC & NC & NC & NC & NC & $Q$ & $\mathbf{Q}$ & NC & $\mathbf{Q}$ & $\mathbf{Q}$ \\
\hline Conversion $\ldots \ldots \ldots \ldots$ & 3,823 & 7 & 35 & 40 & 6 & $\mathbf{Q}$ & 186 & 2,396 & NC & $Q$ & 621 \\
\hline
\end{tabular}

$\mathrm{NC}=$ No cases in sample.

$\mathrm{Q}=$ Data withheld because Relative Standard Errors are greater than 50 percent or fewer than three companies are represented.

Notes: - Data in this table are based on total survey sample (top 35 providers as well as 100 sampled providers). - Totals may not equal sum of components due to independent rounding. "Multifuel" refers to all AFV's capable of operating on more than one fuel (i.e., bi-fuel, flex-fuel, hybrid, and dual-fuel vehicles).

Source: Energy Information Administration, Office of Energy Markets and End Use, Form ElA-885, "Propane Provider Fleet Survey."

Table 3.6.4. Relative Standard Errors for Table 3.6.3 (Percent)

\begin{tabular}{|c|c|c|c|c|c|c|c|c|c|c|c|}
\hline \multirow[b]{3}{*}{ Vehicle Source } & \multirow[b]{3}{*}{ Total } & \multicolumn{10}{|c|}{ Vehicle Type } \\
\hline & & \multicolumn{3}{|c|}{ Passenger Cars } & \multicolumn{5}{|c|}{$\begin{array}{l}\text { Light-Duty Vans/Trucks } \\
(\leq 8,500 \text { lbs. GVW })\end{array}$} & \multicolumn{2}{|c|}{$\begin{array}{c}\text { Medium-/Heavy-Duty } \\
\text { Trucks }\end{array}$} \\
\hline & & $\begin{array}{c}\text { Sub- } \\
\text { compact/ } \\
\text { Compact }\end{array}$ & $\begin{array}{l}\text { Mid- } \\
\text { Size }\end{array}$ & Large & $\begin{array}{l}\text { Mini- } \\
\text { Van }\end{array}$ & $\begin{array}{c}\text { Full-Size } \\
\text { Van }\end{array}$ & $\begin{array}{c}\text { Small } \\
\text { Pickup } \\
\end{array}$ & $\begin{array}{c}\text { Large } \\
\text { Pickup } \\
\end{array}$ & $\begin{array}{l}\text { Sport/ } \\
\text { Utility }\end{array}$ & $\begin{array}{c}8,501 \text { to } \\
26,000 \\
\text { lbs. GVW }\end{array}$ & $\begin{array}{l}>26,000 \\
\text { lbs. GVW }\end{array}$ \\
\hline Total Vehicles ...... & 17 & 0 & 0 & 0 & 0 & 64 & 6 & 33 & 0 & 11 & 25 \\
\hline \multicolumn{12}{|l|}{ Dedicated } \\
\hline Original Equipment ..... & 31 & 0 & 0 & NA & NA & 0 & NA & 83 & 0 & 16 & 54 \\
\hline Conversion $\ldots \ldots \ldots \ldots$ & 16 & 0 & 0 & 0 & 0 & 71 & 7 & 45 & 0 & 14 &, 13 \\
\hline \multicolumn{12}{|l|}{ Multifuel } \\
\hline Original Equipment $\ldots \ldots$ & 36 & NA & NA & NA & NA & NA & 0 & 0 & NA & 97 & 73 \\
\hline Conversion ... & 26 & 0 & 0 & 0 & $\underline{0}$ & 0 & 0 & 38 & NA & 55 & 25 \\
\hline
\end{tabular}

\section{NA $=$ Not applicable.}

Note: "Multifuel" refers to all AFV's capable of operating on more than one fuel (i.e., bi-fuel, flex-fuel, hybrid, and dual-fuel vehicles).

Source: Energy Information Administration, Office of Energy Markets and End Use, Form ElA-885, "Propane Provider Fleet Survey." 
Table 3.6.5. Propane Provider Fleet Vehicle Retirement/Acquisition Plans - 1994

(Number of Vehicles)

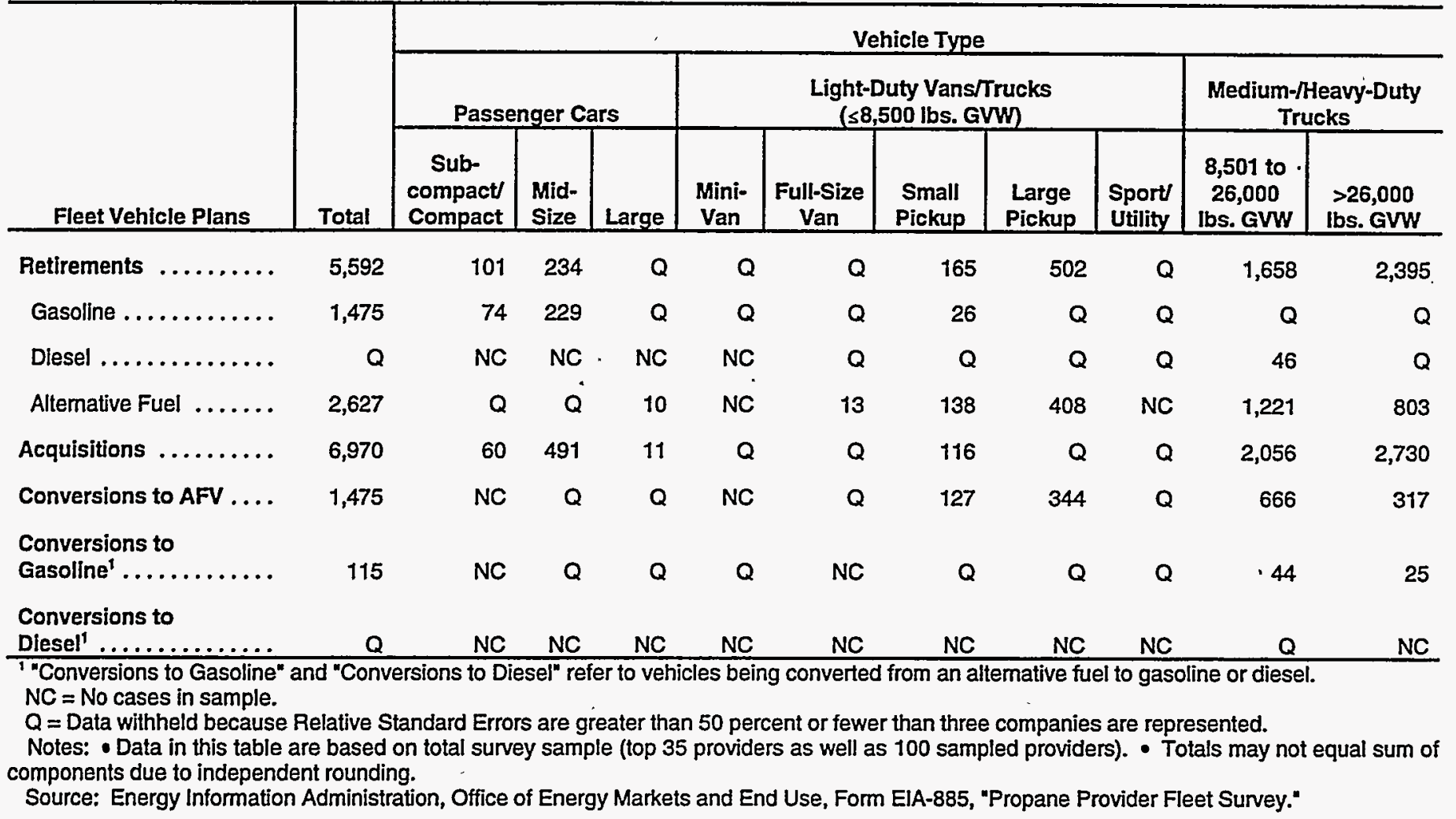

Table 3.6.6. Relative Standard Errors for Table 3.6.5 (Percent)

\begin{tabular}{|c|c|c|c|c|c|c|c|c|c|c|c|}
\hline \multirow[b]{3}{*}{ Fleet Vehicle Plans } & \multirow[b]{3}{*}{ Total } & \multicolumn{10}{|c|}{ Vehicle Type } \\
\hline & & \multicolumn{3}{|c|}{ Passenger Cars } & \multicolumn{5}{|c|}{$\begin{array}{c}\text { Light-Duty Vans } / \text { rucks } \\
\text { ( } \leq 8,500 \text { lbs. GVW) }\end{array}$} & \multicolumn{2}{|c|}{$\begin{array}{c}\text { Medium-/Heavy-Duty } \\
\text { Trucks } \\
\end{array}$} \\
\hline & & $\begin{array}{c}\text { Sub- } \\
\text { compact/ } \\
\text { Compact }\end{array}$ & $\begin{array}{l}\text { Mid- } \\
\text { Size }\end{array}$ & Large & $\begin{array}{c}\text { Mini- } \\
\text { Van }\end{array}$ & $\begin{array}{c}\text { Full-Size } \\
\text { Van }\end{array}$ & $\begin{array}{l}\text { Small } \\
\text { Pickup } \\
\end{array}$ & $\begin{array}{c}\text { Large } \\
\text { Pickup } \\
\end{array}$ & $\begin{array}{l}\text { Sport } \\
\text { Utility } \\
\end{array}$ & $\begin{array}{c}8,501 \text { to } \\
26,000 \\
\text { Ibs. GVW }\end{array}$ & $\begin{array}{l}>26,000 \\
\text { lbs. GVW }\end{array}$ \\
\hline Retirements $\ldots \ldots \ldots$. & 31 & 0 & 47 & 82 & 0 & 85 & 0 & 22 & 95 & 23 & 44 \\
\hline Gasoline ............ & 49 & 0 & 48 & 92 & 0 & 89 & 0 & 86 & 96 & 81 & 70 \\
\hline Diesel ............. & 68 & NA & NA & NA & NA & 0 & 0 & 0 & 0 & 0 & 70 \\
\hline Alternative Fuel ....... & 15 & 0 & 0 & 0 & NA & 0 & 0 & 19 & NA & 17 & 39 \\
\hline Acquisitions ......... & 24 & 0 & 46 & 0 & 96 & 54 & 0 & 51 & 91 & 22 & 28 \\
\hline Conversions to AFV .... & 13 & NA & 0 & 0 & NA & 0 & 0 & 31 & 0 & 23 & 0 \\
\hline $\begin{array}{l}\text { Conversions to } \\
\text { Gasoline' } \ldots \ldots \ldots \ldots \ldots\end{array}$ & 0 & NA & 0 & 0 & 0 & NA & 0 & 0 & 0 & 0 & 0 \\
\hline $\begin{array}{l}\text { Conversions to } \\
\text { Diesel }{ }^{1} \ldots \ldots \ldots \ldots \ldots \ldots\end{array}$ & 100 & NA & $\mathrm{NA}$ & NA & NA & NA & NA & NA & NA & 100 & NA \\
\hline
\end{tabular}


Table 3.6.7. "New" Propane Provider Fleet Vehicles Planned for Service in 1994" (Number of Vehicles)

\begin{tabular}{|c|c|c|c|c|c|c|c|c|c|c|c|}
\hline \multirow[b]{3}{*}{ Fuel Type } & \multirow[b]{3}{*}{ Total } & \multicolumn{10}{|c|}{ Vehicle Type } \\
\hline & & \multicolumn{3}{|c|}{ Passenger Cars } & \multicolumn{5}{|c|}{$\begin{array}{l}\text { Light-Duty Vans/Trucks } \\
(\leq 8,500 \text { lbs. GVW }\end{array}$} & \multicolumn{2}{|c|}{$\begin{array}{c}\text { Medium-/Heavy-Duty } \\
\text { Trucks }\end{array}$} \\
\hline & & $\begin{array}{c}\text { Sub- } \\
\text { compact/ } \\
\text { Compact }\end{array}$ & $\begin{array}{l}\text { Mid- } \\
\text { Size }\end{array}$ & Large & $\begin{array}{l}\text { Mini- } \\
\text { Van }\end{array}$ & $\begin{array}{c}\text { Full-Size } \\
\text { Van }\end{array}$ & $\begin{array}{l}\text { Small } \\
\text { Pickup }\end{array}$ & $\begin{array}{l}\text { Large } \\
\text { Pickup }\end{array}$ & $\begin{array}{l}\text { Sport/ } \\
\text { Utility }\end{array}$ & $\begin{array}{c}8,501 \text { to } \\
26,000 \\
\text { Ibs. GVW }\end{array}$ & $\begin{array}{l}>26,000 \\
\text { lbs. GVW }\end{array}$ \\
\hline $\begin{array}{l}\text { Conventional-Fuel } \\
\text { Vehicles .......... }\end{array}$ & 3,151 & 57 & 467 & 4 & $\mathbf{Q}$ & $\mathbf{Q}$ & $\mathbf{Q}$ & 54 & $\mathbf{Q}$ & $\mathbf{Q}$ & 1,451 \\
\hline Gasoline ......... & 1,400 & 57 & 465 & 3 & $\dot{Q}$ & $\mathbf{Q}$ & $\mathbf{Q}$ & $\mathbf{Q}$ & $Q$ & $\mathbf{Q}$ & $Q$ \\
\hline Diesel .......... & 1,750 & NC & $\mathbf{Q}$ & $\mathbf{Q}$ & NC & $\mathbf{Q}$ & NC & 18 & $Q$ & 356 & 1,366 \\
\hline $\begin{array}{l}\text { Alternative-Fuel } \\
\text { Vehicles .......... }\end{array}$ & 4,373 & $\mathbf{Q}$ & $\mathbf{Q}$ & 10 & $\mathbf{Q}$ & $\mathbf{Q}$ & 158 & 1,180 & $Q$ & 1,629 & 1,350 \\
\hline $\begin{array}{l}\text { Compressed } \\
\text { Natural Gas }\end{array}$ & & $\cdot$ & 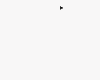 & & & & & & & & \\
\hline Dedicated ....... & $\mathbf{Q}$ & NC & NC & NC & NC & NC & $\mathbf{Q}$ & $\mathbf{Q}$ & NC & NC & NC \\
\hline Multifuel $: \ldots \ldots$. & NC & NC & NC & NC & NC & NC & NC & NC & NC ${ }^{\prime}$ & NC & NC \\
\hline Propane & & & & & & & & & & & \\
\hline Dedicated . . . . . . & 4,226 & NC & $\mathbf{Q}$ & $\mathbf{Q}$ & $Q$ & $\mathbf{Q}$ & 143 & 1,111 & $Q$ & 1,617 & 1,326 \\
\hline Multifuel ........ & 122 & $\mathbf{Q}$ & $\mathbf{Q}$ & 9 & $\mathbf{Q}$ & NC & $\mathbf{Q}$ & 54 & $\mathbf{Q}$ & $\mathbf{Q}$ & $Q$ \\
\hline Total ........... & 7.524 & 60 & 494 & 14 & $\mathbf{Q}$ & $\mathbf{Q}$ & 168 & 1,233 & $Q$ & 2,296 & 2,801 \\
\hline
\end{tabular}

1 "New" Vehicles refers to both newly acquired vehicles and existing vehicles converted to operate on a new, fuel. $\mathrm{NC}=$ No cases in sample.

$Q=$ Data withheld because Relative Standard Errors are greater than 50 percent or fewer than three companies are represented.

Notes: - Data in this table are based on total survey sample (top 35 providers as well as 100 sampled providers). - Totals may not equal sum of components due to independent rounding. "Multifuel" refers to all AFV's capable of operating on more than one fuel (i.e., bi-fuel, flex-fuel, hybrid, and dual-fuel vehicles).

Source: Energy Information Ad̈ministration, Office of Energy Markets and End Use, Form ElA-885, "Propane Provider Fleet Survey." 
Table 3.6.8. Relative Standard Errors for Table 3.6.7 (Percent)

\begin{tabular}{|c|c|c|c|c|c|c|c|c|c|c|c|}
\hline \multirow[b]{3}{*}{ Fuel Type } & \multirow[b]{3}{*}{ Total } & \multicolumn{10}{|c|}{ Vehicle Type } \\
\hline & & \multicolumn{3}{|c|}{ Passenger Cars } & \multicolumn{5}{|c|}{$\begin{array}{c}\text { Light-Duty Vans } / \text { Trucks } \\
(\leq 8,500 \mathrm{lbs} \text {. GVW })\end{array}$} & \multicolumn{2}{|c|}{$\begin{array}{c}\text { Medium-/Heavy-Duty } \\
\text { Trucks }\end{array}$} \\
\hline & & $\begin{array}{c}\text { Sub- } \\
\text { compact } \\
\text { Compact }\end{array}$ & $\begin{array}{l}\text { Mid- } \\
\text { Size }\end{array}$ & Large & $\begin{array}{l}\text { Mini- } \\
\text { Van }\end{array}$ & $\begin{array}{c}\text { Full-Size } \\
\text { Van }\end{array}$ & $\begin{array}{l}\text { Small } \\
\text { Pickup }\end{array}$ & $\begin{array}{l}\text { Large } \\
\text { Pickup }\end{array}$ & $\begin{array}{l}\text { Sportt } \\
\text { Utility }\end{array}$ & $\begin{array}{c}8,501 \text { to } \\
26,000 \\
\text { lbs. GVW }\end{array}$ & $\begin{array}{c}>26,000 \\
\text { lbs. GVW }\end{array}$ \\
\hline $\begin{array}{l}\text { Conventional-Fuel } \\
\text { Vehicles ............ }\end{array}$ & 40 & 0 & 48 & 0 & 96 & 55 & 0 & 0 & 91 & 51 & 41 \\
\hline Gasoline .......... & 42 & 0 & 49 & 0 & 96 & 56 & 0 & 0 & 92 & 78 & 90 \\
\hline Diesel ............ & 39 & NA & 0 & 0 & NA & 0 & NA & 0 & $\mathbf{0}$ & 43 & 43 \\
\hline $\begin{array}{l}\text { Alternative-Fuel } \\
\text { Vehicles .......... }\end{array}$ & 27 & 0 & 0 & 0 & 0 & 0 & 0 & 47 & 0 & 21 & 37 \\
\hline $\begin{array}{l}\text { Compressed } \\
\text { Natural Gas }\end{array}$ & & & & & & & & & & - & \\
\hline Dedicated ....... & 0 & NA & NA & NA & NA & NA & 0 & 0 & NA & NA & NA \\
\hline Multifuel ......... & NA & NA & NA & NA & NA & NA & NA & NA & NA & NA & NA \\
\hline Propane & & & & & & & & & & & \\
\hline Dedicated ........ & 28 & NA & 0 & 0 & 0 & 0 & 0 & 50 & 0 & 21 & 38 \\
\hline Multifuel...$\ldots \ldots$ & 0 & 0 & 0 & 0 & 0 & NA & 0 & 0 & 0 & 0 & $\cdot 0$ \\
\hline Total .. & 23 & 0 & 46 & 0 & 95 & 54 & 0 & 45 & 79 & 21 & 27 \\
\hline
\end{tabular}

NA = Not applicable.

Note: "Multifuel" refers to all AFV's capable of operating on more than one fuel (i.e., bi-fuel, flex-fuel, hybrid, and dual-fuel vehicles).

Source: Energy Information Administration, Office of Energy Markets and End Use, Form ElA-885, "Propane Provider Fleet Survey." 
Table 3.6.9. Propane Provider Fleet Vehicle Fueling Locations, 1993

(Number of Vehicles)

\begin{tabular}{|c|c|c|c|c|c|c|c|c|c|c|c|}
\hline \multirow[b]{3}{*}{$\begin{array}{l}\text { Fuel Type and Fueling } \\
\text { Location }\end{array}$} & \multirow[b]{3}{*}{ Total } & \multicolumn{10}{|c|}{ Vehicle Type } \\
\hline & & \multicolumn{3}{|c|}{ Passenger Cars } & \multicolumn{5}{|c|}{$\begin{array}{c}\text { Light-Duty Vans/Trucks } \\
(\leq 8,500 \text { lbs. GVW })\end{array}$} & \multicolumn{2}{|c|}{$\begin{array}{c}\text { Medium-/Heavy-Duty } \\
\text { Trucks }\end{array}$} \\
\hline & & $\begin{array}{l}\text { Sub- } \\
\text { compact/ } \\
\text { Compact } \\
\end{array}$ & $\begin{array}{l}\text { Mid- } \\
\text { Size }\end{array}$ & Large & $\begin{array}{l}\text { Mini- } \\
\text { Van }\end{array}$ & $\begin{array}{c}\text { Full-Size } \\
\text { Van }\end{array}$ & $\begin{array}{l}\text { Small } \\
\text { Pickup } \\
\end{array}$ & $\begin{array}{l}\text { Large } \\
\text { Pickup } \\
\end{array}$ & $\begin{array}{l}\text { Sport } \\
\text { Utility }\end{array}$ & $\begin{array}{l}8,501 \text { to } \\
26,000 \\
\text { lbs. GVW }\end{array}$ & $\begin{array}{c}>26,000 \\
\text { lbs. GVW }\end{array}$ \\
\hline \multicolumn{12}{|l|}{ Conventional-Fuel Vehicles } \\
\hline Company-Owned ........ & 2,167 & NC & 23 & 3 & $\mathbf{Q}$ & 506 & .54 & 139 & $\mathbf{Q}$ & 437 & 953 \\
\hline \multicolumn{12}{|l|}{ Private } \\
\hline Restricted ............ & 7 & $\mathbf{Q}$ & Q & NC & NC & NC & NC & NC & NC & NC & NC \\
\hline Unrestricted...$\ldots \ldots \ldots$ & 347 & $Q$ & 63 & 22 & $\mathbf{Q}$ & 15 & $\mathbf{Q}$ & $\mathbf{Q}$ & $\mathbf{Q}$ & 48 & 142 \\
\hline \multicolumn{12}{|l|}{ Public } \\
\hline Restricted ............. & $\mathbf{Q}$ & $\mathbf{Q}$ & Q & NC & NC & $\mathbf{Q}$ & NC & NC & $\mathbf{Q}$ & Q & $\cdot \mathrm{Q}$ \\
\hline Unrestricted & 2,089 & 121 & 373 & 28 & 18 & 33 & 50 & 52 & Q & 161 & 1,250 \\
\hline \multicolumn{12}{|l|}{ Alternative-Fuel Vehicles } \\
\hline Company-Owned ........ & 19,534 & 131 & 41 & 65 & 14 & 125 & 1,202 & 3,414 & $\mathbf{Q}$ & 8,318 & 6,179 \\
\hline \multicolumn{12}{|l|}{ Private } \\
\hline Restricted . . . . . . . . . . & $\mathbf{Q}$ & NC & NC & NC & NC & $\mathbf{Q}$ & $\mathbf{Q}$ & NC & Q & NC & NC \\
\hline Unrestricted ........... & NC & NC & NC & NC & NC & NC & NC & NC & NC & NC & NC \\
\hline \multicolumn{12}{|l|}{ Public } \\
\hline Restricted ............ & NC & NC & NC & NC & NC & NC & NC & NC & NC & NC & NC \\
\hline Unrestricted & NC & NC & $\mathrm{NC}$ & NC & NC & NC & NC & NC & NC & NC & NC \\
\hline
\end{tabular}

NC $=$ No cases in sample.

$Q=$ Data withheld because fewer than three companies are represented.

Notes: - Data in this table represent only the top 35 propane providers. - Totals may not equal sum of components due to independent rounding. - A "restricted" location refers to the situation where the fleet fuels at a particular location under the obligation of a fuel purchase agreement. If there is no fuel purchase agreement, the location is considered to be "unrestricted."

Source: Energy Information Administration, Office of Energy Markets and End Use, Form EIA-885, "Propane Provider Fleet Survey." 
Table 3.6.10. Propane Provider Fleet Vehicle Usage for Vehicles Assigned to Employees, 1993 (Number of Vehicles)

\begin{tabular}{|c|c|c|c|c|c|c|c|c|c|c|c|}
\hline \multirow[b]{3}{*}{ Vehicle Usage } & \multirow[b]{3}{*}{ Total } & \multicolumn{10}{|c|}{ Vehicle Type } \\
\hline & & \multicolumn{3}{|c|}{ Passenger Cars } & \multicolumn{5}{|c|}{$\begin{array}{c}\text { Light-Duty Vans/Trucks } \\
(\leq 8,500 \mathrm{lbs} \text {. GVW }\end{array}$} & \multicolumn{2}{|c|}{$\begin{array}{c}\text { Medium-/Heavy-Duty } \\
\text { Trucks }\end{array}$} \\
\hline & & $\begin{array}{l}\text { Sub- } \\
\text { compact/ } \\
\text { Compact }\end{array}$ & $\begin{array}{l}\text { Mid- } \\
\text { Size }\end{array}$ & Large & $\begin{array}{l}\text { Mini- } \\
\text { Van }\end{array}$ & $\begin{array}{c}\text { Full-Size } \\
\text { Van }\end{array}$ & $\begin{array}{c}\text { Small } \\
\text { Pickup }\end{array}$ & $\begin{array}{l}\text { Large } \\
\text { Pickup } \\
\end{array}$ & $\begin{array}{l}\text { Sport } \\
\text { Utility }\end{array}$ & $\begin{array}{c}8,501 \text { to } \\
26,000 \\
\text { Ibs. GVW }\end{array}$ & $\begin{array}{c}>26,000 \\
\text { lbs. GVW }\end{array}$ \\
\hline Total Vehicles .... & 24,236 & 332 & 521 & 117 & 63 & 690 & 1,323 & 3,607 & 76 & 8,967 & 8,539 \\
\hline $\begin{array}{l}\text { Business Use } \\
\text { Only .......... }\end{array}$ & 21,084 & $Q$ & 47 & 48 & 19 & 461 & 522 & 2,681 & 69 & 8,612 & 8,474 \\
\hline $\begin{array}{l}\text { Business Use \& } \\
\text { Commuting ....... }\end{array}$ & 1,603 & 20 & 46 & 48 & 37 & 223 & 169 & 638 & $Q$ & 354 & 65 \\
\hline $\begin{array}{l}\text { Unrestricted Use } \\
\text { (Log) } \ldots \ldots \ldots \ldots\end{array}$ & 1,526 & 162 & 414 & 13 & 6 & $\mathbf{Q}$ & 632 & 287 & $\mathbf{Q}$ & NC & NC \\
\hline $\begin{array}{l}\text { Unrestricted Use } \\
\text { (No Log)........ }\end{array}$ & 23 & NC & 13 & 7 & $\mathbf{Q}$ & NC & NC & $\mathbf{Q}$ & NC & NC & NC \\
\hline
\end{tabular}

NC $=$ No cases in sample.

$\mathrm{Q}=$ Data withheld because fewer than three companies are represented.

Notes: - Data in this table represent only the top 35 propane providers. - Totals may not equal sum of components due to independent rounding.

- "Unrestricted Use" refers to usage that includes business use, commuting, and personal use. This type of usage can be with accounting of personal versus business use (Log) or without such accounting (No Log).

Source: Energy Information Administration, Office of Energy Markets and End Use, Form ElA-885, "Propane Provider Fleet Survey." 
Table 3.6.11. Propane Provider Fleet Vehicle Replacement Cycles, 1993 (Months and Miles)

\begin{tabular}{|c|c|c|c|c|c|c|c|c|c|c|c|}
\hline \multirow[b]{3}{*}{$\begin{array}{l}\text { Cycle Unit and } \\
\text { Fuel Type }\end{array}$} & \multirow[b]{3}{*}{$\begin{array}{c}\text { Fleet } \\
\text { Average }\end{array}$} & \multicolumn{10}{|c|}{ Vehicle Type } \\
\hline & & \multicolumn{3}{|c|}{ Passenger Cars } & \multicolumn{5}{|c|}{$\begin{array}{l}\text { Light-Duty Vans/Trucks } \\
(\leq 8,500 \text { lbs. GVW })\end{array}$} & \multicolumn{2}{|c|}{$\begin{array}{c}\text { Medium-/Heavy-Duty } \\
\text { Trucks }\end{array}$} \\
\hline & & $\begin{array}{c}\text { Sub- } \\
\text { compact } \\
\text { Compact }\end{array}$ & $\begin{array}{l}\text { Mid- } \\
\text { Size } \\
\end{array}$ & Large & $\begin{array}{l}\text { Mini- } \\
\text { Van }\end{array}$ & $\begin{array}{c}\text { Full-Size } \\
\text { Van } \\
\end{array}$ & $\begin{array}{c}\text { Small } \\
\text { Pickup } \\
\end{array}$ & $\begin{array}{c}\text { Large } \\
\text { Pickup } \\
\end{array}$ & $\begin{array}{l}\text { Sport/ } \\
\text { Utility }\end{array}$ & $\begin{array}{c}8,501 \text { to } \\
26,000 \\
\text { Ibs. GVW }\end{array}$ & $\begin{array}{l}>26,000 \\
\text { lbs. GVW }\end{array}$ \\
\hline \multicolumn{12}{|l|}{ Months } \\
\hline $\begin{array}{l}\text { Gasoline/ } \\
\text { Diesel .......... }\end{array}$ & $84^{\circ}$ & 51 & 57 & 68 & 77 & 82 & 93 & 99 & 79 & 96 & 100 \\
\hline $\begin{array}{l}\text { Compressed } \\
\text { Natural Gas ...... }\end{array}$ & $\mathbf{Q}$ & $\mathbf{Q}$ & NC & $Q$ & NC & $\mathbf{Q}$ & $\mathbf{Q}$ & Q & NC & $\mathbf{Q}$ & NC \\
\hline Propane ........ & 91 & 60 & 80 & 55 & 84 & 77 & 99 & 91 & Q & 93 & 95 \\
\hline \multicolumn{12}{|l|}{ Miles } \\
\hline $\begin{array}{l}\text { Gasoline/ } \\
\text { Diesel .......... }\end{array}$ & 216,482 & 111,667 & 94,000 & 121,417 & 120,714 & 131,250 & 125,000 & 142,200 & $\mathbf{Q}$ & 149,500 & 321,625 \\
\hline $\begin{array}{l}\text { Compressed } \\
\text { Natural Gas ..... }\end{array}$ & $\mathbf{Q}$ & $\mathbf{Q}$ & NC & $\mathbf{Q}$ & NC & $Q$ & $\mathbf{Q}$ & $\mathbf{Q}$ & NC & Q & NC \\
\hline Propane ....... & 179,866 & $\mathbf{Q}$ & 166,667 & 176,667 & $\mathbf{Q}$ & 233,333 & 188,125 & 180,688 & $\mathbf{Q}$ & 182,250 & 174,438 \\
\hline
\end{tabular}

$\mathrm{NC}=$ No cases in sample.

$\mathrm{Q}=$ Data witheld because fewer than three companies are represented.

Note: - Data in this table represent only the top 35 propane providers.

Source: Energy Information Administration, Office of Energy Markets and End Use, Form ElA-885, "Propane Provider Fleet Survey." 


\begin{tabular}{|c|c|c|c|c|c|c|c|c|c|c|c|}
\hline \multirow[b]{3}{*}{$\begin{array}{l}\text { Cost and } \\
\text { Fuel Type }\end{array}$} & \multirow[b]{3}{*}{$\begin{array}{c}\text { Fleet } \\
\text { Average }\end{array}$} & \multicolumn{10}{|c|}{ Vehicle Type } \\
\hline & & \multicolumn{3}{|c|}{ Passenger Cars } & \multicolumn{5}{|c|}{$\begin{array}{c}\text { Light-Duty Vans } / \text { rucks } \\
(\leq 8,500 \text { lbs. GVW })\end{array}$} & \multicolumn{2}{|c|}{$\begin{array}{c}\text { Medium-/Heavy-Duty } \\
\text { Trucks }\end{array}$} \\
\hline & & $\begin{array}{c}\text { Sub- } \\
\text { compact } \\
\text { Compact } \\
\end{array}$ & $\begin{array}{l}\text { Mid- } \\
\text { Size }\end{array}$ & Large & $\begin{array}{l}\text { Mini- } \\
\text { Van }\end{array}$ & $\begin{array}{c}\text { Full-Size } \\
\text { Van }\end{array}$ & $\begin{array}{c}\text { Small } \\
\text { Pickup }\end{array}$ & $\begin{array}{l}\text { Large } \\
\text { Pickup } \\
\end{array}$ & $\begin{array}{l}\text { Sport } \\
\text { Utility }\end{array}$ & $\begin{array}{c}8,501 \text { to } \\
26,000 \\
\text { lbs. GVW }\end{array}$ & $\begin{array}{c}>26,000 \\
\text { lbs. GVW }\end{array}$ \\
\hline \multicolumn{12}{|l|}{ Acquisition Costs } \\
\hline $\begin{array}{l}\text { Gasoline/Diesel } \ldots \ldots \text {. } \\
\text { Compressed } \\
\text { Natural Gas }\end{array}$ & 35,802 & 12,167 & 15,451 & 21,687 & $\mathbf{Q}$ & 20,000 & $Q$ & 17,354 & $Q$ & 21,904 & 51,985 \\
\hline Dedicated ........... & NC & NC & NC & NC & NC & NC & NC & NC & NC & NC & NC \\
\hline Multifuel ........... & NC & NC & NC & NC & NC & NC & NC & NC & NC & NC & NC \\
\hline \multicolumn{12}{|l|}{ Propane } \\
\hline Dedicated .......... & 23,238 & NC & NC & $\mathbf{Q}$ & NC & NC & 15,230 & 17,629 & NC & 27,144 & 29,105 \\
\hline Multifuel...$\ldots \ldots$. & 18,233 & $\mathbf{Q}$ & $\mathbf{Q}$ & $\mathbf{Q}$ & $\mathbf{Q}$ & Q & 16,600 & 20,112 & NC & 19,780 & NC \\
\hline $\begin{array}{l}\text { Conversion Costs } \\
\text { Compressed } \\
\text { Natural Gas }\end{array}$ & & & & & & & - & & & & \\
\hline Dedicated .......... & NC & NC & NC & NC & NC & NC & NC & NC & NC & NC & NC \\
\hline Multifuel $\ldots \ldots \ldots \ldots$ & $\mathbf{Q}$ & $\mathbf{Q}$ & NC & $\mathbf{Q}$ & NC & $\mathbf{Q}$ & $\mathbf{Q}$ & $\mathbf{Q}$ & NC & $\mathbf{Q}$ & NC \\
\hline \multicolumn{12}{|l|}{ Propane } \\
\hline Dedicated .......... & 1,378 & $\mathbf{Q}$ & $\mathbf{Q}$ & 1,783 & $\mathbf{Q}$ & 1,367 & 1,500 & 1,197 & $\mathbf{Q}$ & 1,350 & 1,232 \\
\hline Multifuel $\ldots \ldots \ldots \ldots$ & 1,386 & $Q$ & 1,367 & 1,417 & $\mathbf{Q}$ & $\mathbf{Q}$ & 1,279 & 1,283 & NC & 1,150 & $\mathbf{Q}$ \\
\hline
\end{tabular}

NC $=$ No cases in sample.

$Q=$ Data withheld because fewer than three companies are represented.

Notes: - Data in this table represent only the top 35 propane providers. "Multifuel" refers to all AFV's capable of operating on more than one fuel (i.e., bi-fuel, flex-fuel, hybrid, and dual-fuel vehicles).

Source: Energy Information Administration, Office of Energy Markets and End Use, Form ElA-885, "Propane Provider Fleet Survey." 
Table 3.6.13. Alternative-Fuel Vehicle Maintenance Costs Relative to Conventional-Fuel Vehicles in Propane Provider Fleets, 1993

(Percent)

\begin{tabular}{|c|c|c|c|c|c|c|c|c|c|c|}
\hline \multirow[b]{2}{*}{ Fuel Type } & \multicolumn{3}{|c|}{ Passenger Cars } & \multicolumn{5}{|c|}{$\begin{array}{l}\text { Light-Duty Vans/Trucks } \\
(\leq 8,500 \text { lbs. GVW }\end{array}$} & \multicolumn{2}{|c|}{$\begin{array}{l}\text { Medium-/Heavy-Duty } \\
\text { Trucks }\end{array}$} \\
\hline & $\begin{array}{c}\text { Subcompact/ } \\
\text { Compact }\end{array}$ & Mid-Size & Large & Mini-Van & $\begin{array}{c}\text { Full-Size } \\
\text { Van }\end{array}$ & $\begin{array}{c}\text { Small } \\
\text { Pickup } \\
\end{array}$ & $\begin{array}{c}\text { Large } \\
\text { Pickup } \\
\end{array}$ & $\begin{array}{l}\text { Sport/ } \\
\text { Utility }\end{array}$ & $\begin{array}{c}8,501 \text { to } \\
26,000 \\
\text { Ibs. GWW }\end{array}$ & $\begin{array}{l}>26,000 \\
\text { lbs. GVW }\end{array}$ \\
\hline Dedicated .......... & NC & NC & . NC & NC & $\mathbf{Q}$ & NC & NC & NC & NC & NC \\
\hline Multifuel...$\ldots \ldots$. & $Q$ & NC & $\mathbf{Q}$ & NC & $\mathbf{Q}$ & $\mathbf{Q}$ & $\mathbf{Q}$ & $\mathbf{Q}$ & NC & NC \\
\hline \multicolumn{11}{|l|}{ Propane } \\
\hline
\end{tabular}

NC $=$ No cases in sample.

$Q=$ Data withheld because fewer than three companies are represented.

Notes: -Data in this table represent only the top 35 propane providers. - A negative percentage indicates lower maintenance costs for the AFV than for a comparable conventional-fuel vehicle. "Multifuel" refers to all AFV's capable of operating on more than one fuel (i.e., bi-fuel, flex-fuel, hybrid, and dual-fuel vehicles).

Source: Energy Information Administration, Office of Energy Markets and End Use, Form ElA-885, "Propane Provider Fleet Survey." 
Table 3.6.14. Fuel Storage Capacity in Propane Provider Fleet Vehicles, 1993 (Physical Units per Vehicle)

\begin{tabular}{|c|c|c|c|c|c|c|c|c|c|c|}
\hline \multirow{3}{*}{ Fuel Type } & \multicolumn{10}{|c|}{ Vehicle Type } \\
\hline & \multicolumn{3}{|c|}{ Passenger Cars } & \multicolumn{5}{|c|}{$\begin{array}{c}\text { Light-Duty Vans/Trucks } \\
(\leq 8,500 \text { lbs. GVW })\end{array}$} & \multicolumn{2}{|c|}{$\begin{array}{c}\text { Medium-/Heavy-Duty } \\
\text { Trucks }\end{array}$} \\
\hline & $\begin{array}{c}\text { Subcompact } / \\
\text { Compact }\end{array}$ & Mid-Size & Large & Mini-Van & $\begin{array}{c}\text { Full-Size } \\
\text { Van }\end{array}$ & $\begin{array}{l}\text { Small } \\
\text { Pickup }\end{array}$ & $\begin{array}{c}\text { Large } \\
\text { Pickup } \\
\end{array}$ & $\begin{array}{l}\text { Sport' } \\
\text { Utility }\end{array}$ & $\begin{array}{c}8,501 \text { to } \\
26,000 \\
\text { Ibs. GVW }\end{array}$ & $\begin{array}{r}>26,000 \\
\text { lbs. GVW }\end{array}$ \\
\hline \multicolumn{11}{|l|}{ Dedicated } \\
\hline $\begin{array}{l}\text { Gasoline } \\
\text { (gallons) ........ }\end{array}$ & 15 & 17 & 24 & 22 & 29 & 20 & 38 & 23 & 44 & 56 \\
\hline $\begin{array}{l}\text { Diesel } \\
\text { (gallons) ........ }\end{array}$ & NC & NC & $\mathbf{Q}$ & NC & $\mathbf{Q}$ & $\mathbf{Q}$ & 24 & $Q$ & 43 & 105 \\
\hline $\begin{array}{l}\text { CNG } \\
\text { (cubic feet) ...... }\end{array}$ & NC & NC & NC & NC & $\mathbf{Q}$ & $\mathbf{Q}$ & $Q$ & NC & NC & NC \\
\hline $\begin{array}{l}\text { Propane } \\
\text { (gallons) ........ }\end{array}$ & 15 & 39 & $\mathbf{Q}$ & $\mathbf{Q}$ & 68 & 49 & 55 & $Q$ & 370 & 684 \\
\hline \multicolumn{11}{|l|}{ Multifuel } \\
\hline $\begin{array}{l}\text { Gasoline } \\
\text { (gallons) } \ldots \ldots \ldots\end{array}$ & 22 & 18 & 22 & 17 & $Q$ & 21 & 35 & NC & 28 & Q \\
\hline $\begin{array}{l}\text { Diesel } \\
\text { (gallons) ........ }\end{array}$ & NC & NC & NC & NC & NC & NC & NC & NC & NC & $Q$ \\
\hline $\begin{array}{l}\text { CNG } \\
\text { (cubic feet) ...... }\end{array}$ & $\mathbf{Q}$ & NC & $Q$ & NC & $Q$ & $\mathbf{Q}$ & $\mathbf{Q}$ & NC & $\mathbf{Q}$ & NC \\
\hline $\begin{array}{l}\text { Propane } \\
\text { (gallons) ........ }\end{array}$ & 25 & 26 & 27 & 16 &.$Q$ & 37 & 49 & NC & 85 & 57 \\
\hline
\end{tabular}

NC $=$ No cases in sample.

$Q=$ Data withheld because fewer than three companies are represented.

Notes: - Storage capacity for large propane vehicles is inflated because some vehicies are fueled directly from the delivery tanks. $\bullet$ Data in this table represent only the top 35 propane providers. - "Multifuel" refers to all AFV's capable of operating on more than one fuel (i.e., bi-fuel, flex-fuel, hybrid, and dual-fuel vehicles).

Source: Energy Information Administration, Office of Energy Markets and End Use, Form EIA-885, "Propane Provider Fleet Survey." 
Table 3.6.15. Annual Consumption by Fuel and Vehicle Technology for Propane Provider Fleet Vehicles, 1993 (Physical Units per Fleet Vehicle)

\begin{tabular}{|c|c|c|c|c|c|c|c|c|c|c|c|}
\hline \multirow[b]{3}{*}{ Technology and Fuel } & \multirow[b]{3}{*}{$\begin{array}{c}\text { Fleet } \\
\text { Average }\end{array}$} & \multicolumn{10}{|c|}{ Vehicle Type } \\
\hline & & \multicolumn{3}{|c|}{ Pássenger Cars } & \multicolumn{5}{|c|}{$\begin{array}{l}\text { Light-Duty Vans/Trucks } \\
(\leq 8,500 \text { lbs. GVW }\end{array}$} & \multicolumn{2}{|c|}{$\begin{array}{c}\text { Medium-/Heavy-Duty } \\
\text { Trucks }\end{array}$} \\
\hline & & $\begin{array}{c}\text { Sub- } \\
\text { compact/ } \\
\text { Compact }\end{array}$ & $\begin{array}{l}\text { Mid- } \\
\text { Size } \\
\end{array}$ & Large & $\begin{array}{l}\text { Mini- } \\
\text { Van }\end{array}$ & $\begin{array}{c}\text { Full-Size } \\
\text { Van }\end{array}$ & $\begin{array}{l}\text { Small } \\
\text { Pickup }\end{array}$ & $\begin{array}{l}\text { Large } \\
\text { Pickup }\end{array}$ & $\begin{array}{l}\text { Sport } \\
\text { Utility }\end{array}$ & $\begin{array}{l}8,501 \text { to } \\
26,000 \\
\text { Ibs. GVW }\end{array}$ & $\begin{array}{l}>26,000 \\
\text { Ibs. GVW }\end{array}$ \\
\hline \multicolumn{12}{|l|}{ Dedicated Vehicles } \\
\hline Gasoline (gallons) ..... & 1,082 & 675 & 784 & 959 & 689 & 1,032 & 871 & 1,458 & 1,027 & 1,786 & 4,078 \\
\hline Diesel (gallons) . . . . . & 6,512 & NC & NC & $Q$ & NC & $\mathbf{Q}$ & $\mathbf{Q}$ & 1,007 & $Q$ & 1,947 & 7,869 \\
\hline CNG (cubic feet) & $\mathbf{Q}$ & NC & NC & NC & NC & $\mathbf{Q}$ & $\mathbf{Q}$ & $\mathbf{Q}$ & NC & NC & NC \\
\hline Propane (gallóns) ..... & 2,640 & 1,293 & 608 & $\mathbf{Q}$ & $Q$ & 1,051 & 844 & 1,349 & $\mathbf{Q}$ & 3,143 & 4,023 \\
\hline \multicolumn{12}{|l|}{ Multifuel Vehicles } \\
\hline Gasoline (gällons) ..... & 202 & 50 & 275 & 118 & 548 & $Q$ & 101 & 289 & NC & 49 & Q \\
\hline Diesel (gallons) ....... & $Q$ & NC & NC & NC & NC & NC & NC & NC & NC & NC & $Q$ \\
\hline CNG (cubic feet) ... & $Q$ & $Q$ & NC & $Q$ & NC & $\mathbf{Q}$ & $\mathbf{Q}$ & $\mathbf{Q}$ & NC & $\mathbf{Q}$ & NC \\
\hline Propane (gallons) .. & 1,696 & 1,781 & 1,693 & 2,531 & 1,522 & $Q$ & 1,315 & 1.630 & NC & 2,857 & 3,947 \\
\hline
\end{tabular}

NC $=$ No cases in sample.

$Q=$ Data withheld because fewer than three companies are represented.

Notes: - Data in this table represent only the top 35 propane providers. "Multifuel" refers to all AFV's capable of operating on more than one fuel (i.e., bi-fuel, flex-fuel, hybrid, and dual-fuel vehicles).

Source: Energy Information Administration, Office of Energy Markets and End Use, Form ElA-885, "Propane Provider Fleet Survey." 
Table 3.6.16. Annual Miles Traveled by Fuel and Vehicle Technology for Propane Provider Fleet Vehicles, 1993 (Miles per Fleet Vehicle)

\begin{tabular}{|c|c|c|c|c|c|c|c|c|c|c|c|}
\hline \multirow[b]{3}{*}{ Fuel and Technology } & \multirow[b]{3}{*}{$\begin{array}{c}\text { Fleet } \\
\text { Average }\end{array}$} & \multicolumn{8}{|c|}{ Vehicle Type } & \multicolumn{2}{|r|}{. } \\
\hline & & \multicolumn{3}{|c|}{ Passenger Cars } & \multicolumn{5}{|c|}{$\begin{array}{l}\text { Light-Duty Vans/Trucks } \\
(\leq 8,500 \text { lbs. GVW })\end{array}$} & \multicolumn{2}{|c|}{$\begin{array}{c}\text { Medium-/Heavy-Duty } \\
\text { Trucks }\end{array}$} \\
\hline & & $\begin{array}{c}\text { Sub- } \\
\text { compact/ } \\
\text { Compact }\end{array}$ & $\begin{array}{l}\text { Mid- } \\
\text { Size } \\
\end{array}$ & Large & $\begin{array}{l}\text { Mini- } \\
\text { Van }\end{array}$ & $\begin{array}{c}\text { Full-Size } \\
\text { Van }\end{array}$ & $\begin{array}{l}\text { Small } \\
\text { Pickup }\end{array}$ & $\begin{array}{c}\text { Large } \\
\text { Pickup } \\
\end{array}$ & $\begin{array}{l}\text { Sport' } \\
\text { Utility }\end{array}$ & $\begin{array}{c}8,501 \text { to } \\
26,000 \\
\text { lbs. GVW }\end{array}$ & $\begin{array}{c}>26,000 \\
\text { lbs. GVW }\end{array}$ \\
\hline \multicolumn{12}{|l|}{ Dedicated Vehicles } \\
\hline Gasoline ............ & 19,056 & 18,355 & 17,050 & 20,401 & 12,126 & 12,662 & 16,695 & 20,596 & 19,212 & 17,188 & 59,266 \\
\hline Diesel .............. & 47,673 & NC & NC & $Q$ & NC & $Q$ & $\mathbf{Q}$ & 21,041 & $\mathbf{Q}$ & 15,569 & 55,085 \\
\hline CNG...$\ldots \ldots \ldots \ldots$ & $\mathbf{Q}$ & NC & NC & NC & NC & $\mathbf{Q}$ & $Q$ & $\mathbf{Q}$ & NC & NC & NC \\
\hline Propane ............ & 23,997 & 23,666 & 9,357 & $Q$ & $\mathbf{Q}$ & 12,236 & 13,973 & 16,575 & $Q$ & 22,386 & 27,107 \\
\hline \multicolumn{12}{|l|}{ Multifuel Vehicles } \\
\hline Gasoline ............. & 3,426 & 1,280 & 5,633 & 1,883 & 8,333 & $\mathbf{Q}$ & 3,427 & 4,610 & NC & 3,571 & $\mathbf{Q}$ \\
\hline Diesel ... & $\mathbf{Q}$ & NC & NC & NC & NC & NC & NC & NC & NC & NC & $\mathbf{Q}$ \\
\hline CNG $\ldots \ldots \ldots \ldots \ldots$ & $\mathbf{Q}$ & $\mathbf{Q}$ & NC & $\mathbf{Q}$ & NC & $\mathbf{Q}$ & $\mathbf{Q}$ & $Q$ & NC & $\mathbf{Q}$ & NC \\
\hline Propane ............. & 18,768 & 33,831 & 24,213 & 23,260 & 16,333 & $Q$ & 20,031 & 15,116 & NC & 19,342 & 19,712 \\
\hline
\end{tabular}

NC $=$ No cases in sample.

$Q=$ Data withheld because fewer than three companies are represented.

Notes: - Data in this table represent only the top 35 propane providers. "Multifuel" refers to all AFV's capable of operating on more than one fuel (i.e., bi-fuel, flex-fuel, hybrid, and dual-fuel vehicles).

Source: Energy Information Administration, Office of Energy Markets and End Use, Form EIA-885, "Propane Provider Fleet Survey." 
Table 3.6.17. Fleet Vehicles Operated by Electric Utilities as of December 31, 1993 (Number of Vehicles)

\begin{tabular}{|c|c|c|c|c|c|c|c|c|c|c|}
\hline \multirow[b]{3}{*}{ Fuel Type } & \multirow[b]{3}{*}{ Total } & \multicolumn{9}{|c|}{ Vehicle Type } \\
\hline & & \multicolumn{3}{|c|}{ Passenger Cars } & \multicolumn{5}{|c|}{$\begin{array}{l}\text { Light-Duty Vans/Trucks } \\
(\leq 8,500 \text { lbs. GVW })\end{array}$} & \multirow{2}{*}{$\begin{array}{c}\text { Medium/ } \\
\text { Heavy-Duty } \\
\text { Trucks } \\
\end{array}$} \\
\hline & & $\begin{array}{c}\text { Subcompact/ } \\
\text { Compact }\end{array}$ & Mid-Size & Large & Mini-Van & $\begin{array}{c}\text { Full-Size } \\
\text { Van }\end{array}$ & $\begin{array}{l}\text { Small } \\
\text { Pickup }\end{array}$ & $\begin{array}{l}\text { Large } \\
\text { Pickup }\end{array}$ & $\begin{array}{l}\text { Sport/ } \\
\text { Utility }\end{array}$ & \\
\hline \multicolumn{11}{|l|}{ Conventional-Fuel } \\
\hline Vehicles........... & 196,241 & 19,589 & 14,965 & 3,248 & 7,011 & 11,567 & 22,091 & 37,137 & 11,134 & 69,499 \\
\hline Gasoline ......... & 155,070 & 19,588 & 14,949 & 3,238 & 6,997 & 11,003 & 21,870 & 34,480 & 10,358 & 32,587 \\
\hline Diesel . . . . . . . . . & 41,171 & 1 & 16 & 10 & 14 & 564 & 221 & 2,657 & 776 & 36,912 \\
\hline \multicolumn{11}{|l|}{ Alternative-Fuel } \\
\hline $\begin{array}{l}\text { Compressed } \\
\text { Natural Gas }\end{array}$ & & & & & & & & & & \\
\hline Dedicated ...... & 821 & 0 & 4 & 3 & 5 & 516 & 13 & 212 & 42 & 26 \\
\hline Multifuel ........ & 2,935 & 92 & 233 & 16 & 128 & 206 & 360 & 1,047 & 452 & 401 \\
\hline \multicolumn{11}{|l|}{ Propane } \\
\hline Dedicated ....... & 489 & 1 & 0 & 0 & 0 & 21 & 52 & 91 & 6 & 318 \\
\hline Multifuel ........ & 169 & 1 & 0 & 0 & 3 & 3 & 12 & 120 & 11 & 19 \\
\hline \multicolumn{11}{|l|}{$\begin{array}{l}\text { Methanol/Ethanol } \\
\text { Blends }\end{array}$} \\
\hline Dedicated .. & 523 & 11 & 47 & '26 & 15 & 20 & 47 & 222 & 13 & 122 \\
\hline Multifuel ........ & 412 & 79 & 52 & 9 & 11 & 30 & 62 & 136 & 7 & 26 \\
\hline \multicolumn{11}{|l|}{ Electricity } \\
\hline Dedicated ...... & 237 & 60 & 6 & 1 & 31 & 50 & 46 & 3 & 4 & 36 \\
\hline Multifuel ........ & 0 & 0 & 0 & 0 & 0 & 0 & 0 & 0 & 0 & 0 \\
\hline $\begin{array}{l}\text { Other Altemative } \\
\text { Fuels }\end{array}$ & & . & & & . & & & & & \\
\hline Dedicated ........ & 9 & 0 & 0 & 0 & 0 & 7 & 1 & 0 & 0 & 1 \\
\hline Multifuel ......... & 0 & 0 & 0 & 0 & 0 & 0 & 0 & 0 & 0 & 0 \\
\hline Total $\ldots \ldots \ldots \ldots \ldots$ & 201,836 & 19,833 & 15,307 & 3,303 & 7,204 & 12,420 & 22,684 & 38,968 & 11,669 & 70,448 \\
\hline
\end{tabular}

Note: "Multifuel" refers to all AFV's capable of operating on more than one fuel (i.e., bi-fuel, flex-fuel, hybrid, and dual-fuel vehicles).

Source: Energy Information Administration, Office of Coal, Nuclear, Electric, and Alternative Fuels, Form ElA-861, Schedule VII, "Electric Utility Fleet Survey." 
Table 3.6.18. 1994 Electric Utility Fleet Vehicle Retirement/Acquisition Plans (Number of Vehicles)

\begin{tabular}{|c|c|c|c|c|c|c|c|c|c|c|}
\hline \multirow[b]{3}{*}{ Fleet Vehicle Plans } & \multirow[b]{3}{*}{ Total } & \multicolumn{9}{|c|}{ Vehicle Type } \\
\hline & & \multicolumn{3}{|c|}{ Passenger Cars } & \multicolumn{5}{|c|}{$\begin{array}{c}\text { Light-Duty Vans } / \text { Trucks } \\
(\leq 8,500 \text { lbs. GVW }\end{array}$} & \multirow{2}{*}{$\begin{array}{c}\text { Medium/ } \\
\text { Heavy- } \\
\text { Duty } \\
\text { Trucks } \\
\end{array}$} \\
\hline & & $\begin{array}{c}\text { Subcompact } \\
\text { Compact }\end{array}$ & Mid-Size & Large & Mini-Van & $\begin{array}{c}\text { Full-Size } \\
\text { Van }\end{array}$ & $\begin{array}{c}\text { Small } \\
\text { Pickup }\end{array}$ & $\begin{array}{l}\text { Large } \\
\text { Pickup }\end{array}$ & $\begin{array}{l}\text { Sport } \\
\text { Utility }\end{array}$ & \\
\hline Retirements ...... & 18,956 & 3,059 & 1,966 & 381 & 659 & 1,075 & 1,983 & 4,171 & 1,076 & 4,586 \\
\hline Gasoline ......... & 16,438 & 3,052 & 1,911 & 378 & 652 & 1,014 & 1,895 & 3,780 & 1,020 & 2,736 \\
\hline Diesel ........... & 2,063 & 0 & 2 & 0 & 2 & 21 & 32 & 202 & 41 & 1,763 \\
\hline Alternative-Fuel...... & 455 & 7 & 53 & 3 & 5 & 40 & 56 & 189 & 15 & 87 \\
\hline Acquisitions $\ldots \ldots \ldots \ldots$ & 18,182 & 2,815 & 1,539 & 290 & 806 & 1,067 & 1,929 & 4,223 & 946 & 4,567 \\
\hline Conversions to AFV ..... & 724 & 31 & 27 & 3 & 52 & 30 & 128 & 368 & 35 & 50 \\
\hline
\end{tabular}

Source: Energy Information Administration, Office of Coal, Nuclear, Electric, and Altemative Fuels, Form ElA-861, Schedule VII, "Electric Utility Fleet Survey." 
Table 3.6.19. "New" Electric Utility Fleet Vehicles Planned for Service in $1994^{1}$ (Number of Vehicles)

\begin{tabular}{|c|c|c|c|c|c|c|c|c|c|c|}
\hline \multirow[b]{3}{*}{ Fuel Type } & \multirow[b]{3}{*}{ Total } & \multicolumn{9}{|c|}{ Vehicle Type } \\
\hline & & \multicolumn{3}{|c|}{ Passenger Cars } & \multicolumn{5}{|c|}{$\begin{array}{l}\text { Light-Duty Vans/Trucks } \\
(\leq 8,500 \text { lbs. GVW }\end{array}$} & \multirow{2}{*}{$\begin{array}{c}\text { Medium/ } \\
\text { Heavy-Duty } \\
\text { Trucks }\end{array}$} \\
\hline & & $\begin{array}{c}\text { Subcompact/ } \\
\text { Compact }\end{array}$ & Mid-Size & Large & Mini-Van & $\begin{array}{c}\text { Full-Size } \\
\text { Van }\end{array}$ & $\begin{array}{l}\text { Small } \\
\text { Pickup }\end{array}$ & $\begin{array}{l}\text { Large } \\
\text { Pickup } \\
\end{array}$ & $\begin{array}{l}\text { Sport/ } \\
\text { Utility }\end{array}$ & \\
\hline \multicolumn{11}{|l|}{ Conventional-Fuel } \\
\hline Vehicles ............ & 16,611 & 2,616 & 1,413 & 281 & 644 & 865 & 1,719 & 3,874 & 896 & 4,303 \\
\hline Gasoline ......... & 13,388 & 2,616 & 1,413 & 281 & 644 & 847 & 1,684 & 3,574 & 826 & 1,503 \\
\hline Diesel ............ & 3,223 & 0 & 0 & 0 & 0 & 18 & 35 & 300 & 70 & 2,800 \\
\hline Alternative-Fuel & & & . & & & & & & & \\
\hline Vehicles ............. & 1,727 & 133 & 142 & 7 & 178 & 206 & 299 & 465 & 57 & 240 \\
\hline \multicolumn{11}{|l|}{$\begin{array}{l}\text { Compressed } \\
\text { Natural Gas }\end{array}$} \\
\hline Dedicated ....... & 208 & 0 & 3 & 0 & 102 & 47 & 13 & 27 & 4 & 12 \\
\hline Multifuel ........ & 841 & 36 & 77 & 3 & 55 & 67 & 122 & .380 & 47 & 54 \\
\hline \multicolumn{11}{|l|}{ Propane } \\
\hline Dedicated ....... & 44 & 0 & 0 & 0 & 0 & 1 & 7 & 5 & 0 & 31 \\
\hline Multifuel ......... & 83 & 13 & 8 & 0 & 5 & 19 & 25 & 9 & 3 & 1 \\
\hline \multicolumn{11}{|l|}{$\begin{array}{l}\text { Methanol/Ethanol } \\
\text { Blends }\end{array}$} \\
\hline Dedicated ....... & 161 & 0 & 4 & 3 & 9 & 58 & 4 & 16 & 0 & 67 \\
\hline Multifuel ........ & 120 & 36 & 47 & 1 & 1 & 0 & 9 & 23 & 2 & 1 \\
\hline Electricity & & & & & " & & & & & \\
\hline Dedicated ....... & 253 & 43 & 2 & 0 & 5 & 14 & 114 & 5 & 0 & 70 \\
\hline Multifuel . ........ & 12 & 5 & 0 & 0 & 1 & 0 & 5 & 0 & 1 & 0 \\
\hline \multicolumn{11}{|l|}{$\begin{array}{l}\text { Other Altemative } \\
\text { Fuels }\end{array}$} \\
\hline Dedicated...$\ldots$ & 0 & 0 & 0 & 0 & 0 & 0 & 0 & 0 & 0 & 0 \\
\hline Multifuel ......... & 5 & 0 & 1 & 0 & 0 & 0 & 0 & 0 & 0 & 4 \\
\hline Totàl $\ldots \ldots \ldots \ldots \ldots$ & 18,338 & 2,749 & 1,555 & 288 & 822 & 1,071 & 2,018 & 4,339 & 953 & 4,543 \\
\hline
\end{tabular}

"New" Vehicles refers to both newly acquired vehicles and existing vehicles converted to operate on a new fuel. Note: "Multifuel" refers to all AFV's capable of operating on more than one fuel (i.e., bi-fuel, flex-fuel, hybrid, and dual-fuel vehicles).

Source: Energy Information Administration, Office of Coal, Nuclear, Electric, and Altemative Fuels, Form ElA-861, Schedule VII, "Electric Utility Fleet Survey." 
Table 3.6.20. Fleet Vehicles Operated By Natural Gas Suppliers as of December 31, 1993 (Number of Vehicles)

\begin{tabular}{|c|c|c|c|c|c|c|c|c|c|c|}
\hline \multirow[b]{3}{*}{ Fuel Type } & \multirow[b]{3}{*}{ Total } & \multicolumn{9}{|c|}{ Vehicle Type } \\
\hline & & \multicolumn{3}{|c|}{ Passenger Cars } & \multicolumn{5}{|c|}{$\begin{array}{c}\text { Light-Duty Vans/Trucks } \\
(\leq 8,500 \text { lbs. GVW })\end{array}$} & \multirow{2}{*}{$\begin{array}{c}\text { Medium/ } \\
\text { Heavy-Duty } \\
\text { Trucks }\end{array}$} \\
\hline & & $\begin{array}{c}\text { Subcompact/ } \\
\text { Compact }\end{array}$ & Mid-Size & Large & Mini-Van & $\begin{array}{c}\text { Full-Size } \\
\text { Van } \\
\end{array}$ & $\begin{array}{c}\text { Small } \\
\text { Pickup }\end{array}$ & $\begin{array}{l}\text { Large } \\
\text { Pickup } \\
\end{array}$ & $\begin{array}{l}\text { Sport/ } \\
\text { Utility }\end{array}$ & \\
\hline \multicolumn{11}{|l|}{ Conventional-Fuel } \\
\hline Gasoline ......... & 104,434 & 10,416 & 11,609 & 3,649 & 5,134 & 11,465 & 13,629 & 25,070 & 5,440 & 18,022 \\
\hline Diesel............ & 17,842 & 0 & 17 & 3 & 7 & 341 & 59 & 1,074 & 291 & 16,050 \\
\hline \multicolumn{11}{|l|}{ Alternative-Fuel } \\
\hline Vehicles ............ & 16,048 & 585 & 791 & 335 & 495 & 3,610 & 1,839 & 5,347 & 638 & 2,408 \\
\hline \multicolumn{11}{|l|}{$\begin{array}{l}\text { Compressed } \\
\text { Natural Gas }\end{array}$} \\
\hline Dedicated ....... & 2,223 & 7 & 19 & 31 & 21 & 965 & 118 & 935 & 31 & 96 \\
\hline Multifuel ......... & 11,809 & 567 & 756 & 291 & 447 & 2,505 & 1,612 & 3,464 & 602 & 1,565 \\
\hline \multicolumn{11}{|l|}{ Propane } \\
\hline Dedicated ....... & 1,005 & 2 & 13 & 8 & 17 & 99 & 87 & 185 & 3 & 591 \\
\hline Multifuel ......... & 948 & 0 & 3 & 5 & 2 & 16 & 19 & 763 & 2 & 138 \\
\hline \multicolumn{11}{|l|}{ Electricity } \\
\hline Dedicated...$\ldots$. & 37 & 8 & 0 & 0 & 7 & 18 & 3 & 0 & 0 & 1 \\
\hline Multifuel ......... & 0 & 0 & 0 & 0 & 0 & 0 & 0 & 0 & 0 & 0 \\
\hline \multicolumn{11}{|l|}{$\begin{array}{l}\text { Other Alternative } \\
\text { Fuels }\end{array}$} \\
\hline Dedicated ....... & 26 & 1 & 0 & 0 & 1 & 7 & 0 & 0 & 0 & 17 \\
\hline Multifuel ......... & 0 & 0 & 0 & 0 & 0 & 0 & 0 & 0 & 0 & 0 \\
\hline Total .... & 138,324 & 11,001 & 12,417 & 3,987 & 5,636 & 15,416 & 15,527 & 31,491 & 6,369 & 36,480 \\
\hline
\end{tabular}

Note: "Multifuel" refers to all alternative-fuel vehicles capable of operating on more than one fuel (i.e., bi-fuel, flex-fuel, hybrid, and dual-fuel vehicles).

Source: Energy Information Administration, Office of Oil and Gas, Form ElA-176, Schedule B, "Natural Gas Supplier Fleet Survey." 
Table 3.6.21. Alternative-Fuel Fleet Vehicles in Natural Gas Supplier Fleets by Source, 1993 (Number of Vehicles)

\begin{tabular}{|c|c|c|c|c|c|c|c|c|c|c|}
\hline \multirow[b]{3}{*}{ Vehicle Source } & \multirow[b]{3}{*}{ Total } & \multicolumn{9}{|c|}{ Vehicle Type } \\
\hline & & \multicolumn{3}{|c|}{ Passenger Cars } & \multicolumn{5}{|c|}{$\begin{array}{l}\text { Light-Duty Vans/Trucks } \\
(\leq 8,500 \text { lbs. GVW })\end{array}$} & \multirow{2}{*}{$\begin{array}{c}\text { Medium/ } \\
\text { Heavy-Duty } \\
\text { Trucks }\end{array}$} \\
\hline & & $\begin{array}{c}\text { Subcompact } \\
\text { Compact }\end{array}$ & Mid-Size & Large & Mini-Van & $\begin{array}{c}\text { Full-Size } \\
\text { Van }\end{array}$ & $\begin{array}{l}\text { Small } \\
\text { Pickup }\end{array}$ & $\begin{array}{l}\text { Large } \\
\text { Pickup }\end{array}$ & $\begin{array}{l}\text { Sport/ } \\
\text { Utility }\end{array}$ & \\
\hline \multicolumn{11}{|l|}{ Total Alternative-Fuel } \\
\hline \multicolumn{11}{|l|}{ Dedicated } \\
\hline Original Equipment .... . & 1,582 & 2 & 24 & 16 & 8 & 697 & 23 & 721 & 3 & 88 \\
\hline Conversion ......... & 1,401 & 14 & 18 & 15 & 33 & 404 & 98 & 252 & 29 & 538 \\
\hline \multicolumn{11}{|l|}{ Multifuel } \\
\hline Original Equipment .... & 55 & 0 & 1 & 0 & 0 & 5 & 0 & 13 & 5 & 31 \\
\hline Conversion ......... & 13,010 & 569 & 748 & 304 & 454 & 2,504 & 1,718 & 4,361 & 601 & 1,751 \\
\hline
\end{tabular}

Note: "Multifuel" refers to all alternative-fuel vehicles capable of operating on more than one fuel' (i.e., bi-fuel, flex-fuel, hybrid, and dual-fuel vehicles). Source: Energy Information Administration, Office of Oil and Gas, Form ElA-176, Schedule B, "Natural Gas Supplier Fleet Survey." 
Table 3.6.22. 1994 Natural Gas Supplier Fleet Vehicle Retirement/Acquisition Plans (Number of Vehicles)

\begin{tabular}{|c|c|c|c|c|c|c|c|c|c|c|}
\hline \multirow[b]{3}{*}{ Fleet Vehicle Plans } & \multirow[b]{3}{*}{ Total } & \multicolumn{9}{|c|}{ Vehicle Type } \\
\hline & & \multicolumn{3}{|c|}{ Passenger Cars } & \multicolumn{5}{|c|}{$\begin{array}{c}\text { Light-Duty Vans/Trucks } \\
(\leq 8,500 \text { lbs. GVW })\end{array}$} & \multirow{2}{*}{$\begin{array}{c}\text { Medium/ } \\
\text { Heavy-Duty } \\
\text { Trucks }\end{array}$} \\
\hline & & $\begin{array}{c}\text { Subcompact } \\
\text { Compact }\end{array}$ & Mid-Size & Large & Mini-Van & $\begin{array}{c}\text { Full-Size } \\
\text { Van }\end{array}$ & $\begin{array}{l}\text { Small } \\
\text { Pickup }\end{array}$ & $\begin{array}{l}\text { Large } \\
\text { Pickup }\end{array}$ & $\begin{array}{l}\text { Sport } \\
\text { Utility }\end{array}$ & \\
\hline Retirements $\ldots . \ldots \ldots$. & 17,088 & 1,320 & 2,105 & 590 & 694 & 1,805 & 1,836 & 4,796 & 735 & 3,207 \\
\hline Gasoline .......... & 14,522 & 1,304 & 2,004 & 530 & 660 & 1,679 & 1,701 & 4,024 & 686 & 1,934 \\
\hline Diesel ..... & 1,334 & 0 & 34 & 2 & 9 & 19 & 1 & 105 & 23 & 1,141 \\
\hline Alternative-Fuel ...... & 1,232 & 16 & 67. & 58 & 25 & $107^{\circ}$ & 134 & 667 & 26 & 132 \\
\hline Acquisitions ......... & 14,374 & 799 & 1,664 & 421 & 748 & 1,564 & 1,522 & 4,147 & 564 & 2,945 \\
\hline Conversions to AFV ..... & 1,623 & 60 & 85 & 79 & 79 & 181 & 164 & 821 & 40 & 114 \\
\hline
\end{tabular}


Table 3.6.23. "New" Natural Gas Supplier Fleet Vehicles Planned for Service in 1994" (Number of Vehicles)

\begin{tabular}{|c|c|c|c|c|c|c|c|c|c|c|}
\hline \multirow[b]{3}{*}{ Fuel Type } & \multirow[b]{3}{*}{ Total } & \multicolumn{9}{|c|}{ Vehicle Type } \\
\hline & & \multicolumn{3}{|c|}{ Passenger Cars } & \multicolumn{5}{|c|}{$\begin{array}{c}\text { Light-Duty Vans/Trucks } \\
(\leq 8,500 \text { lbs. GVW) }\end{array}$} & \multirow{2}{*}{$\begin{array}{c}\text { Medium/ } \\
\text { Heavy-Duty } \\
\text { Trucks }\end{array}$} \\
\hline & & $\begin{array}{c}\text { Subcompact } \\
\text { Compact }\end{array}$ & Mid-Size & Large & Mini-Van & $\begin{array}{c}\begin{array}{c}\text { Full-Size } \\
\text { Van }\end{array} \\
\end{array}$ & $\begin{array}{c}\text { Small } \\
\text { Pickup }\end{array}$ & $\begin{array}{c}\text { Large } \\
\text { Pickup }\end{array}$ & $\begin{array}{l}\text { Sport } \\
\text { Utility }\end{array}$ & \\
\hline \multicolumn{11}{|l|}{ Conventional-Fuel } \\
\hline Gasoline....... & 9,911 & 680 & 1,413 & 363 & 481 & 936 & 1,182 & 3,131 & 485 & 1,240 \\
\hline Diesel ............ & 1,463 & 0 & 0 & 0 & 0 & 13 & 1 & 81 & 14 & 1,354 \\
\hline Alternative-Fuel & & - & & & & & & & & \\
\hline Vehicles ............ & 4,623 & 179 & 336 & 137 & 346 & 796 & 503 & 1,756 & . 105 & 465 \\
\hline \multicolumn{11}{|l|}{$\begin{array}{l}\text { Compressed } \\
\text { Natural Gas }\end{array}$} \\
\hline Dedicated ....... & 420 & 6 & 33 & 23 & 47 & 213 & 10 & 61 & 1 & 26 \\
\hline Multifuel $\ldots . . .$. & 3,674 & 161 & 297 & 112 & 208 & 504 & 466 & 1,475 & 104 & 347 \\
\hline \multicolumn{11}{|l|}{ Propane } \\
\hline Dedicated ....... & 197 & 4 & 0 & 0 & 89 & 54 & 5 & 9 & 0 & 36 \\
\hline Multifuel ........ & 257 & 0 & 0 & 2 & 0 & 0 & 9 & 196 & 0 & 50 \\
\hline \multicolumn{11}{|l|}{$\begin{array}{l}\text { Methanol/Ethanol } \\
\text { Blends }\end{array}$} \\
\hline Dedicated ....... & 1 & 0 & 0 & 0 & 1 & 0 & 0 & 0 & 0 & 0 \\
\hline Flex-Fuel ........ & 23 & 0 & 0 & 0 & 0 & 23 & 0 & 0 & 0 & 0 \\
\hline \multicolumn{11}{|l|}{ Electricity } \\
\hline - Dedicated ....... & 25 & 8 & 0 & 0 & 1 & 1 & 13 & 0 & 0 & 2 \\
\hline Multifuel ......... & 0 & 0 & 0 & 0 & 0 & 0 & 0 & 0 & 0 & 0 \\
\hline $\begin{array}{l}\text { Other Altemative } \\
\text { Fuels }\end{array}$ & & & & & & & & . & & \\
\hline Dedicated ....... & 0 & 0 & 0 & 0 & 0 & 0 & 0 & 0 & 0 & 0 \\
\hline Multifuel ........ & 26 & 0 & 6 & 0 & 0 & 1 & 0 & 15 & 0 & 4 \\
\hline Total $\ldots \ldots \ldots \ldots \ldots$ & 15,997 & 859 & 1,749 & 500 & 827 & 1,745 & 1,686 & 4,968 & 604 & 3,059 \\
\hline
\end{tabular}

"New" Vehicles refers to both newly acquired vehicles and existing vehicles converted to operate on a new fuel.

Note: "Multifuel" refers to all altemative-fuel vehicles capable of operating on more than one fuel (i.e., bi-fuel, flex-fuel, hybrid, and dual-fuel vehicles).

Source: Energy Information Administration, Office of Oil and Gas, Form ElA-176, Schedule B, "Natural Gas Supplier Fleet Survey." 
Table 3.6.24. Natural Gas Supplier Fleet Vehicle Fueling Locations, 1993

(Number of Vehicles)

\begin{tabular}{|c|c|c|c|c|c|c|c|c|c|c|}
\hline \multirow[b]{3}{*}{$\begin{array}{l}\text { Fuel Type and Fueling } \\
\text { Location } \\
\end{array}$} & \multirow[b]{3}{*}{ Total } & \multicolumn{9}{|c|}{ Vehicle Type } \\
\hline & & \multicolumn{3}{|c|}{ Passenger Cars } & \multicolumn{5}{|c|}{$\begin{array}{l}\text { Light-Duty Vans } / \text { Trucks } \\
(\leq 8,500 \text { lbs. GVW) }\end{array}$} & \multirow{2}{*}{$\begin{array}{c}\text { Medium/ } \\
\text { Heavy-Duty } \\
\text { Trucks }\end{array}$} \\
\hline & & $\begin{array}{c}\text { Subcompact/ } \\
\text { Compact }\end{array}$ & Mid-Size & Large & Mini-Van & $\begin{array}{c}\text { Full-Size } \\
\text { Van }\end{array}$ & $\begin{array}{c}\text { Small } \\
\text { Pickup }\end{array}$ & $\begin{array}{c}\text { Large } \\
\text { Pickup } \\
\end{array}$ & $\begin{array}{l}\text { Sport } \\
\text { Utility }\end{array}$ & \\
\hline \multicolumn{11}{|l|}{$\begin{array}{l}\text { Conventional-Fuel } \\
\text { Vehicles }\end{array}$} \\
\hline Company-Owned ..... & 84,553 & 8,606 & 7,359 & 1,857 & 3,876 & 9,353 & 8,979 & 13,833 & 4,155 & 26,535 \\
\hline \multicolumn{11}{|l|}{ Public } \\
\hline Restricted...$\ldots \ldots$. & 4,420 & 337 & 601 & 103 & 186 & 353 & 585 & 1,196 & 108 & 951 \\
\hline Unrestricted ......... & 30,950 . & 1,420 & 3,315 & 1,628 & 1,026 & 1,789 & 3,808 & 10,231 & 1,411 & 6,322 \\
\hline Other $\ldots \ldots \ldots \ldots \ldots$ & 394 & 4 & 93 & 0 & 15 & 114 & 82 & 59 & 2 & 25 \\
\hline $\begin{array}{l}\text { Alternative-Fuel } \\
\text { Vehicles }\end{array}$ & & & & & & & & & - & \\
\hline Company-Owned ..... & 15,044 & 558 & 739 & 266 & 476 & 3,464 & 1,801 & 4,827 & 627 & 2,286. \\
\hline Private...$\ldots \ldots \ldots$ & 326 & 1 & 8 & 2 & 5 & 48 & 10 & 193 & 6 & 53 \\
\hline \multicolumn{11}{|l|}{ Public } \\
\hline Restricted...$\ldots \ldots$. & 78 & 1 & 0 & 0 & 2 & 38 & 5 & 30 & 0 & 2 \\
\hline Unrestricted ......... & 589 & 24 & 44 & 66 & 11 & 55 & 22 & 295 & 5 & 67 \\
\hline Other ............. & 11 & 1 & 0 & 1 & 1 & 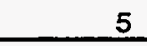 & 1 & 2 & 0 & 0 \\
\hline
\end{tabular}


Table 3.6.25. Natural Gas Supplier Fleet Vehicle Usage for Vehicles Assigned to Employees, 1993 (Number of Vehicles)

\begin{tabular}{|c|c|c|c|c|c|c|c|c|c|c|}
\hline \multirow[b]{3}{*}{ Vehicle Úsage } & \multirow[b]{3}{*}{ Total } & \multicolumn{9}{|c|}{ Vehicle Type } \\
\hline & & \multicolumn{3}{|c|}{ Passenger Cars } & \multicolumn{5}{|c|}{$\begin{array}{c}\text { Light-Duty Vans } / T r u c k s \\
(\leq 8,500 \text { lbs. GVW })\end{array}$} & \multirow{2}{*}{$\begin{array}{c}\text { Medium/ } \\
\text { Heavy-Duty } \\
\text { Trucks } \\
\end{array}$} \\
\hline & & $\begin{array}{c}\text { Subcompact } \\
\text { Compact }\end{array}$ & Mid-Size & Large & Mini-Van & $\begin{array}{c}\text { Full-Size } \\
\text { Van }\end{array}$ & $\begin{array}{c}\text { Small } \\
\text { Pickup }\end{array}$ & $\begin{array}{l}\text { Large } \\
\text { Pickup }\end{array}$ & $\begin{array}{l}\text { Sport } \\
\text { Utility } \\
\end{array}$ & \\
\hline Total Vehicles .... & 138,324 & 11,001 & 12,417 & 3,987 & 5,636 & 15,416 & 15,527 & 31,491 & 6,369 & 36,480 \\
\hline $\begin{array}{l}\text { Business Use } \\
\text { Only ........... }\end{array}$ & 106,177 & 7,827 & 5,992 & 1,321 & 4,236 & 13,511 & 12,603 & 21,530 & 4,553 & 34,604 \\
\hline $\begin{array}{l}\text { Business Use \& } \\
\text { Commuting } \ldots \ldots \text {. }\end{array}$ & 22,662 & 1,966 & 3,392 & 1,319 & 977 & 1,723 & 2,323 & 8,225 & 1,279 & 1,458 \\
\hline $\begin{array}{l}\text { Unrestricted Use } \\
\text { (Log) . ......... }\end{array}$ & 8,511 & 1,185 & 2,574 & 1,246 & 422 & 179 & 591 & 1,467 & 477 & 370 \\
\hline $\begin{array}{l}\text { Unrestricted Use } \\
\text { (No Log) .......... }\end{array}$ & 944 & 22 & 457 & 98 & 0 & 0 & 8 & 262 & 54 & 43 \\
\hline Other Usage ..... & 30 & 1 & 2 & 3 & 1 & 3 & 2. & 7 & 6 & 5 \\
\hline
\end{tabular}


Table 3.6.26. Natural Gas Supplier Fleet Vehicle Daily Miles Traveled Range, 1993 - (Number of Vehicles)

\begin{tabular}{|c|c|c|c|c|c|c|c|c|c|c|}
\hline \multirow{3}{*}{$\begin{array}{l}\text { Miles Traveled } \\
\text { Range } \\
\text { (Miles per } \\
\text { Operating Day) }\end{array}$} & \multirow[b]{3}{*}{ Total } & \multicolumn{9}{|c|}{ Vehicle Type } \\
\hline & & \multicolumn{3}{|c|}{ Passenger Cars } & \multicolumn{5}{|c|}{$\begin{array}{c}\text { Light-Duty Vans/Trucks } \\
(\leq 8,500 \text { lbs. GVW })\end{array}$} & \multirow[b]{2}{*}{$\begin{array}{c}\text { Medium } \\
\text { Heavy-Duty } \\
\text { Trucks } \\
\end{array}$} \\
\hline & & $\begin{array}{c}\text { Subcompact } \\
\text { Compact }\end{array}$ & Mid-Size & Large & Minj-Van & $\begin{array}{c}\text { Full-Size } \\
\text { Van }\end{array}$ & $\begin{array}{c}\text { Small } \\
\text { Pickup }\end{array}$ & $\begin{array}{c}\text { Large } \\
\text { Pickup } \\
\end{array}$ & $\begin{array}{l}\text { Sport } \\
\text { Utility } \\
\end{array}$ & \\
\hline Total Vehicles ...... & 138,324 & 11,001 & 12,417 & 3,987 & 5,636 & 15,416 & 15,527 & 31,491 & 6,369 & 36,480 \\
\hline 0 to $50 \ldots$ & 75,142 & 6,168 & 6,006 & 1,376 & 2,924 & 7,473 & 8,382 & 12,849 & 3,678 & 26,286 \\
\hline 51 to $100 \ldots \ldots \ldots \ldots$ & 51,512 & 4,631 & 5,550 & 1,671 & 2,224 & 7,023 & 6,280 & 13,456 & 2,098 & 8,579 \\
\hline 101 to $150 \ldots \ldots \ldots \ldots$ & 7,902 & 166 & 655 & 509 & 345 & 754 & 582 & 3,339 & 457 & 1,095 \\
\hline 151 to $200 \ldots \ldots \ldots \ldots$ & 2,179 & 21 & 104 & 90 & 130 & 130 & 247 & 1,057 & 100 & 300 \\
\hline 201 to $300 \ldots \ldots \ldots$ & 1,117 & 10 & 89 & 310 & 8 & 32 & 34 & 530 & 32 & 72 \\
\hline More than $300 \ldots$ & 472 & 5 & 13 & 31 & 5 & 4 & 2 & 260 & 4 & 148 \\
\hline
\end{tabular}

Source: Energy Information Administration, Office of Oil and Gas, Form ElA-176, Schedule B, "Natural Gas Supplier Fleet Survey." 
Table 3.6.27. Natural Gas Supplier Fleet Vehicle Replacement Cycles, 1993 (Months and Miles)

\begin{tabular}{|c|c|c|c|c|c|c|c|c|c|c|}
\hline \multirow[b]{3}{*}{ Cycle Unit } & \multirow[b]{3}{*}{$\begin{array}{c}\text { Fleet } \\
\text { Average }\end{array}$} & \multicolumn{9}{|c|}{ Vehicle Type } \\
\hline & & \multicolumn{3}{|c|}{ Passenger Cars } & \multicolumn{5}{|c|}{$\begin{array}{c}\text { Light-Duty Vans/Trucks } \\
\text { ( } \leq 8,500 \text { lbs. GVW) }\end{array}$} & \multirow{2}{*}{$\begin{array}{c}\text { Medium } \\
\text { Heavy- } \\
\text { Duty } \\
\text { Trucks }\end{array}$} \\
\hline & & $\begin{array}{c}\text { Subcompact/ } \\
\text { Compact }\end{array}$ & Mid-Size & Large & Mini-Van & $\begin{array}{c}\text { Full-Size } \\
\text { Van }\end{array}$ & $\begin{array}{l}\text { Small } \\
\text { Pickup }\end{array}$ & $\begin{array}{l}\text { Large } \\
\text { Pickup }\end{array}$ & $\begin{array}{l}\text { Sport/ } \\
\text { Utility }\end{array}$ & \\
\hline Months ........ & 70 & 67 & 61 & 57 & 67 & 72 & 70 & 69 & 67 & 93 \\
\hline Miles $\ldots \ldots \ldots \ldots \ldots$ & 94,530 & 87,283 & 89,569 & 87,796 & 96,601 & 96,104 & 95,853 & 96,574 & 95,488 & 103,888 \\
\hline
\end{tabular}


Table 3.6.28. Annual Consumption per Vehicle by Fuel and Vehicle Technology for Natural Gas Supplier Fleet Vehicles, 1993

(Physical Units)

\begin{tabular}{|c|c|c|c|c|c|c|c|c|c|c|}
\hline \multirow[b]{3}{*}{$\begin{array}{c}\text { Fuel and } \\
\text { Vehicle Type }\end{array}$} & \multirow[b]{3}{*}{$\begin{array}{c}\text { Fleet } \\
\text { Average } \\
\end{array}$} & \multicolumn{9}{|c|}{ Vehicle Type } \\
\hline & & \multicolumn{3}{|c|}{ Passenger Cars } & \multicolumn{5}{|c|}{$\begin{array}{l}\text { Light-Duty Vans/Trucks } \\
(\leq 8,500 \text { lbs. GVW })\end{array}$} & \multirow{2}{*}{$\begin{array}{c}\text { Medium } \\
\text { Heavy- } \\
\text { Duty } \\
\text { Trucks } \\
\end{array}$} \\
\hline & & $\begin{array}{c}\text { Subcompact/ } \\
\text { Compact }\end{array}$ & Mid-Size & Large & $\begin{array}{l}\text { Mini- } \\
\text { Van }\end{array}$ & $\begin{array}{c}\text { Full-Size } \\
\text { Van }\end{array}$ & $\begin{array}{c}\text { Small } \\
\text { Pickup } \\
\end{array}$ & $\begin{array}{c}\text { Large } \\
\text { Pickup } \\
\end{array}$ & $\begin{array}{l}\text { Sport/ } \\
\text { Utility }\end{array}$ & \\
\hline \multicolumn{11}{|l|}{ Dedicated Vehicles } \\
\hline Gasoline (gallons) ..... & 977 & 607 & 860 & 774 & 1,037 & 1,086 & 817 & 1,091 & 1,570 & 1,203 \\
\hline Diesel (gallons) ....... & 1,376 & NA & 181 & 397 & 170 & 795 & 708 & 1,471 & 559 & 1,331 \\
\hline CNG (cubic feet) ...... & 102,430 & 0 & 93,047 & 90,139 & 64,065 & 78,555 & 123,409 & 135,012 & 73,356 & 128,352 \\
\hline Propane (gallons) ..... & 1,001 & 650 & 1,020 & 1,008 & 918 & 991 & 737 & 987 & 1,820 . & 1,118 \\
\hline Electricity (kWh) $\ldots .$. & 1,196 & 780 & NA & NA & 1,250 & 0 & 3,900 & NA & NA & 0 \\
\hline \multicolumn{11}{|l|}{ Multifuel Vehicles } \\
\hline Gasoline (gallons) ..... & 315 & 193 & 291 & 202 & 396 & 333 & 278 & 288 & 423 & 658 \\
\hline Dlesel (gallons) ....... & 50 & 20 & 0 & 0 & 0 & 15 & 22 & 29 & 29 & 210 \\
\hline CNG (cubic feet) ...... & 279,350 & 129,808 & 93,222 & 133,269 & 155,012 & 331,452 & 293,188 & 313,782 & 247,974 & 413,472 \\
\hline Propane (gallons) ..... & 1,350 & NA & 520 & NA & 157 & 619 & 996. & 1,301 & 0 & 2,421 \\
\hline Electricity (kWh) & NA & NA & NA & NA & NA & NA & NA & NA & NA & NA \\
\hline
\end{tabular}

NA $=$ Not Applicable.

Note: "Multifuel" refers to all altemative-fuel vehicles capable of operating on more than one fuel (i.e., bi-fuel, flex-fuel, hybrid, and dual-fuel vehicles). Source: Energy Information Administration, Office of Oil and Gas, Form ElA-176, Schedule B, "Natural Gas Supplier Fleet Survey." 



\subsection{Data Quality}

\section{Propane Provider Fleet Survey}

Unlike the Electric Utility Fleet Survey and the Natural Gas Supplier Fleet Survey, the Propane Provider Fleet Survey was conducted as a sample survey and, therefore, the data collected are subject to sampling and nonsampling error. However, the sampling error will affect only portions of the data collected. The data that were collected from the top 35 providers, but not the 100 sampled companies, are not subject to sampling error because that part of the survey was a census.

\section{Nonsampling Error}

Nonsampling errors are errors of the survey process and include both random errors and systematic errors or biases. The magnitudes of nonsampling biases cannot be estimated from the sample data. Thus, avoidance of systematic biases is a primary objective of all stages of survey design. Subsequent to conducting a survey, problems of unit nonresponse and item nonresponse need to be addressed. The treatment of these types of errors in the Propane Provider Fleet Survey are discussed below.

\section{Unit Nonresponse}

Unit nonresponse is the type of nonresponse that occurs when no data are available for a survey respondent. Most unit nonresponse occurs when a respondent is unavailable or refuses to cooperate. There was one instance of unit nonresponse in the top 35 providers portion of the Propane Provider Fleet Survey that was accounted for using a simple weight adjustment. One respondent among the top 35 providers was also a respondent to the Natural Gas Supplier Fleet Survey. In order to prevent duplication of the data collection and to reduce burden on the respondent, that particular provider was released from the Propane Provider Fleet Survey. The remaining 33 responding providers were given a weight of $34 / 33=1.03$ to account for the nonresponding provider. Within the sample portion of the survey, there was 100 percent response.

\section{Imputation for Item Nonresponse}

There were three variables on the Propane Provider Fleet Survey that required imputation due to item nonresponse. Those variables were fuel storage capacity, vehicle fuel consumption, and vehicle miles traveled (VMT). For fuel storage capacity, the hot-deck procedure was used to impute for missing responses. In hot-decking, when a certain response is missing for a given respondent, another respondent, called a donor, is randomly chosen to furnish its reported value for that missing item. The donated value is then assigned to the nonrespondent company.

Due to the complex nature of consumption and miles-traveled data, it was determined that the hot-deck procedure would not be adequate. Therefore, missing responses for consumption and miles traveled were derived using nonmissing data items for the nonrespondent companies along with data from outside sources. The outside data used were average fuel economies (in miles per unit of fuel) for each fuel and each vehicle type. For those companies that did not report consumption data, but did report VMT, the missing consumption data were imputed by dividing the reported VMT by the appropriate fuel economy estimate.

If a respondent did not report either consumption or VMT, a more complicated derivation was necessary. First, an average VMT per vehicle was computed from all reported values for each fuel and vehicle type. Consumption was then imputed as gallons per vehicle by dividing the appropriate average VMT per vehicle by the appropriate fuel economy estimate. There were two respondents who were unable to report the consumption data by vehicle type, but were able to provide the total consumption of each fuel. For these two respondents, the consumption was first imputed as described; the ratio was adjusted using the reported total consumption. The ratio was computed by dividing the reported 
total consumption by the sum (over all vehicle types) of imputed consumption. Once the consumption was imputed, those newly imputed data were used to impute VMT by multiplying the imputed consumption by the appropriate fuel economy estimate.

\section{Sampling Error}

The random differences between the survey estimate and the true population value that occur because of the particular sample that was selected are known as sampling errors. The average sampling error, averaged over all possible samples, should be zero. Although the sampling error is nonzero and unknown for the particular sample chosen, the sample design permits sampling errors to be estimated. The typical magnitude of the sampling error is measured by the "standard error" of the estimate. Standard errors in this report are given as percents of their estimated values, that is, as relative standard errors (RSE's).

For a given survey statistic, $Y$, the relative standard error, $R S E(Y)$ is computed as follows:

$$
\begin{gathered}
S_{h}{ }^{2}=\frac{\sum_{i}\left(Y_{i}-\bar{Y}^{2}\right)^{2}}{n_{h}-1} \\
\sigma=\sqrt{\sum_{h}\left(\frac{N-n}{n}\right) N_{h} S_{h}^{2}} \\
\text { RSE }=\left(\frac{\sigma}{Y}\right) * 100
\end{gathered}
$$

where,

$\begin{array}{lll}\mathrm{n} & = & \text { total sample size } \\ \mathrm{n}_{\mathrm{h}} & = & \text { sample size in stratum } \mathrm{h} \\ \mathrm{N} & = & \text { total population size, and } \\ \mathrm{N}_{\mathrm{h}} & = & \text { population size in stratum } \mathrm{h} .\end{array}$

For this survey, there were four strata representing the four Census regions. The propane provider frame, omitting the top 35 providers, was separated into these four strata before the sample of 100 companies was selected. The top 35 providers did not contribute to sampling error because they were in the sample with certainty. However, for determining RSE's, the contribution of the top 35 providers was kept in the denominator. RSE's for applicable tables are included in the "3.6 Detailed Tables" section.

\section{Electric Utility Fleet Survey}

Because the Electric Utility Fleet Survey was conducted as a census survey, the data collected are not subject to sampling error. However, as with all surveys, non-sampling errors can occur. These types of errors cannot be estimated using sample data. No adjustments for either unit or item nonresponse were performed on the data collected in the Electric Utility Fleet Survey.

\section{Natural Gas Suppliers Fleet}

Because the Natural Gas Supplier Fleet Survey was conducted as a census survey, the data collected are not subject to sampling error. However, as with all surveys, non-sampling errors can occur. These types of errors cannot be estimated using sample data. 
Analysis of the natural gas consumption data from the Natural Gas Supplier Fleet Survey revealed inconsistencies for some of the respondents. These problems were likely caused by respondents reporting their natural gas consumption in units other than those specified on the questionnaire. Natural gas consumption for these respondents was accounted for by imputation.

The imputation process was as follows: Average natural gas consumption per vehicle per operating day was computed for the cases with reliable data. This average was multiplied by the vehicle-days per year (defined as the number of natural gas vehicles multiplied by the number of operating days per year) for the cases with unreliable data to produce a value of aggregate consumption for those cases. 

Section 4

\section{Consumer Vehicle Preferences}




\subsection{Introduction}

The major aims of this study are to analyze and summarize the results of a national telephone survey of consumer vehicle preferences and attitudes toward alternative-fuel vehicles. The study approach, the sample design specifications, the questionnaire, and the processing specifications were developed by students enrolled in a survey practicum course at the University of Maryland. This course is one of the graduate degree requirements of the Joint Program in Survey Methodology sponsored by the University of Maryland, the University of Michigan, and Westat, Inc. The professor for the course, who oversaw all aspects of the survey, was Dr. Stanley Presser.

The eligible population for the study consisted of telephone households in the continental United States that owned or leased one or more motor vehicles driven on a regular basis. The respondent was the adult in the household most knowledgeable about the use of the household's vehicle(s). Interviewing for the survey occurred from February 17 to May 16, 1994, in the Maryland Survey Research Center (SRC) Telephone Facility on the College Park campus. The total number of respondents was 1,712 .

\section{Highlights}

The following are selected findings, estimated by analysis of the data obtained from the Consumer Preference Survey, concerning the consumer population.

- Eighty-seven percent use personal vehicles as their main type of transportation

- Fifty-nine percent belong to households with two persons over the age of 18

- Eighty-five percent have heard of alternative-fuel vehicles

- Sixty-two percent feel that electricity is a safer vehicle fuel than gasoline

- Seventy-seven percent are concerned about outdoor air pollution in their area

- Sixty-one percent feel that vehicle emissions are extremely or very dangerous

- Forty-eight percent consider themselves to be environmentalists

- More than one-half are willing to refuel a vehicle twice as often as usual to reduce vehicle emissions

- About one-third are willing to reduce their current trunk or cargo space by one-half in order to reduce vehicle emissions

In order to understand much of the data presented in this report, it is necessary to understand the design of the questionnaire and the way in which data were collected. The next section provides this essential information.

\section{Design of the Questionnaire}

The questionnaire opened with an eligibility question about the number of vehicles in the household. If the household owned or leased one or more vehicles, a question was asked to identify the adult in the household who knew most about the vehicle(s) and how they were used. If this adult was someone other than the initial informant, this person was contacted and the number of vehicles was asked again. 
The remainder of the questionnaire fell into three broad categories: 1) vehicle questions, 2) vehicle preference questions, and 3) questions concerning attitudes about pollution and the environment.

\section{Vehicle Questions}

For households with four or fewer vehicles, the main part of the interview began with a series of questions about each vehicle (year, make, model, whether bought new or used, and size and usage of trunk (cargo) space), its regular uses (whether driven to work, school, or as part of a job, and if so, how frequently and how far), and its special uses (overnight trips or whether it was entered into competitions). Questions were also asked about fueling patterns and respondent general satisfaction with the vehicle. These questions were, for the most part, asked in order to select the vehicle that was to serve as the vehicle to be replaced in the vehicle preference section of the questionnaire. Consequently, analysis of these variables is not included in this report. The survey assumed that the least used vehicle was the vehicle with the highest likelihood of being replaced by a modified vehicle.

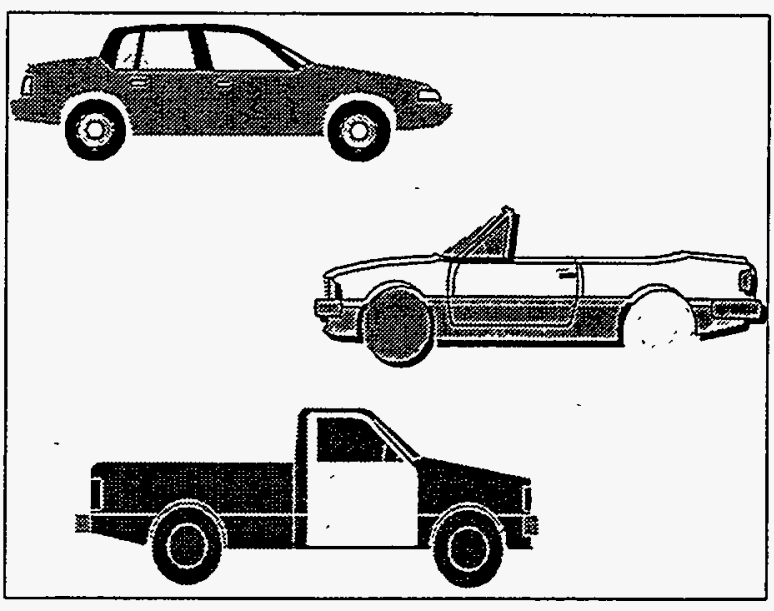

To reduce respondent burden, the very small number of households with more than four vehicles were asked only about the two vehicles driven the least. This was done because in the vehicle preference section the respondent was asked to choose between a modified vehicle and the vehicle in the household used the least. For households with multiple vehicles, the least used was defined as the one least often fueled. If a tie occurred between two vehicles, it was broken according to which had the least used trunk space, then according to which had the fewest overnight trips, and then by random selection.

Estimates for vehicle preference questions may include bias because of the sample's design. Bias may have been introduced in one of two ways. First, while the least-used household vehicle seems a plausible choice as the most likely vehicle to be a candidate for replacement by a modified vehicle, no data are available to support this conclusion. The household vehicle chosen for the vehicle preference questions might not have been the vehicle that the respondent would have chosen if given the choice. Therefore, with respect to the vehicle population, the study cannot claim to represent preferences over the entire stock, or even over the subset of vehicles most likely to be replaced by modified vehicles. The population that is covered can be described most accurately as the subpopulation of least-used vehicles in U.S. households. Second, the respondent may not have been the most appropriate person to make decisions about the vehicle addressed in the questionnaire. The respondents were chosen on the basis of their knowledge of all the household vehicles, not on the basis of whether or not they were directly responsible for the upkeep and operation of the least-used vehicle. Consequently, the respondent may not have been the household member who was the main driver of the vehicle to be replaced or the member in the position to make purchasing decisions regarding the vehicle. Likewise, the personal characteristics, opinions, and concerns for the environment are those of the respondent and not the main driver of the vehicle to be replaced, except where otherwise stated. This population would most closely represent the subpopulation of most vehicle-knowledgeable persons in U.S. households. With these caveats in mind, some national estimates based on responses about households' least-used vehicles are given below.

\section{Characteristics of Vehicles to be Replaced}

$73 \%$ were domestic vehicles

$70 \%$ were automobiles

$51 \%$ were bought used

$38 \%$ were $1985-1989$ models

$32 \%$ were 1990-1994 models

$70 \%$ of consumers were very/extremely satisfied with this vehicle

$61 \%$ were used by someone in the household to commute to work. $44 \%$ were used to make overnight trips 


\section{Vehicle Preference Questions}

The respondent was asked a series of hypothetical choice questions between a new model of the household's least-used vehicle and a less-polluting modified vehicle that was identical to the regular vehicle except for certain limitations or "penalty" characteristics. The limitations of the modified vehicle are similar to those currently associated with alternativefuel vehicles (AFV) and imply behavioral changes for the operator. The questionnaire contained three scenarios:

1. The modified vehicle has only one-half the trunk (cargo) space of the regular vehicle.

2. The respondent must drive 15 minutes out of the way to buy fuel for the modified vehicle.

3. The modified vehicle must be refueled twice as often as the regular vehicle.

Respondents were asked to choose which vehicle they would purchase, given each limitation individually and in combination.

Within each individual scenario, respondents who said they would choose the modified vehicle were asked which they would choose if the modified vehicle cost $\$ 1,000$ more than the regular vehicle. Respondents who chose the regular vehicle were asked which they would choose if the modified vehicle was $\$ 1,000$ less than the regular vehicle. Figure4.1.1,illustrates the flow of the vehicle preference section of the questionnaire. In the figure, " $M$ " means that the respondent chose the modified vehicle. "R" means that they chose the regular vehicle. 
Figure 4.1.1. Flow Chart of the Questionnaire

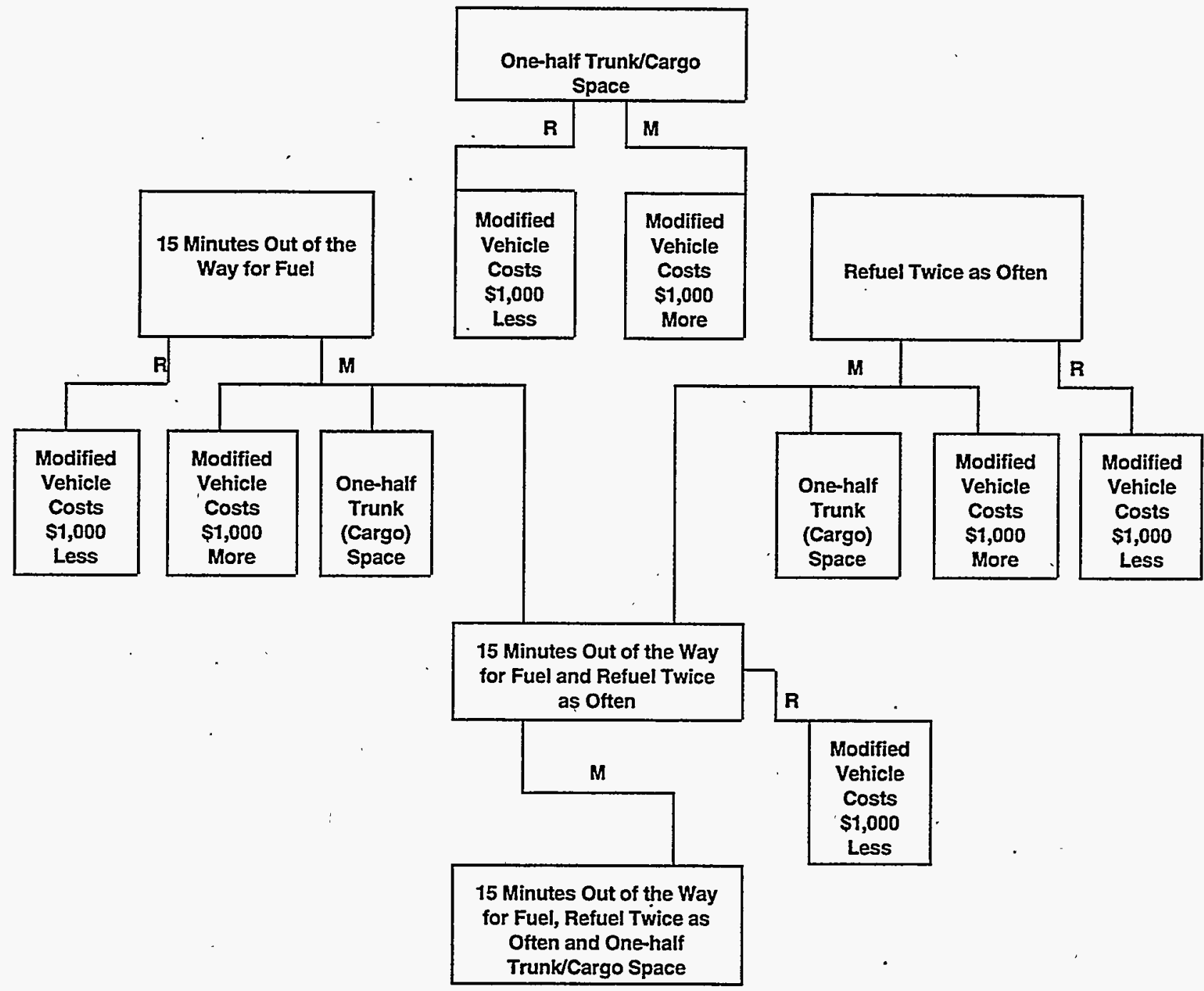

Source: Energy Information Administration, Office of Energy Markets and En'd Use, Joint Program in Survey Methodology Consumer Vehicle Preference Survey.

Additionally, for a random half-sample, the modified vehicle was described as producing half as much air pollution as a regular vehicle; for the other half, the modified vehicle was described as producing no air pollution. Although the two categories were general, the modified vehicle that produced no air pollution was intended to represent electric-powered vehicles. The vehicle that produced half as much air pollution as a regular vehicle represented other alternative-fuel vehicles, such as those powered by natural gas, propane, and other non-petroleum fuels.

\section{Attitudinal Questions .}

The final section of the questionnaire measured respondent awareness of AFV's and attitudes about air pollution and environmentalism. Questions included ascertained: (I) whether and to what extent respondents had heard of alternative-fuel vehicles, (2) respondents' perception of the relative safety of alternative fuels to gasoline, (3) respondents' concerns about air pollution in their area, and (4) whether and to what extent respondents considered themselves environmentalists. 


\section{Organization of this Report}

Sections 4.2 and 4.3 address three general topics: (1) consumer characteristics and their general attitudes and concerns about air pollution, (2) prospective vehicle purchasers' receptiveness to behavioral changes they might have to make to operate an alternative-fuel vehicle, and (3) price differentials between conventional vehicles and alternative-fuel vehicles that consumers will accept in making purchasing decisions. The detailed tables for the survey are found in section 4.4. Section 4.5 contains the relative standard errors for the estimates found throughout this section of the report. Data quality and methodology issues are briefly discussed in section 4.6 . 



\subsection{Consumer Characteristics, Awareness, and Concerns}

The Consumer Preference Survey contained questions to learn respondent demographic characteristics, consumer knowledge of alternative-fuel vehicles, perception of the relative safety of alternative fuels, and general concerns for the environment.

\section{Consumer Characteristics}

The Consumer Preference Survey found that 39 Figure 4.2.1. Household Annual Income by Census percent of the telephone household population has one household vehicle, 42 percent has two, 12 percent has three, and 7 percent has four or more. Sixty-seven percent of the population has an average annual household income of $\$ 30,000$ or more. For these households, nearly 75 percent owned two or more vehicles. In contrast, 64 percent of households with annual income of less than $\$ 30,000$ owned only one vehicle.

Nineteen percent of the population lives in the Northeast, 25 percent in the Midwest, 35 percent in the South, and 21 percent in the West. Within each Census Region the household annual income is distributed as shown in Figure 4.2.1. The Northeast has the highest percentage of people earning $\$ 30,000$ or more annually, and the South has the highest percentage of people who earn less than $\$ 30,000$. Most households have one or two vehicles (about 80 Region

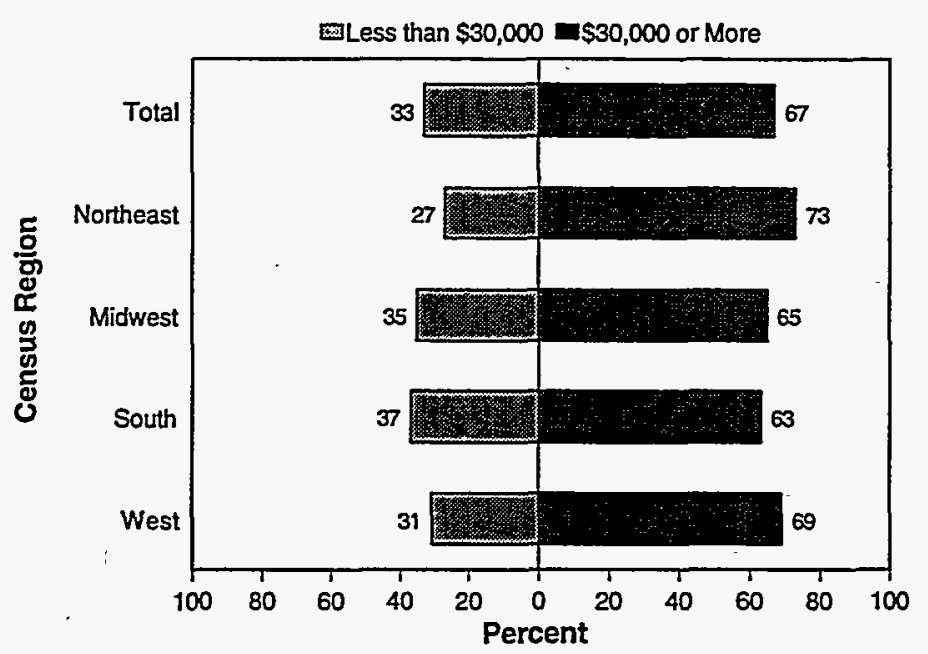
percent). The distribution of the number of vehicles is shown in Figure 4.2.2.

Figure 4.2.2. Number of Vehicles by Census Region

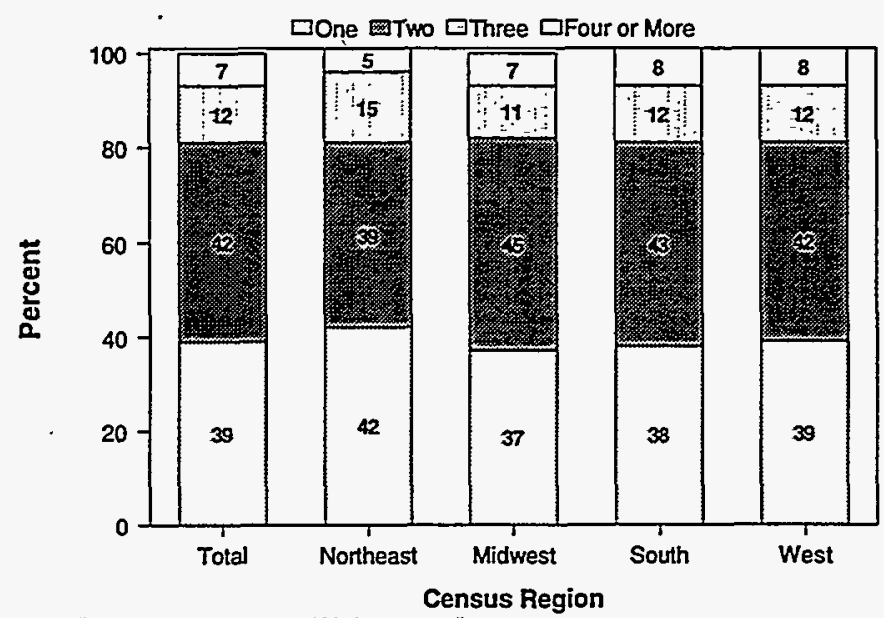

Note: Percents may not sum to 100 due to rounding.

Source: Energy Information Administration, Office of Energy Markets and End Use, Joint Program in Survey Methodology Consumer Vehicle Preference Survey. 
The relationship between the number of vehicles and annual income in households is shown in Figure 4.2.3.

Figure 4.2.3. Household Annual Income by Number of Vehicles

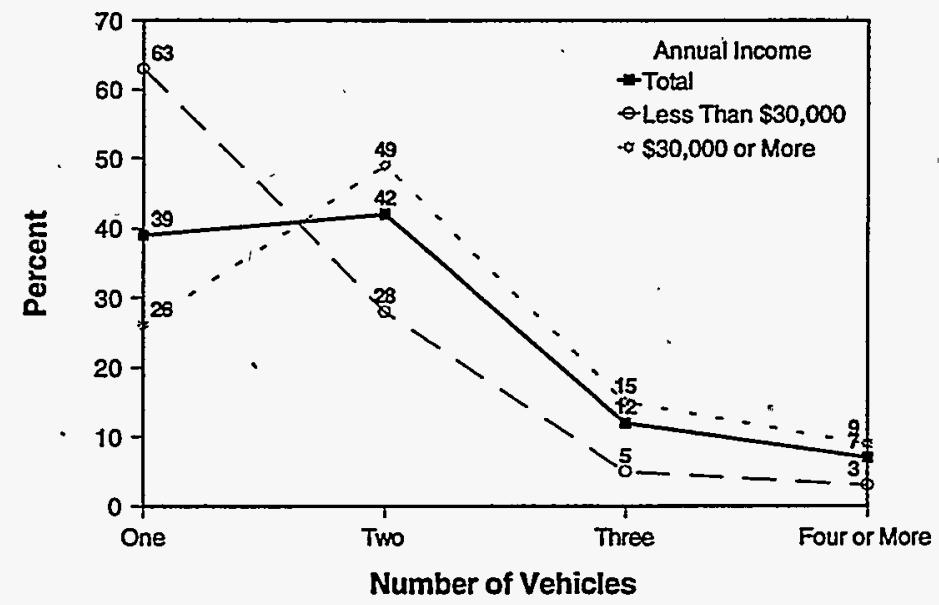

Source: Energy Information Administration, Office of Energy Markets and End Use, Joint Program in Survey Methodology Consumer Vehicle Preference Survey.

Other consumer characteristic estimates are given below.

\section{Consumer Characteristics}

$87 \%$ used personal vehicles as their main type of transportation

$67 \%$ had household income greater than $\$ 30,000$

$69 \%$ lived in single-family detached homes

$86 \%$ had high school or college education

$59 \%$ belonged to household with two persons over 18 years of age

$85 \%$ were white

\section{Consumer Awareness}

Most consumers ( 85 percent) had heard of alternative-fuel vehicles, although only slightly more than one-half of the population knew more than "just a little" about them. By far, the perception of fuel safety of alternative fuels was strongest for electricity, with 62 percent stating it was a safer vehicle fuel than gasoline. The following summarizes consumers' awareness of alternative-fuel vehicles and opinions of the relative safety of alternative fuels.

\section{Consumer Awareness and Opinions}

$85 \%$ had heard of alternative-fuel vehicles

$18 \%$ felt that natural gas was a safer vehicle fuel than gasoline

$29 \%$ felt that gasoline was a safer vehicle fuel than natural gas

$11 \%$ felt that propane was a safer vehicle fuel than gasoline

$41 \%$ felt that gasoline was a safer vehicle fuel than propane

$62 \%$ felt that electricity was a safer vehicle fuel than gasoline

$12 \%$ felt that gasoline was a safer vehicle fuel than electricity 


\section{Consumer Concern}

Concern for the environment was greatest in the Northeast and West Census regions (Figure 4.2.4). Figure 4.2.4. Level of Concern for the Environment by
Census Region

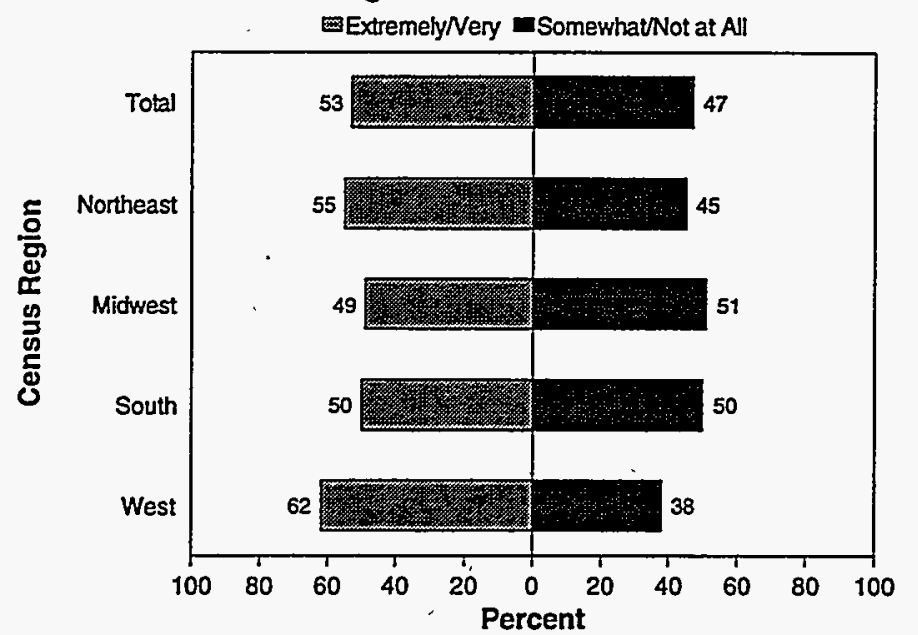

Source: Energy Information Administration, Office of Energy Markets and End Use. Joint Program in Survey Methodology Consumer Vehicle Preference Survey.

Overall, consumers are concerned about the environment and consider themselves environmentalists; however, of the 48 percent who consider themselves environmentalists, only 22 percent are members of any environmental organization.

\section{Consumer Concern for Environment}

$77 \%$ were concerned about outdoor air pollution in their area

Of these, $53 \%$ were extremely/very concerned

$61 \%$ feel that vehicle emissions are extremely/very dangerous

$48 \%$ consider themselves to be environmentalists 



\subsection{Consumer Receptiveness to Behavioral Changes and Price Differentials}

Respondents were asked whether they would purchase a new model of the household's least used vehicle, or a less-polluting modified vehicle (AFV) identical to the regular vehicle except for certain limitations that might require respondents to change their normal behavior associated with operating a vehicle. Three simple cases were first addressed: the modified vehicle would have only half the trunk space of the regular vehicle; the modified vehicle would require refueling at a station that was 15 minutes out of the way for the respondent; and, the modified vehicle would need to be refueled twice as often as the regular vehicle. If the respondent answered that they would choose the modified vehicle with the single limitation over the regular vehicle, then they were asked about their vehicle choice if the modified vehicle had any combination of these same three limitations. Additionally, in all the single limitation scenarios, respondents were asked a question regarding the price of the modified vehicle to learn if a $\$ 1,000$ difference in price would influence the respondents' original vehicle preference. Respondents who had chosen the regular vehicle were asked their preference if the modified vehicle cost $\$ 1,000$ less. Respondents who chose the modified vehicle were asked their preference if the modified vehicle cost $\$ 1,000$ more.

\section{Single Vehicle Limitations}

The following table presents consumer vehicle preferences; expressed in percents, when given three possible modified vehicle limitations.

Table 4.3.1. Overview of Vehicle Preference by Modified Vehicle Limitations, 1994 (Percent)

\begin{tabular}{|c|c|c|c|c|c|c|}
\hline \multirow[b]{2}{*}{ Vehicle Limitation } & \multicolumn{3}{|c|}{$\begin{array}{c}\text { Modified Vehicle Pollutes Half as Much as } \\
\text { Regular Vehicle }\end{array}$} & \multicolumn{3}{|c|}{ Modified Vehicle Does Not Pollute } \\
\hline & $\begin{array}{l}\text { Regular } \\
\text { Vehicle }\end{array}$ & $\begin{array}{c}\text { Modified } \\
\text { Vehicle }\end{array}$ & Don't Know & $\begin{array}{l}\text { Regular } \\
\text { Vehicle }\end{array}$ & $\begin{array}{l}\text { Modified } \\
\text { Vehicle }\end{array}$ & $\begin{array}{l}\text { Don't } \\
\text { Know }\end{array}$ \\
\hline $\begin{array}{l}\text { One-half Trunk (Cargo) } \\
\text { Space .................. }\end{array}$ & 6 & & $\mathbf{Q}$ & 5 & 3 & $\mathbf{Q}$ \\
\hline $\begin{array}{l}15 \text { Minutes Out of the Way } \\
\text { to Refuel } . . . \ldots \ldots \ldots \ldots . . .\end{array}$ & 5 & 4 & $\mathbf{Q}$ & 4 & 5 & $\mathbf{Q}$ \\
\hline Refuel Twice as Often ... & 4 & 5 & $\mathbf{Q}$ & 3 & 5 & $\mathbf{Q}$ \\
\hline \multicolumn{7}{|c|}{$\begin{array}{l}\text { Q = Data withheld either because the Relative Standard Error (RSE) was greater than } 50 \text { percent or fewer than } 10 \text { households were } \\
\text { sampled. } \\
\text { Source: Energy Information Administration, Office of Energy Markets and End Use, Joint Program in Survey Methodology Consumer Vehicle } \\
\text { Preference Survey. }\end{array}$} \\
\hline \multicolumn{7}{|c|}{$\begin{array}{l}\text { Between the two options of giving up one-half of the trunk (cargo) space of a regular vehicle and having to refuel the } \\
\text { modified vehicle twice as often, consumers in both pollution level groups were clearly more willing to refuel more often. } \\
\text { Twenty-one percent more consumers were willing to refuel twice as often than were willing to give up trunk space when } \\
\text { the modified vehicle polluted half as much as a regular vehicle, } 22 \text { percent more if the modified vehicle did not pollute at } \\
\text { all. Not much can be said, however, concerning consumer willingness to drive } 15 \text { minutes out of the way to refuel in } \\
\text { comparison to the other two options. The differences were statistically insignificant. }\end{array}$} \\
\hline
\end{tabular}

With one exception, within each limitation scenario, differences among the pollution level groups' vehicle choice were statistically insignificant. The exception occurred when the respondent had to drive 15 minutes out of the way to refuel the 
modified vehicle. Eleven percent fewer respondents chose the regular vehicle if the modified vehicle did not pollute than if it polluted half as much as a regular vehicle.

The following sections look at the behavioral changes and the effect of price differentials on vehicle choice associated with each of the vehicle limitations.

\section{Giving Up Trunk Space}

Potential vehicle purchasers were most reluctant to give up half the amount of trunk (cargo) space of their current vehicle even if it meant halving or eliminating the pollution produced in operating a vehicle. Vehicle choice was related to the size of the trunk of the consumer's current vehicle (Table 4.3.2).

Table 4.3.2. Vehicle Preference Regarding Loss of One-Half Trunk Space, by Size of Current Vehicle Trunk, 1994 (Percent)

\begin{tabular}{|c|c|c|c|c|c|c|c|c|c|}
\hline \multirow[b]{2}{*}{ Trunk Size } & \multicolumn{4}{|c|}{$\begin{array}{l}\text { Modified Vehicle Pollutes Half as Much as } \\
\text { Regular Vehicle }\end{array}$} & \multicolumn{5}{|c|}{ Modified Vehicle Does Not Pollute } \\
\hline & $\begin{array}{l}\text { Regular } \\
\text { Vehicle }\end{array}$ & $\begin{array}{c}\text { Modified } \\
\text { Vehicle }\end{array}$ & $\begin{array}{l}\text { Don't } \\
\text { Know }\end{array}$ & & $\begin{array}{l}\text { Regular } \\
\text { Vehicle }\end{array}$ & $\begin{array}{c}\text { Modified } \\
\text { Vehicle }\end{array}$ & & $\begin{array}{l}\text { Don't } \\
\text { Know }\end{array}$ & \\
\hline Large .............. & & & & $\mathbf{Q}$ & & & 40 & & Q \\
\hline Medium...$\ldots \ldots \ldots$ & & & & $\mathbf{Q}$ & & . & $Q$ & & $Q$ \\
\hline Small ............. & & & & $\mathbf{Q}$ & & & 60 & & Q \\
\hline No Trunk ........... & & & . & $\mathbf{Q}$ & & & $Q$ & & $\mathbf{Q}$ \\
\hline
\end{tabular}

$Q=$ Data withheld either because the Relative Standard Error (RSE) was greater than 50 percent or fewer than 10 households were sampled.

Source: Energy Information Administration, Office of Energy Markets and End Use, Joint Program in Survey Methodology Consumer Vehicle Preference Survey.

As expected, those who currently had large or medium-sized trunks were less willing to replace their vehicle with one with only one-half the trunk space no matter how much pollution was reduced. This result suggests that a large trunk may have been an important factor in the purchasing decision of their current vehicle, and it continued to be a deciding factor in the selection of a new vehicle. Consumers whose current vehicles had small trunks were more likely to choose the modified vehicle, perhaps because trunk space was not as important as other considerations in their vehicle-purchasing decision.

A result that appears surprising is that the majority of respondents who reported that their current vehicle had no trunk at all were unwilling to buy the modified vehicle. The explanation lies in the wording of the trunk size and preference questions. The question concerning current vehicle trunk size was asked about the space contained in the trunk of the vehicle alone, while the vehicle preference question included both trunk space and cargo space. Therefore, a respondent who answered that the current vehicle had no trunk most often had a truck, van, station-wagon, or sport-utility vehicle; all have cargo space but no trunk. In fact, about 70 percent of those who stated that their current vehicle had no trunk were referring to one of these types of vehicles. Since these vehicles are often purchased for their hauling capacity, it makes sense that reducing the cargo space by one-half would not be a compromise many would be willing to make. For those respondents who were not referring to one of these types of vehicles ( 30 percent), it is feasible that they were referring to an automobile with a hatchback or whose back seat was used for cargo rather than passengers. It could also be that the respondent simply would not purchase another vehicle without a trunk or other cargo space again.

Price Differential. In both price cases, trunk (cargo) space seemed more important to consumers than $\$ 1,000$. Consumers who were willing to give up trunk (cargo) space were not willing to pay $\$ 1,000$ extra to do so. The question of how much pollution was reduced had little impact (Table 4.3.3). Consumers who chose the regular vehicle originally were not swayed 
to choose the modified vehicle by $\$ 1,000$. The price reduction was little incentive to accept the reduction in trunk space for most people (Table 4.3.3).

Table 4.3.3. Vehicle Preference Incorporating Price Differential Based on Original Vehicle Choice, 1994 (Percent)

\begin{tabular}{c|c|c|c|c|c|c}
\hline & \multicolumn{3}{|c|}{$\begin{array}{c}\text { Modified Vehicle Pollutes Half as Much as } \\
\text { Regular Vehicle }\end{array}$} & \multicolumn{3}{|c}{ Modified Vehicle Does Not Pollute } \\
\cline { 2 - 6 } $\begin{array}{c}\text { Differential Cost of } \\
\text { Modified Vehicle }\end{array}$ & $\begin{array}{c}\text { Regular } \\
\text { Vehicle }\end{array}$ & $\begin{array}{c}\text { Modified } \\
\text { Vehicle }\end{array}$ & $\begin{array}{c}\text { Don't } \\
\text { Know }\end{array}$ & $\begin{array}{c}\text { Regular } \\
\text { Vehicle }\end{array}$ & $\begin{array}{c}\text { Modified } \\
\text { Vehicle }\end{array}$ & $\begin{array}{c}\text { Don't } \\
\text { Know }\end{array}$ \\
\hline
\end{tabular}

$\begin{array}{llccccc}\$ 1,000 \text { More } \ldots \ldots \ldots \ldots \ldots & 68 & 26 & Q & 69 & 27 & Q \\ \$ 1,000 \text { Less } \ldots \ldots \ldots \ldots . & 88 & Q & Q & 79 & Q & Q\end{array}$

$Q=$ Data withheld either because the Relative Standard Error (RSE) was greater than 50 percent or fewer than 10 households were sampled.

Source: Energy Information Administration, Office of Energy Markets and End Use, Joint Program in Survey Methodology Consumer Vehicle Preference Survey.

\section{Driving 15 Minutes Out of the Way to Refuel}

Respondents were nearly equally divided about Figure 4.3.1. Consumers Willing to Drive 15 Minutes Out of whether they were willing to drive a short distance out of their way for fuel in order to drive a vehicle that pollutes less. Unlike giving up trunk space, willingness to purchase the modified vehicle did differ between the two pollution levels of the modified vehicle. Fortyone percent of the group given the halfpolluting modified vehicle scenario and 51 percent of the non-polluting vehicle group were willing to travel 15 minutes out of their way. Consumers offered a vehicle that did not pollute at all chose the modified vehicle at a higher rate than those who were offered a vehicle that polluted only half as much. This trend was especially strong among respondents who live in the West or the Northeast. Figure 4.3.1 illustrates the difference between the two groups by Census region.

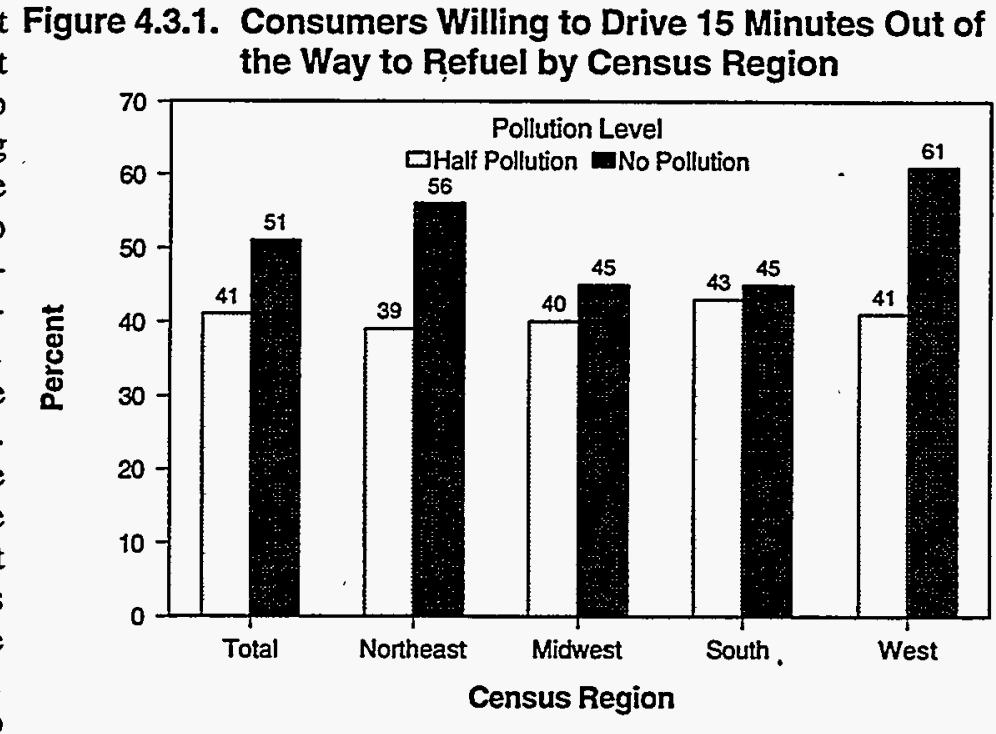

Source: Energy Information Administration, Office of Energy Markets and End Use, Joint Program in Survey Methodology Consumer Vehicle Preference Survey.

Respondents' willingness to drive 15 minutes out of the way to refuel did not appear to be affected by their usual frequency of gas purchase (Table 4.3.4). 
Table 4.3.4. Willingness to Drive 15 Minutes Out of the Way to Refuel by Frequency of Usual Gas Purchase, 1994

(Percent)

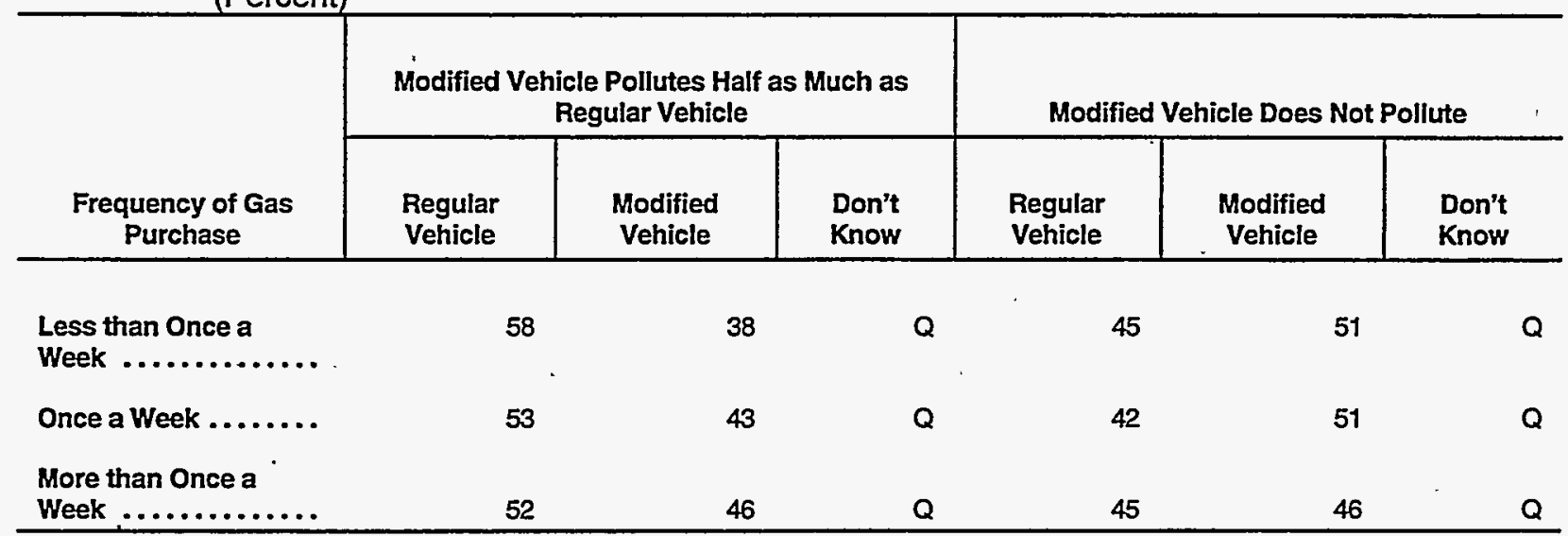

$Q=$ Data withheld either because the Relative Standard Error (RSE) was greater than 50 percent or fewer than 10 households were sampled.

Source: Energy Information Administration, Office of Energy Markets and End Use, Joint Program in Survey Methodology Consumer Vehicle Preference Survey.

Price Differential. Nearly one-third of respondents who chose the regular vehicle over the modified vehicle that has to be driven 15 minutes out of the way to refuel said they would choose the modified vehicle if it cost $\$ 1,000$ less. There was practically no difference among the pollution-reduction level groups (Table 4.3.5).

On the other hand, when those who originally chose the modified vehicle were asked if they would pay an additional $\$ 1,000$ for the vehicle, over one-third said they would not. A larger percentage of potential consumers was "lost" because of a price increase than was "gained" from a price decrease (Table 4.3.5).

Table 4.3.5. Vehicle Preference Incorporating Price Differential Based on Original Vehicle Choice, 1994 (Percent)

\begin{tabular}{|c|c|c|c|c|c|c|}
\hline \multirow[b]{2}{*}{$\begin{array}{l}\text { Differential Cost of } \\
\text { Modified Vehicle }\end{array}$} & \multicolumn{3}{|c|}{$\begin{array}{l}\text { Modified Vehicle Pollutes Half as Much as } \\
\text { Regular Vehicle }\end{array}$} & \multicolumn{3}{|c|}{ Modified Vehicle Does Not Pollute } \\
\hline & $\begin{array}{l}\text { Regular } \\
\text { Vehicle }\end{array}$ & $\begin{array}{l}\text { Modified } \\
\text { Vehicle }\end{array}$ & $\begin{array}{l}\text { Don't } \\
\text { Know }\end{array}$ & $\begin{array}{l}\text { Regular } \\
\text { Vehicle }\end{array}$ & $\begin{array}{c}\text { Modified } \\
\text { Vehicle }\end{array}$ & $\begin{array}{l}\text { Don't } \\
\text { Know }\end{array}$ \\
\hline$\$ 1,000$ More . . . . . . . . . . & 40 & & $\mathbf{Q}$ & & & \\
\hline$\$ 1,000$ Less $\ldots . . . \ldots .$. & 68 & 2 & $\mathbf{Q}$ & & & \\
\hline
\end{tabular}

$Q=$ Data withheld either because the Relative Standard Error (RSE) was greater than 50 percent or fewer than 10 households were sampled.

Source: Energy Information Administration, Office of Energy Markets and End Use, Joint Program in Survey Methodology Consumer Vehicle Preference Survey.

\section{Refueling Twice as Often}

Of the limitations specified in this study for the modified vehicle, the one that respondents seemed most willing to accept in order to reduce the amount of pollution emitted was refueling twice as often. More than half chose the modified vehicle, 54 percent among those offered a vehicle polluting half as much, and 57 percent among those offered the choice of a nonpolluting vehicle. Frequency of regular fuel purchases affected willingness to purchase the modified vehicle only minimally (Table 4.3.6). In the non-polluting modified vehicle cases, people who fueled once a week or more were more willing to refuel twice as often than those who refueled less than once a week. 
Table 4.3.6. Willingness Refuel Twice as Often by Frequency of Usual Gas Purchase, 1994 (Percent)

\begin{tabular}{|c|c|c|c|c|c|c|}
\hline \multirow[b]{2}{*}{$\begin{array}{c}\text { Frequency of Gas } \\
\text { Purchase }\end{array}$} & \multicolumn{3}{|c|}{$\begin{array}{l}\text { Modified Vehicle Pollutes Half as Much as } \\
\text { Regular Vehicle }\end{array}$} & \multicolumn{3}{|c|}{ Modified Vehicle Does Not Pollute } \\
\hline & $\begin{array}{l}\text { Regular } \\
\text { Vehicle }\end{array}$ & $\begin{array}{l}\text { Modified } \\
\text { Vehicle }\end{array}$ & $\begin{array}{l}\text { Don't } \\
\text { Know }\end{array}$ & $\begin{array}{l}\text { Regular } \\
\text { Vehicle }\end{array}$ & $\begin{array}{l}\text { Modified } \\
\text { Vehicle }\end{array}$ & $\begin{array}{l}\text { Don't } \\
\text { Know }\end{array}$ \\
\hline $\begin{array}{l}\text { Less than Once a } \\
\text { Week ............... }\end{array}$ & 40 & 55 & $c$ & 39 & 53 & $\mathbf{Q}$ \\
\hline Once a Week ......... & 41 & 54 & $\mathrm{c}$ & 33 & 61 & Q \\
\hline $\begin{array}{l}\text { More than Once a } \\
\text { Week } \ldots \ldots \ldots \ldots \ldots \text {......... }\end{array}$ & 47 & 52 & C & 40 & 56 & $Q$ \\
\hline
\end{tabular}

Price Differential. The price differential affected the original purchasing decision in much the same way as it affected the scenario requiring drivers to drive 15 minutes out of the way to refuel. The $\$ 1,000$ price increase persuaded more people to change their choice from the modified vehicle to the regular one than the $\$ 1,000$ price decrease persuaded people to choose the modified vehicle after choosing the regular one (Table 4.3.7).

Table 4.3.7. Vehicle Preference Incorporating Price Differential Based on Original Vehicle Choice, 1994 (Percent)

\begin{tabular}{|c|c|c|c|c|c|c|}
\hline \multirow[b]{2}{*}{$\begin{array}{l}\text { Differential Cost of } \\
\text { Modified Vehicle }\end{array}$} & \multicolumn{3}{|c|}{$\begin{array}{l}\text { Modified Vehicle Pollutes Half as Much as } \\
\text { Regular Vehicle }\end{array}$} & \multicolumn{3}{|c|}{ Modified Vehicle Does Not Pollute } \\
\hline & $\begin{array}{l}\text { Regular } \\
\text { Vehicle }\end{array}$ & $\begin{array}{l}\text { Modified } \\
\text { Vehicle }\end{array}$ & $\begin{array}{l}\text { Don't } \\
\text { Know }\end{array}$ & $\begin{array}{l}\text { Regular } \\
\text { Vehicle }\end{array}$ & $\begin{array}{l}\text { Modified } \\
\text { Vehicle }\end{array}$ & $\begin{array}{l}\text { Don't } \\
\text { Know }\end{array}$ \\
\hline$\$ 1,000$ More . . . . . . . . . . & 37 & 5 & $\mathbf{Q}$ & 31 & 63 & $\mathbf{Q}$ \\
\hline$\$ 1,000$ Less $\quad \ldots \ldots \ldots \ldots$ & 67 & 2 & $\mathbf{Q}$ & 72 & 22 & $\mathbf{Q}$ \\
\hline
\end{tabular}

\section{Combinations of Vehicle Limitations}

Table 4.3.8 presents vehicle preference estimates given different combinations of vehicle limitations. Only those who responded that they would choose the modified vehicle given the single limitation were asked about combinations of limitations. Therefore, the populations these estimates represent are depleted populations of the total (Figure 4.1.1). 
Table 4.3.8. Overview of Vehicle Preference by Combinations of Modified Vehicle Limitations for Depleted Populations, 1994

(Percent)

\begin{tabular}{|c|c|c|c|c|c|c|}
\hline \multirow[b]{2}{*}{ Vehicle Limitation } & \multicolumn{3}{|c|}{$\begin{array}{l}\text { Modified Vehicle Pollutes Half as Much } \\
\text { as Regular Vehicle }\end{array}$} & \multicolumn{3}{|c|}{ Modified Vehicle Does Not Pollute } \\
\hline & $\begin{array}{l}\text { Regular } \\
\text { Vehicle }\end{array}$ & $\begin{array}{l}\text { Modified } \\
\text { Vehicle }\end{array}$ & $\begin{array}{l}\text { Don't } \\
\text { Know }\end{array}$ & $\begin{array}{l}\text { Regular } \\
\text { Vehicle }\end{array}$ & $\begin{array}{l}\text { Modified } \\
\text { Vehicle }\end{array}$ & $\begin{array}{l}\text { Don't } \\
\text { Know }\end{array}$ \\
\hline $\begin{array}{l}15 \text { Minutes Out of the Way and } \\
\text { One-half Trunk (Cargo) Space }\end{array}$ & 49 & 48 & $\mathbf{Q}$ & 5 & 45 & $\mathbf{Q}$ \\
\hline $\begin{array}{l}\text { Refuel Twice as Often and One- } \\
\text { half Trunk (Cargo) Space .... }\end{array}$ & 51 & 47 & $\mathbf{Q}$ & 46 & 52 & $\mathbf{Q}$ \\
\hline $\begin{array}{l}15 \text { Minutes Out of the Way and } \\
\text { Refuel Twice as Often ........ }\end{array}$ & 24 & 75 & $\mathbf{Q}$ & 20 & 76 & $\mathbf{Q}$ \\
\hline $\begin{array}{l}15 \text { Minutes Out of the Way, } \\
\text { Refuel Twice as Often and One- } \\
\text { half Trunk (Cargo) Space .... }\end{array}$ & 38 & 61 & $\mathbf{Q}$ & 3 & 62 & $\mathbf{Q}$ \\
\hline
\end{tabular}

The addition of limited trunk or cargo space in the modified vehicle lost, by far, the largest proportion of consumers willing to purchase a modified vehicle. How much pollution reduction the modified vehicle attained seemed to make little difference in vehicle choice.

Consumers who were willing to drive 15 minutes out of the way and refuel twice as often individually, were usually willing to do so in combination ( 75 percent and 76 percent). Of these, the addition of the loss of trunk (cargo) space lost a somewhat smaller proportion of people willing to buy the modified vehicle than in the double combinations involving trunk (cargo) space.

\section{Conclusions}

Overall, consumers seem fairly willing to accept vehicles with characteristics of alternative-fuel vehicles. The scenarios of having to drive 15 minutes out of the way to fuel the modified vehicle and having to refuel the modified vehicle twice as often gained wider acceptance than the scenario in which trunk (cargo) space was reduced. Perhaps, this suggests that particular attention should be paid to solving the problem of limited trunk (cargo) space associated with those AFV's that require a great amount of space for fuel storage. There seemed to be a difference in vehicle preference when a price differential was introduced. More respondents were dissuaded from purchasing the modified vehicle if it cost $\$ 1,000$ more than were persuaded to purchase the modified vehicle if it cost $\$ 1,000$ less. For the most part, consumer preferences were not affected by how much pollution was reduced. 


\subsection{Detailed Tables}


Table 4.4.1. Consumer Characteristics by Level of Concern for the Environment, 1994 (Percent)

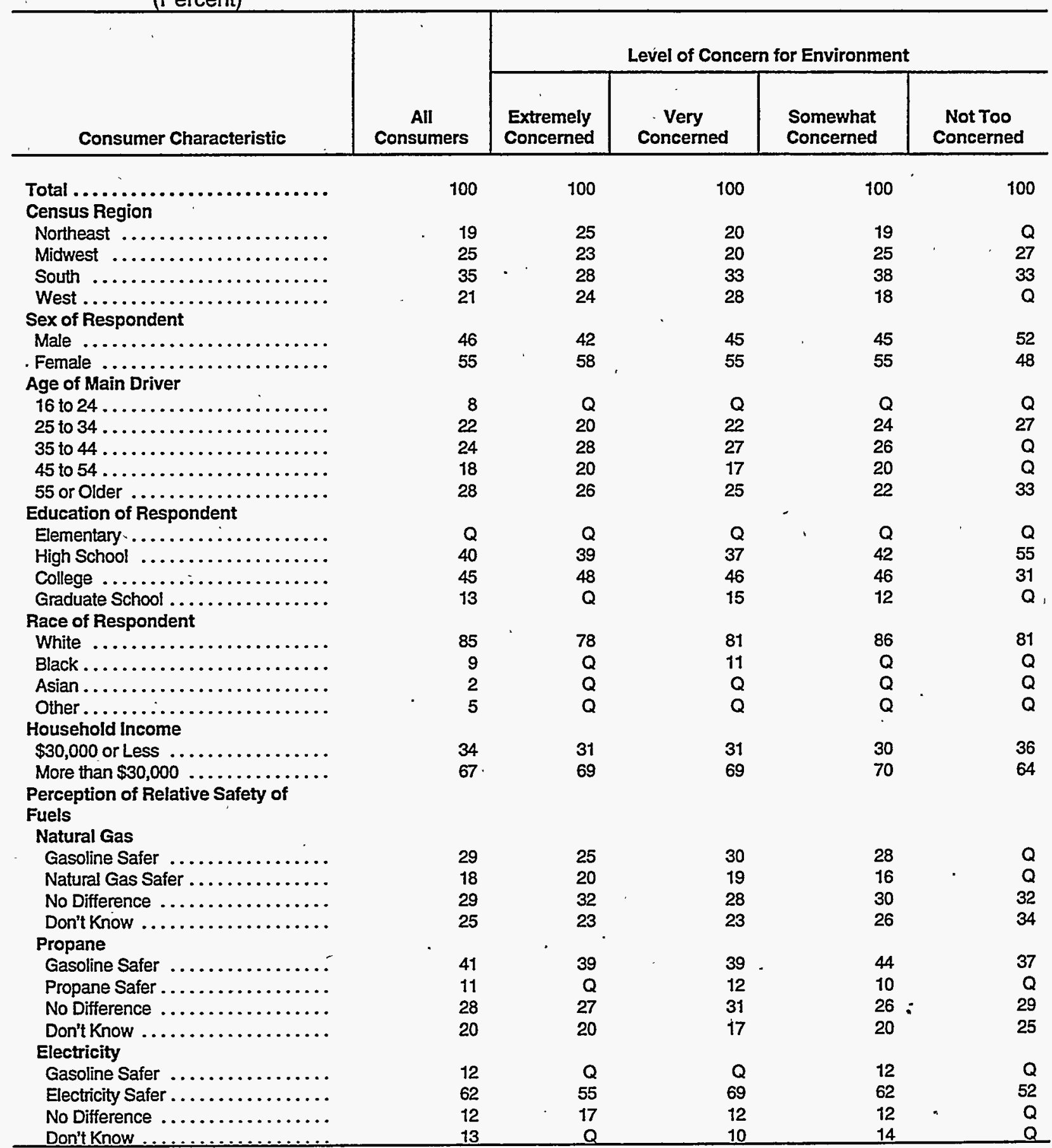

See footnotes at end of table. 
Table 4.4.1. Consumer Characteristics by Level of Concern for the Environment, 1994 (Continued) (Percent)

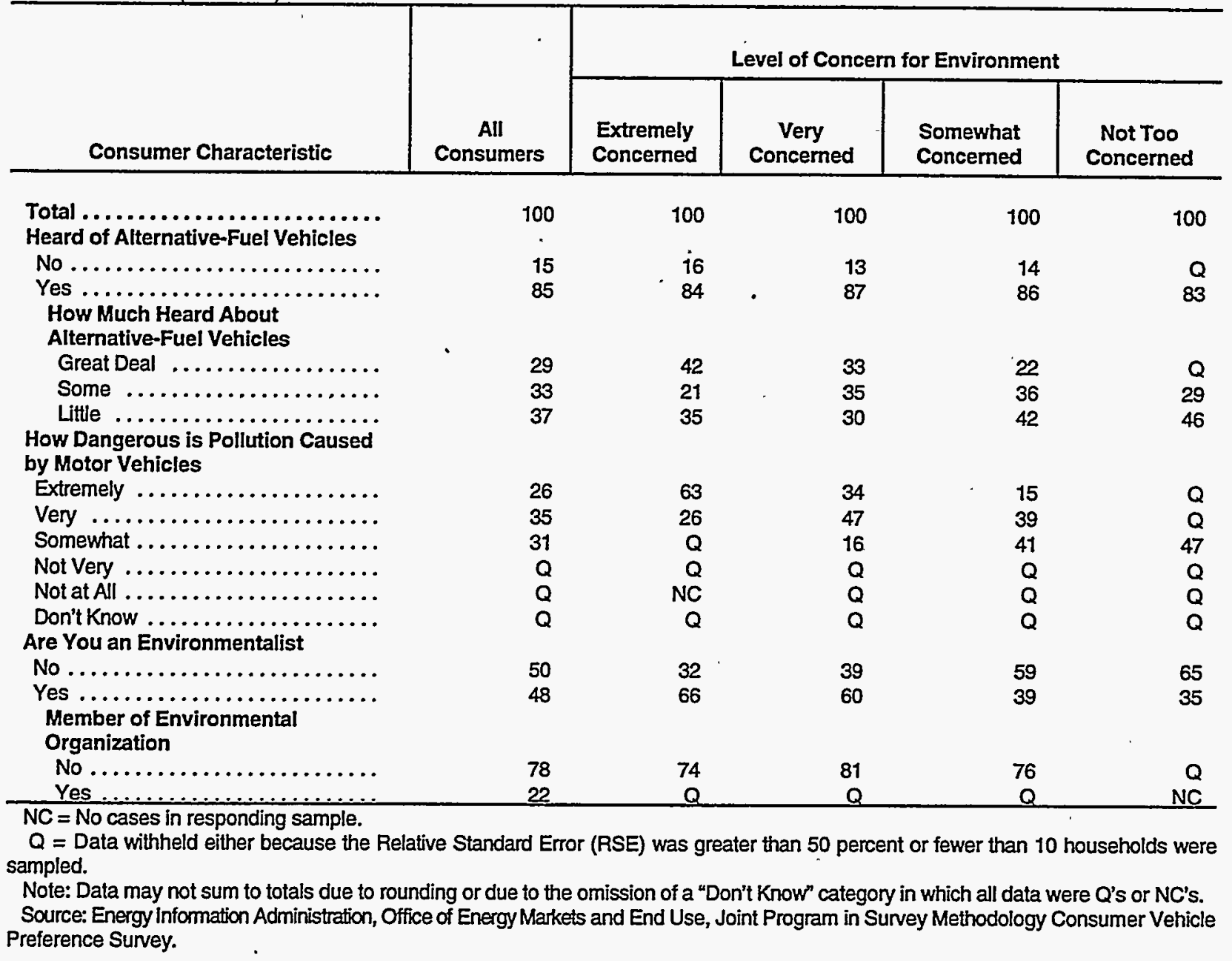


Table 4.4.2. Consumer Characteristics by Census Region, 1994

(Percent)

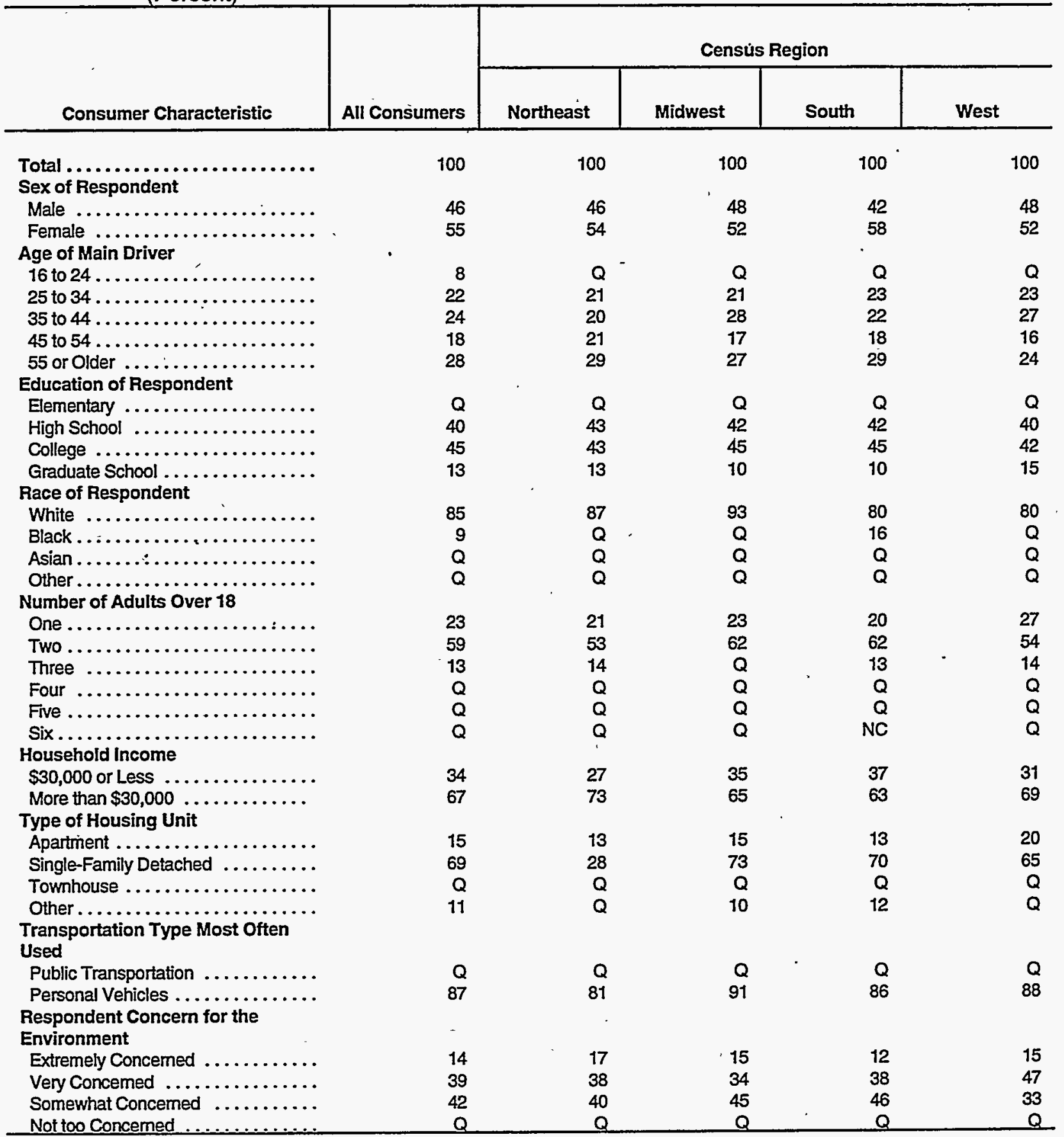

See footnotes at end of table. 
Table 4.4.2. Consumer Characteristics by Census Region, 1994 (Continued) (Percent)

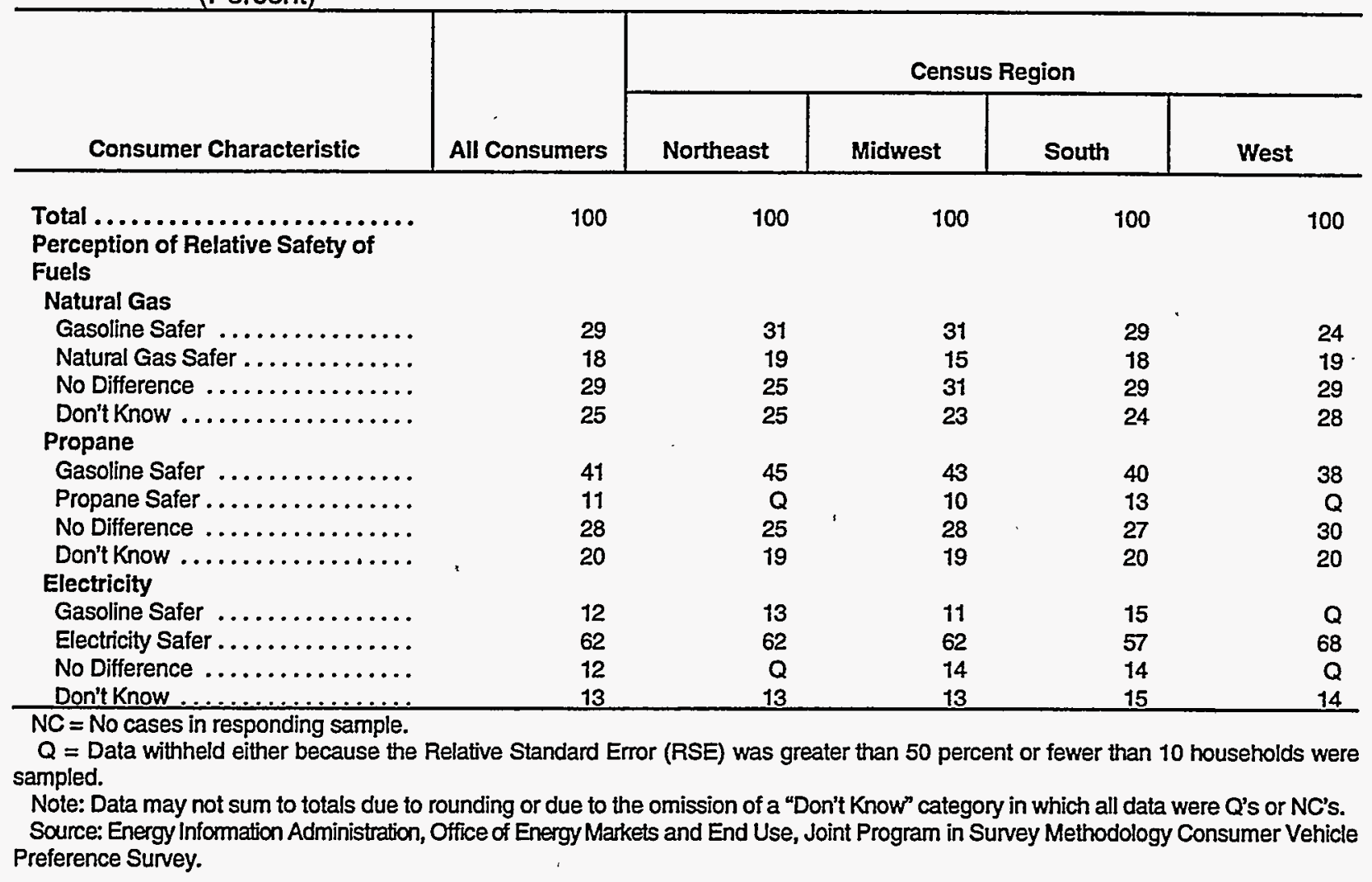


Table 4.4.3. Vehicle Choice When Modified Vehicle Has Half the Trunk/Cargo Space of a Regular Vehicle, 1994

(Percent)

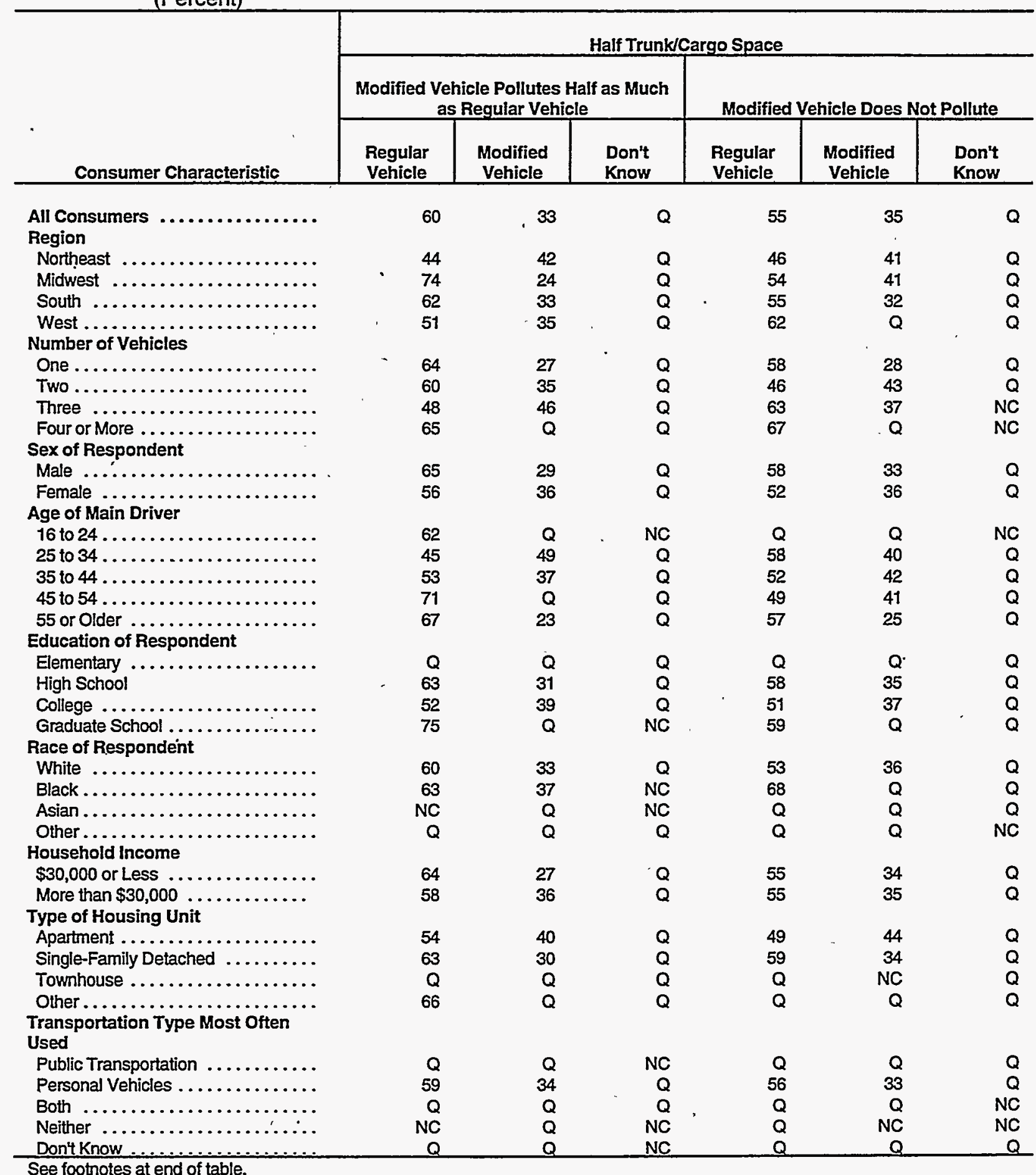


Table 4.4.3. Vehicle Choice When Modified Vehicle Has Half the Trunk/Cargo Space of a Regular Vehicle, 1994 (Continued) (Percent)

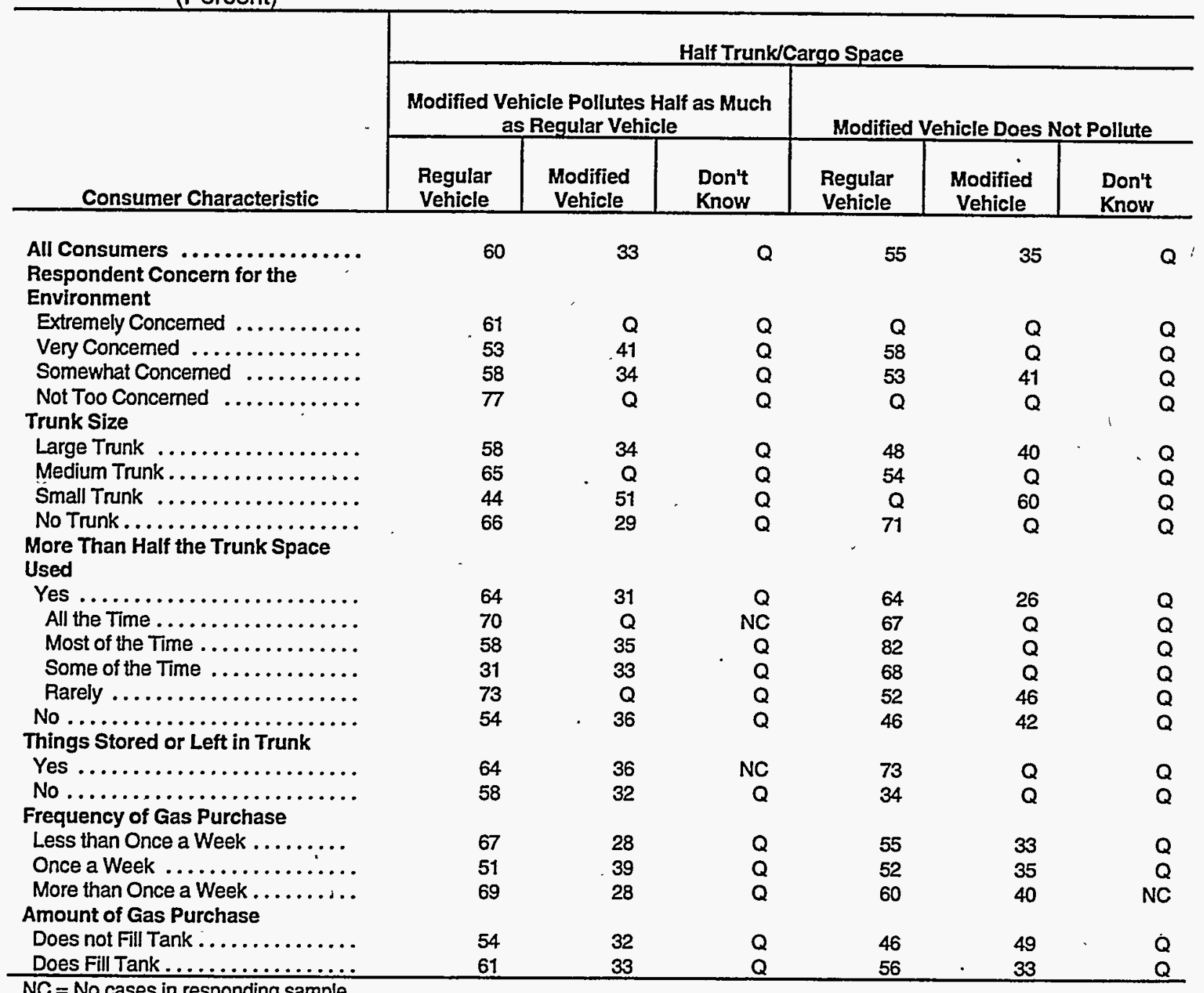

NC = No cases in responding sample.

$\mathbf{Q}=$ Data withheld either because the Relative Standard Error (RSE) was greater than 50 percent or fewer than 10 households were sampled.

Note: Data may not sum to totals due to rounding or due to the omission of a "Don't Know" category in which all data were Q's or NC's. Source: Energy Information Administration, Office of Energy Markets and End Use, Joint Program in Survey Methodology Consumer Vehicle Preference Survey. 
Table 4.4.4. Vehicle Choice When Modified Vehicle Has Half the Trunk/Cargo Space of a Regular Vehicle and the Modified Vehicle Costs \$1,000 More, 1994 (Percent)

\begin{tabular}{|c|c|c|c|c|c|c|}
\hline \multirow{3}{*}{ Consumer Characteristic } & \multicolumn{6}{|c|}{ Half Trunk/Cargo Space and Costs $\$ 1,000$ More } \\
\hline & \multicolumn{3}{|c|}{$\begin{array}{c}\text { Modified Vehicle Pollutes Half as Much } \\
\text { as Regular Vehicle }\end{array}$} & \multicolumn{3}{|c|}{ Modified Vehicle Does Not Pollute } \\
\hline & $\begin{array}{l}\text { Regular } \\
\text { Vehicle } \\
\end{array}$ & $\begin{array}{l}\text { Modified } \\
\text { Vehicle }\end{array}$ & $\begin{array}{l}\text { Don't } \\
\text { Know }\end{array}$ & $\begin{array}{l}\text { Regular } \\
\text { Vehicle }\end{array}$ & $\begin{array}{l}\text { Modified } \\
\text { Vehicle }\end{array}$ & $\begin{array}{l}\text { Don't } \\
\text { Know }\end{array}$ \\
\hline $\begin{array}{l}\text { All Consumers } \ldots \ldots \ldots \ldots \ldots \ldots \\
\text { Region }\end{array}$ & 68 & 26 & $\mathbf{Q}$ & 69 & 27 & Q \\
\hline Northeast $\ldots \ldots \ldots \ldots \ldots \ldots \ldots$. & 83 & $\mathbf{Q}$ & $Q$ & 64 & $\mathbf{Q}$ & NC \\
\hline Midwiest $\ldots \ldots \ldots \ldots \ldots \ldots \ldots$ & 63 & $\mathbf{Q}$ & $\mathbf{Q}$ & 67 & $\mathbf{Q}$ & NC \\
\hline South $\ldots \ldots \ldots \ldots \ldots \ldots \ldots$ & 65 & $\mathbf{Q}$ & $\mathbf{Q}$ & 69 & $\mathbf{Q}$ & $\mathbf{Q}$ \\
\hline West $\ldots \ldots \ldots \ldots \ldots \ldots \ldots \ldots$. & $\mathbf{Q}$ & $\mathbf{Q}$ & NC & $\mathbf{Q}$ & $\mathbf{Q}$ & NC \\
\hline \multicolumn{7}{|l|}{ Number of Vehicles } \\
\hline One...$\ldots \ldots \ldots \ldots \ldots \ldots$ & 73 & $\mathbf{Q}$ & $\mathbf{Q}$ & 79 & $Q$ & Q \\
\hline Two $\ldots \ldots \ldots \ldots \ldots \ldots \ldots \ldots$ & 65 & $\vec{Q}$ & $\vec{Q}$ & 65 & $\vec{Q}$ & Q \\
\hline Three $\ldots \ldots \ldots \ldots \ldots \ldots \ldots \ldots$ & 73 & $\vec{Q}$ & NC & 80 & $\mathbf{Q}$ & NC \\
\hline Four or More $\ldots \ldots \ldots \ldots \ldots \ldots$ & $\mathbf{Q}$ & $\overrightarrow{\mathbf{Q}}$ & NC & $\mathbf{Q}$ & $\mathbf{Q}$ & Q \\
\hline \multicolumn{7}{|l|}{ Sex of Respondent } \\
\hline Male $\ldots \ldots \ldots \ldots \ldots \ldots \ldots \ldots$ & 60 & 37 & $\mathbf{Q}$ & 55 & 38 & Q \\
\hline Female $\ldots \ldots \ldots \ldots \ldots \ldots \ldots \ldots$ & 74 & $\mathbf{Q}$ & $\overrightarrow{\mathbf{Q}}$ & 78 & $\mathbf{Q}$ & Q \\
\hline \multicolumn{7}{|l|}{ Age of Main Driver } \\
\hline 16 to $24 \ldots \ldots \ldots \ldots \ldots \ldots \ldots$ & $\mathbf{Q}$ & $\mathbf{Q}$ & $\mathbf{Q}$ & $\mathbf{Q}$ & $\mathbf{Q}$ & NC \\
\hline 25 to $34 \ldots \ldots \ldots \ldots \ldots \ldots \ldots$ & 85 & $\widehat{Q}$ & $\vec{Q}$ & 58 & $\overline{\mathbf{Q}}$ & NC \\
\hline 35 to $44 \ldots \ldots \ldots \ldots \ldots \ldots \ldots$ & 57 & $\overrightarrow{\mathbf{Q}}$ & $\vec{Q}$ & 72 & $\vec{Q}$ & Q \\
\hline 45 to $54 \ldots \ldots \ldots \ldots \ldots \ldots \ldots$ & $Q$ & $\vec{Q}$ & $\bar{Q}$ & 81 & $\mathbf{Q}$ & NC \\
\hline 55 or Older $\ldots \ldots \ldots \ldots \ldots \ldots \ldots$ & 61 & $\hat{Q}$ & $\vec{Q}$ & 62 & $\vec{Q}$ & $Q$ \\
\hline \multicolumn{7}{|l|}{ Education of Respondent } \\
\hline Elementary.$\ldots \ldots \ldots \ldots \ldots \ldots$ & $Q$ & $Q$ & NC & NC & $\mathbf{Q}$ & NC \\
\hline High School & 67 & $Q$ & $\mathbf{Q}$ & 77 & $\vec{Q}$ & Q \\
\hline College $\ldots \ldots \ldots \ldots \ldots \ldots \ldots$ & 69 & $\bar{Q}$ & $\mathbf{Q}$ & 65 & $\bar{Q}$ & $\mathbf{Q}$ \\
\hline Graduate School $\ldots \ldots \ldots \ldots \ldots \ldots$ & $Q$ & $\mathbf{Q}$ & NC & $\mathbf{Q}$ & $\mathbf{Q}$ & $\vec{Q}$ \\
\hline \multicolumn{7}{|l|}{ Race of Respondent } \\
\hline White $\ldots \ldots \ldots \ldots \ldots \ldots \ldots$ & 71 & 23 & $\mathbf{Q}$ & 65 & 30 & Q \\
\hline Black $\ldots \ldots \ldots \ldots \ldots \ldots \ldots$ & $Q$ & $\mathbf{Q}$ & $\overline{\mathbf{Q}}$ & $\mathbf{Q}$ & NC & NC \\
\hline Asian $\ldots \ldots \ldots \ldots \ldots \ldots \ldots \ldots \ldots$ & $Q$ & NC & $\mathrm{NC}$ & NC & $Q$ & NC \\
\hline 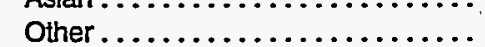 & $\mathbf{Q}$ & $Q$ & NC & $\mathbf{Q}$ & NC & NC \\
\hline \multicolumn{7}{|l|}{ Household Income } \\
\hline$\$ 30,000$ or Less . . . . . . . . . . . & 69 & $Q$ & $\mathbf{Q}$ & 89 & $Q$ & NC \\
\hline More than $\$ 30,000 \ldots \ldots \ldots \ldots$ & 67 & 27 & $\mathbf{Q}$ & 55 & 37 & Q \\
\hline \multicolumn{7}{|l|}{ Type of Housing Unit } \\
\hline 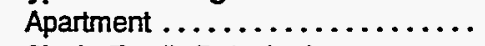 & 83 & $\mathbf{Q}$ & $\mathbf{Q}$ & 95 & NC & Q \\
\hline Single-Family Detached .......... & 60 & 34 & $\mathbf{Q}$ & 58 & 32 & $Q$ \\
\hline Townhouse $\ldots \ldots \ldots \ldots \ldots \ldots$ & $\mathbf{Q}$ & NC & NC & NC & NC & NC \\
\hline Other $\ldots \ldots \ldots \ldots \ldots \ldots \ldots \ldots$ & $\bar{Q}$ & $Q$ & $\mathbf{Q}$ & $Q$ & NC & NC \\
\hline \multicolumn{7}{|l|}{ Transportation Type Most Often } \\
\hline \multicolumn{7}{|l|}{ Used } \\
\hline Public Transportation . . . . . . . . . . & $\mathbf{Q}$ & NC & NC & $Q$ & $\mathbf{Q}$ & NC \\
\hline Personal Vehicles .............. & 68 & 25 & $\mathbf{Q}$ & 75 & $\mathbf{Q}$ & Q \\
\hline Both $\ldots \ldots \ldots \ldots \ldots \ldots \ldots \ldots$ & $\mathbf{Q}$ & NC & NC & $\mathbf{Q}$ & $\mathbf{Q}$ & NC \\
\hline Neither $\ldots \ldots \ldots \ldots \ldots \ldots \ldots$. & $\mathbf{Q}$ & NC & NC & NC & NC & NC \\
\hline Don't know & Q & NC & NC & $Q$ & NC & NC \\
\hline
\end{tabular}

See footnotes at end of table. 
Table 4.4.4. Vehicle Choice When Modified Vehicle Has Half the Trunk/Cargo Space of a Regular Vehicle and the Modified Vehicle Costs $\$ 1,000$ More, 1994 (Continued) (Percent)

\begin{tabular}{|c|c|c|c|c|c|c|}
\hline \multirow[b]{3}{*}{ Consumer Characteristic } & \multicolumn{6}{|c|}{ Half Trunk/Cargo Space and Costs $\$ 1,000$ More } \\
\hline & \multicolumn{3}{|c|}{$\begin{array}{c}\text { Modified Vehicle Pollutes Half as Much } \\
\text { as Regular Vehicle }\end{array}$} & \multicolumn{3}{|c|}{ Modified Vehicle Does Not Pollute } \\
\hline & $\begin{array}{l}\text { Regular } \\
\text { Vehicle }\end{array}$ & $\begin{array}{l}\text { Modified } \\
\text { Vehicle }\end{array}$ & $\begin{array}{l}\text { Don't } \\
\text { Know }\end{array}$ & $\begin{array}{l}\text { Regular } \\
\text { Vehicle }\end{array}$ & $\begin{array}{l}\text { Modified } \\
\text { Vehicle }\end{array}$ & $\begin{array}{l}\text { Don't } \\
\text { Know }\end{array}$ \\
\hline $\begin{array}{l}\text { All Consumers } \ldots \ldots \ldots \ldots \ldots \ldots \\
\text { Respondent Concern for the } \\
\text { Environment }\end{array}$ & 68 & 26 & $\mathbf{Q}$ & 69 & 27 & $\mathbf{Q}$ \\
\hline Extremely Concerned ........... & $\mathbf{Q}$ & $\mathbf{Q}$ & NC & $\mathbf{Q}$ & NC & NC \\
\hline Very Concemed.$\ldots \ldots \ldots \ldots \ldots$ & 55 & $\mathbf{Q}$ & $\mathbf{Q}$ & $\mathbf{Q}$ & Q & $\mathbf{Q}$ \\
\hline Somewhat Concemed...$\ldots \ldots \ldots$ & 64 & $\mathbf{Q}$ & $\vec{Q}$ & 63 & $\vec{Q}$ & $\tilde{Q}$ \\
\hline Not Too Concerned . ........... & $\mathbf{Q}$ & $\mathbf{Q}$ & $\mathbf{Q}$ & $\mathbf{Q}$ & $\overline{\mathbf{Q}}$ & NC \\
\hline \multicolumn{7}{|l|}{ Trunk Size } \\
\hline Large Trunk ............... & 65 & 33 & $\mathbf{Q}$ & 60 & 35 & Q \\
\hline Medium Trunk. ............. & $\mathbf{Q}$ & NC & $\mathbf{Q}$ & $\mathbf{Q}$ & $\mathbf{Q}$ & $\vec{Q}$ \\
\hline Small Trunk ................ & 62 & $\mathbf{Q}$ & $\mathbf{Q}$ & 63 & $\mathbf{Q}$ & $\vec{Q}$ \\
\hline No Trunk .................. & 78 & $\mathbf{Q}$ & $\mathbf{Q}$ & 87 & $\mathbf{Q}$ & NC \\
\hline \multicolumn{7}{|l|}{$\begin{array}{l}\text { More Than Half the Trunk Space } \\
\text { Used }\end{array}$} \\
\hline Yes $\ldots \ldots \ldots \ldots \ldots \ldots \ldots \ldots$. & 65 & $\mathbf{Q}$ & $\mathbf{Q}$ & 57 & $\mathbf{Q}$ & $\mathbf{Q}$ \\
\hline All the Time...$\ldots \ldots \ldots \ldots \ldots$ & $\mathbf{Q}$ & $\mathbf{Q}$ & NC & $\mathbf{Q}$ & NC & NC \\
\hline Most of the Time ............ & $\mathbf{Q}$ & $\mathbf{Q}$ & $\mathbf{Q}$ & NC & $\mathbf{Q}$ & $\mathbf{Q}$ \\
\hline Some of the Time ........... & 65 & $\mathbf{Q}$ & $\mathbf{Q}$ & $Q$ & $\mathbf{Q}$ & $\mathbf{Q}$ \\
\hline Rarely .................. & $\mathbf{Q}$ & $\mathbf{Q}$ & NC & $\mathbf{Q}$ & $\mathbf{Q}$ & NC \\
\hline \multicolumn{7}{|l|}{ Things Stored or Left in Trunk } \\
\hline Yes...$\ldots \ldots \ldots \ldots \ldots \ldots \ldots$ & 80 & $\mathbf{Q}$ & NC & $Q$ & $\mathbf{Q}$ & NC \\
\hline No $\ldots \ldots \ldots \ldots \ldots \ldots \ldots \ldots \ldots$ & 55 & $\mathbf{Q}$ & $\mathbf{Q}$ & $Q$ & $\bar{Q}$ & $\mathbf{Q}$ \\
\hline \multicolumn{7}{|l|}{ Frequency of Gas Purchase } \\
\hline Less than Once a Week ......... & 77 & $\mathbf{Q}$ & $\mathbf{Q}$ & 59 & 37 & $\mathbf{Q}$ \\
\hline Once a Week ............... & 66 & $\mathbf{Q}$ & $\mathbf{Q}$ & 82 & $\mathbf{Q}$ & $\mathbf{Q}$ \\
\hline More than Once a Week ....... & $\mathbf{Q}$ & $\mathbf{Q}$ & $\mathbf{Q}$ & $\mathbf{Q}$ & $\mathbf{Q}$ & $\mathbf{Q}$ \\
\hline \multicolumn{7}{|l|}{ Amount of Gas Purchase } \\
\hline Does not Fill Tank . . . . . . . . . . . . & 71 & $\mathbf{Q}$ & $\mathbf{Q}$ & 84 & $\mathbf{Q}$ & $\mathbf{Q}$ \\
\hline Does Fill Tank . . . . . . . . . . . & 67 & 28 & $\mathbf{Q}$ & 65 & 31 & $\bar{Q}$ \\
\hline
\end{tabular}

NC $=$ No cases in responding sample.

$Q=$ Data withheld either because the Relative Standard Error (RSE) was greater than 50 percent or fewer than 10 households were sampled.

Note: Data may not sum to totals due to rounding or due to the omission of a "Don't Know" category in which all data were Q's or NC's . Source: Energy Information Administration, Office of Energy Markets and End Use, Joint Program in Survey Methodology Consumer Vehicle Preference Survey. 
Table 4.4.5. Vehicle Choice When Modified Vehicle Has Half the Trunk/Cargo Space of a Regular Vehicle and the Modified Vehicle Costs $\$ 1,000$ Less, 1994 (Percent)

\begin{tabular}{|c|c|c|c|c|c|c|}
\hline \multirow[b]{3}{*}{ Consumer Characteristic } & \multicolumn{6}{|c|}{ Half Trunk/Cargo Space and Costs $\$ 1,000$ Less } \\
\hline & \multicolumn{3}{|c|}{$\begin{array}{l}\text { Modified Vehicle Pollutes Half as Much } \\
\text { as Regular Vehicle }\end{array}$} & \multicolumn{3}{|c|}{ Modified Vehicle Does Not Pollute } \\
\hline & $\begin{array}{l}\text { Regular } \\
\text { Vehicle }\end{array}$ & $\begin{array}{l}\text { Modified } \\
\text { Vehicle }\end{array}$ & $\begin{array}{l}\text { Don't } \\
\text { Know }\end{array}$ & $\begin{array}{l}\text { Regular } \\
\text { Vehicle }\end{array}$ & $\begin{array}{l}\text { Modified } \\
\text { Vehicle }\end{array}$ & $\begin{array}{l}\text { Don't } \\
\text { Know }\end{array}$ \\
\hline $\begin{array}{l}\text { All Consumers } \ldots \ldots \ldots \ldots \ldots \ldots \text {. } \\
\text { Region }\end{array}$ & 88 & $\mathbf{Q}$ & $\mathbf{Q}$ & 79 & $\mathbf{Q}$ & $\mathbf{Q}$ \\
\hline Northeast $\ldots \ldots \ldots \ldots \ldots \ldots \ldots$ & 95 & $\mathbf{Q}$ & NC & 73 & $\mathbf{Q}$ & NC \\
\hline Midwest $\ldots \ldots \ldots \ldots \ldots \ldots \ldots$ & 86 & $\mathbf{Q}$ & $\mathbf{Q}$ & 80 & $\mathbf{Q}$ & $\mathbf{Q}$ \\
\hline South $\ldots \ldots \ldots \ldots \ldots \ldots \ldots \ldots$ & 92 & $\mathbf{Q}$ & $\mathbf{Q}$ & 83 & $\mathbf{Q}$ & $\mathbf{Q}$ \\
\hline West.$\ldots \ldots \ldots \ldots \ldots \ldots \ldots \ldots$ & 75 & $\mathbf{Q}$ & $\mathbf{Q}$ & 75 & $\mathbf{Q}$ & $\mathbf{Q}$ \\
\hline \multicolumn{7}{|l|}{ Number of Yehicles } \\
\hline One..$\ldots \ldots \ldots \ldots \ldots \ldots \ldots$ & 85 & $\mathbf{Q}$ & $\mathbf{Q}$ & 71 & $\mathbf{Q}$ & $\mathbf{Q}$ \\
\hline Two $\ldots \ldots \ldots \ldots \ldots \ldots \ldots$ & 90 & $\mathbf{Q}$ & $\mathbf{Q}$ & 92 & $\mathbf{Q}$ & $\mathbf{Q}$ \\
\hline Three $\ldots \ldots \ldots \ldots \ldots \ldots \ldots \ldots$ & 86 & $\mathbf{Q}$ & NC & 77 & $\mathbf{Q}$ & NC \\
\hline Four or More ............... & 90 & NC & $\mathbf{Q}$ & 85 & $\mathbf{Q}$ & $\mathbf{Q}$ \\
\hline \multicolumn{7}{|l|}{ Sex of Respondent } \\
\hline Male...$\ldots \ldots \ldots$ & 90 & $\mathbf{Q}$ & $\mathbf{Q}$ & 87 & $\mathbf{Q}$ & $\mathbf{Q}$ \\
\hline Female $\ldots \ldots \ldots \ldots \ldots \ldots \ldots$ & 85 & $\mathbf{Q}$ & $\mathbf{Q}$ & 73 & $\mathbf{Q}$ & $\mathbf{Q}$ \\
\hline \multicolumn{7}{|l|}{ Age of Main Driver } \\
\hline 16 to $24 \ldots \ldots \ldots \ldots \ldots \ldots \ldots$ & $Q$ & $\mathbf{Q}$ & $\mathbf{Q}$ & $Q$ & $\mathbf{Q}$ & $\mathbf{Q}$ \\
\hline 25 to $34 \ldots \ldots \ldots \ldots \ldots \ldots$ & 92 & $\mathbf{Q}$ & $\mathbf{Q}$ & 82 & $Q$ & NC \\
\hline 35 to $44 \ldots \ldots \ldots \ldots \ldots \ldots \ldots$ & 84 & $\mathbf{Q}$ & NC & 97 & NC & $\mathbf{Q}$ \\
\hline 45 to $54 \ldots \ldots \ldots \ldots \ldots \ldots \ldots$ & 90 & $\overrightarrow{\mathbf{Q}}$ & $\mathbf{Q}$ & 76 & $\mathbf{Q}$ & NC \\
\hline 55 or Older $\ldots \ldots \ldots \ldots \ldots \ldots \ldots$ & 93 & $\mathbf{Q}$ & $\mathbf{Q}$ & 73 & $Q$ & $\mathbf{Q}$ \\
\hline \multicolumn{7}{|l|}{ Education of Respondent } \\
\hline Elementary ............. & $\mathbf{Q}$ & NC & NC & $\mathbf{Q}$ & $\mathbf{Q}$ & NC \\
\hline High School & 84 & $\mathbf{Q}$ & $\mathbf{Q}$ & 78 & $\mathbf{Q}$ & $\mathbf{Q}$ \\
\hline College $\ldots \ldots \ldots \ldots \ldots$ & 93 & $\mathbf{Q}$ & $\mathbf{Q}$ & 83 & $\mathbf{Q}$ & $\mathbf{Q}$ \\
\hline Graduate School .............. & 89 & $\overline{\mathbf{Q}}$ & $\mathbf{Q}$ & $-\mathbf{Q}$ & $\mathbf{Q}$ & $\mathbf{Q}$ \\
\hline \multicolumn{7}{|l|}{ Race of Respondent } \\
\hline White $\ldots \ldots \ldots \ldots \ldots \ldots \ldots$ & 86 & $\mathbf{Q}$ & $\mathbf{Q}$ & 82 & $\mathbf{Q}$ & $\mathbf{Q}$ \\
\hline Black $\ldots \ldots \ldots \ldots \ldots \ldots \ldots$ & 94 & $\mathbf{Q}$ & NC & 77 & $\mathbf{Q}$ & $\mathbf{Q}$ \\
\hline Asian $\ldots \ldots \ldots \ldots \ldots \ldots \ldots \ldots$ & NC & NC & NC & $\mathbf{Q}$ & $Q$ & $\mathbf{Q}$ \\
\hline Other $\ldots \ldots \ldots \ldots \ldots \ldots \ldots \ldots$ & $\mathbf{Q}$ & NC & NC & $\mathbf{Q}$ & NC & NC \\
\hline \multicolumn{7}{|l|}{ Household Income } \\
\hline$\$ 30,000$ or Less $\ldots \ldots \ldots \ldots \ldots$ & 88 & $\mathbf{Q}$ & $\mathbf{Q}$ & 76 & $\mathbf{Q}$ & $\mathbf{Q}$ \\
\hline More than $\$ 30,000 \ldots \ldots \ldots \ldots$ & 87 & $\widehat{Q}$ & $\vec{Q}$ & 82 & $\vec{Q}$ & $\vec{Q}$ \\
\hline \multicolumn{7}{|l|}{ Type of Housing Unit } \\
\hline Apartment $\ldots \ldots \ldots \ldots \ldots \ldots \ldots$ & 67 . & $\mathbf{Q}$ & $\mathbf{Q}$ & 72 & $\mathbf{Q}$ & NC \\
\hline Single-Family Detached ......... & 89 & $\mathbf{Q}$ & $\mathbf{Q}$ & 79 & $\mathbf{Q}$ & $\mathbf{Q}$ \\
\hline Townhouse $\ldots \ldots \ldots \ldots \ldots \ldots$ & $\mathbf{Q}$ & NC & NC & $\mathbf{Q}$ & NC & $\mathbf{Q}$ \\
\hline Other $\ldots \ldots \ldots \ldots \ldots \ldots \ldots \ldots$ & 100. & NC & NC & $\mathbf{Q}$ & NC & NC \\
\hline \multicolumn{7}{|l|}{ Transportation Type Most Often } \\
\hline Used & & & & & & \\
\hline Public Transportation...$\ldots \ldots$. . & $Q$ & NC & NC. & $Q$ & NC & NC \\
\hline Personal Vehicles .............. & 86 & $\mathbf{Q}$ & $Q$ & 76 & $\mathbf{Q}$ & $\mathbf{Q}$ \\
\hline Both $\ldots \ldots \ldots \ldots \ldots \ldots \ldots \ldots$ & $Q$ & $\mathbf{Q}$ & NC & $\mathbf{Q}$ & NC & NC \\
\hline Neither $\ldots \ldots \ldots \ldots \ldots \ldots \ldots \ldots$ & $\widehat{N C}$ & NC & NC & $\mathbf{Q}$ & NC & NC \\
\hline Don't Know... & $\mathrm{Q}$ & NC & NC & $\vec{Q}$ & NC & $Q$ \\
\hline
\end{tabular}

See footrotes at end of table. 
Table 4.4.5. Vehicle Choice When Modified Vehicle Has Half the Trunk/Cargo Space of a Regular Vehicle and the Modified Vehicle Costs $\$ 1,000$ Less, 1994 (Continued) (Percent)

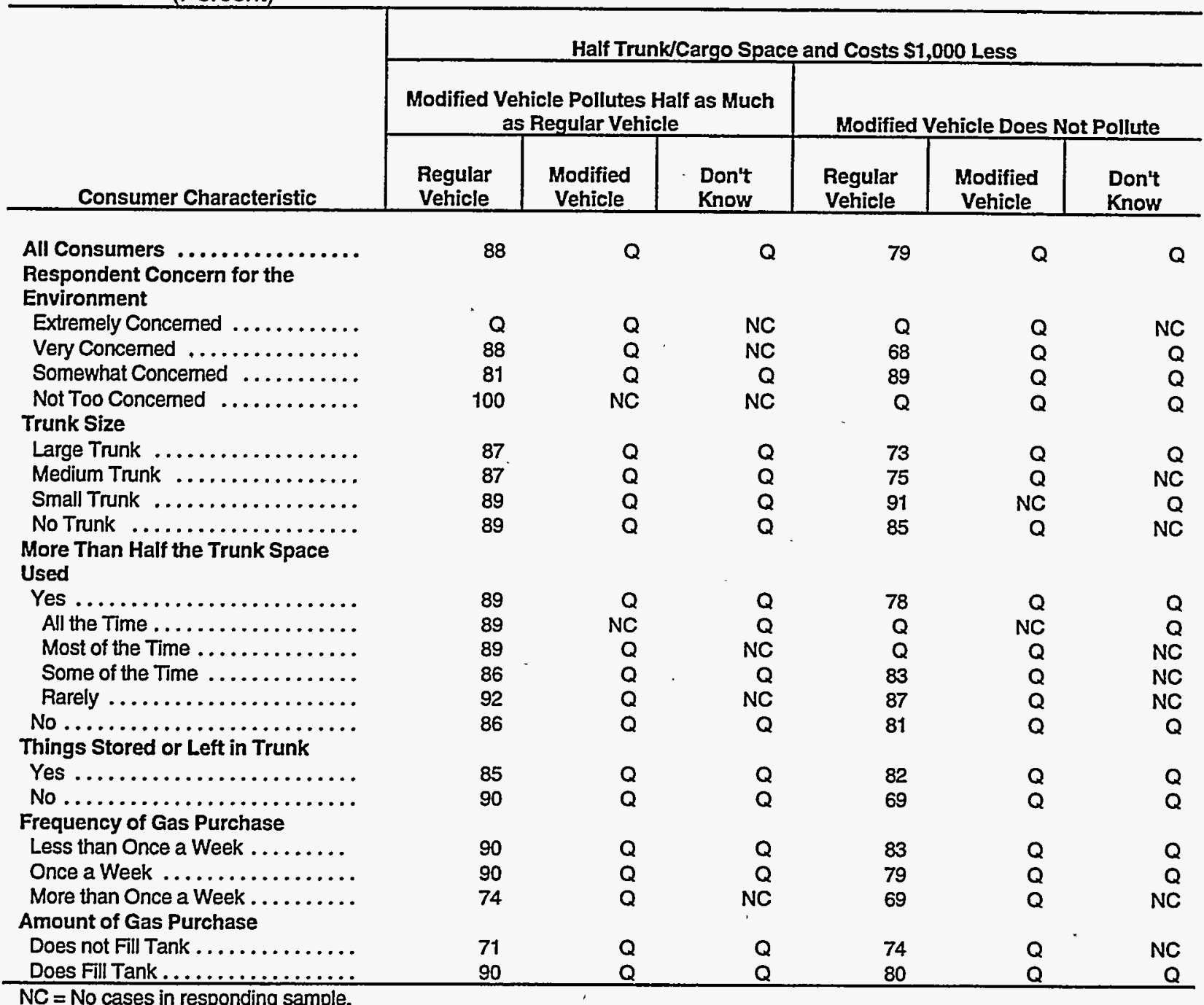

$\mathrm{NC}=$ No cases in responding sample.

$Q=$ Data withheld either because the Relative Standard Error (RSE) was greater than 50 percent or fewer than 10 households were sampled.

Note: Data may not sum to totals due to rounding or due to the omission of a "Don't Know" category in which all data were Q's or NC's.

Source: Energy Information Administration, Office of Energy Markets and End Use, Joint Program in Survey Methodology Consumer Vehicle Preference Survey. 
Table 4.4.6. Vehicle Choice When Consumer Must Drive 15 Minutes Out of the Way to Refuel the Modified Vehicle, 1994 (Percent)

\begin{tabular}{|c|c|c|c|c|c|c|}
\hline \multirow[b]{3}{*}{ Consumer Characteristic } & \multicolumn{6}{|c|}{ Consumer Must Drive 15 Minutes Out of the Way to Buy Fuel } \\
\hline & \multicolumn{3}{|c|}{$\begin{array}{c}\text { Modified Vehicle Pollutes Half as Much } \\
\text { as Regular Vehicle }\end{array}$} & \multicolumn{3}{|c|}{ Modified Vehicle Does Not Pollute } \\
\hline & $\begin{array}{l}\text { Regular } \\
\text { Vehicle }\end{array}$ & $\begin{array}{l}\text { Modified } \\
\text { Vehicle }\end{array}$ & $\begin{array}{l}\text { Don't } \\
\text { Know }\end{array}$ & $\begin{array}{l}\text { Regular } \\
\text { Vehicle }\end{array}$ & $\begin{array}{l}\text { Modified } \\
\text { Vehicle }\end{array}$ & $\begin{array}{l}\text { Don't } \\
\text { Know }\end{array}$ \\
\hline $\begin{array}{l}\text { All Consumers } \ldots \ldots \ldots \ldots \ldots \ldots \ldots \\
\text { Reqion }\end{array}$ & 55 & 41 & $\mathbf{Q}$ & 44 & 51 & $\mathbf{Q}$ \\
\hline Northeast $\ldots \ldots \ldots \ldots \ldots \ldots \ldots$ & 56 & 39 & $\mathbf{Q}$ & 39 & 56 & $Q$ \\
\hline Midwest . . . . . . . . . . . . . & 56 & 40 & $\mathbf{Q}$ & 50 & 45 & $\mathbf{Q}$ \\
\hline South $\ldots \ldots \ldots \ldots \ldots \ldots \ldots \ldots$ & 52 & 43 & $\hat{Q}$ & 48 & 45 & $\hat{Q}$ \\
\hline West $\ldots \ldots \ldots \ldots \ldots \ldots \ldots \ldots$ & 57 & 41 & $\hat{Q}$ & 36 & 61 & $\mathbf{Q}$ \\
\hline \multicolumn{7}{|l|}{ Number of Vehicles } \\
\hline One $\ldots \ldots \ldots \ldots \ldots \ldots \ldots$ & 52 & 42 & $\mathbf{Q}$ & 42 & 51 & $Q$ \\
\hline Two $\ldots \ldots \ldots \ldots \ldots \ldots \ldots \ldots \ldots$ & 60 & 37 & $\mathbf{Q}$ & 45 & 49 & $\mathbf{Q}$ \\
\hline Three $\ldots \ldots \ldots \ldots \ldots \ldots \ldots \ldots$ & 50 & 47 & $\hat{Q}$ & 44 & 53 & $\mathbf{Q}$ \\
\hline Four or More $\ldots \ldots \ldots \ldots \ldots \ldots$ & 45 & 51 & $\mathbf{Q}$ & 51 & 48 & $\vec{Q}$ \\
\hline \multicolumn{7}{|l|}{ Sex of Respondent } \\
\hline 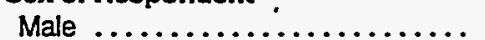 & 58 & 40 & $\mathbf{Q}$ & 43 & 54 & $Q$ \\
\hline Female $\ldots \ldots \ldots \ldots \ldots \ldots \ldots \ldots$ & 53 & 42 & $\mathbf{Q}$ & 45 & 48 & $Q$ \\
\hline \multicolumn{7}{|l|}{ Age of Main Driver } \\
\hline 16 to $24 \ldots \ldots \ldots \ldots \ldots \ldots \ldots$ & 48 & 48 & $\mathbf{Q}$ & 38 & 53 & $Q$ \\
\hline 25 to $34 \ldots \ldots \ldots \ldots \ldots \ldots \ldots$ & 53 & 44 & $\mathbf{Q}$ & 45 & 50 & $\widehat{Q}$ \\
\hline 35 to $44 \ldots \ldots \ldots \ldots \ldots \ldots \ldots \ldots$ & 54 & 44 & $\mathbf{Q}$ & 39 & 58 & $\widehat{Q}$ \\
\hline 45 to $54 \ldots \ldots \ldots \ldots \ldots \ldots \ldots \ldots \ldots$ & 55 & 43 & $\mathbf{Q}$ & 45 & 50 & $\mathbf{Q}$ \\
\hline \multirow{2}{*}{\multicolumn{7}{|c|}{ Education of Respondent }} \\
\hline & & & & & & \\
\hline Elementary ................... & 68 & $\mathbf{Q}$ & $\mathbf{Q}$ & $\mathbf{Q}$ & $\mathbf{Q}$ & $\mathbf{Q}$ \\
\hline High School $\ldots \ldots \ldots \ldots \ldots \ldots \ldots$ & 58 & 37 & $\mathbf{Q}$ & 48 & 47 & $\vec{Q}$ \\
\hline College $\ldots \ldots \ldots \ldots \ldots \ldots \ldots$ & 51 & 45 & $\widehat{Q}$ & 43 & 51 & $\mathbf{Q}$ \\
\hline Graduate School . . . . . . . . . . . . & 55 & 42 & $\mathbf{Q}$ & 33 & 64 & $\widehat{Q}$ \\
\hline \multicolumn{7}{|l|}{ Race of Respondent } \\
\hline White .............. & 56 & 40 & $\mathbf{Q}$ & 43 & 51 & $\mathbf{Q}$ \\
\hline Black,$\ldots \ldots \ldots \ldots \ldots \ldots \ldots$ & 50 & 48 & $\tilde{Q}$ & 47 & 47 & $\vec{Q}$ \\
\hline Asian.$\ldots \ldots \ldots \ldots \ldots \ldots \ldots \ldots \ldots$ & $\mathbf{Q}$ & $\mathbf{Q}$ & NC & $Q$ & $\mathbf{Q}$ & $\mathbf{Q}$ \\
\hline Other $\ldots \ldots \ldots \ldots \ldots \ldots \ldots \ldots$ & 48 & 49 & $Q$ & 46 & 48 & $\mathbf{Q}$ \\
\hline \multicolumn{7}{|l|}{ Household Income } \\
\hline$\$ 30,000$ or Less $\ldots \ldots \ldots \ldots \ldots$ & 53 & 42 & $\mathbf{Q}$ & 44 & 48 & $\mathbf{Q}$ \\
\hline More than $\$ 30,000 \ldots \ldots \ldots \ldots$ & 56 & 41 & $\mathbf{Q}$ & 44 . & 52 & $\vec{Q}$ \\
\hline \multicolumn{7}{|l|}{ Type of Housing Unit } \\
\hline Apartment $\ldots \ldots \ldots \ldots \ldots \ldots$ & 47 & 48 & $\mathbf{Q}$ & 35 & 56 & $\mathbf{Q}$ \\
\hline Single-Family Detached .......... & 58 & 38 & $\mathbf{Q}$ & 49 & 47 & $\mathbf{Q}$ \\
\hline Townhouse $\ldots \ldots \ldots \ldots \ldots \ldots \ldots$ & 53 & 44 & $\mathbf{Q}$ & 35 & 64 & $\vec{Q}$ \\
\hline Other $\ldots \ldots \ldots \ldots \ldots \ldots \ldots \ldots$ & 48 & 50 & $\widehat{Q}$ & 29 & 59 & $\vec{Q}$ \\
\hline \multicolumn{7}{|l|}{ Transportation Type Most Often } \\
\hline \multicolumn{7}{|l|}{ Used } \\
\hline Public Transportation ............ & $\mathbf{Q}$ & $\mathbf{Q}$ & $\mathbf{Q}$ & 39 & 57 & $\mathbf{Q}$ \\
\hline Personal Vehicles $\ldots \ldots \ldots \ldots \ldots \ldots$ & 58 & 39 & $\mathbf{Q}$ & 45 & 49 & $\vec{Q}$ \\
\hline Both $\ldots \ldots \ldots \ldots \ldots \ldots \ldots \ldots$ & 53 & 44 & $\vec{Q}$ & 32 & 61 & $\vec{Q}$ \\
\hline Neither $\ldots \ldots \ldots \ldots \ldots \ldots \ldots \ldots \ldots$ & $\mathbf{Q}$ & NC & NC & $Q$ & NC & NC \\
\hline Don't know .... & $Q$ & $Q$ & $Q$ & 0 & $Q$ & $Q$ \\
\hline
\end{tabular}

See footnotes at end of table. 
Table 4.4.6. Vehicle Choice When Consumer Must Drive 15 Minutes Out of the Way to Refuel the Modified Vehicle, 1994 (Continued) (Percent)

\begin{tabular}{|c|c|c|c|c|c|c|}
\hline \multirow[b]{3}{*}{ Consumer Characteristic } & \multicolumn{6}{|c|}{ Consumer Must Drive 15 Minutes Out of the Way to Buy Fuel } \\
\hline & \multicolumn{3}{|c|}{$\begin{array}{c}\text { Modified Vehicle Pollutes Half as Much } \\
\text { as Regular Vehicle }\end{array}$} & \multicolumn{3}{|c|}{ Modified Vehicle Does Not Pollute } \\
\hline & $\begin{array}{l}\text { Regular } \\
\text { Vehicle }\end{array}$ & $\begin{array}{c}\text { Modified } \\
\text { Vehicle }\end{array}$ & $\begin{array}{l}\text { Don't } \\
\text { Know } \\
\end{array}$ & $\begin{array}{l}\text { Regular } \\
\text { Vehicle } \\
\end{array}$ & $\begin{array}{l}\text { Modified } \\
\text { Vehicle }\end{array}$ & $\begin{array}{l}\text { Don't } \\
\text { Know }\end{array}$ \\
\hline $\begin{array}{l}\text { All Consumers } \ldots \ldots \ldots \ldots \ldots \ldots \\
\text { Respondent Concern for the } \\
\text { Environment }\end{array}$ & 55 & 41 & $\mathbf{Q}$ & 44 & 51 & $\mathbf{Q}$ \\
\hline Extremely Concemed ............ & 38 & 56 & $\mathbf{Q}$ & 28 & 68 & $\mathbf{Q}$ \\
\hline Very Concemed...$\ldots \ldots \ldots \ldots$ & 50 & 47 & $\mathbf{Q}$ & 36 & 59 & Q \\
\hline Somewhat Concemed ........... & 56 & 42 & $\mathbf{Q}$ & 48 & 47 & Q \\
\hline Not Too Concerned...$\ldots \ldots \ldots$ & 64 & $\mathbf{Q}$ & $\mathbf{Q}$ & 52 & 48 & NC \\
\hline Frequency of Gas Purchase & & & & & & \\
\hline Less than Once a Week .......... & 58 & 38 & Q & 45 & 51 & $\mathbf{Q}$ \\
\hline Once a Week . . . . . . . . . . . . . . & 53 & 43 & $\mathbf{Q}$ & 42 & 51 & $\mathbf{Q}$ \\
\hline More than Once a Week .......... & 52 & 46 & $\mathbf{Q}$ & 45 & 46 & Q \\
\hline Amount of Gas Purchase & & & & & & \\
\hline $\begin{array}{l}\text { Does not Fill Tank } \ldots \ldots \ldots \ldots \ldots \\
\text { Does Fill Tank } \ldots \ldots \ldots \ldots \ldots\end{array}$ & $\begin{array}{l}59 \\
54\end{array}$ & $\begin{array}{l}38 \\
42\end{array}$ & $\begin{array}{l}Q \\
Q\end{array}$ & $\begin{array}{l}41 \\
44\end{array}$ & $\begin{array}{l}52 \\
50\end{array}$ & $\begin{array}{l}Q \\
Q\end{array}$ \\
\hline
\end{tabular}

NC $=$ No cases in responding sample.

$Q=$ Data withheld either because the Relative Standard Error (RSE) was greater than $\mathbf{5 0}$ percent or fewer than 10 households were sampled.

Note: Data may not sum to totals due to rounding or due to the omission of a "Don't Know' category in which all data were Q's or NC's.

Source: Energy Information Administration, Office of Energy Markets and End Use, Joint Program in Survey Methodology Consumer Vehicle Preference Survey. 
Table 4.4.7. Vehicle Choice When Consumer Must Drive 15 Minutes Out of the Way to Refuel the Modified Vehicle and the Modified Vehicle Costs \$1,000 More, 1994 (Percent)

\begin{tabular}{|c|c|c|c|c|c|c|}
\hline \multirow[b]{3}{*}{ Consumer Characteristic } & \multicolumn{6}{|c|}{ Drive 15 Minutes Out of the Way for Fuel and Modified Vehicle Costs $\$ 1,000$ More } \\
\hline & \multicolumn{3}{|c|}{$\begin{array}{l}\text { Modified Vehicle Pollutes Half as Much } \\
\text { as Regular Vehicle }\end{array}$} & \multicolumn{3}{|c|}{ Modified Vehicle Does Not Pollute } \\
\hline & $\begin{array}{l}\text { Regular } \\
\text { Vehicle }\end{array}$ & $\begin{array}{l}\text { Modified } \\
\text { Vehicle }\end{array}$ & $\begin{array}{l}\text { Don't } \\
\text { Know }\end{array}$ & $\begin{array}{l}\text { Regular } \\
\text { Vehicle }\end{array}$ & $\begin{array}{l}\text { Modified } \\
\text { Vehicle }\end{array}$ & $\begin{array}{l}\text { Don't } \\
\text { Know }\end{array}$ \\
\hline $\begin{array}{l}\text { All Consumers } \ldots \ldots \ldots \ldots \ldots \ldots \\
\text { Region }\end{array}$ & \multicolumn{5}{|c|}{ Region } & Q \\
\hline Northeast $\ldots \ldots \ldots \ldots \ldots \ldots \ldots$ & .48 & 45 & $\mathbf{Q}$ & 28 & 65 & $\mathbf{Q}$ \\
\hline Midwest $\ldots \ldots \ldots \ldots \ldots \ldots \ldots \ldots$ & 36 & 52 & $\mathbf{Q}$ & 35 & 61 & $\mathbf{Q}$ \\
\hline South $\ldots \ldots \ldots \ldots \ldots \ldots \ldots \ldots$ & 42 & 55 & $\mathbf{Q}$ & 34 & 60 & Q \\
\hline West $\ldots \ldots \ldots \ldots \ldots \ldots \ldots \ldots$ & 36 & 62 & $\mathbf{Q}$ & 37 & 59 & Q \\
\hline \multicolumn{7}{|l|}{ Number of Vehicles } \\
\hline One............ & 39 & 53 & $\mathbf{Q}$ & 35 & 59 & $\mathbf{Q}$ \\
\hline Two ..................... & 43 & 51 & $\mathbf{Q}$ & 32 & 62 & $\mathbf{Q}$ \\
\hline Three $\ldots \ldots \ldots \ldots \ldots \ldots \ldots \ldots$ & 42 & 55 & $\mathbf{Q}$ & 31 & 67 & $\mathbf{Q}$ \\
\hline Four or More ................ & $\mathbf{Q}$ & 67 & $\mathbf{Q}$ & 35 & 53 & Q \\
\hline \multicolumn{7}{|l|}{ Sex of Respondent } \\
\hline Male...$\ldots \ldots \ldots$ & 41 & 54 & $\mathbf{Q}$ & 37 & 56 & Q \\
\hline \multirow{2}{*}{\multicolumn{7}{|c|}{ Age of Main Driver }} \\
\hline & & & & & & \\
\hline 16 to $24 \ldots \ldots \ldots$ & 32 & 68 & NC & $\mathbf{Q}$ & 60 & $\mathbf{Q}$ \\
\hline 25 to $34 \ldots . . \ldots$. & 40 & 57 & $\mathbf{Q}$ & 38 & 61 & $\mathbf{Q}$ \\
\hline 35 to $44 \ldots \ldots \ldots \ldots \ldots \ldots \ldots$ & 47 & 49 & $\mathbf{Q}$ & 27 & 68 & $\mathbf{Q}$ \\
\hline 45 to $54 \ldots \ldots \ldots \ldots \ldots \ldots \ldots$ & 48 & 48 & $\mathbf{Q}$ & 33 & 64 & $\mathbf{Q}$ \\
\hline 55 or Older $\ldots \ldots \ldots \ldots \ldots \ldots \ldots$ & 29 & 54 & $\mathbf{Q}$ & 36 & 51 & $\mathbf{Q}$ \\
\hline \multicolumn{7}{|l|}{ Education of Respondent } \\
\hline Elementary $\ldots \ldots \ldots \ldots \ldots \ldots$ & $\mathbf{Q}$ & $\mathbf{Q}$ & NC & $\mathbf{Q}$ & $\mathbf{Q}$ & $\mathbf{Q}$ \\
\hline High School $\ldots \ldots \ldots \ldots \ldots \ldots$ & 33 & 61 & $\mathbf{Q}$ & 31 & 63 & Q \\
\hline College $\ldots \ldots \ldots \ldots \ldots \ldots \ldots$ & 42 & 50 & $\mathbf{Q}$ & 33 & 63 & $\mathbf{Q}$ \\
\hline Graduate School ............. & 58 & 42 & NC & 35 & 57 & $\mathbf{Q}$ \\
\hline \multicolumn{7}{|l|}{ Race of Respondent } \\
\hline White $\ldots \ldots \ldots \ldots \ldots \ldots \ldots$ & 42 & 52 & $\mathbf{Q}$ & 33 & 60 & $\mathbf{Q}$ \\
\hline Black ................... & $\mathbf{Q}$ & 60 & $\mathbf{Q}$ & 35 & 65 & NC \\
\hline Asian .................... & $\mathbf{Q}$ & $\mathbf{Q}$ & NC & $\mathbf{Q}$ & $Q$ & Q \\
\hline Other $\ldots \ldots \ldots \ldots \ldots \ldots \ldots \ldots$ & $\mathbf{Q}$ & 67 & $Q$ & $\mathbf{Q}$ & 55 & NC \\
\hline \multicolumn{7}{|l|}{ Household Income } \\
\hline$\$ 30,000$ or Less $\ldots \ldots \ldots \ldots \ldots \ldots$ & 43 & 48 & $\mathbf{Q}$ & 34 & 61 & $\mathbf{Q}$ \\
\hline More than $\$ 30,000 \ldots \ldots \ldots \ldots$ & 38 & 57 & $\mathbf{Q}$ & 33 & 61 & Q \\
\hline \multicolumn{7}{|l|}{ Type of Housing Unit } \\
\hline Apartment $\ldots \ldots \ldots \ldots \ldots \ldots \ldots$ & 37 & 53 & $\mathbf{Q}$ & 41 & 56 & $Q$ \\
\hline Single-Family Detached .......... & 40 & 54 & $\mathbf{Q}$ & 34 & 60 & $\mathbf{Q}$ \\
\hline Townhouse $\ldots \ldots \ldots \ldots \ldots \ldots$ & $\mathbf{Q}$ & $\mathbf{Q}$ & NC & Q $\mathbf{Q}$ & 82 & Q \\
\hline Other $\ldots \ldots \ldots \ldots \ldots \ldots \ldots \ldots$ & 45 & 51 & $\mathbf{Q}$ & 33 & 63 & $\overline{\mathbf{Q}}$ \\
\hline \multirow{2}{*}{\multicolumn{7}{|c|}{$\begin{array}{l}\text { Transportation Type Most Often } \\
\text { Used }\end{array}$}} \\
\hline & & & & & & \\
\hline Public Transportation . . . . . . . . . . & $\mathbf{Q}$ & $\mathbf{Q}$ & $\mathbf{Q}$ & $\mathbf{Q}$ & 73 & $\mathbf{Q}$ \\
\hline Personal Vehicles . . . . . . . . . . & 42 & 53 & $\mathbf{Q}$ & 34 & 60 & $\mathbf{Q}$ \\
\hline Both,$\ldots \ldots \ldots \ldots \ldots \ldots \ldots$ & $Q$ & 56 & $\mathbf{Q}$ & 34 & 64 & $\mathbf{Q}$ \\
\hline Don't know. & $\mathrm{Q}$ & $\mathrm{Q}$ & NC & $\mathbf{Q}$ & $Q$ & Q \\
\hline
\end{tabular}

See footnotes at end of table. 
Table 4.4.7. Vehicle Choice When Consumer Must Drive 15 Minutes Out of the Way to Refuel the Modified Vehicle and the Modified Vehicle Costs \$1,000 More, 1994 (Continued) (Percent)

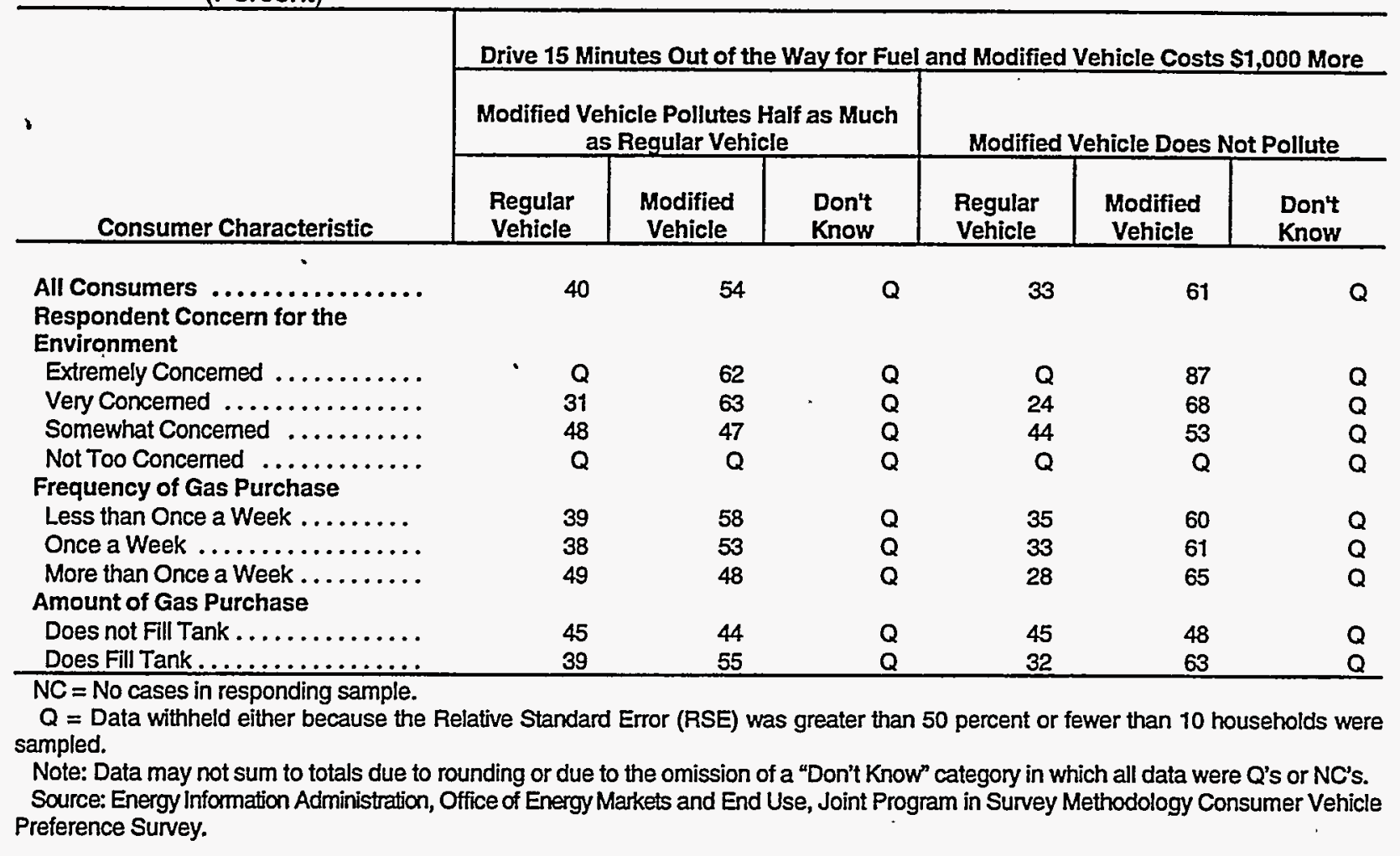


Table 4.4.8. Vehicle Choice When Consumer Must Drive 15 Minutes Out of the Way to Refuel the Modified Vehicle and the Modified Vehicle Costs $\$ 1,000$ Less, 1994 (Percent)

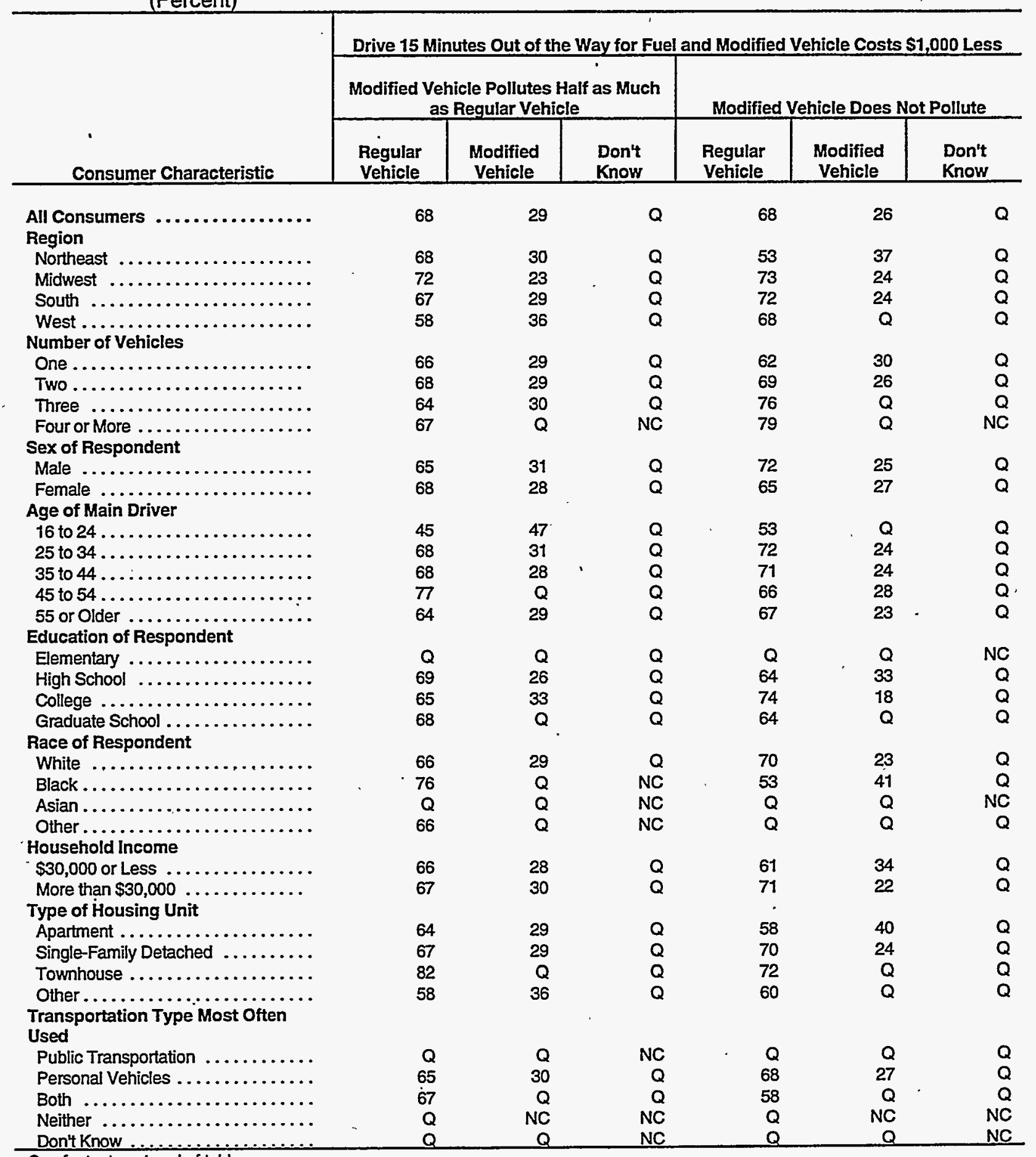

See footnotes at end of table. 
Table 4.4.8. Vehicle Choice When Consumer Must Drive 15 Minutes Out of the Way to Refuel the Modified Vehicle and the Modified Vehicle Costs $\$ 1,000$ Less, 1994 (Continued) (Percent)

\begin{tabular}{|c|c|c|c|c|c|c|}
\hline \multirow[b]{3}{*}{ Consumer Characteristic } & \multicolumn{6}{|c|}{ Drive 15 Minutes Out of the Way for Fuel and Modified Vehicle Costs \$1,000 Less } \\
\hline & \multicolumn{3}{|c|}{$\begin{array}{c}\text { Modified Vehicle Pollutes Half as Much } \\
\text { as Regular Vehicle }\end{array}$} & \multicolumn{3}{|c|}{ Modified Vehicle Does Not Pollute } \\
\hline & $\begin{array}{l}\text { Regular } \\
\text { Vehicle } \\
\end{array}$ & $\begin{array}{l}\text { Modified } \\
\text { Vehicle }\end{array}$ & $\begin{array}{l}\text { Don't } \\
\text { Know }\end{array}$ & $\begin{array}{l}\text { Regular } \\
\text { Vehicle } \\
\end{array}$ & $\begin{array}{l}\text { Modified } \\
\text { Vehicle }\end{array}$ & $\begin{array}{l}\text { Don't } \\
\text { Know }\end{array}$ \\
\hline $\begin{array}{l}\text { All Consumers } \ldots \ldots \ldots \ldots \ldots \ldots \\
\text { Respondent Concern for the } \\
\text { Environment }\end{array}$ & 68 & 29 . & Q & 68 & 26 & $\mathbf{Q}$ \\
\hline Extremely Concemed ........... & 69 & $\mathbf{Q}$ & Q & 72 & $\mathbf{Q}$ & $\mathbf{Q}$ \\
\hline Very Concemed .............. & 68 & 29 & $\vec{Q}$ & 62 & 34 & $\bar{Q}$ \\
\hline Somewhat Concemed...$\ldots \ldots$. & 65 & 30 & Q & 71 & 22 & Q \\
\hline $\begin{array}{l}\text { Not Too Concerned ............. } \\
\text { Frequency of Gas Purchase }\end{array}$ & \multicolumn{5}{|c|}{ Frequency of Gas Purchase } & NC \\
\hline Less than Once a Week.... & 64 & 30 & $\mathbf{Q}$ & 69 & 24 & Q \\
\hline Once a Week .................. & 66 & 31 & $\mathbf{Q}$ & 67 & 28 & $\vec{Q}$ \\
\hline More than Once a Week .......... & 77 & $\mathbf{Q}$ & Q & 69 & $\mathbf{Q}$ & $\mathbf{Q}$ \\
\hline \multicolumn{7}{|l|}{ Amount of Gas Purchase } \\
\hline Does not Fill Tank . . . . . . . . . . . . & 61 & 29 & Q & 80 & $\mathbf{Q}$ & NC \\
\hline Does Fill Tank . . . . . . . . . . . . . & 68 & 29 & Q & 67 & 27 & $\mathbf{Q}$ \\
\hline
\end{tabular}

NC $=$ No cases in responding sample.

$Q=$ Data withheld either because the Relative Standard Error (RSE) was greater than 50 percent or fewer than 10 households were sampled.

Note: Data may not sum to totals due to rounding or due to the omission of a "Don't Know" category in which all data were Q's or NC's.

Source: Energy Information Administration, Office of Energy Markets and End Use, Joint Program in Survey Methodology Consumer Vehicle Preference Survey. 
Table 4.4.9. Vehicle Choice When Consumer Must Refuel the Modified Vehicle Twice as Often as a Regular Vehicle, 1994 (Percent)

\begin{tabular}{|c|c|c|c|c|c|c|}
\hline \multirow[b]{3}{*}{ Consumer Characteristic } & \multicolumn{6}{|c|}{ Modified Vehicle Must be Fueled Twice as Often } \\
\hline & \multicolumn{3}{|c|}{$\begin{array}{l}\text { Modified Vehicle Pollutes Half as Much } \\
\text { as Regular Vehicle }\end{array}$} & \multicolumn{3}{|c|}{ Modified Vehicle Does Not Pollute } \\
\hline & $\begin{array}{l}\text { Regular } \\
\text { Vehicle }\end{array}$ & $\begin{array}{c}\text { Modified } \\
\text { Vehicle }\end{array}$ & $\begin{array}{l}\text { Don't } \\
\text { Know }\end{array}$ & $\begin{array}{l}\text { Regular } \\
\text { Vehicle }\end{array}$ & $\begin{array}{l}\text { Modified } \\
\text { Vehicle }\end{array}$ & $\begin{array}{l}\text { Don't } \\
\text { Know }\end{array}$ \\
\hline $\begin{array}{l}\text { All Consumers } \ldots \ldots \ldots \ldots \ldots \ldots \ldots \\
\text { Region }\end{array}$ & 42 & $\cdot$ & $\mathbf{Q}$ & 37 & 57 & $\mathbf{Q}$ \\
\hline Northeast $\ldots \ldots \ldots \ldots \ldots \ldots \ldots$ & 37 & 58 & $Q$ & 33 & 60 & $\mathbf{Q}$ \\
\hline Midwest $\ldots \ldots \ldots \ldots \ldots \ldots \ldots$ & 43 & 53 & $\vec{Q}$ & 42 & 55 & $\mathbf{Q}$ \\
\hline South $\ldots \ldots \ldots \ldots \ldots \ldots \ldots$ & 46 & 49 & $\vec{Q}$ & 36 & 58 & $\mathbf{Q}$ \\
\hline West $\ldots \ldots \ldots \ldots \ldots \ldots \ldots \ldots$ & 36 & 61 & $\mathbf{Q}$ & 36 & 55 & $\mathbf{Q}$ \\
\hline \multicolumn{7}{|l|}{ Number of Vehicles } \\
\hline 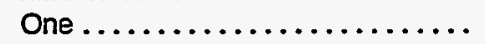 & 43 & 52 & $\mathbf{Q}$ & $\cdot 39$ & 53 & $\mathbf{Q}$ \\
\hline Two $\ldots \ldots \ldots \ldots \ldots \ldots \ldots \ldots$ & 40 & 55 & $\overrightarrow{\mathbf{Q}}$ & 33 & 61 & $\mathbf{Q}$ \\
\hline Three $\ldots \ldots \ldots \ldots \ldots \ldots \ldots \ldots$ & 46 & 51 & $\overrightarrow{\mathbf{Q}}$ & 36 & 63 & $\mathbf{Q}$ \\
\hline Four or More ............... & 36 & 62 & $\mathbf{Q}$ & 42 & 51 & $\mathbf{Q}$ \\
\hline \multicolumn{7}{|l|}{ Sex of Respondent } \\
\hline Male $\ldots \ldots \ldots \ldots \ldots \ldots \ldots \ldots$ & 45 & 51 & $\mathbf{Q}$ & 37 & 58 & $\mathbf{Q}$ \\
\hline $\begin{array}{l}\text { Female } \ldots \ldots \ldots \ldots \ldots \ldots \ldots \\
\text { Age of Main Driver }\end{array}$ & 39 & 57 & $\mathbf{Q}$ & 36 & 56 & $\mathbf{Q}$ \\
\hline 16 to $24 \ldots \ldots \ldots \ldots \ldots \ldots \ldots$ & 30 & 67 & $\mathbf{Q}$ & $Q$ & 78 & $\mathbf{Q}$ \\
\hline 25 to $34 \ldots \ldots \ldots \ldots \ldots \ldots \ldots$ & 42 & 54 & $\vec{Q}$ & 37 & 60 & $\mathbf{Q}$ \\
\hline 35 to $44 \ldots \ldots \ldots \ldots \ldots \ldots \ldots$ & 34 & 63 & $\mathbf{Q}$ & 31 & 65 & $\mathbf{Q}$ \\
\hline 45 to $54 \ldots \ldots \ldots \ldots \ldots \ldots \ldots$ & 42 & 54 & $\mathbf{Q}$ & 33 & 58 & $\mathbf{Q}$ \\
\hline 55 or Older $\ldots \ldots \ldots \ldots \ldots \ldots$ & 51 & 42 & $\mathbf{Q}$ & 48 & 42 & $\mathbf{Q}$ \\
\hline \multicolumn{7}{|l|}{ Education of Respondent } \\
\hline 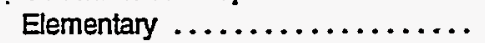 & 60 & 40 & NC & 50 & $\mathbf{Q}$ & $\mathbf{Q}$ \\
\hline High School $\ldots \ldots \ldots \ldots \ldots \ldots \ldots$ & 52 & 44 & $Q$ & 41 & 54 & $\mathbf{Q}$ \\
\hline College $\ldots \ldots \ldots \ldots \ldots \ldots \ldots$ & 31 & 65 & $\vec{Q}$ & 36 & 57 & $\mathbf{Q}$ \\
\hline Graduate School ............. & 36 & 56 & $\mathbf{Q}$ & 24 & 71 & $\mathbf{Q}$ \\
\hline \multicolumn{7}{|l|}{ Race of Respondent } \\
\hline White $\ldots \ldots \ldots \ldots \ldots \ldots \ldots$ & 42 & 54 & $\mathbf{Q}$ & 36 & 57 & $\mathbf{Q}$ \\
\hline Black .................. & 52 & 44 & $\vec{Q}$ & 45 & 52 & $\mathbf{Q}$ \\
\hline 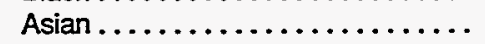 & $\mathbf{Q}$ & 83 & $Q$ & $\mathbf{Q}$ & 57 & $Q$ \\
\hline Other..$\ldots \ldots \ldots \ldots \ldots \ldots$ & 31 & 68 & $\mathbf{Q}$ & $\mathbf{Q}$ & 65 & $\mathbf{Q}$ \\
\hline \multicolumn{7}{|l|}{ Household income } \\
\hline$\$ 30,000$ or Less $\ldots \ldots \ldots \ldots \ldots$. . . . & 48 & 47 & $\mathbf{Q}$ & 40 & 53 & $\mathbf{Q}$ \\
\hline More than $\$ 30,000 \ldots \ldots \ldots \ldots$ & 38 & 58 & $\vec{Q}$ & 35 & 59 & $\mathbf{Q}$ \\
\hline \multicolumn{7}{|l|}{ Type of Housing Unit } \\
\hline Apartment $\ldots \ldots \ldots \ldots \ldots \ldots \ldots$ & 37 & 58 & $\mathbf{Q}$ & 37 & 58 & Q \\
\hline Single-Family Detached . . . . . . . . & 43 & 53 & $\vec{Q}$ & 38 & 56 & $\mathbf{Q}$ \\
\hline Townhouse $\ldots \ldots \ldots \ldots \ldots \ldots$ & 36 & 61 & $\vec{Q}$ & $\mathbf{Q}$ & 67 & $\mathbf{Q}$ \\
\hline Other $\ldots \ldots \ldots \ldots \ldots \ldots \ldots$ & 39 & 56 & $\vec{Q}$ & 31 & 61 & $\mathbf{Q}$ \\
\hline \multirow{2}{*}{\multicolumn{7}{|c|}{$\begin{array}{l}\text { Transportation Type Most Often } \\
\text { Used }\end{array}$}} \\
\hline & & & & & & \\
\hline Public Transportation ........... & $\mathbf{Q}$ & $\mathbf{Q}$ & NC & 36 & 60 & $\mathbf{Q}$ \\
\hline Personal Vehicles ............... & 43 & 53 & $\mathbf{Q}$ & 37 & 56 & Q \\
\hline Both $\ldots \ldots \ldots \ldots \ldots \ldots \ldots$ & 31 & 61 & $\vec{Q}$ & 25 & 69 & Q \\
\hline Neither $\ldots \ldots \ldots \ldots, \ldots \ldots, \ldots$ & $\mathbf{Q}$ & NC & NC & $Q$ & $Q$ & NC \\
\hline Don't know. & $\mathbf{Q}$ & $\mathbf{Q}$ & NC & $Q$ & $Q$ & $\mathbf{Q}$ \\
\hline
\end{tabular}

See footnotes at end of table. 
Table 4.4.9. Vehicle Choice When Consumer Must Must Refuel the Modified Vehicle Twice as Often as a Regular Vehicle, 1994 (Continued) (Percent)

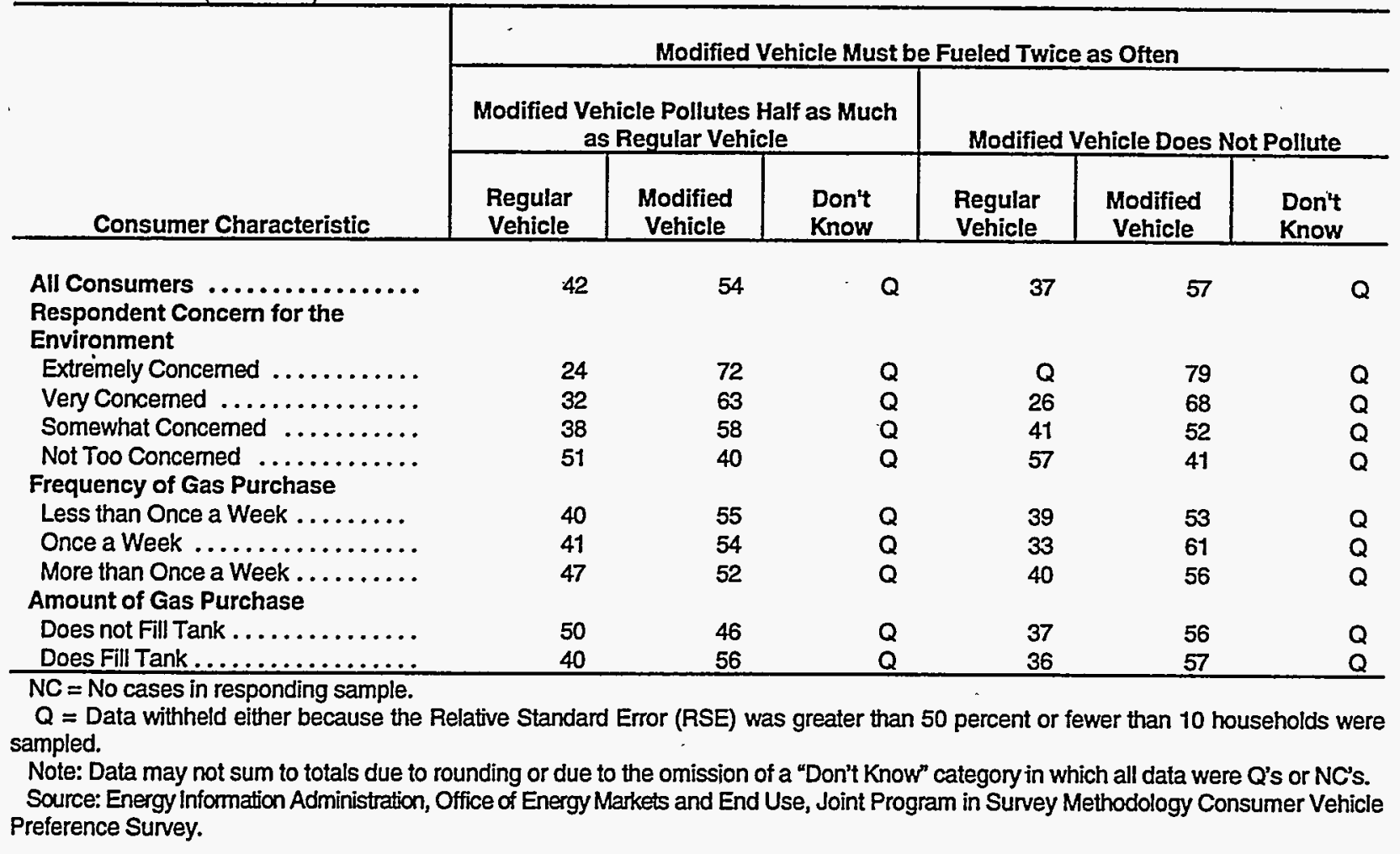


Table 4.4.10. Vehicle Choice When Consumer Must Refuel the Modified Vehicle Twice as Often as a Regular Vehicle and the Modified Vehicle Costs \$1,000 More; 1994 (Percent)

\begin{tabular}{|c|c|c|c|c|c|c|}
\hline \multirow[b]{3}{*}{ Consumer Characteristic } & \multicolumn{6}{|c|}{ Must Refuel Twice as Often and Vehicle Cost $\$ 1,000$ More } \\
\hline & \multicolumn{3}{|c|}{$\begin{array}{c}\text { Modified Vehicle Pollutes Half as Much } \\
\text { as Regular Vehicle }\end{array}$} & \multicolumn{3}{|c|}{ Modified Vehicle Does Not Pollute } \\
\hline & $\begin{array}{l}\text { Regular } \\
\text { Vehicle }\end{array}$ & $\begin{array}{l}\text { Modified } \\
\text { Vehicle }\end{array}$ & $\begin{array}{l}\text { Don't } \\
\text { Know }\end{array}$ & $\begin{array}{l}\text { Regular } \\
\text { Vehicle }\end{array}$ & $\begin{array}{l}\text { Modified } \\
\text { Vehicle }\end{array}$ & $\begin{array}{l}\text { Don't } \\
\text { Know }\end{array}$ \\
\hline $\begin{array}{l}\text { All Consumers } \ldots \ldots \ldots \ldots \ldots \ldots \ldots \\
\text { Region }\end{array}$ & \multicolumn{4}{|c|}{ Region } & 63 & $\mathbf{Q}$ \\
\hline Northeast $\ldots \ldots \ldots \ldots \ldots \ldots \ldots$ & 30 & 62 & $\mathbf{Q}$ & 24 & 70 & $\mathbf{Q}$ \\
\hline Midwest $\ldots \ldots \ldots \ldots \ldots \ldots$ & 37 & 49 & $\mathbf{Q}$ & 31 & 62 & $\mathbf{Q}$ \\
\hline South $\ldots \ldots \ldots \ldots \ldots \ldots \ldots$ & 44 & 51 & $\vec{Q}$ & 33 & 60 & $\mathbf{Q}$ \\
\hline West $\ldots \ldots \ldots \ldots \ldots \ldots \ldots \ldots$ & 31 & 64 & $\mathbf{Q}$ & 32 & 61 & $\mathbf{Q}$ \\
\hline \multicolumn{7}{|l|}{ Number of Vehicles } \\
\hline One..$\ldots \ldots \ldots \ldots \ldots \ldots \ldots$ & 35 & 54 & $\mathbf{Q}$ & 29 & 63 & Q \\
\hline Two...$\ldots \ldots \ldots \ldots \ldots \ldots$ & 38 & 56 & $\overline{\mathbf{Q}}$ & 34 & 59 & $\vec{Q}$ \\
\hline Three $\ldots \ldots \ldots \ldots \ldots \ldots \ldots \ldots$ & 33 & 59 & $\vec{Q}$ & 26 & 73 & $\mathbf{Q}$ \\
\hline Four or More ............... & 40 & 57 & $\mathbf{Q}$ & $\mathbf{Q}$ & 73 & NC \\
\hline Sex of Respondent & . & & & . & & \\
\hline Male $\ldots \ldots \ldots \ldots \ldots \ldots \ldots \ldots$ & 40 & 53 & $Q$ & 36 & 59 & $\mathbf{Q}$ \\
\hline $\begin{array}{l}\text { Female } \ldots \ldots \ldots \ldots \ldots \ldots \ldots \ldots \\
\text { Age of Main Driver }\end{array}$ & 33 & 57 & $Q$ & 26 & 67 & $\mathbf{Q}$ \\
\hline 16 to $24 \ldots \ldots \ldots \ldots \ldots \ldots \ldots$ & 33 & 67 & NC & 36 & 57 & $\mathbf{Q}$ \\
\hline 25 to $34 \ldots \ldots \ldots \ldots \ldots \ldots \ldots$ & 37 & 56 & $Q$ & 30 & 68 & 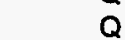 \\
\hline 35 to $44 \ldots \ldots \ldots \ldots \ldots \ldots \ldots$ & 38 & 56 & $\mathbf{Q}$ & 24 & 73 & Q \\
\hline 45 to $54 \ldots \ldots \ldots \ldots \ldots \ldots \ldots$ & 38 & 54 & $\mathbf{Q}$ & 35 & 60 & Q \\
\hline 55 or Older $\ldots \ldots \ldots \ldots \ldots \ldots \ldots$ & 34 & 49 & $Q$ & 34 & 50 & Q \\
\hline \multicolumn{7}{|l|}{ Education of Respondent } \\
\hline Elementary..$\ldots \ldots \ldots \ldots \ldots \ldots$ & $\mathbf{Q}$ & $\mathbf{Q}$ & NC & $\mathbf{Q}$ & $\mathbf{Q}$ & NC \\
\hline High School...$\ldots \ldots \ldots \ldots \ldots$ & 35 & 59 & $\mathbf{Q}$ & 29 & 61 & $Q$ \\
\hline College $\ldots \ldots \ldots \ldots \ldots \ldots \ldots$ & 37 & 53 & $Q$ & 32 & 64 & $\mathbf{Q}$ \\
\hline Graduate School ............... & 41 & 51 & $\mathbf{Q}$ & 25 & 71 & $\bar{Q}$ \\
\hline \multicolumn{7}{|l|}{ Race of Respondent } \\
\hline White...$\ldots \ldots$. & 39 & 52 & $\mathbf{Q}$ & 33 & 61 & $\mathbf{Q}$ \\
\hline Black .................. & $\mathbf{Q}$ & 65 & $\mathbf{Q}$ & $\mathbf{Q}$ & 70 & $Q$ \\
\hline Asian.$\ldots \ldots \ldots \ldots \ldots \ldots \ldots$ & $\mathbf{Q}$ & $\mathbf{Q}$ & NC & $\mathbf{Q}$ & $\mathbf{Q}$ & Q \\
\hline Other..$\ldots \ldots \ldots \ldots \ldots \ldots \ldots$ & $\vec{Q}$ & 81 & NC & NC & 87 & Q \\
\hline \multicolumn{7}{|l|}{ Household Income } \\
\hline$\$ 30,000$ or Less $\ldots \ldots \ldots \ldots \ldots \ldots$ & 41. & 48 & $\mathbf{Q}$ & 31 & 63 & $\mathbf{Q}$ \\
\hline More than $\$ 30,000 \ldots \ldots \ldots \ldots$ & 34 & 59 & $\mathbf{Q}$ & 31 & 63 & Q \\
\hline \multicolumn{7}{|l|}{ Type of Housing Unit } \\
\hline Apartment $\ldots \ldots \ldots \ldots \ldots \ldots \ldots \ldots$ & 37 & 54 & $\mathbf{Q}$ & 37 & 57 & $\mathbf{Q}$ \\
\hline Single-Family Detached ......... & 35 & 56 & $\mathbf{Q}$ & 31 & 63 & Q \\
\hline Townhouse ................. & $\mathbf{Q}$ & 63 & NC & $\mathbf{Q}$ & 65 & Q \\
\hline Other $\ldots \ldots \ldots \ldots \ldots \ldots \ldots \ldots$ & 42 & 51 & $\mathbf{Q}$ & $\mathbf{Q}$ & 70 & Q \\
\hline Transportation Type Most Often & . & & & & & \\
\hline \multicolumn{7}{|l|}{ Used } \\
\hline Public Transportation ............ & $Q$ & $\mathbf{Q}$ & $\mathbf{Q}$ & $\mathbf{Q}$ & 72 & NC \\
\hline Personal Vehicles .............. & 38 & 56 & $\mathbf{Q}$ & 31 & 62 & $\mathbf{Q}$ \\
\hline Both $\ldots \ldots \ldots \ldots \ldots \ldots \ldots \ldots$ & $\mathbf{Q}$ & 58 & $\mathbf{Q}$ & $\mathbf{Q}$ & 65 & Q \\
\hline Neither $\ldots \ldots \ldots \ldots \ldots \ldots \ldots$ & NC & NC & NC & NC & $Q$ & NC \\
\hline Don't Know..... & $\mathrm{Q}$ & $\mathbf{Q}$ & $\mathbf{Q}$ & $Q$ & $Q$ & $Q$ \\
\hline
\end{tabular}

See footnotes at end of table. 
Table 4.4.10. Vehicle Choice When Consumer Must Refuel the Modified Vehicle Twice as Often as a Regular Vehicle and the Modified Vehicle Costs \$1,000 More, 1994 (Continued) (Percent)

\begin{tabular}{|c|c|c|c|c|c|c|}
\hline \multirow[b]{3}{*}{ Consumer Characteristic } & \multicolumn{6}{|c|}{ Must Refuel Twice as Often and Vehicle Cost $\$ 1,000$ More } \\
\hline & \multicolumn{3}{|c|}{$\begin{array}{l}\text { Modified Vehicle Pollutes Half as Much } \\
\text { as Regular Vehicle }\end{array}$} & \multicolumn{3}{|c|}{ Modified Vehicle Does Not Pollute } \\
\hline & $\begin{array}{l}\text { Regular } \\
\text { Vehicle }\end{array}$ & $\begin{array}{l}\text { Modified } \\
\text { Vehicle }\end{array}$ & $\begin{array}{l}\text { Don't } \\
\text { Know }\end{array}$ & $\begin{array}{l}\text { Regular } \\
\text { Vehicle }\end{array}$ & $\begin{array}{l}\text { Modified } \\
\text { Vehicle }\end{array}$ & $\begin{array}{l}\text { Don't } \\
\text { Know }\end{array}$ \\
\hline $\begin{array}{l}\text { All Consumers ................ } \\
\text { Respondent Concern for the } \\
\text { Environment }\end{array}$ & 37 & 56 & $\mathbf{Q}$ & 31 & 63 & $\mathrm{C}$ \\
\hline Extremely Concemed ............ & $Q$ & 78 & $\mathbf{Q}$ & $\mathbf{Q}$ & 80 & Q \\
\hline Very Concemed ............... & 28 & 66 & $\mathbf{Q}$ & 22 & 71 & Q \\
\hline Somewhat Concerned .......... & 50 & 42 & $\vec{Q}$ & $\overline{40}$ & 56 & $\mathrm{Q}$ \\
\hline Not Joo Concerned ............ & Q & $\mathbf{Q}$ & $\mathbf{Q}$ & $\mathbf{Q}$ & $Q$ & Q \\
\hline \multicolumn{7}{|l|}{ Frequency of Gas Purchase } \\
\hline Less than Once a Week .......... & 34 & 58 & $\mathbf{Q}$ & 36 & 59 & Q \\
\hline Once a Week ................. & 37 & 55 & $\mathbf{Q}$ & 25 & 69 & $Q$ \\
\hline More than Once a Week ........... & 42 & 49 & $\mathbf{Q}$ & 35 & 56 & Q \\
\hline Amount of Gas Purchase & & & & & & \\
\hline 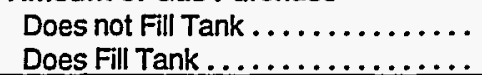 & $\begin{array}{l}41 \\
36\end{array}$ & $\begin{array}{l}52 \\
56\end{array}$ & $\begin{array}{l}Q \\
Q\end{array}$ & $\begin{array}{l}31 \\
31\end{array}$ & $\begin{array}{l}69 \\
62\end{array}$ & NC \\
\hline
\end{tabular}

$\mathrm{NC}=$ No case in responding sample.

$Q=$ Data withheld either because the Relative Standard Error (RSE) was greater than $\mathbf{5 0}$ percent or fewer than $\mathbf{1 0}$ households were sampled.

Note: Data may not sum to totals due to rounding or due to the omission of a "Don't Know" category in which all data were Q's or NC's.

Source: Energy Information Administration, Office of Energy Markets and End Use, Joint Program in Survey Methodology Consumer Vehicle Preference Survey. 
Table 4.4.11. Vehicle Choice When Consumer Must Refuel the Modified Vehicle Twice as. Often as a Regular Vehicle and the Modified Vehicle Costs \$1,000 Less, 1994 (Percent)

\begin{tabular}{|c|c|c|c|c|c|c|}
\hline \multirow[b]{3}{*}{ Consumer Characteristic } & \multicolumn{6}{|c|}{ Must Fuel Twice as Often but Vehicle Costs $\$ 1,000$ Less } \\
\hline & \multicolumn{3}{|c|}{$\begin{array}{l}\text { Modified Vehicle Pollutes Half as Much } \\
\text { as Regular Vehicle }\end{array}$} & \multicolumn{3}{|c|}{ Modified Vehicle Does Not Pollute } \\
\hline & $\begin{array}{l}\text { Regular } \\
\text { Vehicle }\end{array}$ & $\begin{array}{l}\text { Modified } \\
\text { Vehicle }\end{array}$ & $\begin{array}{l}\text { Don't } \\
\text { Know }\end{array}$ & $\begin{array}{l}\text { Regular } \\
\text { Vehicle } \\
\end{array}$ & $\begin{array}{c}\text { Modified } \\
\text { Vehicle }\end{array}$ & $\begin{array}{l}\text { Don't } \\
\text { Know }\end{array}$ \\
\hline $\begin{array}{l}\text { All Consumers } \ldots \ldots \ldots \ldots \ldots \ldots \ldots \\
\text { Reqion }\end{array}$ & 67 & 25 & $Q$ & 72 & 22 & $\mathbf{Q}$ \\
\hline Northeast... & 52 & 38 & $\mathbf{Q}$ & 62 & 36 & $\mathbf{Q}$ \\
\hline Midwest $\ldots \ldots \ldots \ldots \ldots \ldots \ldots \ldots$ & 74 & 20 & $\mathbf{Q}$ & 66 & 24 & $\mathbf{Q}$ \\
\hline South $\ldots \ldots \ldots \ldots \ldots \ldots \ldots \ldots \ldots$ & 71 & 20 & $\vec{Q}$ & 77 & 21 & $\widehat{Q}$ \\
\hline West $\ldots \ldots \ldots \ldots \ldots \ldots \ldots \ldots \ldots$ & 59 & 35 & $\bar{Q}$ & 80 & $\mathbf{Q}$ & $\hat{Q}$ \\
\hline \multicolumn{7}{|l|}{ Number of Vehicles } \\
\hline One $\ldots \ldots \ldots \ldots \ldots \ldots \ldots \ldots$ & 64 & 27 & $\mathbf{Q}$ & 74 & 20 & $\mathbf{Q}$ \\
\hline Two $\ldots \ldots \ldots \ldots \ldots \ldots \ldots \ldots$ & 70 & 23 & $\hat{Q}$ & 73 & 22 & $\bar{Q}$ \\
\hline Three $\ldots \ldots \ldots \ldots \ldots \ldots \ldots \ldots$ & 71 & $\mathbf{Q}$ & $\vec{Q}$ & 59 & 34 & $Q$ \\
\hline Four or More $\ldots \ldots \ldots \ldots \ldots \ldots$ & 53 & $\mathbf{Q}$ & $\mathbf{Q}$ & 77 & $\mathbf{Q}$ & $\mathbf{Q}$ \\
\hline \multicolumn{7}{|l|}{ Sex of Respondent } \\
\hline Male $\ldots \ldots \ldots \ldots \ldots \ldots \ldots$ & 72 & 21 & $\mathbf{Q}$ & 81 & $\mathbf{Q}$ & $\mathbf{Q}$ \\
\hline Female $\ldots \ldots \ldots \ldots \ldots \ldots \ldots$ & 62 & 30 & $\mathbf{Q}$ & 64 & 30 & $\mathbf{Q}$ \\
\hline \multicolumn{7}{|l|}{ Age of Main Driver } \\
\hline 16 to $24 \ldots \ldots \ldots$ & 51 & 49 & NC & $\mathbf{Q}$ & $\mathbf{Q}$ & NC \\
\hline 25 to $34 \ldots \ldots \ldots$ & 64 & 32 & $\mathbf{Q}$ & 77 & $\mathbf{Q}$ & $\mathbf{Q}$ \\
\hline 35 to $44 \ldots \ldots \ldots \ldots \ldots \ldots \ldots$ & 68 & 23 & $\mathbf{Q}$ & 77 & $\mathbf{Q}$ & $\mathbf{Q}$ \\
\hline 45 to $54 \ldots \ldots \ldots \ldots \ldots \ldots \ldots$ & 69 & 29 & $\mathbf{Q}$ & 65 & 34 & $\mathbf{Q}$ \\
\hline 55 or Older $\ldots \ldots \ldots \ldots \ldots \ldots$ & 71 & $\mathbf{Q}$ & $\mathbf{Q}$ & 69 & 22 & $\mathbf{Q}$ \\
\hline \multicolumn{7}{|l|}{ Education of Respondent } \\
\hline Elementary $\ldots \ldots \ldots \ldots \ldots \ldots$ & 79 & $\mathbf{Q}$ & $\mathbf{Q}$ & Q. & $\mathbf{Q}$ & $\mathbf{Q}$ \\
\hline High School $\ldots . \ldots \ldots \ldots \ldots \ldots$. & 66 & 25 & $\mathbf{Q}$ & 71 & 24 & $\mathbf{Q}$ \\
\hline College $\ldots \ldots \ldots \ldots \ldots \ldots \ldots$. & 68 & 27 & $\mathbf{Q}$ & 73 & 20 & $\mathbf{Q}$ \\
\hline Graduate School .............. & 60 & $\mathbf{Q}$ & $\mathbf{Q}$ & 73 & $\mathbf{Q}$ & $\mathbf{Q}$ \\
\hline \multicolumn{7}{|l|}{ Race of Respondent } \\
\hline White $\ldots \ldots \ldots \ldots \ldots \ldots \ldots$ & 66 & 26 & $\mathbf{Q}$ & 71 & 23 & $\mathbf{Q}$ \\
\hline Black ................. & 74 & $\mathbf{Q}$ & $\mathbf{Q}$ & 72 & $\mathbf{Q}$ & NC \\
\hline 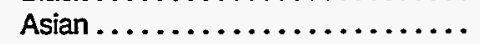 & NC & $\mathbf{Q}$ & NC & $Q$ & NC & $\mathbf{Q}$ \\
\hline Other..$\ldots \ldots \ldots \ldots \ldots \ldots$ & . 81 & $\vec{Q}$ & $\mathbf{Q}$ & $Q$ & $\mathbf{Q}$ & NC \\
\hline \multicolumn{7}{|l|}{ Household Income } \\
\hline$\$ 30,000$ or Less $\ldots \ldots \ldots \ldots \ldots \ldots$ & 66 & 22 & $\mathbf{Q}$ & 73 & 21 & $\mathbf{Q}$ \\
\hline More than $\$ 30,000 \ldots \ldots \ldots \ldots$ & 68 & $\overline{28}$ & $\vec{Q}$ & 71 & 23 & $\mathbf{Q}$ \\
\hline \multicolumn{7}{|l|}{ Type of Housing Unit } \\
\hline Apartment $\ldots \ldots \ldots \ldots \ldots \ldots \ldots$ & 60 & 34 & $Q$ & 80 & $\mathbf{Q}$ & Q \\
\hline Single-Family Detached .......... & 70 & 22 & $\vec{Q}$. & 70 & 22 & $Q$ \\
\hline Townhouse $\ldots \ldots \ldots \ldots \ldots \ldots$ & $\mathbf{Q}$ & $\vec{Q}$ & $\overline{\mathrm{Q}}$ & $Q$ & $\mathbf{Q}$ & NC \\
\hline other $\ldots \ldots \ldots \ldots \ldots \ldots \ldots \ldots$ & 53 & 37 & $\widehat{Q}$ & 64 & 36 & NC \\
\hline \multicolumn{7}{|l|}{ Transportation Type Most Often } \\
\hline \multicolumn{7}{|l|}{ Used } \\
\hline Public Transportation ........... & $\mathbf{Q}$ & $\mathbf{Q}$ & NC & $\mathbf{Q}$ & $\mathbf{Q}$ & NC \\
\hline Personal Vehicles ................ & 65 & 26 & $Q$ & 71 & 22 & Q \\
\hline Both $\ldots \ldots \ldots \ldots \ldots \ldots \ldots$ & 82 & $Q$ & NC & 76 & $\bar{Q}$ & $\mathbf{Q}$ \\
\hline Neither $\ldots \ldots \ldots \ldots \ldots \ldots \ldots$ & $\overrightarrow{N C}$ & $Q$ & NC & $\mathbf{Q}$ & NC & NC \\
\hline 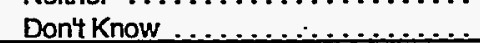 & $\mathrm{Q}$ & $\mathrm{Q}$ & NC & $\mathbf{Q}$ & $\mathrm{Q}$ & NC \\
\hline
\end{tabular}


Table 4.4.11. Vehicle Choice When Consumer Must Refuel the Modified Vehicle Twice as Often as a Regular Vehicle and the Modified Vehicle Costs \$1,000 Less, 1994 (Continued) (Percent)

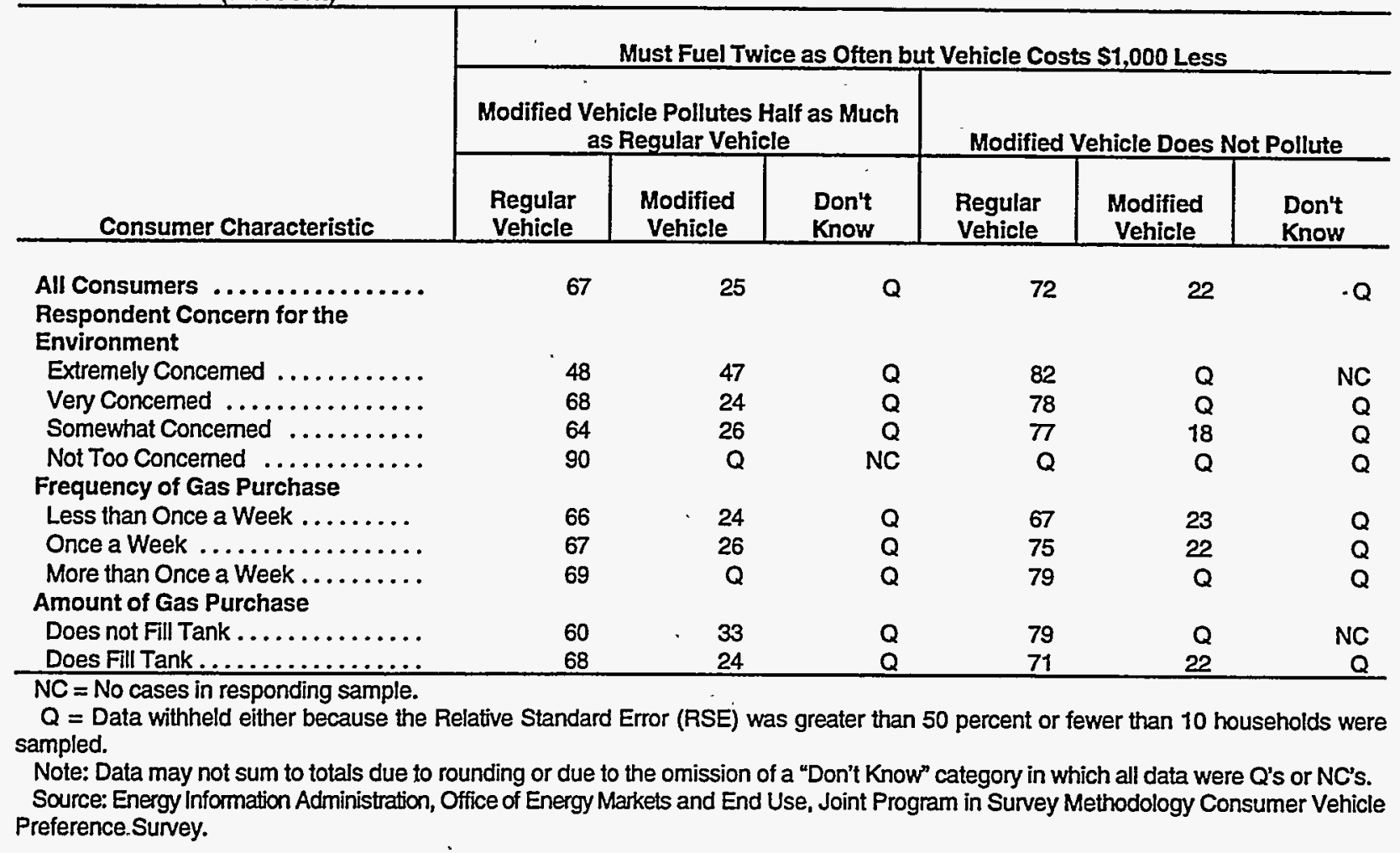


Table 4.4.12. Vehicle Choice When Consumer Must Drive 15 Minutes Out of the Way to Refuel the Modified Vehicle and the Modified Vehicle Has Half the Trunk/Cargo Space of a Regular Vehicle, 1994 (Percent)

\begin{tabular}{|c|c|c|c|c|c|c|}
\hline \multirow[b]{3}{*}{ Consumer Characteristic } & \multicolumn{6}{|c|}{ Consumer Must Drive 15 Minutes Out of the Way and Half Trunk/Cargo Space } \\
\hline & \multicolumn{3}{|c|}{$\begin{array}{l}\text { Modified Vehicle Pollutes Half as Much } \\
\text { as Regular Vehicle }\end{array}$} & \multicolumn{3}{|c|}{ Modified Vehicle Does Not Pollute } \\
\hline & $\begin{array}{l}\text { Regular } \\
\text { Vehicle }\end{array}$ & $\begin{array}{l}\text { Modified } \\
\text { Vehicle }\end{array}$ & $\begin{array}{l}\text { Don't } \\
\text { Know }\end{array}$ & $\begin{array}{l}\text { Regular } \\
\text { Vehicle }\end{array}$ & $\begin{array}{l}\text { Modified } \\
\text { Vehicle }\end{array}$ & $\begin{array}{l}\text { Don't } \\
\text { Know }\end{array}$ \\
\hline $\begin{array}{l}\text { All Consumers } \ldots \ldots \ldots \ldots \ldots \ldots \ldots \\
\text { Region }\end{array}$ & \multicolumn{5}{|c|}{ Region } & $\mathbf{Q}$ \\
\hline Northeast $\ldots \ldots \ldots \ldots \ldots \ldots$ & 68 & $\mathbf{Q}$ & NC & 54 & 39 & $\mathbf{Q}$ \\
\hline Midwest $\ldots \ldots \ldots \ldots \ldots \ldots \ldots$ & 40 & 60 & NC & 47 & 50 & Q \\
\hline South $\ldots \ldots \ldots \ldots \ldots \ldots \ldots \ldots$ & 54 & 44 & $\mathbf{Q}$ & 54 & 44 & Q \\
\hline West $\ldots \ldots \ldots \ldots \ldots \ldots \ldots \ldots$ & 38 & 54 & $\mathbf{Q}$ & 49 & 49 & $\mathbf{Q}$ \\
\hline \multicolumn{7}{|l|}{ Number of Vehicles } \\
\hline One $\ldots \ldots \ldots \ldots \ldots \ldots \ldots \ldots$ & 42 & 56 & $\mathbf{Q}$ & 50 & 48 & $\mathbf{Q}$ \\
\hline Two $\ldots \ldots \ldots \ldots \ldots \ldots \ldots \ldots$ & 52 & 44 & $\mathbf{Q}$ & 53 & 40 & $\mathbf{Q}$ \\
\hline Three $\ldots \ldots \ldots \ldots \ldots \ldots \ldots \ldots$ & 58 & $\mathbf{Q}$ & NC & $\mathbf{Q}$ & $\mathbf{Q}$ & NC \\
\hline Four or More . ............... & $\mathbf{Q}$ & $\mathbf{Q}$ & NC & $\mathbf{Q}$ & $\mathbf{Q}$ & NC \\
\hline \multicolumn{7}{|l|}{ Sex of Respondent } \\
\hline Male $\ldots \ldots \ldots \ldots$ & 51 & 48 & $\mathbf{Q}$ & 50 & 45 & $\mathbf{Q}$ \\
\hline Female $\ldots \ldots \ldots \ldots \ldots \ldots \ldots \ldots$ & \multicolumn{5}{|c|}{ Age of Main Driver } & Q \\
\hline 16 to $24 \ldots \ldots \ldots \ldots \ldots \ldots \ldots$ & $\mathbf{Q}$ & $\mathbf{Q}$ & NC & $\mathbf{Q}$ & $\mathbf{Q}$ & NC \\
\hline 25 to $34 \ldots \ldots \ldots \ldots \ldots \ldots \ldots$ & 55 & 43 & $\mathbf{Q}$ & 56 & 41 & $\mathbf{Q}$ \\
\hline 35 to $44 \ldots \ldots \ldots \ldots \ldots \ldots \ldots$ & 35 & 65 & NC & 62 & 38 & NC \\
\hline 45 to $54 \ldots \ldots \ldots \ldots \ldots \ldots \ldots$ & 64 & $\mathbf{Q}$ & NC & 58 & 42 & NC \\
\hline 55 or Older $\ldots \ldots \ldots \ldots \ldots \ldots$ & 42 & 50 & $\mathbf{Q}$ & 44 & 48 & Q \\
\hline \multicolumn{7}{|l|}{ Education of Respondent } \\
\hline Elementary $\ldots \ldots \ldots \ldots \ldots \ldots \ldots$ & $\mathbf{Q}$ & $\mathbf{Q}$ & NC & $Q$ & $\mathbf{Q}$ & NC \\
\hline High School $\ldots \ldots \ldots \ldots \ldots \ldots \ldots$ & 49 & 48 & $\mathbf{Q}$ & 42 & 55 & Q \\
\hline College $\ldots \ldots \ldots \ldots \ldots \ldots \ldots$ & 52 & 48 & NC & 57 & 38 & Q \\
\hline Graduate School ............. & $\mathbf{Q}$ & $Q$ & $\mathbf{Q}$ & 63 & $\mathbf{Q}$ & NC \\
\hline \multicolumn{7}{|l|}{ Race of Respondent } \\
\hline White $\ldots \ldots \ldots \ldots \ldots \ldots \ldots$ & 51 & 46 & $\mathbf{Q}$ & 41 & 45 & Q \\
\hline Black ................ & $\mathbf{Q}$ & $\mathbf{Q}$ & NC & 61 & $Q$ & NC \\
\hline$A \operatorname{sian} \ldots \ldots \ldots \ldots \ldots \ldots \ldots \ldots$ & $\overrightarrow{\mathrm{Q}}$ & $\bar{Q}$ & NC & $\mathbf{Q}$ & $\mathbf{Q}$ & NC \\
\hline 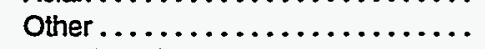 & $\vec{Q}$ & $\vec{Q}$ & NC & $\vec{Q}$ & $\vec{Q}$ & NC \\
\hline \multicolumn{7}{|l|}{ Household Income } \\
\hline$\$ 30,000$ or Less $\ldots \ldots \ldots \ldots \ldots$ & 29 & 69 & $\mathbf{Q}$ & 37 & 58 & Q \\
\hline More than $\$ 30,000 \ldots \ldots \ldots \ldots$ & 60 & 37 & $\mathbf{Q}$ & 59 & 38 & $\mathbf{Q}$ \\
\hline \multicolumn{7}{|l|}{ Type of Housing Unit } \\
\hline Apartment $\ldots \ldots \ldots \ldots \ldots \ldots \ldots$ & $Q^{\circ}$ & 60 & $\mathbf{Q}$ & 45 & 50 & $Q$ \\
\hline Single-Family Detached ......... & 51 & 47 & $\mathbf{Q}$ & 53 & 43 & $Q$ \\
\hline Townhouse.$\ldots \ldots \ldots \ldots \ldots$. & $Q$ & $\mathbf{Q}$ & NC & $\mathbf{Q}$ & $Q$ & NC \\
\hline Other.$\ldots \ldots \ldots \ldots \ldots \ldots \ldots$ & $\vec{Q}$ & 47 & $\mathbf{Q}$ & 58 & $\vec{Q}$ & NC \\
\hline \multirow{2}{*}{\multicolumn{7}{|c|}{$\begin{array}{l}\text { Transportation Type Most Often } \\
\text { Used }\end{array}$}} \\
\hline & & & & & & \\
\hline Public Transportation ........... & $\mathbf{Q}$ & NC & NC & $\mathbf{Q}$ & $\mathbf{Q}$ & NC \\
\hline Personal Vehicles . ........... & 51 & 46 & $Q$ & 53 & 42 & $\mathbf{Q}$ \\
\hline Both $\ldots \ldots \ldots \ldots \ldots \ldots \ldots \ldots$ & $\mathbf{Q}$ & $\mathbf{Q}$ & NC & $\mathbf{Q}$ & $\mathbf{Q}$ & NC \\
\hline Neither $\ldots \ldots \ldots \ldots \ldots \ldots \ldots \ldots$ & NC. & NC & NC & NC & NC & NC \\
\hline Don't know ................... & NC & $\mathbf{Q}$ & NC & $Q$ & $Q$ & NC \\
\hline
\end{tabular}

See footnotes at end of table. 
Table 4.4.12. Vehicle Choice When Consumer Must Drive 15 Minutes Out of the Way to Refuel the Modified Vehicle and the Modified Vehicle Has Half the Trunk/Cargo Space of a Regular Vehicle, 1994 (Continued) (Percent)

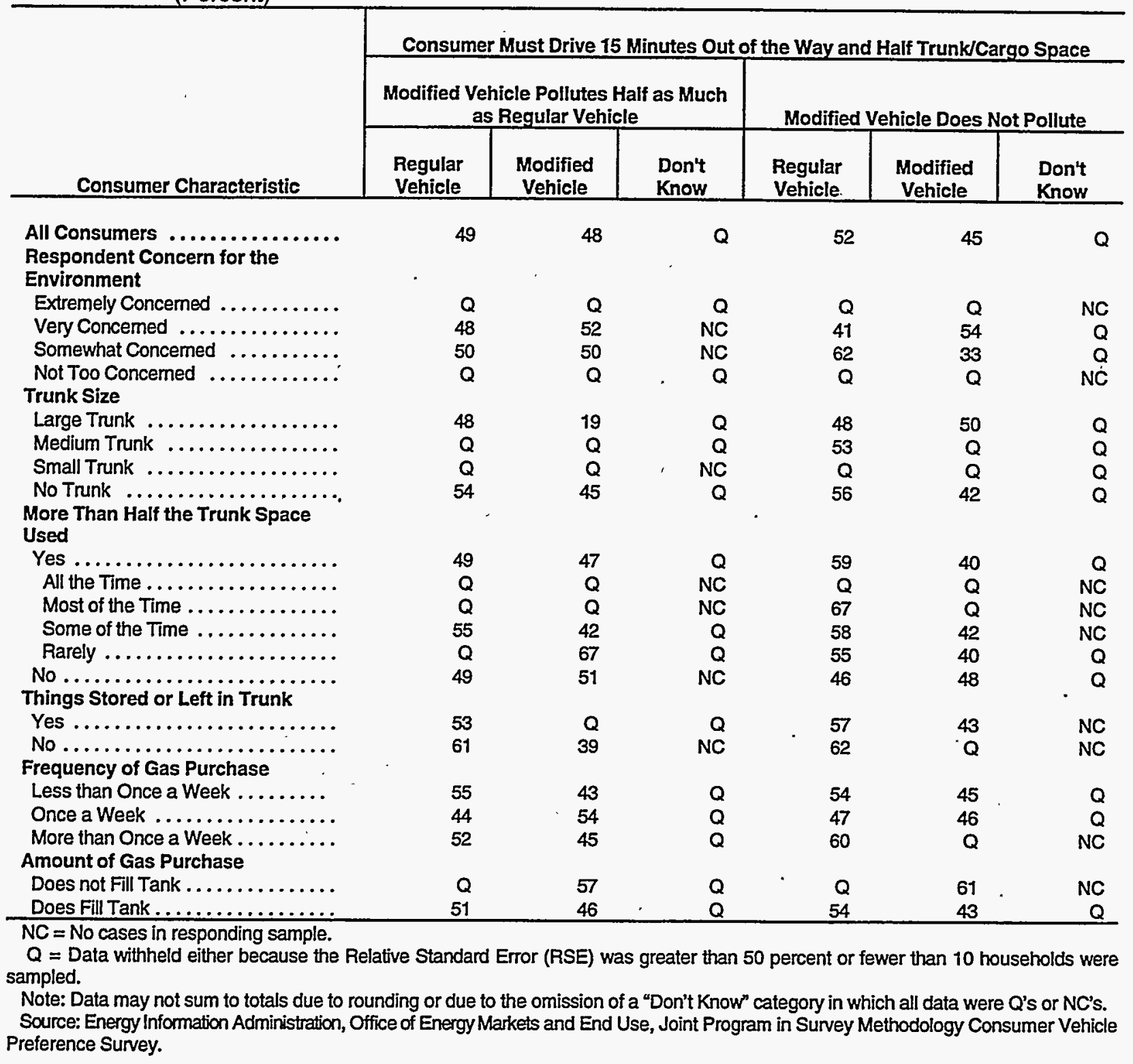


Table 4.4.13. Vehicle Choice When Consumer Must Refuel Modified Vehicle Tiwice as Often as a Regular Vehicle and the Modified Vehicle Has Half the Trunk/Cargo Space of a Regular Vehicle, 1994 (Percent)

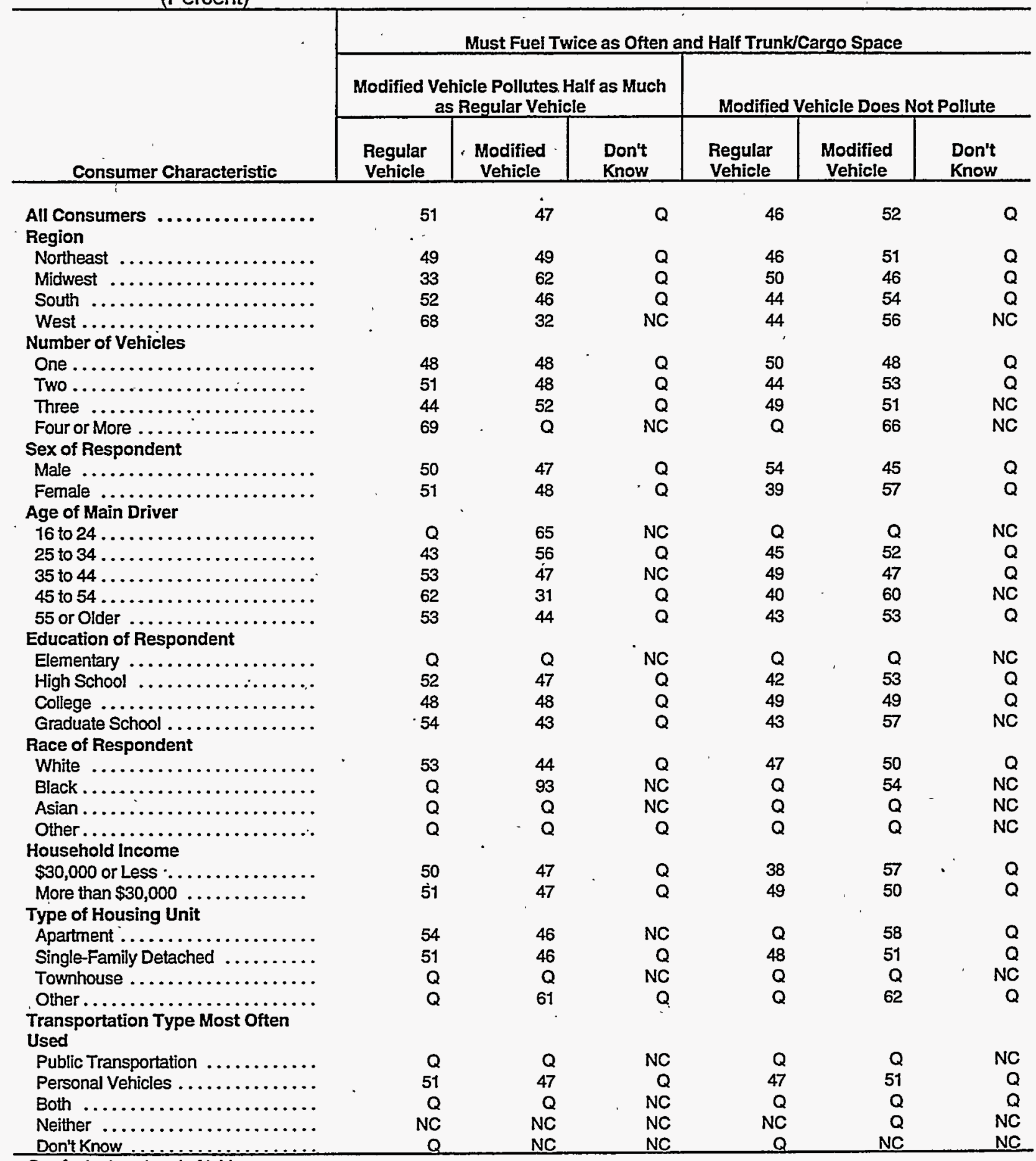

See footnotes at end of table. 
Table 4.4.13. Vehicle Choice When Consumer Must Refuel Modified Vehicle Twice as Often as a Regular Vehicle and the Modified Vehicle Has Half the Trunk/Cargo Space of a Regular Vehicle, 1994 (Continued) (Percent)

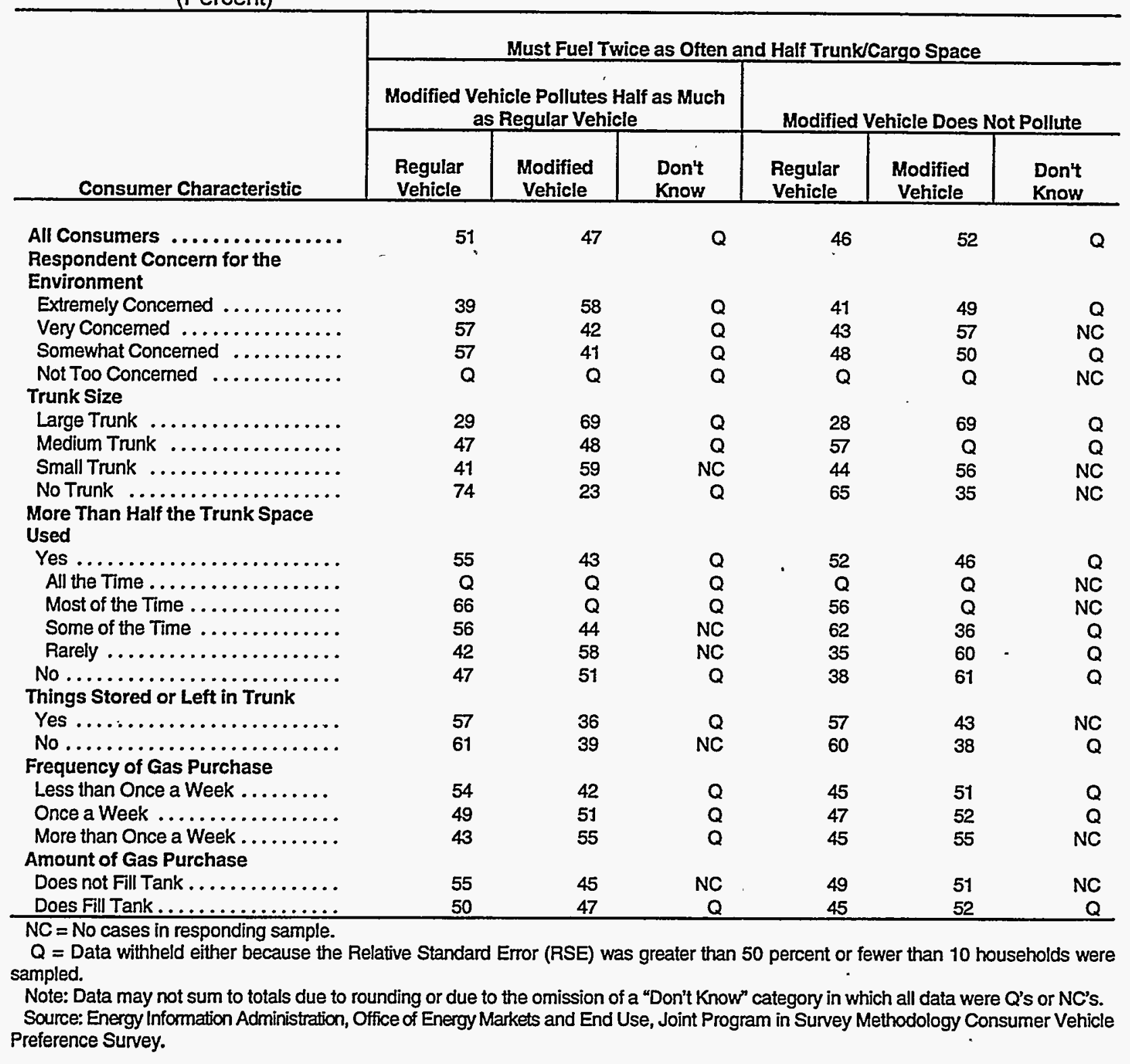


Table 4.4.14. Vehicle Choice When Consumer Must Drive 15 Minutes Out of the Way to Refuel Modified Vehicle and Modified Vehicle Must be Refueled Twice as Often as a Regular Vehicle, 1994 (Percent)

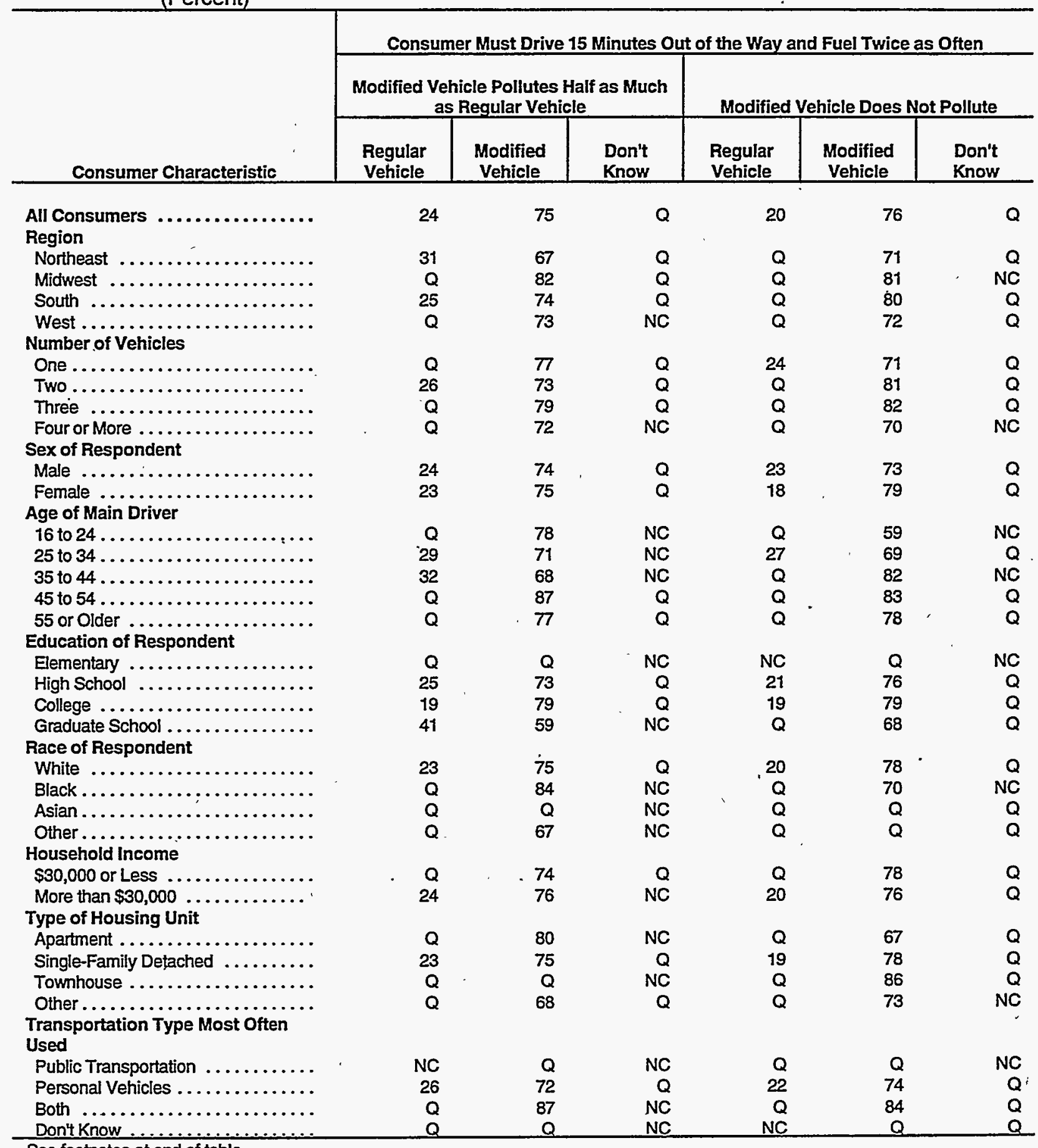

See footnotes at end of table. 
Table 4.4.14. Vehicle Choice When Consumer Must Drive 15 Minutes Out of the Way to Refuel Modified Vehicle and Modified Vehicle Must be Refueled Twice as Often as a Regular Vehicle, 1994 (Continued) (Percent)

\begin{tabular}{|c|c|c|c|c|c|c|}
\hline \multirow[b]{3}{*}{ Consumer Characteristic } & \multicolumn{6}{|c|}{ Consumer Must Drive 15 Minutes Out of the Way and Fuel Twice as Often } \\
\hline & \multicolumn{3}{|c|}{$\begin{array}{c}\text { Modified Vehicle Pollutes Half as Much } \\
\text { as Regular Vehicle }\end{array}$} & \multicolumn{3}{|c|}{ Modified Vehicle Does Not Pollute } \\
\hline & $\begin{array}{l}\text { Regular } \\
\text { Vehicle } \\
\end{array}$ & $\begin{array}{c}\text { Modified } \\
\text { Vehicle }\end{array}$ & $\begin{array}{l}\text { Don't } \\
\text { Know }\end{array}$ & $\begin{array}{l}\text { Regular } \\
\text { Vehicle } \\
\end{array}$ & $\begin{array}{l}\text { Modified } \\
\text { Vehicle }\end{array}$ & $\begin{array}{l}\text { Don't } \\
\text { Know }\end{array}$ \\
\hline $\begin{array}{l}\text { All Consumers } \ldots \ldots \ldots \ldots \ldots \ldots \\
\text { Respondent Concern for the } \\
\text { Environment }\end{array}$ & 24 & 75 & $\mathbf{Q}$ & 20 & 76 & $\mathbf{Q}$ \\
\hline Extremely Concemed ........... & $\mathbf{Q}$ & 82 & $\mathbf{Q}$ & $\mathbf{Q}$ & 85 & $\mathbf{Q}$ \\
\hline Very Concemed .............. & $\bar{Q}$ & 80 & NC & 20 & 78 & $Q$ \\
\hline Somewhat Concemed $\ldots \ldots \ldots \ldots$. & 30 & 70 & NC & 27 & 70 & $Q$ \\
\hline $\begin{array}{l}\text { Not Too Concerned .............. } \\
\text { Frequency of Gas Purchase }\end{array}$ & $\mathbf{Q}$ & $\mathbf{Q}$ & $\mathbf{Q}$ & $\mathbf{Q}$ & $\mathbf{Q}$ & $\mathbf{Q}$ \\
\hline Less than Once a Week .......... & $\mathbf{Q}$ & 80 & $\mathbf{Q}$ & 21 & 75 & $Q$ \\
\hline Once a Week ................ & 24 & 76 & NC & 19 & 79 & $\bar{Q}$ \\
\hline $\begin{array}{l}\text { More than Once a Week ......... } \\
\text { Amount of Gas Purchase }\end{array}$ & 38 & 60 & $Q$ & $\mathbf{Q}$ & 71 & $\mathbf{Q}$ \\
\hline $\begin{array}{l}\text { Does not Fill Tank ............... } \\
\text { Does Fill Tank ............... }\end{array}$ & $\begin{array}{r}Q \\
23\end{array}$ & $\begin{array}{l}72 \\
75\end{array}$ & $\begin{array}{r}\text { NC } \\
Q\end{array}$ & $\begin{array}{r}Q \\
19\end{array}$ & $\begin{array}{l}72 \\
77\end{array}$ & $\begin{array}{r}\text { NC } \\
\mathbf{Q}\end{array}$ \\
\hline
\end{tabular}

$\mathrm{NC}=$ No case in responding sample.

$Q=$ Data withheld either because the Relative Standard Error (RSE) was greater than 50 percent or fewer than 10 households were sampled.

Note: Data may not sum to totals due to rounding or due to the omission of a "Don't Know" category in which all data were Q's or NC's.

Source: Energy Information Administration, Office of Energy Markets and End Use, Joint Program in Survey Methodology Consumer Vehicle Preference Survey. 
Table 4.4.15. Vehicle Choice When Consumer Must Drive 15 Minutes Out of the Way to Refuel the Modified Vehicle, the Modified Vehicle Must be Refueled Twice as Often as a Regular Vehicle, and the Modified Vehicle Costs \$1,000 Less, 1994 (Percent)

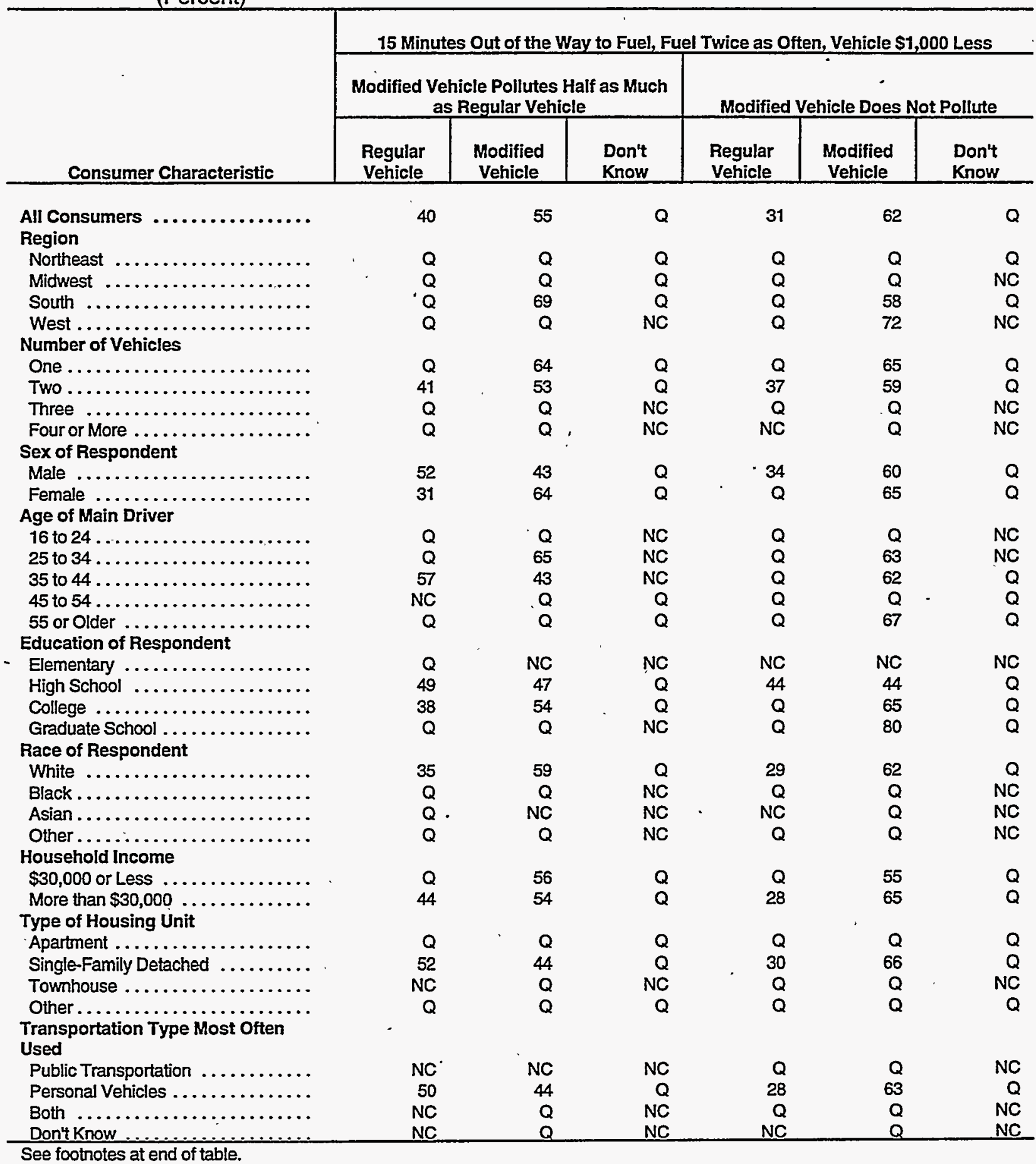


Table 4.4.15. Vehicle Choice When Consumer Must Drive 15 Minutes Out of the Way to Refuel the Modified Vehicle, the Modified Vehicle Must be Refueled Twice as Often as a Regular Vehicle, and the Modified Vehicle Costs \$1,000 Less, 1994 (Continued) (Percent)

\begin{tabular}{|c|c|c|c|c|c|c|}
\hline \multirow[b]{3}{*}{ Consumer Characteristic } & \multicolumn{6}{|c|}{15 Minutes Out of the Way to Fuel, Fuel Twice as Often, Vehicle $\$ 1,000$ Less } \\
\hline & \multicolumn{3}{|c|}{$\begin{array}{c}\text { Modified Vehicle Pollutes Half as Much } \\
\text { as Regular Vehicle }\end{array}$} & \multicolumn{3}{|c|}{ Modified Vehicle Does Not Pollute } \\
\hline & $\begin{array}{l}\text { Regular } \\
\text { Vehicle } \\
\end{array}$ & $\begin{array}{l}\text { Modified } \\
\text { Vehicle }\end{array}$ & $\begin{array}{l}\text { Don't } \\
\text { Know }\end{array}$ & $\begin{array}{l}\text { Regular } \\
\text { Vehicle }\end{array}$ & $\begin{array}{c}\text { Modified } \\
\text { Vehicle }\end{array}$ & $\begin{array}{l}\text { Don't } \\
\text { Know }\end{array}$ \\
\hline $\begin{array}{l}\text { All Consumers } \ldots \ldots \ldots \ldots \ldots \ldots \ldots \\
\text { Respandent Concern for the } \\
\text { Environment }\end{array}$ & 40 & 55 & $\mathbf{Q}$ & 31 & 62 & $\mathbf{Q}$ \\
\hline Extremely Concemed ........... & $\mathbf{Q}$ & $\mathbf{Q}$ & $\mathbf{Q}$ & Q & $\mathbf{Q}$ & NC \\
\hline Very Concemed ............. & 51 & $\mathbf{Q}$ & NC & $\vec{Q}$ & 56 & $\mathbf{Q}$ \\
\hline Somewhat Concemed .......... & 40 & 60 & NC & $\overrightarrow{\mathbf{Q}}$ & 61 & $\mathbf{Q}$ \\
\hline Not Too Concerned ............ & $\mathbf{Q}$ & $\mathbf{Q}$ & $\mathbf{Q}$ & $\mathbf{Q}$ & $\mathbf{Q}$ & NC \\
\hline \multicolumn{7}{|l|}{ Frequency of Gas Purchase } \\
\hline Less than Once a Week . . . . . . . . . & 48 & 44 & $\mathbf{Q}$ & $\mathbf{Q}$ & 61 & $\mathbf{Q}$ \\
\hline Once a Week ................ & 34 & 63 & $\mathbf{Q}$ & $\mathbf{Q}$ & 66 & $\mathbf{Q}$ \\
\hline More than Once a Week .......... & $\mathbf{Q}$ & $\mathbf{Q}$ & $\bar{Q}$ & $\vec{Q}$ & $\mathbf{Q}$ & $\mathbf{Q}$ \\
\hline \multicolumn{7}{|l|}{ Amount of Gas Purchase } \\
\hline Does not Fill Tank . ............ & $\mathbf{Q}$ & $\mathbf{Q}$ & NC & $Q$ & $\mathbf{Q}$ & NC \\
\hline Does Fill Tank . . . . . . . . . . . . . . & 34 & 60 & $Q$ & 29 & 63 & $\mathbf{Q}$ \\
\hline \multicolumn{7}{|c|}{$\begin{array}{l}\text { NC = No cases in responding sample. } \\
Q=\text { Data withheld either because the Relative Standard Error (RSE) was greater than } 50 \text { percent or fewer than } 10 \text { households were } \\
\text { sampled. } \\
\text { Note: Data may not sum to totals due to rounding or due to the omission of a "Don't Know" category in which all data were Q's or NC's. } \\
\text { Source: Energy Information Administration, Office of Energy Markets and End Use, Joint Program in Survey Methodology Consumer Vehicle } \\
\text { Preference Survey. }\end{array}$} \\
\hline
\end{tabular}


Table 4.4.16. Vehicle Choice When Consumer Must Drive 15 Minutes Out of the Way to Refuel the Modified Vehicle, the Modified Vehicle Must be Refueled Twice as Often as a Regular Vehicle, and the Modified Vehicle Has Half the Trunk/Cargo Space of a Regular Vehicle, 1994

(Percent)

\begin{tabular}{|c|c|c|c|c|c|c|}
\hline \multirow[b]{3}{*}{ Consumer Characteristic } & \multicolumn{6}{|c|}{ Drive 15 minutes out of the Way, Fuel Twice as Often, Half Trunk/Cargo Space } \\
\hline & \multicolumn{3}{|c|}{$\begin{array}{c}\text { Modified Vehicle Pollutes Half as Much } \\
\text { as Regular Vehicle }\end{array}$} & \multicolumn{3}{|c|}{ Modified Vehicle Does Not Pollute } \\
\hline & $\begin{array}{l}\text { Regular } \\
\text { Vehicle }\end{array}$ & $\begin{array}{c}\text { Modified } \\
\text { Vehicle }\end{array}$ & \multirow{2}{*}{$\begin{array}{r}\begin{array}{r}\text { Don't } \\
\text { Know }\end{array} \\
\end{array}$} & \multirow{2}{*}{$\begin{array}{r}\begin{array}{l}\text { Regular } \\
\text { Vehicle }\end{array} \\
34\end{array}$} & \multirow{2}{*}{$\begin{array}{r}\begin{array}{l}\text { Modified } \\
\text { Vehicle }\end{array} \\
62\end{array}$} & $\begin{array}{l}\text { Don't } \\
\text { Know }\end{array}$ \\
\hline $\begin{array}{l}\text { All Consumers } \ldots \ldots \ldots \ldots \ldots \ldots \ldots \\
\text { Region }\end{array}$ & 38 & 61 & & & & $\mathbf{Q}$ \\
\hline Northeast $\ldots \ldots \ldots \ldots \ldots \ldots \ldots$ & 56 & 43 & $\mathbf{Q}$ & 32 & 66 & $\mathbf{Q}$ \\
\hline Midwest $\ldots \ldots \ldots \ldots \ldots \ldots \ldots$ & 35 & 63 & $\mathbf{Q}$ & 40 & 59 & $\mathbf{Q}$ \\
\hline South $\ldots \ldots \ldots \ldots \ldots \ldots \ldots$ & 34 & 64 & $\mathbf{Q}$ & 33 & 63 & $\mathbf{Q}$ \\
\hline West $\ldots \ldots \ldots \ldots \ldots \ldots \ldots \ldots$ & $\mathbf{Q}$ & 68 & NC & 33 & 58 & $\mathbf{Q}$ \\
\hline \multicolumn{7}{|l|}{ Number of Vehicles } \\
\hline One............ & 27 & 71 & $\mathbf{Q}$ & 25 & 71 & $\mathbf{Q}$ \\
\hline Two $\ldots \ldots \ldots \ldots \ldots \ldots \ldots$ & 42 & 57 & $\mathbf{Q}$ & 42 & 54 & $\mathbf{Q}$ \\
\hline Three $\ldots \ldots \ldots \ldots \ldots \ldots \ldots \ldots$ & 45 & 53 & $\mathbf{Q}$ & 39 & 56 , & $\mathbf{Q}$ \\
\hline \multicolumn{7}{|l|}{ Sex of Respondent } \\
\hline Male $\ldots \ldots \ldots \ldots \ldots \ldots \ldots$ & 39 & 59 & $\mathbf{Q}$ & 34 & 62 & $\mathbf{Q}$ \\
\hline Female $\ldots \ldots \ldots \ldots \ldots \ldots \ldots$ & 36 & 63 & $\mathbf{Q}$ & 34 & 61 & $\mathbf{Q}$ \\
\hline \multicolumn{7}{|l|}{ Age of Màin Driver } \\
\hline 16 to $24 \ldots \ldots \ldots$. & $\mathbf{Q}$ & 61 & NC & $\mathbf{Q}$ & 69 & NC \\
\hline 25 to $34 \ldots \ldots \ldots \ldots \ldots \ldots \ldots$ & 36 & 64 & NC & 33 & 65 & $\mathbf{Q}$ \\
\hline 35 to $44 \ldots \ldots \ldots \ldots \ldots \ldots \ldots$ & 45 & 53 & $\mathbf{Q}$ & 34 & 63 & $\mathbf{Q}$ \\
\hline 45 to $54 \ldots \ldots \ldots \ldots \ldots \ldots \ldots$ & $\mathbf{Q}$ & 71 & $\mathbf{Q}$ & 29 & 64 & $\mathbf{Q}$ \\
\hline 55 or Older $\ldots \ldots \ldots \ldots \ldots \ldots$ & 37 & 60 & $\mathbf{Q}$ & 43 & 51 & $\mathbf{Q}$ \\
\hline \multicolumn{7}{|l|}{ Education of Respondent } \\
\hline 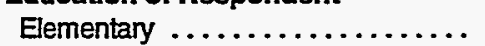 & $\mathbf{Q}$ & $\mathbf{Q}$ & NC & $\mathbf{Q}$ & $\mathbf{Q}$ & NC \\
\hline High School $\ldots . . \ldots \ldots \ldots \ldots$. & 33 & 63 & $\mathbf{Q}$ & 24 & 71 & $\mathbf{Q}$ \\
\hline College $\ldots \ldots \ldots \ldots \ldots \ldots \ldots$ & 41 & 59 & $\bar{Q}$ & 39 & 57 & $\mathbf{Q}$ \\
\hline Graduate School..$\ldots \ldots \ldots \ldots \ldots$ & $\ddot{Q}$ & $\mathbf{Q}$ & NC & 43 & 55 & $\mathbf{Q}$ \\
\hline \multicolumn{7}{|l|}{ Race } \\
\hline White $\ldots \ldots \ldots \ldots \ldots \ldots \ldots \ldots$ & 42 & 57 & Q & 35 & 61 & $\mathbf{Q}$ \\
\hline Black $\ldots \ldots \ldots \ldots \ldots \ldots \ldots \ldots$ & $\mathbf{Q}$ & $\mathbf{Q}$ & $\bar{Q}$ & $Q$ & $Q$ & $\mathbf{Q}$ \\
\hline Asian.$\ldots \ldots \ldots \ldots \ldots \ldots \ldots \ldots$ & NC & $\mathbf{Q}$ & $\mathrm{NC}$ & $\widehat{Q}$ & $\vec{Q}$ & NC \\
\hline Other,$\ldots \ldots \ldots \ldots \ldots \ldots \ldots \ldots \ldots$ & $\mathbf{Q}$ & $\mathbf{Q}$ & NC & $Q$ & $\hat{Q}$ & NC \\
\hline Household Income & & & & & & \\
\hline$\$ 30,000$ or Less . . . . . . . . . . . . . & 31 & 69 & $\mathbf{Q}$ & 25 & 75 & NC \\
\hline More than $\$ 30,000 \ldots \ldots \ldots \ldots$. & 41 & 57 & $\bar{Q}$ & 39 & 55 & $\mathbf{Q}$ \\
\hline \multicolumn{7}{|l|}{ Type of Housing Unit } \\
\hline Apartment...$\ldots \ldots \ldots \ldots \ldots$ & 32 & 68 & NC & $\mathbf{Q}$ & 85 & NC \\
\hline Single-Family Detached .......... & 38 & 60 & $Q$ & 42 & 54 & $\mathbf{Q}$ \\
\hline Townhouse ................ & $Q$ & $\mathbf{Q}$ & NC & $\mathbf{Q}$ & $Q$ & $\mathbf{Q}$ \\
\hline Other $\ldots \ldots \ldots \ldots \ldots \ldots \ldots \ldots$ & $\hat{Q}$ & 69 & NC & $\bar{Q}$ & 63 & $\mathbf{Q}$ \\
\hline \multicolumn{7}{|l|}{ Transportation Type Most Often } \\
\hline \multicolumn{7}{|l|}{ Used } \\
\hline Public Transportation ........... & $Q^{\prime}$ & $Q$ & NC & $\mathbf{Q}$ & $\mathbf{Q}$ & NC \\
\hline Personal Vehicies .............. & 41. & 59 & $\mathbf{Q}$ & 35 & 60 & $Q$ \\
\hline Both $\ldots \ldots \ldots \ldots \ldots \ldots \ldots$ & $Q$ & 76 & NC & $\mathbf{Q}$ & 74 & NC \\
\hline Don't Know ... & NC & $Q$ & NC & NC & $Q$ & NC \\
\hline
\end{tabular}

See footnotes at end of table. 
Table 4.4.16. Vehicle Choice When Consumer Must Drive 15 Minutes Out of the Way to Refuel the Modified Vehicle, the Modified Vehicle Must be Refueled Twice as Often as a Regular Vehicle, and the Modified Vehicle Has Half the Trunk/Cargo Space of a Regular Vehicle, 1994 (Continued) (Percent)

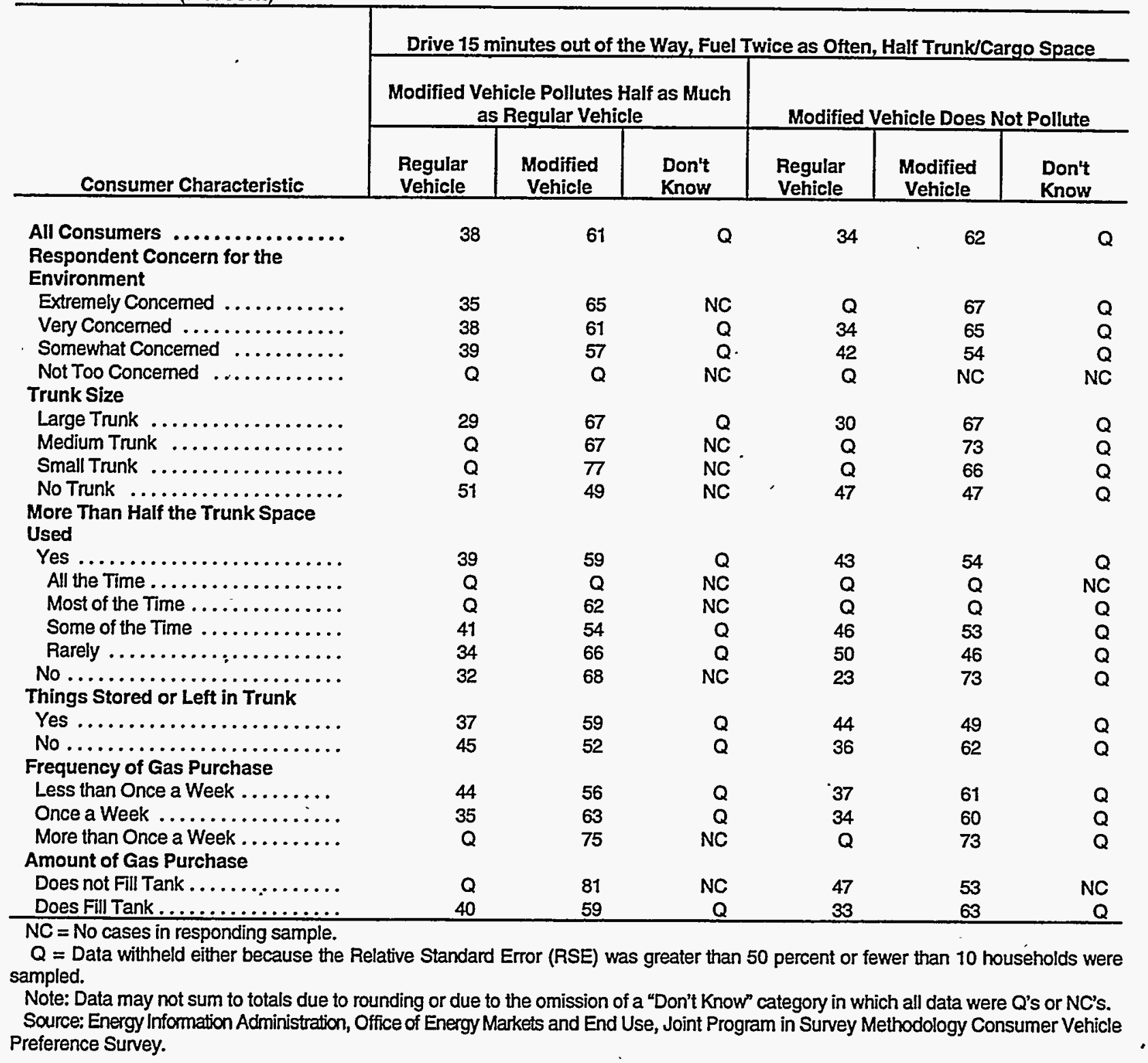





\subsection{Relative Standard Error Tables}


Table 4.5.1. Relative Standard Errors for Consumer Characteristics by Level of Concern for the Environment, 1994 (Percent)

\begin{tabular}{|c|c|c|c|c|c|c|}
\hline \multirow[b]{2}{*}{ Consumer Characteristic } & \multirow[b]{2}{*}{$\begin{array}{c}\text { All } \\
\text { Consumers }\end{array}$} & \multicolumn{5}{|c|}{ Level of Concern for Environment } \\
\hline & & $\begin{array}{l}\text { Extremely } \\
\text { Concerned }\end{array}$ & $\begin{array}{c}\text { Very } \\
\text { Concerned }\end{array}$ & $\begin{array}{l}\text { Somewhat } \\
\text { Concerned }\end{array}$ & & $\begin{array}{l}\text { Not Too } \\
\text { Concerned }\end{array}$ \\
\hline $\begin{array}{l}\text { Total . . ....................... } \\
\text { Census Region }\end{array}$ & 0 & 0 & 0 & 0 & 2 & 0 \\
\hline Northeast $\ldots \ldots \ldots \ldots \ldots \ldots \ldots \ldots$ & 13 & 30 & 24 & 23 & & 72 \\
\hline Midwest $. . . . . \ldots \ldots \ldots \ldots . . . . .$. & 9 & 32 & 22 & 16 & & 45 \\
\hline South $\ldots \ldots \ldots \ldots \ldots \ldots \ldots$ & 6 & 24 & 12 & 10 & & 33 \\
\hline West $\ldots \ldots \ldots \ldots \ldots \ldots \ldots \ldots \ldots$, & 13 & 34 & 17 & 27 & & 64 \\
\hline \multicolumn{7}{|l|}{ Sex of Respondent } \\
\hline Male $\ldots \ldots \ldots \ldots \ldots \ldots \ldots \ldots$ & 4 & 16 & 8, & 8 & & 19 \\
\hline Female $\ldots \ldots \ldots \ldots \ldots \ldots \ldots \ldots$ & 3 & 9 & 6 & 6 & & 21 \\
\hline \multicolumn{7}{|l|}{ Age of Main Driver } \\
\hline 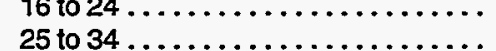 & $\begin{array}{l}34 \\
11\end{array}$ & $\begin{array}{r}137 \\
40\end{array}$ & $\begin{array}{l}58 \\
21\end{array}$ & $\begin{array}{l}55 \\
18\end{array}$ & & $\begin{array}{r}194 \\
48\end{array}$ \\
\hline 35 to $44 \ldots \ldots \ldots \ldots \ldots \ldots \ldots \ldots$ & 10 & 26 & 17 & 16 & & 75 \\
\hline 45 to $54 \ldots \ldots \ldots \ldots \ldots \ldots \ldots \ldots$ & 14 & 41 & 26 & 22 & & 77 \\
\hline 55 or Older $\ldots \ldots \ldots \ldots \ldots \ldots$ & 8 & 27 & 17 & 19 & & 35 \\
\hline \multicolumn{7}{|l|}{ Education of Respondent } \\
\hline Elementary .................. & 96 & 340 & 222 & 392 & & 479 \\
\hline High School $\ldots \ldots \ldots \ldots \ldots \ldots \ldots$ & 5 & 17 & 11 & 9 & & 17 \\
\hline College,$\ldots \ldots \ldots \ldots \ldots \ldots \ldots \ldots$ & 5 & 13 & 8 & 8 & & 37 \\
\hline Graduate School $\ldots \ldots \ldots \ldots \ldots \ldots$ & 22 & 73 & 32 & 39 & & 146 \\
\hline \multicolumn{7}{|l|}{ Race of Respondent } \\
\hline White $\ldots \ldots \ldots \ldots \ldots \ldots \ldots \ldots$ & 1 & 5 & 3 & 2 & & 7 \\
\hline Black $\ldots \ldots \ldots \ldots \ldots \ldots \ldots \ldots \ldots$ & 30 & 62 & 47 & 61 & & 209 \\
\hline Asian $\ldots \ldots \ldots \ldots \ldots \ldots \ldots \ldots \ldots$ & 140 & 621 & 202 & 344 & & 892 \\
\hline Other $, \ldots, \ldots, \ldots, \cdots, \cdots, \cdots, \cdots$ & 58 & 131 & 85 & 104 & & 147 \\
\hline Household Income & & & - & & & \\
\hline$\$ 30,000$ or Less $\ldots . . . \ldots \ldots \ldots$ & 7 & 22 & 14 & 13 & & 33 \\
\hline More than $\$ 30,000 \ldots \ldots \ldots \ldots \ldots$ & 2 & 7 & 4 & 4 & & 13 \\
\hline \multicolumn{7}{|l|}{$\begin{array}{l}\text { Perception of Relative Safety of } \\
\text { Fuels }\end{array}$} \\
\hline \multicolumn{7}{|l|}{ Natural Gas } \\
\hline Gasoline Safer . . . . . . . . . . . . . . & 8 & 31 & 15 & 15 & & $\pi 7$ \\
\hline Natural Gas Safer . . . . . . . . . . . . & 14 & 36 & 24 & 29 & & 72 \\
\hline No Difference ................ & 8 & 23 & 15 & 13 & & 39 \\
\hline Don't know . . . . . . . . . . . . . & 10 & 31 & 20 & 16 & & 33 \\
\hline \multicolumn{7}{|l|}{ Propane } \\
\hline Gasoline Safer & 5 & 17 & 10 & 8 & $!$ & 30 \\
\hline Propane Safer ............... & 23 & 54 & 40 & 46 & & 151 \\
\hline No Difference $\ldots \ldots \ldots \ldots \ldots \ldots \ldots$ & 8 & 28 & 14 & 16 & & 43 \\
\hline Don't know . . . . . . . . . . . . . & 12 & 38 & 26 & 21 & & 47 \\
\hline \multicolumn{7}{|l|}{ Electricity } \\
\hline Gasoline Safer & 21 & 57 & 51 & 36 & & 71 \\
\hline Electricity Safer . . . . . . . . . . . & 3 & 10 & 4 & 5 & & 19 \\
\hline No Difference $\ldots \ldots \ldots \ldots \ldots \ldots \ldots$ & 21 & 49 & 43 & 35 & & 111 \\
\hline Don't Know ............ & 18 & 56 & 46 & 31 & & 74 \\
\hline
\end{tabular}

See footnotes at end of table. 
Table 4.5.1. Relative Standard Errors for Consumer Characteristics by Level of Concern for the Environment, 1994 (Continued) (Percent)

\begin{tabular}{|c|c|c|c|c|c|}
\hline \multirow[b]{2}{*}{ Consumer Characteristic } & \multirow[b]{2}{*}{$\begin{array}{c}\text { All } \\
\text { Consumers }\end{array}$} & \multicolumn{4}{|c|}{ Level of Concern for the Environment } \\
\hline & & $\begin{array}{l}\text { Extremely } \\
\text { Concerned }\end{array}$ & $\begin{array}{c}\text { Very } \\
\text { Concerned }\end{array}$ & $\begin{array}{l}\text { Somewhat } \\
\text { Concerned }\end{array}$ & $\begin{array}{l}\text { Not Too } \\
\text { Concerned }\end{array}$ \\
\hline 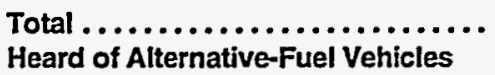 & 0 & 0 & 0 & 0 & 0 \\
\hline No $\ldots \ldots \ldots \ldots \ldots \ldots \ldots \ldots \ldots \ldots$ & 17 & 49 & 38 & 32 & 71 \\
\hline $\begin{array}{l}\text { Yes ........................... } \\
\text { How Much Heard About } \\
\text { Alternative-Fuel Vehicles }\end{array}$ & 1 & 4 & 2 & 2 & $\cdot$ \\
\hline Great Deal $\ldots \ldots \ldots \ldots \ldots \ldots \ldots$ & 9 & 17 & 13 & 22 & 59 \\
\hline Some $\ldots \ldots \ldots \ldots \ldots \ldots$ & .7 & 37 & 13 & 11 & 44 \\
\hline Little .................... & 6 & 22 & 15 & 9 & 25 \\
\hline $\begin{array}{l}\text { How Dangerous is Pollution Caused } \\
\text { by Motor Vehicles }\end{array}$ & & & & & \\
\hline Extremely..$\ldots \ldots \ldots \ldots \ldots \ldots$ & 9 & 9 & 13 & 31 & 63 \\
\hline Very $\ldots \ldots \ldots \ldots \ldots \ldots \ldots \ldots$ & 6 & 27 & 8 & 10 & 70 \\
\hline Somewhat ................ & 7 & 109 & 27 & 9 & 22 \\
\hline Not Very $\ldots \ldots \ldots \ldots \ldots \ldots \ldots$ & 52 & 380 & 278 & 193 & 175 \\
\hline Not at All $\ldots \ldots \ldots \ldots \ldots \ldots \ldots$ & 281 & NC & 2,686 & 1,134 & 486 \\
\hline $\begin{array}{l}\text { Don't Know ..................... } \\
\text { Are You an Environmentalist }\end{array}$ & 132 & 472 & 591 & 216 & 454 \\
\hline No $\ldots \ldots \ldots \ldots \ldots \ldots \ldots \ldots \ldots$ & 4 & 24 & 10 & 5 & 13 \\
\hline $\begin{array}{l}\text { Yes } \ldots \ldots \ldots \ldots \ldots \ldots \ldots \ldots \ldots \ldots \ldots \\
\text { Member of Environmental } \\
\text { Organization }\end{array}$ & 4 & 7 & 5 & 9 & . \\
\hline No $\ldots \ldots \ldots \ldots \ldots \ldots \ldots \ldots$ & 6 & 14 & 8 & 17 & $\mathbf{0}$ \\
\hline Yes $\ldots \ldots \ldots \ldots \ldots \ldots \ldots$ & 38 & 61 & 70 & 101 & NC \\
\hline
\end{tabular}

$\mathrm{NC}=$ No cases in responding sample.

Source: Energy Information Administration, Office of Energy Markets and End Use, Joint Program in Survey Methodology Consumer Vehicle Preference Survey. 
Table 4.5.2. Relative Standard Errors for Consumer Characteristics by Census Region, 1994 (Percent)

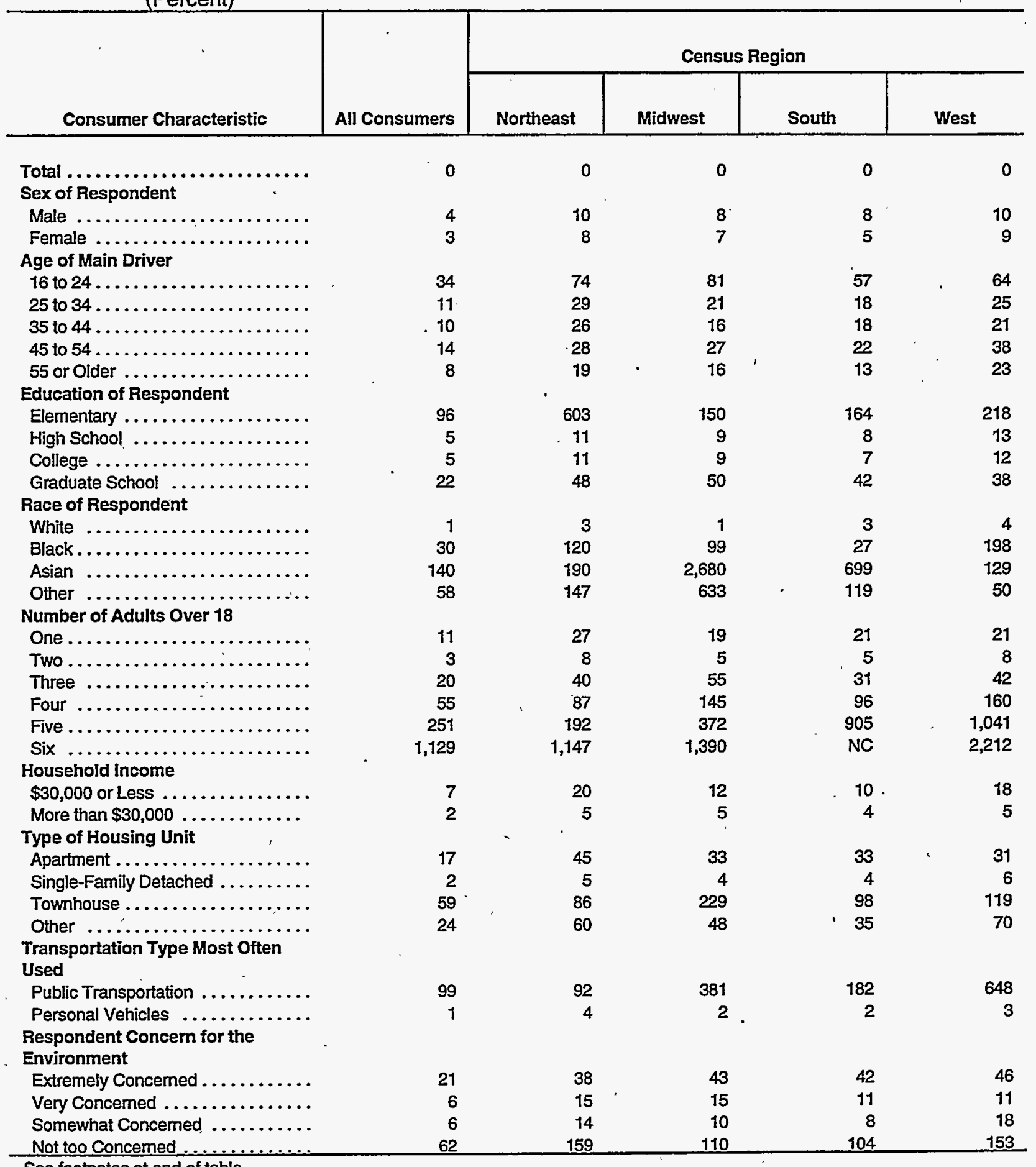


Table 4.5.2. Relative Standard Errors for Consumer Characteristics by Census Region, 1994 (Continued) (Percent)

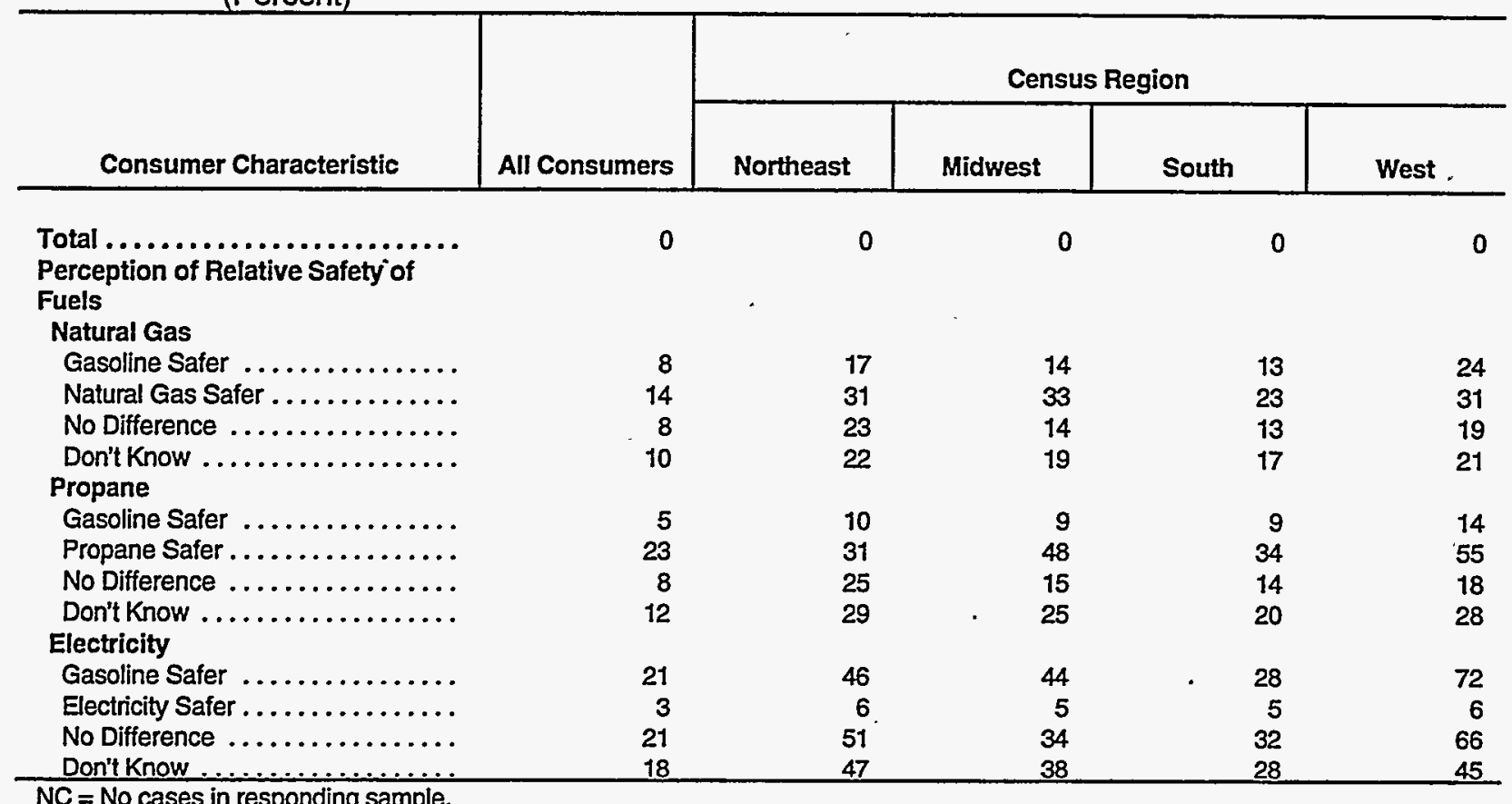

NC $=$ No cases in responding sample.

Source: Energy Information Administration, Office of Energy Markets and End Use, Joint Program in Survey Methodology Consumer Vehicle Preference Survey. 
Table 4.5.3. Relative Standard Errors for Vehicle Choice When Modified Vehicle Has Half the Trunk/Cargo Space of a Regular Vehicle, 1994

(Percent)

\begin{tabular}{|c|c|c|c|c|c|c|}
\hline \multirow[b]{3}{*}{ Consumer Characteristic } & \multicolumn{6}{|c|}{ Half Trunk/Cargo Space } \\
\hline & \multicolumn{3}{|c|}{$\begin{array}{c}\text { Modified Vehicle Pollutes Half as Much } \\
\text { as Regular Vehicle }\end{array}$} & \multicolumn{3}{|c|}{ Modified Vehicle Does Not Pollute } \\
\hline & $\begin{array}{l}\text { Regular } \\
\text { Vehicle }\end{array}$ & $\begin{array}{l}\text { Modified } \\
\text { Vehicle }\end{array}$ & $\begin{array}{l}\text { Don't } \\
\text { Know }\end{array}$ & $\begin{array}{l}\text { Regular } \\
\text { Vehicle }\end{array}$ & $\begin{array}{c}\text { Modified } \\
\text { Vehicle }\end{array}$ & $\begin{array}{l}\text { Don't } \\
\text { Know }\end{array}$ \\
\hline $\begin{array}{l}\text { All Consumers } \ldots \ldots \ldots \ldots \ldots \ldots \text {. } \\
\text { Region }\end{array}$ & 7 & 16 & 99 & 9 & 17 & 66 \\
\hline Northeast $\ldots \ldots \ldots \ldots \ldots \ldots$ & 27 & 28 & 125 & 27 & 36 & 152 \\
\hline Midwest $\ldots \ldots \ldots \ldots \ldots \ldots \ldots$ & 8 & 38 & 561 & 17 & 26 & 298 \\
\hline South $\ldots \ldots \ldots \ldots \ldots \ldots \ldots$ & 11. & 27 & 202 & 14 & 28 & 75 \\
\hline \multicolumn{7}{|l|}{ Number of Vehicles } \\
\hline One $\ldots \ldots \ldots \ldots \ldots \ldots \ldots$ & 10 & 35 & 121 & 12 & 32 & 76 \\
\hline Two $\ldots \ldots \ldots \ldots \ldots \ldots \ldots \ldots$ & 10 & 22 & 205 & 19 & 21 & 95 \\
\hline Three $\ldots \ldots \ldots \ldots \ldots \ldots \ldots$ & 28 & 32 & 298 & 20 & 41 & NC \\
\hline \multicolumn{7}{|l|}{ Sex of Respondent } \\
\hline 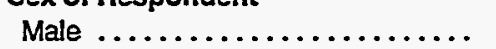 & 8 & 27 & 188 & 12 & 27 & 115 \\
\hline $\begin{array}{l}\text { Female } \ldots \ldots \ldots \ldots \ldots \ldots \ldots \ldots \\
\text { Age of Main Driver }\end{array}$ & 11 & 20 & 113 & 13 & 21 & 80 \\
\hline 16 to $24 \ldots \ldots \ldots \ldots \ldots \ldots$ & 28 & 48 & NC & 40 & 63 & NC \\
\hline 25 to $34 \ldots \ldots \ldots \ldots \ldots \ldots \ldots$ & 23 & 23 & 274 & 20 & 32 & 693 \\
\hline 35 to $44 \ldots \ldots \ldots \ldots \ldots \ldots \ldots$ & 19 & 31 & 150 & 20 & 30 & 262 \\
\hline 45 to $54 \ldots \ldots \ldots \ldots \ldots \ldots \ldots$ & 12 & 50 & 760 & 25 & 32 & 169 \\
\hline 55 or Older $\ldots \ldots \ldots \ldots \ldots \ldots \ldots$ & 9 & 40 & 120 & 13 & 39 & 58 \\
\hline \multicolumn{7}{|l|}{ Education of Respondent } \\
\hline Elementary $\ldots \ldots \ldots \ldots \ldots \ldots$ & 46 & 104 & 132 & 49 & 350 & 80 \\
\hline High School,$\ldots \ldots \ldots \ldots \ldots \ldots$ & 9 & 25 & 163 & 12 & 26 & 137 \\
\hline College $\ldots \ldots \ldots \ldots \ldots \ldots \ldots$ & 14 & 23 & 137 & 14 & 22 & 89 \\
\hline Graduate School...$\ldots \ldots \ldots \ldots$ & 14 & 65 & NC & 28 & 53 & 528 \\
\hline \multicolumn{7}{|l|}{ Race of Respondent } \\
\hline White $\ldots \ldots \ldots \ldots \ldots \ldots \ldots$ & 7 & 18 & 102 & 10 & 17 & 66 \\
\hline Black $\ldots \ldots \ldots \ldots \ldots \ldots \ldots$ & 21 & 47 & NC & 19 & 74 & 567 \\
\hline Asian $\ldots \ldots \ldots \ldots \ldots \ldots \ldots$ & NC & 0 & NC & 30 & 459 & 259 \\
\hline $\begin{array}{l}\text { Other } \ldots \ldots \ldots \ldots \ldots \ldots \ldots \\
\text { Household Income }\end{array}$ & 34 & 182 & 205 & 72 & 89 & NC \\
\hline$\$ 30,000$ or Less . ............... & 10 & 33 & 116 & 14 & 27 & 102 \\
\hline More than $\$ 30,000 \ldots \ldots \ldots \ldots$ & 9 & 18 & 166 & 11 & 21 & 87 \\
\hline \multicolumn{7}{|l|}{ Type of Housing Unit } \\
\hline Apartment $\ldots \ldots \ldots \ldots \ldots \ldots$ & 25 & 38 & 319 & 32 & 36 & 284 \\
\hline Single-Family Detached .......... & 7 & 21 & 121 & 9 & 19 & 100 \\
\hline Townhouse $\ldots \ldots \ldots \ldots \ldots \ldots$ & 116 & 28 & 373 & 62 & NC & 69 \\
\hline Other $\ldots \ldots \ldots \ldots \ldots \ldots \ldots \ldots$ & 19 & 64 & 260 & 63 & 48 & 81 \\
\hline \multicolumn{7}{|l|}{$\begin{array}{l}\text { Transportation Type Most Often } \\
\text { Used }\end{array}$} \\
\hline Public Transportation ............ & 48 & 153 & NC & 63 & 80 & 268 \\
\hline Personal Vehicles ............ & 8 & 18 & 115 & 10 & 21 & 68 \\
\hline Both $\ldots \ldots \ldots \ldots \ldots \ldots$ & 31 & 116 & 197 & 61 & 52 & NC \\
\hline Neither $\ldots \ldots \ldots \ldots \ldots \ldots \ldots \ldots$ & NC & 0 & NC & 0 & NC & NC \\
\hline Don't Know ... & 180 & 50 & NC & 44 & 259 & 166 \\
\hline
\end{tabular}

See footnotes at end of table. 
Table 4.5.3. Relative Standard Errors for Vehicle Choice When Modified Vehicle Has Half the Trunk/Cargo Space of a Regular Vehicle, 1994 (Continued) (Percent)

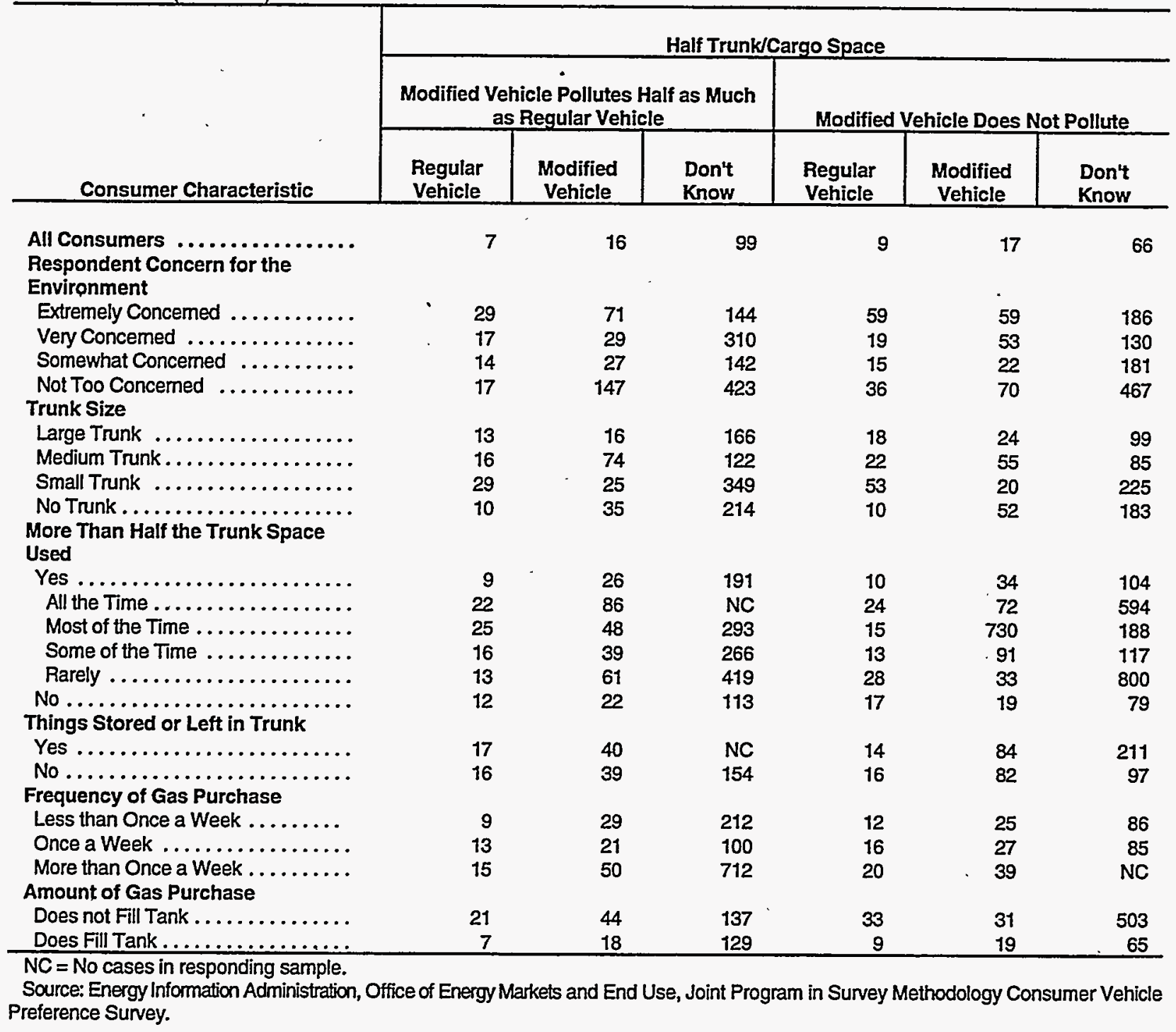


Table 4.5.4. Relative Standard Errors for Vehicle Choice When Modified Vehicle Has Half the Trunk/Cargo Space of a Regular Vehicle and the Modified Vehicle Costs $\$ 1,000$ More, 1994 (Percent)

\begin{tabular}{|c|c|c|c|c|c|c|}
\hline \multirow[b]{3}{*}{ Consumer Characteristic } & \multicolumn{6}{|c|}{ Half Trunk/Cargo Space and Costs $\$ 1,000$ More } \\
\hline & \multicolumn{3}{|c|}{$\begin{array}{c}\text { Modified Vehicle Pollutes Half as Much } \\
\text { as Regular Vehicle }\end{array}$} & \multicolumn{3}{|c|}{ Modified Yehicle Does Not Pollute } \\
\hline & $\begin{array}{l}\text { Regular } \\
\text { Vehicle } \\
\end{array}$ & $\begin{array}{c}\text { Modified } \\
\text { Vehicle }\end{array}$ & $\begin{array}{l}\text { Don't } \\
\text { Know }\end{array}$ & $\begin{array}{l}\text { Regular } \\
\text { Vehicle }\end{array}$ & $\begin{array}{c}\text { Modified } \\
\text { Vehicle }\end{array}$ & $\begin{array}{l}\text { Don't } \\
\text { Know }\end{array}$ \\
\hline $\begin{array}{l}\text { All Consumers } \ldots \ldots \ldots \ldots \ldots \ldots \ldots \\
\text { Region }\end{array}$ & 10 & 39 & 163 & 10 & 40 & 236 \\
\hline Northeast.$\ldots \ldots \ldots \ldots \ldots \ldots$ & 12 & 235 & 303 & 27 & 75 & NC \\
\hline Midwest $\ldots \ldots \ldots \ldots \ldots \ldots \ldots$ & 20 & 74 & 262 & 18 & 57 & NC \\
\hline South $\ldots \ldots \ldots \ldots \ldots \ldots \ldots$ & 18 & 57 & 217 & 16 & 97 & 135 \\
\hline \multicolumn{7}{|l|}{ Number of Vehicles } \\
\hline One $\ldots \ldots \ldots \ldots \ldots \ldots \ldots \ldots$ & 15 & 117 & 181 & 11 & 118 & 350 \\
\hline Two $\ldots . . \ldots \ldots \ldots \ldots \ldots \ldots$ & 14 & 51 & 224 & 16 & 56 & 401 \\
\hline Three $\ldots \ldots \ldots \ldots \ldots \ldots \ldots$ & 22 & 82 & NC & 18 & 129 & NC \\
\hline \multicolumn{6}{|l|}{ Sex of Respondent } & 300 \\
\hline Male $\ldots \ldots \ldots \ldots \ldots \ldots \ldots$ & 18 & 38 & 420 & 22 & 43 & 244 \\
\hline \multicolumn{7}{|l|}{ Age of Main Driver } \\
\hline 16 to $24 \ldots \ldots \ldots \ldots \ldots \ldots \ldots$ & 20 & 496 & 288 & 28 & 225 & NC \\
\hline 25 to $34 \ldots \ldots \ldots \ldots \ldots \ldots \ldots$ & 10 & 187 & 533 & 28 & 50 & NC \\
\hline 35 to $44 \ldots \ldots \ldots \ldots \ldots \ldots \ldots$ & 25 & 54 & 511 & 19 & 114 & 272 \\
\hline 45 to $54 \ldots \ldots \ldots \ldots \ldots \ldots \ldots$ & 45 & 51 & 398 & 14 & 134 & NC \\
\hline \multicolumn{7}{|l|}{ Education of Respondent } \\
\hline Elementary...$\ldots \ldots \ldots$ & 36 & 204 & NC & NC & 0 & NC \\
\hline High School ................ & 14 & 70 & 133 & 12 & 89 & 771 \\
\hline College...$\ldots \ldots \ldots \ldots \ldots \ldots$ & 15 & 54 & 676 & 15 & 51 & 273 \\
\hline Graduate School $\ldots \ldots \ldots \ldots \ldots$ & 36 & 85 & NC & 44 & 115 & 329 \\
\hline \multicolumn{7}{|l|}{ Race of Respondent } \\
\hline White $\ldots \ldots \ldots \ldots \ldots \ldots \ldots \ldots$ & 10 & 47 & 182 & 11 & 39 & 222 \\
\hline 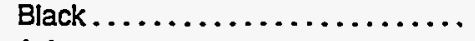 & 63 & 57 & 312 & 0 & NC & NC \\
\hline Asian $\ldots \ldots \ldots \ldots \ldots \ldots \ldots$ & 0 & NC & NC & NC & 0 & NC \\
\hline $\begin{array}{l}\text { Other } \ldots \ldots \ldots \ldots \ldots \ldots \ldots \ldots \\
\text { Household Income }\end{array}$ & 96 & 133 & NC & 0 & NC & NC \\
\hline$\$ 30,000$ or Less $\ldots \ldots \ldots \ldots \ldots \ldots$ & 16 & 75 & 248 & 7 & 158 & NC \\
\hline More than $\$ 30,000 \ldots \ldots \ldots \ldots$ & 12 & 45 & 217 & 18 & 35 & 180 \\
\hline \multicolumn{7}{|l|}{ Type of Housing Unit } \\
\hline Apartment .................. & 15 & 348 & 398 & 8 & NC & 483 \\
\hline Single-Family Detached ......... & 14 & 34 & 194 & 15 & 32 & 250 \\
\hline Townhouse ................ & 0 & NC & NC & NC & NC & NC \\
\hline Other $\ldots \ldots \ldots \ldots \ldots \ldots \ldots \ldots$ & 37 & 146 & 304 & 0 & NC & NC \\
\hline \multicolumn{7}{|l|}{$\begin{array}{l}\text { Transportation Type Most Often } \\
\text { Used }\end{array}$} \\
\hline Public Transportation ........... & 0 & NC & NC & 54 & 168 & NC \\
\hline Personal Vehicles...$\ldots \ldots \ldots$. & 11 & 46 & 165 & 9 & 61 & 490 \\
\hline Both $\ldots \ldots \ldots \ldots \ldots \ldots \ldots \ldots \ldots$ & 0 & NC & NC & 69 & 93 & NC \\
\hline Neither ................... & 0 & NC & NC & NC & NC & NC \\
\hline Don't know . . . . . . . . . . . . . . . & $\underline{0}$ & NC & NC & 0 & NC & NC \\
\hline
\end{tabular}

See footnotes at end of table. 
Table 4.5.4. Relative Standard Errors for Vehicle Choice When Modified Vehicle Has Half the Trunk/Cargo Space of a Regular Vehicle and the Modified Vehicle Costs $\$ 1,000$ More, 1994 (Continued) (Percent)

\begin{tabular}{|c|c|c|c|c|c|c|}
\hline \multirow[b]{3}{*}{ Consumer Characteristic } & \multicolumn{6}{|c|}{ Half Trunk/Cargo Space and Costs $\$ 1,000$ More } \\
\hline & \multicolumn{3}{|c|}{$\begin{array}{c}\text { Modified Vehicle Pollutes Half as Much } \\
\text { as Regular Vehicle }\end{array}$} & \multicolumn{3}{|c|}{ Modified Vehicle Does Not Pollute } \\
\hline & $\begin{array}{l}\text { Regular } \\
\text { Vehicle } \\
\end{array}$ & $\begin{array}{c}\text { Modified } \\
\text { Vehicle }\end{array}$ & $\begin{array}{l}\text { Don't } \\
\text { Know }\end{array}$ & $\begin{array}{l}\text { Regular } \\
\text { Vehicle }\end{array}$ & $\begin{array}{c}\text { Modified } \\
\text { Vehicle }\end{array}$ & $\begin{array}{l}\text { Don't } \\
\text { Know }\end{array}$ \\
\hline $\begin{array}{l}\text { All Consumers } \ldots \ldots \ldots \ldots \ldots \ldots \ldots \\
\text { Respondent Concern for the } \\
\text { Environment }\end{array}$ & 10 & 39 & 163 & 10 & 40 & 236 \\
\hline Extremely Concemed ........... & 50 & 91 & NC & $\dot{0}$ & NC & NC \\
\hline Very Concemed .............. & 28 & 56 & 279 & 29 & 109 & 447 \\
\hline Somewhat Concemed $\ldots \ldots \ldots \ldots$ & 18 & 62 & 209 & 17 & 54 & 248 \\
\hline Not Too Concerned..$\ldots \ldots \ldots \ldots$ & 194 & 177 & 123 & 228 & 32 & NC \\
\hline \multicolumn{7}{|l|}{ Trunk Size } \\
\hline Large Trunk ............... & 17 & 47 & 685 & 20 & 46 & 376 \\
\hline Medium Trunk . . . . . . . . . . . & 23 & NC & 146 & 33 & 99 & 415 \\
\hline Small Trunk $\ldots \ldots \ldots \ldots \ldots \ldots$ & 24 & 74 & 470 & 22 & 89 & 274 \\
\hline \multicolumn{6}{|l|}{$\begin{array}{l}\text { More Inan Halt the Irunk Space } \\
\text { Used }\end{array}$} & NC \\
\hline Yes...$\ldots \ldots \ldots \ldots \ldots \ldots \ldots$ & 16 & 56 & 186 & 22 & 48 & 352 \\
\hline All the Time ................ & 31 & 236 & NC & 0 & NC & NC \\
\hline Most of the Time ............. & 36 & 151 & 185 & NC & 0 & 336 \\
\hline Some of the Time ............ & 25 & 101 & 232 & 58 & 78 & 505 \\
\hline 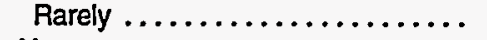 & 38 & 63 & NC & 47 & 47 & NC \\
\hline $\begin{array}{l}\text { No } \ldots \ldots \ldots \ldots \ldots \ldots \ldots \\
\text { Things Stored or Left in Trunk }\end{array}$ & 12 & 71 & 267 & 12 & 58 & 433 \\
\hline Yes...$\ldots \ldots \ldots \ldots \ldots \ldots \ldots$ & 17 & 130 & NC & 22 & 170 & NC \\
\hline $\begin{array}{l}\text { No } \ldots \ldots \ldots \ldots \ldots \ldots \ldots \ldots \ldots \ldots \\
\text { Frequency of Gas Purchase }\end{array}$ & 32 & 101 & 110 & 35 & 131 & 352 \\
\hline Less than Once a Week ......... & 11 & 95 & 261 & 18 & 41 & 402 \\
\hline Once a Week ................ & 15 & 53 & 259 & 10 & 165 & 368 \\
\hline More than Once a Week .......... & 50 & 53 & 345 & 32 & $\pi$ & 453 \\
\hline Amount of Gas Purchase & & & & & & \\
\hline Does not Fill Tank . ............. & 10 & 39 & 375 & 14 & 343 & 448 \\
\hline Does Fill Tank ................. & 44 & 173 & 78 & 12 & 38 & 273 \\
\hline
\end{tabular}


Table 4.5.5. Relative Standard Errors for Vehicle Choice When Modified Vehicle Has Half the Trunk/Cargo Space of a Regular Vehicle and the Modified Vehicle Costs $\$ 1,000$ Less, 1994 (Percent)

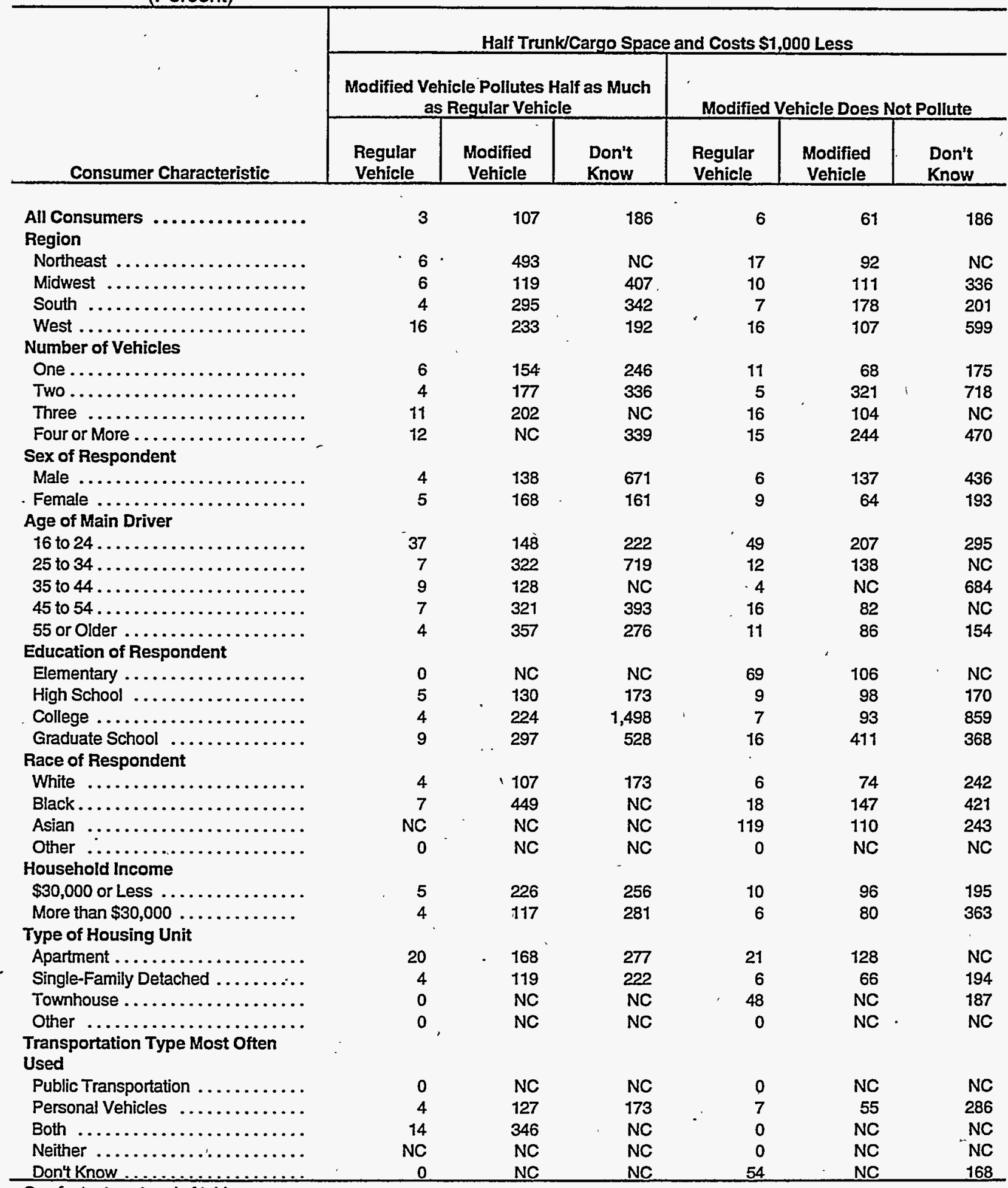

See footnotes at end of table. 
Table 4.5.5. Relative Standard Errors for Vehicle Choice When Modified Vehicle Has Half the Trunk/Cargo Space of a Regular Vehicle and the Modified Vehicle Costs $\$ 1,000$ Less, 1994 (Continued) (Percent)

\begin{tabular}{|c|c|c|c|c|c|c|}
\hline \multirow[b]{3}{*}{ Consumer Characteristic } & \multicolumn{6}{|c|}{ Half Trunk/Cargo Space and Costs $\$ 1,000$ Less } \\
\hline & \multicolumn{3}{|c|}{$\begin{array}{l}\text { Modified Vehicle Pollutes Half as Much } \\
\text { as Regular Vehicle }\end{array}$} & \multicolumn{3}{|c|}{ Modified Vehicle Does Not Pollute } \\
\hline & $\begin{array}{l}\text { Regular } \\
\text { Vehicle } \\
\end{array}$ & $\begin{array}{l}\text { Modified } \\
\text { Vehicle }\end{array}$ & $\begin{array}{l}\text { Don't } \\
\text { Know }\end{array}$ & $\begin{array}{l}\text { Regular } \\
\text { Vehicle }\end{array}$ & $\begin{array}{l}\text { Modified } \\
\text { Vehicle }\end{array}$ & $\begin{array}{l}\text { Don't } \\
\text { Know }\end{array}$ \\
\hline $\begin{array}{l}\text { All Consumers .................. } \\
\text { Respondent Concern for the } \\
\text { Environment }\end{array}$ & 3 & 107 & 186 & 6 & 61 & 186 \\
\hline Extremely Concemed ........... & 11 & 375 & NC & 34 & 186 & NC \\
\hline Very Concemed.$\ldots \ldots \ldots \ldots \ldots$ & 7 & 178 & NC & 18 & 101 & 266 \\
\hline Somewhat Concemed .......... & 9 & 214 & 144 & 6 & 176 & 946 \\
\hline $\begin{array}{l}\text { Not Too Concemed } \ldots \ldots \ldots \ldots \ldots \\
\text { Trunk Size }\end{array}$ & 0 & NC & NC & 26 & 347 & 280 \\
\hline Large Trunk $\ldots \ldots \ldots \ldots \ldots \ldots$ & 6 & 161 & 538 & 12 & 112 & 167 \\
\hline Medium Trunk $\ldots \ldots \ldots \ldots \ldots \ldots$ & 9 & 190 & 674 & 15 & 97 & NC \\
\hline 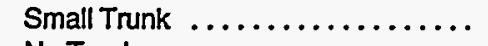 & 10 & 538 & 288 & 11 & NC & 368 \\
\hline $\begin{array}{l}\text { No Trunk } \ldots \ldots \ldots \ldots \ldots \ldots \ldots \\
\text { More Than Half the Trunk Space } \\
\text { Used }\end{array}$ & 5 & 346 & 227 & 7 & 103 & NC \\
\hline Yes...$\ldots \ldots \ldots \ldots \ldots \ldots \ldots$ & 5 & 171 & 229 & 8 & 74 & 477 \\
\hline All the Time $\ldots \ldots \ldots \ldots \ldots \ldots$ & 13 & NC & 317 & 16 & NC & 184 \\
\hline Most of the Time..$\ldots \ldots \ldots \ldots$ & 11 & 324 & NC & 38 & 56 & NC \\
\hline Some of the Time ............ & 8 & 345 & 213 & 10 & 125 & NC \\
\hline Rarely $\ldots \ldots \ldots \ldots \ldots \ldots \ldots$ & 7 & 216 & NC & 12 & 207 & NC \\
\hline $\begin{array}{l}\text { No ............................... } \\
\text { Things Stored or Left in Trunk }\end{array}$ & 6 & 167 & 276 & 9 & 128 & 195 \\
\hline 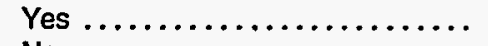 & 10 & 228 & 581 & 11 & 154 & 620 \\
\hline No $\ldots \ldots \ldots \ldots \ldots \ldots \ldots \ldots$ & 7 & 907 & 209 & 15 & 84 & 551 \\
\hline Frequency of Gas Purchase & & & & & & \\
\hline Less than Once a Week ......... & 4 & 552 & 175 & 7 & 110 & 309 \\
\hline Once a Week ................ & 5 & 158 & 461 & 10 & 121 & 189 \\
\hline More than Once a Week . .......... & 14 & 85 & NC & 18 & 76 & NC \\
\hline Amount of Gas Purchase & & & & & & \\
\hline Does not Fill Tank ............... & 16 & 122 & 322 & 20 & 110 & NC \\
\hline Does Fill Tank . . . . . . . . . . . . . & 3 & 146 & 233 & 6 & 70 & 177 \\
\hline
\end{tabular}


Table 4.5.6. Relative Standard Errors for Vehicle Choice When Consumer Must Drive 15 Minutes Out of the Way to Refuel the Modified Vehicle, 1994 (Percent)

\begin{tabular}{|c|c|c|c|c|c|c|}
\hline \multirow[b]{3}{*}{ Consumer Characteristic } & \multicolumn{6}{|c|}{ Consumer Must Drive 15 Minutes Out of the Way to Buy Fuel } \\
\hline & \multicolumn{3}{|c|}{$\begin{array}{c}\text { Modified Vehicle Pollutes Half as Much } \\
\text { as Regular Vehicle }\end{array}$} & \multicolumn{3}{|c|}{ Modified Vehicle Does Not Pollute } \\
\hline & $\begin{array}{l}\text { Regular } \\
\text { Vehicle }\end{array}$ & $\begin{array}{l}\text { Modified } \\
\text { Vehicle }\end{array}$ & $\begin{array}{l}\text { Don't } \\
\text { Know }\end{array}$ & $\begin{array}{l}\text { Regular } \\
\text { Vehicle } \\
\end{array}$ & $\begin{array}{l}\text { Modified } \\
\text { Vehicle }\end{array}$ & $\begin{array}{l}\text { Don't } \\
\text { Know }\end{array}$ \\
\hline $\begin{array}{l}\text { All Consiumers } \ldots \ldots \ldots \ldots \ldots \ldots \ldots \\
\text { Region }\end{array}$ & 5 & 7 & 96 & 7 & 6 & 70 \\
\hline Northeast $\ldots \ldots \ldots \ldots \ldots \ldots \ldots$ & 11 & 19 & 204 & 17 & 11 & 166 \\
\hline Midwest $\ldots \ldots \ldots \ldots \ldots \ldots \ldots$ & 8 & 14 & 180 & 11 & 13 & 179 \\
\hline South $\ldots \ldots \ldots \ldots \ldots \ldots \ldots$ & 9 & 11 & 131 & 10 & 11 & 80 \\
\hline \multicolumn{7}{|l|}{ Number of Vehicles } \\
\hline One $\ldots \ldots \ldots \ldots \ldots \ldots \ldots$ & 9 & 12 & 109 & 11 & 8 & 87 \\
\hline Two ..................... & 6 & 12 & 202 & 10 & 9 & 111 \\
\hline Three $\ldots \ldots \ldots \ldots \ldots \ldots \ldots \ldots$ & 16 & 16 & 396 & 18 & 14 & 374 \\
\hline Four or More $\ldots \ldots \ldots \ldots \ldots \ldots$ & 23 & 20 & 360 & 21 & 21 & 994 \\
\hline \multicolumn{7}{|l|}{ Sex of Respondent } \\
\hline Male $\ldots \ldots \ldots \ldots \ldots \ldots \ldots$ & 6 & 11 & 244 & 10 & 7 & 172 \\
\hline $\begin{array}{l}\text { Female } \ldots \ldots \ldots \ldots \ldots \ldots \ldots \ldots \\
\text { Age of Main Driver }\end{array}$ & 7 & 9 & 96 & 9 & 8 & 71 \\
\hline 16 to $24 \ldots \ldots \ldots \ldots \ldots \ldots \ldots$ & 20 & 19 & 327 & 33 & 20 & 184 \\
\hline 25 to $34 \ldots \ldots \ldots \ldots \ldots \ldots \ldots$ & 10 & 14 & 366 & 14 & 12 & 223 \\
\hline 35 to $44 \ldots \ldots \ldots \ldots \ldots \ldots \ldots \ldots$ & 10 & 13 & 280 & 15 & 9 & 238 \\
\hline 45 to $54 \ldots \ldots \ldots \ldots \ldots \ldots \ldots$ & 11 & 17 & 348 & 14 & 13 & 184 \\
\hline 55 or Older $\ldots \ldots \ldots \ldots \ldots \ldots$ & 8 & 19 & 98 & 11 & 12 & 85 \\
\hline \multicolumn{7}{|l|}{ Education of Respondent } \\
\hline Elementary .................. & 20 & 64 & 586 & 51 & 62 & 74 \\
\hline High School $\ldots \ldots \ldots \ldots \ldots \ldots$ & 7 & 12 & 117 & 9 & 10 & 139 \\
\hline College $\ldots \ldots \ldots \ldots \ldots \ldots \ldots$ & 8 & 10 & 170 & 10 & 8 & 96 \\
\hline Graduate School $\ldots \ldots \ldots \ldots \ldots \ldots$ & 14 & 22 & 490 & 26 & 11 & 367 \\
\hline \multicolumn{7}{|l|}{ Race of Respondent } \\
\hline White $\ldots \ldots \ldots \ldots \ldots \ldots \ldots$ & 5 & 8 & 96 & 7 & 6 & 82 \\
\hline Black ................... & 19 & 21 & 558 & 20 & 20 & 214 \\
\hline Asian...$\ldots \ldots \ldots \ldots \ldots$ & 32 & 57 & NC & 48 & . 49 & 163 \\
\hline $\begin{array}{l}\text { Other } \ldots \ldots \ldots \ldots \ldots \ldots \ldots \ldots \\
\text { Household Income }\end{array}$ & 27 & 26 & 734 & 31 & 30 & 310 \\
\hline$\$ 30,000$ or Less $\ldots \ldots \ldots \ldots \ldots$ & 9 & 12 & 127 & 11 & 10 & 84 \\
\hline More than $\$ 30,000 \ldots \ldots \ldots \ldots$ & 6 & 9 & 139 & 8 & 7 & 111 \\
\hline \multicolumn{7}{|l|}{ Type of Housing Unit } \\
\hline Apartment $\ldots \ldots \ldots \ldots \ldots \ldots$ & 16 & 16 & 223 & 23 & 12 & 141 \\
\hline Single-Family Detached . . . . . . . . & 5 & 9 & 110 & 7 & 7 & 104 \\
\hline Townhouse $\ldots \ldots \ldots \ldots \ldots \ldots$ & 27 & 35 & 655 & 38 & 19 & 870 \\
\hline Other $\ldots \ldots \ldots \ldots \ldots \ldots \ldots \ldots$ & 18 & 17 & 445 & 34 & 13 & 99 \\
\hline \multicolumn{7}{|l|}{$\begin{array}{l}\text { Transportation Type Most Often } \\
\text { Used }\end{array}$} \\
\hline Public Transportation ............ & 47 & 48 & 407 & 41 & 25 & 555 \\
\hline Personal Vehicles ............ & 5 & 9 & 130 & 7 & 7 & 82 \\
\hline Both $\ldots \ldots \ldots \ldots \ldots \ldots \ldots$ & 21 & 25 & 409 & 36 & 17 & 232 \\
\hline Neither $\ldots \ldots \ldots \ldots \ldots \ldots \ldots$ & 0 & NC & NC & 0 & NC & NC \\
\hline Don't Know ... & 70 & 74 & 252 & 70 & 43 & 218 \\
\hline
\end{tabular}

See footnotes at end of table. 
Table 4.5.6. Relative Standard Errors for Vehicle Choice When Consumer Must Drive 15 Minutes Out of the Way to Refuel the Modified Vehicle, 1994 (Continued) (Percent)

\begin{tabular}{|c|c|c|c|c|c|c|}
\hline \multirow[b]{3}{*}{ Consumer Characteristic } & \multicolumn{6}{|c|}{ Consumer Must Drive 15 Minutes Out of the Way to Buy Fuel } \\
\hline & \multicolumn{3}{|c|}{$\begin{array}{c}\text { Modified Vehicle Pollutes Half as Much } \\
\text { as Regular Vehicle }\end{array}$} & \multicolumn{3}{|c|}{$\begin{array}{l}- \\
\text { Modified Vehicle Does Not Pollute }\end{array}$} \\
\hline & $\begin{array}{l}\text { Regular } \\
\text { Vehicle } \\
\end{array}$ & $\begin{array}{l}\text { Modified } \\
\text { Vehicle }\end{array}$ & $\begin{array}{l}\text { Don't } \\
\text { Know }\end{array}$ & $\begin{array}{l}\text { Regular } \\
\text { Vehicle } \\
\end{array}$ & $\begin{array}{l}\text { Modified } \\
\text { Vehicle } \\
\end{array}$ & $\begin{array}{l}\text { Don't } \\
\text { Know } \\
\end{array}$ \\
\hline $\begin{array}{l}\text { All Consumers } \ldots \ldots \ldots \ldots \ldots \ldots \\
\text { Respondent Concern for the } \\
\text { Environment }\end{array}$ & 5 & 7 & 96 & 7 & 6 & 70 \\
\hline Extremely Concemed ........... & 26 & 15 & 164 & 36 & 10 & 275 \\
\hline Very Concemed .............. & 11 & 11 & 232 & 16 & 8 & 143 \\
\hline Somewhat Concemed .......... & 8 & 13 & 242 & 10 & 11 & 135 \\
\hline Not Too Concerned ............. & 18 & 53 & 300 & 26 & 34 & NC \\
\hline Frequency of Gas Purchase & & & & & & \\
\hline Less than Once a Week ......... & 7 & 12 & 138 & 9 & 8 & 153 \\
\hline Once a Week ................. & 8 & 11 & 138 & 11 & 8 & 92 \\
\hline $\begin{array}{l}\text { More than Once a Week .......... } \\
\text { Amount of Gas Purchase }\end{array}$ & 14 & 17 & 409 & 17 & 16 & 132 \\
\hline Does not Fill Tank . . . . . . . . . . . . . & 11 & 22 & 316 & 21 & 15 & 165 \\
\hline Does Fill Tank . . . . . . . . . . . . . & 5 & 8 & 100 & 7 & 6 & $\pi$ \\
\hline
\end{tabular}

$\mathrm{NC}=$ No cases in responding sample.

Source: Energy Information Administration, Office of Energy Markets and End Use, Joint Program in Survey Methodology Consumer Vehicle Preference Survey. 
Table 4.5.7. Relative Standard Errors for Vehicle Choice When Consumer Must Drive 15 Minutes Out of the Way to Refuel the Modified Vehicle and the Modified Vehicle Costs $\$ 1,000$ More, 1994

(Percent)

\begin{tabular}{|c|c|c|c|c|c|c|}
\hline \multirow[b]{3}{*}{ Consumer Characteristic } & \multicolumn{6}{|c|}{ Drive 15 Minutes Out of the Way for Fuel and Modified Vehicle Costs $\$ 1,000$ More } \\
\hline & \multicolumn{3}{|c|}{$\begin{array}{c}\text { Modified Vehicle Pollutes Half as Much } \\
\text { as Regular Vehicle }\end{array}$} & \multicolumn{3}{|c|}{ Modified Vehicle Does Not Pollute } \\
\hline & $\begin{array}{l}\text { Regular } \\
\text { Vehicle }\end{array}$ & \multirow{2}{*}{$\begin{array}{r}\begin{array}{c}\text { Modified } \\
\text { Vehicle }\end{array} \\
8\end{array}$} & \multirow{2}{*}{$\begin{array}{r}\begin{array}{r}\text { Don't } \\
\text { Know }\end{array} \\
95\end{array}$} & \multirow{2}{*}{$\begin{array}{r}\begin{array}{l}\text { Regular } \\
\text { Vehicle }\end{array} \\
14\end{array}$} & \multirow{2}{*}{$\begin{array}{r}\begin{array}{c}\text { Modified } \\
\text { Vehicle }\end{array} \\
6\end{array}$} & \multirow{2}{*}{$\begin{array}{r}\begin{array}{r}\text { Don't } \\
\text { Know }\end{array} \\
91\end{array}$} \\
\hline $\begin{array}{l}\text { All Consumers } \ldots \ldots \ldots \ldots \ldots \ldots \ldots \\
\text { Reqion }\end{array}$ & 12 & & & & & \\
\hline Northeast. ................ & 23 & 25 & 187 & 37 & 11 & 163 \\
\hline 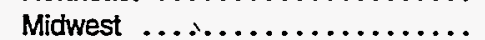 & 24 & 15 & 91 & 27 & 12 & 242 \\
\hline South $\ldots \ldots \ldots \ldots \ldots \ldots \ldots$ & 17 & 12 & 301 & 22 & 10 & 140 \\
\hline West $\ldots \ldots \ldots \ldots \ldots \ldots \ldots \ldots$ & 33 & 15 & 483 & $\overline{27}$ & 13 & 231 \\
\hline \multicolumn{7}{|l|}{ Number of Vehicles } \\
\hline 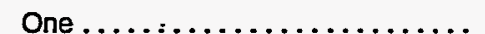 & 20 & 13 & 129 & 21 & 9 & 118 \\
\hline Two $\ldots \ldots \ldots \ldots \ldots \ldots \ldots \ldots \ldots \ldots \ldots$ & 16 & 13 & 147 & 22 & 9 & 167 \\
\hline Three $\ldots \ldots \ldots \ldots \ldots \ldots \ldots$ & 29 & 18 & 356 & 40 & 13 & 961 \\
\hline Four or More $\ldots \ldots \ldots \ldots \ldots \ldots$ & 58 & 18 & 572 & 46 & 26 & 177 \\
\hline \multicolumn{7}{|l|}{ Sex of Respondent } \\
\hline Male...$\ldots \ldots \ldots \ldots \ldots \ldots$ & 17 & 11 & 164 & 18 & 9 & 100 \\
\hline Female $\ldots \ldots \ldots \ldots \ldots \ldots \ldots$ & 16 & 10 & 114 & 20 & 7 & 175 \\
\hline \multicolumn{7}{|l|}{ Age of Main Driver } \\
\hline 16 to $24 \ldots \ldots \ldots \ldots \ldots \ldots \ldots$ & 41 & 16 & NC & 50 & 22 & 386 \\
\hline 25 to $34 \ldots \ldots \ldots \ldots \ldots \ldots \ldots$ & 23 & 14 & 366 & 26 & 12 & 1,002 \\
\hline 35 to $44 \ldots \ldots \ldots \ldots \ldots \ldots \ldots$ & 18 & 17 & 317 & 33 & 9 & 216 \\
\hline 45 to $54 \ldots \ldots \ldots \ldots \ldots \ldots \ldots \ldots$ & 23 & 21 & 275 & 30 & 12 & 464 \\
\hline 55 or Older $\ldots \ldots \ldots \ldots \ldots \ldots$ & 38 & 16 & 72 & 24 & 15 & 74 \\
\hline \multicolumn{7}{|l|}{ Education of Respondent } \\
\hline Elementary .................. & 85 & 39 & NC & 20 & 514 & 316 \\
\hline High School $\ldots \ldots \ldots \ldots \ldots \ldots$. & 23 & 10 & 147 & 25 & 9 & 137 \\
\hline College $\ldots \ldots \ldots \ldots \ldots \ldots \ldots$ & 16 & 12 & 108 & 20 & 8 & 173 \\
\hline Graduate School ............... & 21 & 33 & NC & 32 & 16 & 173 \\
\hline \multicolumn{7}{|l|}{ Race of Respondent } \\
\hline White...$\ldots \ldots$. & 12 & 9 & 101 & 15 & 6 & 87 \\
\hline Black ............... & 50 & 23 & 259 & 40 & 18 & NC \\
\hline Asian $\ldots \ldots \ldots \ldots \ldots \ldots$ & 121 & 37 & NC & 387 & 22 & 318 \\
\hline Other $\ldots \ldots \ldots \ldots \ldots \ldots \ldots$ & 71 & 23 & 574 & 56 & $\overline{32}$ & NC \\
\hline \multicolumn{7}{|l|}{ Household Income } \\
\hline$\$ 30,000$ or Less $\ldots \ldots \ldots \ldots \ldots \ldots$ & 18 & 16 & 127 & 24 & 10 & 149 \\
\hline More than $\$ 30,000 \ldots \ldots \ldots \ldots$ & 15 & 9 & 137 & 16 & 7 & 115 \\
\hline \multicolumn{7}{|l|}{ Type of Housing Unit } \\
\hline Apartment $\ldots \ldots \ldots \ldots \ldots \ldots \ldots$ & 31 & 19 & 152 & 28 & 16 & 335 \\
\hline Single-Family Detached ......... & 14 & 9 & 115 & 17 & 7 & 96 \\
\hline Townhouse $\ldots \ldots \ldots \ldots \ldots \ldots$ & 68 & 30 & NC & 114 & 14 & 783 \\
\hline Other $\ldots \ldots \ldots \ldots \ldots \ldots \ldots \ldots$ & 27 & 23 & 403 & 37 & 15 & 297 \\
\hline Transportation Type Most Often & & & & & & \\
\hline \multicolumn{7}{|l|}{ Used } \\
\hline Public Transportation ........ & 162 & 66 & 170 & . 106 & 22 & 518 \\
\hline Personal Vehicles . . . . . . . . & 13 & 9 & 134 & 16 & 7 & 109 \\
\hline Both $\ldots \ldots \ldots \ldots \ldots \ldots \ldots$ & 52 & 27 & 215 & 48 & 20 & 709 \\
\hline Don't know............ & 47 & 193 & NC & 130 & 64 & 216 \\
\hline
\end{tabular}

\footnotetext{
See footnotes at end of table.
} 
Table 4.5.7. Relative Standard Errors for Vehicle Choice When Consumer Must Drive 15 Minutes Out of the Way to Refuel the Modified Vehicle and the Modified Vehicle Costs $\$ 1,000$ More, 1994 (Continued) (Percent)

\begin{tabular}{|c|c|c|c|c|c|c|}
\hline \multirow[b]{3}{*}{ Consumer Characteristic } & \multicolumn{6}{|c|}{ Drive 15 Minutes Out of the Way for Fuel and Modified Vehicle Costs $\$ 1,000$ More } \\
\hline & \multicolumn{3}{|c|}{$\begin{array}{c}\text { Modified Vehicle Pollutes Half as Much } \\
\text { as Regular Vehicle }\end{array}$} & \multicolumn{3}{|c|}{ Modified Vehicle Does Not Pollute } \\
\hline & $\begin{array}{l}\text { Regular } \\
\text { Vehicle }\end{array}$ & $\begin{array}{l}\text { Modified } \\
\text { Vehicle }\end{array}$ & $\begin{array}{l}\text { Don't } \\
\text { Know }\end{array}$ & $\begin{array}{l}\text { Regular } \\
\text { Vehicle }\end{array}$ & $\begin{array}{l}\text { Modified } \\
\text { Vehicle }\end{array}$ & $\begin{array}{l}\text { Don't } \\
\text { Know }\end{array}$ \\
\hline All Consumers ............ & 12 & 8 & 95 & 14 & 6 & 91 \\
\hline $\begin{array}{l}\text { Respondent Concern for the } \\
\text { Environment }\end{array}$ & . & & & & & \\
\hline Extremely Concemed ....... & 59 & 16 & 122 & 153 & 6 & 223 \\
\hline 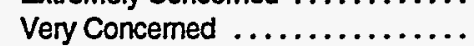 & 28 & 10 & 176 & 31 & 8 & 132 \\
\hline Somewhat Concemed ........... & 16 & 16 & 217 & 18 & 13 & 300 \\
\hline Not Too Concerned $\ldots \ldots \ldots \ldots \ldots$ & 39 & 114 & 180 & 23 & 133 & 447 \\
\hline \multicolumn{7}{|l|}{ Frequency of Gas Purchase } \\
\hline Less than Once a Week .......... & 18 & 10 & 229 & 20 & 9 & 139 \\
\hline Once a Week .................. & 19 & 12 & 95 & 20 & 9 & 157 \\
\hline More than Once a Week .......... & 22 & 24 & 451 & 46 & 14 & 176 \\
\hline \multicolumn{7}{|l|}{ Amount of Gas Purchase } \\
\hline Does not Fill Tank ............. & 29 & 24 & 304 & 27 & 24 & 210 \\
\hline Does Fill Tank . . . . . . . . . . . . & 13 & 8 & 99 & 15 & 6 & 100 \\
\hline
\end{tabular}

$\mathrm{NC}=$ No cases in responding sample.

Source: Energy Information Administration, Office of Energy Markets and End Use, Joint.Program in Survey Methodology Consumer Vehicle Preference Survey. 
Table 4.5.8. Relative Standard Errors for Vehicle Choice When Consumer Must Drive 15 Minutes Out of the. Way to Refuel the Modified Vehicle and the Modified Vehicle Costs $\$ 1,000$ Less, 1994 (Percent)

\begin{tabular}{|c|c|c|c|c|c|c|}
\hline \multirow[b]{3}{*}{ Consumer Characteristic } & \multicolumn{6}{|c|}{ Drive 15 Minutes Out of the Way for Fuel and Modified Vehicle Costs $\$ 1,000$ Less } \\
\hline & \multicolumn{3}{|c|}{$\begin{array}{l}\text { Modified Vehicle Pollutes Half as Much } \\
\text { as Regular Vehicle }\end{array}$} & \multicolumn{3}{|c|}{ Modified Vehicle Does Not Pollute } \\
\hline & $\begin{array}{l}\text { Regular } \\
\text { Vehicle }\end{array}$ & $\begin{array}{c}\text { Modified } \\
\text { Vehicle }\end{array}$ & $\begin{array}{l}\text { Don't } \\
\text { Know }\end{array}$ & $\begin{array}{l}\text { Regular } \\
\text { Vehicle }\end{array}$ & $\begin{array}{c}\text { Modified } \\
\text { Vehicle }\end{array}$ & $\begin{array}{l}\text { Don't } \\
\text { Know }\end{array}$ \\
\hline All Consumers ............... & 4 & 16 & 118 & 5 & 19 & 95 \\
\hline Region & & & & & & \\
\hline Northeast $\ldots \ldots \ldots \ldots \ldots \ldots \ldots$ & 10 & 38 & 485 & 18 & 30 & 129 \\
\hline Midwest $\ldots \ldots \ldots \ldots \ldots \ldots \ldots \ldots$ & 7 & 35 & 184 & 8 & 37 & 297 \\
\hline South $\ldots \ldots \ldots \ldots \ldots \ldots \ldots \ldots$ & 7 & 28 & 232 & 7 & 34 & 240 \\
\hline West..$\ldots \ldots \ldots \ldots \ldots \ldots \ldots$ & 14 & 28 & 210 & 13 & 63 & 142 \\
\hline \multicolumn{7}{|l|}{ Number of Vehicles } \\
\hline One...$\ldots \ldots \ldots \ldots \ldots \ldots \ldots$ & 8 & 26 & 181 & 9 & 25 & 127 \\
\hline Two ..................... & 6 & 23 & 177 & 7 & 29 & 199 \\
\hline Three $\ldots \ldots \ldots \ldots \ldots \ldots \ldots \ldots$ & 15 & 46 & 263 & 10 & 114 & 142 \\
\hline Four or More ............... & 17 & 53 & NC & 12 & 83 & NC \\
\hline \multicolumn{7}{|l|}{ Sex of Respondent } \\
\hline Male $\ldots \ldots \ldots \ldots$ & 7 & 22 & 168 & 6 & 29 & 255 \\
\hline Female $\ldots \ldots \ldots \ldots \ldots \ldots \ldots$ & 6. & 23 & 167 & 7 & 25 & 93 \\
\hline \multicolumn{7}{|l|}{ Age of Main Driver } \\
\hline 16 to $24 \ldots \ldots \ldots$ & 29 & 32 & 394 & 34 & 46 & 564 \\
\hline 25 to $34 \ldots \ldots \ldots \ldots \ldots \ldots \ldots$ & 9 & 30 & 1,437 & 9 & 46 & 354 \\
\hline 35 to $44 \ldots \ldots \ldots \ldots \ldots \ldots \ldots$ & 9 & 33 & 246 & 9 & 43 & 219 \\
\hline 45 to $54 \ldots \ldots \ldots \ldots \ldots \ldots \ldots$ & 8 & 55 & 490 & 12 & 37 & 234 \\
\hline 55 or Older $\ldots \ldots \ldots \ldots \ldots \ldots \ldots$ & 9 & 30 & 120 & 9 & 39 & 115 \\
\hline Education of Respondent & & . & & & & \\
\hline Elementary $\ldots \ldots \ldots \ldots \ldots \ldots$ & 43 & 56 & 262 & 47 & 70 & NC \\
\hline High School $\ldots \ldots \ldots \ldots \ldots \ldots$ & 6 & 26 & 187 & 8 & 23 & 229 \\
\hline College $\ldots \ldots \ldots \ldots \ldots \ldots \ldots$ & 7 & 21 & 444 & 6 & 40 & 113 \\
\hline Graduate School .............. & 13 & 66 & 121 & 18 & 58 & 178 \\
\hline \multicolumn{7}{|l|}{ Race of Respondent } \\
\hline White $\ldots \ldots \ldots \ldots \ldots \ldots \ldots$ & 5 & 17 & 109 & 5 & 23 & 100 \\
\hline Black $\ldots \ldots \ldots \ldots \ldots \ldots \ldots$ & 12 & 72 & NC & 24 & 34 & 333 \\
\hline Asian ..................... & 34 & 96 & NC & 20 & 239 & NC \\
\hline Other.$\ldots \ldots \ldots \ldots \ldots \ldots \ldots$ & 22 & 64 & NC & 37 & 52 & 469 \\
\hline \multicolumn{7}{|l|}{ Household Income } \\
\hline$\$ 30,000$ or Less $\ldots \ldots \ldots \ldots \ldots \ldots$ & 8 & 29 & 164 & 10 & 24 & 221 \\
\hline More than $\$ 30,000 \ldots \ldots \ldots \ldots$ & 5 & 19 & 165 & 5 & 28 & 103 \\
\hline \multicolumn{7}{|l|}{ Type of Housing Unit } \\
\hline Apartment $\ldots \ldots \ldots \ldots \ldots \ldots \ldots$. & 14 & 42 & 306 & 19 & 32 & 904 \\
\hline Single-Family Detached ......... & 5 & 18 & 151 & 5 & 24 & 116 \\
\hline Townhouse .................. & 15 & 193 & 571 & 20 & 138 & 248 \\
\hline 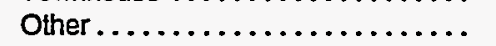 & 18 & 40 & 262 & 23 & 72 & 142 \\
\hline \multicolumn{7}{|l|}{ Transportation Type Most Often } \\
\hline Used & & . & & & & \\
\hline Public Transportation ........... & 28 & 144 & NC & 20 & 195 & 402 \\
\hline Personal Vehicles ............ & 5 & 17 & 129 & 6 & 21 & 131 \\
\hline Both $\ldots \ldots \ldots \ldots \ldots \ldots \ldots$ & 19 & 65 & 672 & 27 & 66 & 259 \\
\hline Neither.$\ldots \ldots \ldots \ldots \ldots \ldots \ldots$ & 0 & NC & NC & 0 & NC & NC \\
\hline Don't know. . & 48 & 152 & NC & 35 & 184 & NC \\
\hline
\end{tabular}

See footnotes at end of table. 
Table 4.5.8. Relative Standard Errors for Vehicle Choice When Consumer Must Drive 15 Minutes Out of the Way to Refuel the Modified Vehicle and the Modified Vehicle Costs $\$ 1,000$ Less, 1994 (Continued) (Percent)

\begin{tabular}{|c|c|c|c|c|c|c|}
\hline \multirow[b]{3}{*}{ Consumer Characteristic } & \multicolumn{6}{|c|}{ Drive 15 Minutes Out of the Way for Fuel and Modified Vehicle Costs $\$ 1,000$ Less } \\
\hline & \multicolumn{3}{|c|}{$\begin{array}{c}\text { Modified Vehicle Pollutes Half as Much } \\
\text { as Regular Vehicle }\end{array}$} & \multicolumn{3}{|c|}{ Modified Vehicle Does Not Pollute } \\
\hline & $\begin{array}{l}\text { Regular } \\
\text { Vehicle }\end{array}$ & $\begin{array}{l}\text { Modified } \\
\text { Vehicle }\end{array}$ & $\begin{array}{l}\text { Don't } \\
\text { Know }\end{array}$ & $\begin{array}{l}\text { Regular } \\
\text { Vehicle }\end{array}$ & $\begin{array}{l}\text { Modified } \\
\text { Vehicle }\end{array}$ & $\begin{array}{l}\text { Don't } \\
\text { Know }\end{array}$ \\
\hline $\begin{array}{l}\text { All Consumers } \ldots \ldots \ldots \ldots \ldots \ldots \\
\text { Respondent Concern for the } \\
\text { Environment }\end{array}$ & 4 & 16 & 118 & 5 & 19 & 95 \\
\hline Extremely Concerned ........... & 17 & 63 & 732 & 16 & 78 & 688 \\
\hline Very Concemed...$\ldots \ldots \ldots \ldots$ & 9 & 31 & 262 & 12 & 27 & 281 \\
\hline Somewhat Concemed .......... & 8 & 26 & 217 & 7 & 40 & 138 \\
\hline $\begin{array}{l}\text { Not Too Concerned ............. } \\
\text { Frequency of Gas Purchase }\end{array}$ & 12 & 224 & 500 & 23 & 71 & NC \\
\hline Less than Once a Week .......... & 7 & 22 & 123 & 7 & 32 & 127 \\
\hline Once a Week ................ & 7 & 23 & 288 & 8 & 26 & 162 \\
\hline $\begin{array}{l}\text { More than Once a Week .......... } \\
\text { Amount of Gas Purchase }\end{array}$ & 9 & 66 & 470 & 12 & 51 & 286 \\
\hline Does not Fill Tank .............. & 14 & 17 & 137 & 10 & 75 & NC \\
\hline Does Fill Tank . . . . . . . . . . . . . . & 5 & 41 & 164 & 5 & 20 & 89 \\
\hline
\end{tabular}


Table 4.5.9. Relative Standard Errors for Vehicle Choice When Consumer Must Refuel the Modified Vehicle Twice as Often as a Regular Vehicle, 1994 (Percent)

\begin{tabular}{|c|c|c|c|c|c|c|}
\hline \multirow[b]{3}{*}{ Consumer Characteristic } & \multicolumn{6}{|c|}{ Modified Vehicle Must be Fueled Twice as Often } \\
\hline & \multicolumn{3}{|c|}{$\begin{array}{c}\text { Modified Vehicle Pollutes Half as Much } \\
\text { as Regular Vehicle }\end{array}$} & \multicolumn{3}{|c|}{ Modified Vehicle Does Not Pollute } \\
\hline & $\begin{array}{l}\text { Regular } \\
\text { Vehicle }\end{array}$ & $\begin{array}{l}\text { Modified } \\
\text { Vehicle }\end{array}$ & $\begin{array}{l}\text { Don't } \\
\text { Know }\end{array}$ & $\begin{array}{l}\text { Regular } \\
\text { Vehicle }\end{array}$ & $\begin{array}{l}\text { Modified } \\
\text { Yehicle }\end{array}$ & $\begin{array}{l}\text { Don't } \\
\text { Know }\end{array}$ \\
\hline All Consumers .............. & 7 & 5 & 85 & 8 & 5 & 61 \\
\hline \multicolumn{7}{|l|}{ Region } \\
\hline Northeast $\ldots \ldots \ldots \ldots \ldots \ldots \ldots$ & 20 & 11 & 224 & 22 & 9 & 127 \\
\hline Midwest $. . . \ldots \ldots \ldots \ldots \ldots . . . .$. & 12 & 9 & 175 & 14 & 10 & 128 \\
\hline South $\ldots \ldots \ldots \ldots \ldots \ldots \ldots$ & 10 & 9 & 115 & 14 & 7 & 98 \\
\hline West.$\ldots \ldots \ldots \ldots \ldots \ldots \ldots \ldots$ & 21 & 10 & 263 & 20 & 11 & 98 \\
\hline \multicolumn{7}{|l|}{ Number of Vehicles } \\
\hline One..$\ldots \ldots \ldots \ldots \ldots \ldots \ldots$ & 11 & 9 & 151 & 12 & 8 & 82 \\
\hline Two $\ldots \ldots \ldots \ldots \ldots \ldots \ldots \ldots$ & 11 & 7 & 117 & 15 & 6 & 91 \\
\hline Three..$\ldots \ldots \ldots \ldots \ldots \ldots \ldots$. & 18 & 15 & 328 & 23 & 11 & 691 \\
\hline Four orMore $. . . . \ldots \ldots \ldots . .$. & 34 & 14 & 286 & 26 & 20 & 233 \\
\hline \multicolumn{7}{|l|}{ Sex of Respondent $\because \cdots$} \\
\hline Male $\ldots \ldots \ldots \ldots \ldots \ldots \ldots$ & 9 & 8 & 126 & 12 & ' 7 & 114 \\
\hline Female $\ldots \ldots \ldots \ldots \ldots \ldots \ldots$ & 10 & 6 & 115 & 11 & 6 & 70 \\
\hline \multicolumn{7}{|l|}{ Age of Main Driver } \\
\hline 16 to $24 \ldots \ldots \ldots \ldots \ldots \ldots \ldots$ & 38 & 11 & 352 & 82 & 9 & 305 \\
\hline 25 to $34 \ldots \ldots \ldots \ldots \ldots \ldots \ldots$ & 15 & 10 & 197 & 19 & 9 & 292 \\
\hline 35 to $44 \ldots \ldots \ldots \ldots \ldots \ldots \ldots$ & 19 & 7 & 260 & 20 & 7 & 206 \\
\hline 45 to $54 \ldots \ldots \ldots \ldots \ldots \ldots \ldots$ & 17 & 12 & 253 & 21 & 10 & 98 \\
\hline 55 or Older ................. & 10 & 14 & 105 & 11 & 13 & 73 \\
\hline \multicolumn{7}{|l|}{ Education of Respondent } \\
\hline Elementary . . . . . . . . . . . . . . & 25 & 44 & NC & 36 & 52 & 169 \\
\hline High School $\ldots \ldots \ldots \ldots \ldots \ldots \ldots$ & 8 & 10 & 125 & 11 & 8 & 123 \\
\hline College $\ldots \ldots \ldots \ldots \ldots \ldots \ldots$ & 15 & 5 & 148 & 13 & 7 & 78 \\
\hline Graduate School .............. & 25 & 14 & 159 & 40 & 8 & 204 \\
\hline \multicolumn{7}{|l|}{ Race of Respondent } \\
\hline White $\ldots \ldots \ldots \ldots \ldots \ldots \ldots \ldots$ & 8 & 5 & 90 & 9 & 5 & 60 \\
\hline Black.$\ldots \ldots \ldots \ldots \ldots \ldots$ & 19 & 24 & 282 & 20 & $18^{\circ}$ & 520 \\
\hline Asian $\ldots \ldots \ldots \ldots \ldots \ldots \ldots$ & 227 & 16 & 436 & 60 & 30 & 437 \\
\hline Other.$\ldots \ldots \ldots \ldots \ldots \ldots \ldots \ldots$ & 47 & 16 & 865 & 52 & 18 & 704 \\
\hline \multicolumn{7}{|l|}{ Household income } \\
\hline$\$ 30,000$ or Less $\ldots \ldots \ldots \ldots \ldots \ldots$ & 10 & 10 & 132 & 13 & 9 & 90 \\
\hline More than $\$ 30,000 \ldots \ldots \ldots \ldots \ldots$ & 10 & 5 & 111 & 11 & 5 & 82 \\
\hline \multicolumn{7}{|l|}{ Type of Housing Unit } \\
\hline Apartment $\ldots \ldots \ldots \ldots \ldots \ldots \ldots$ & 23 & 11 & 229 & 23 & 11 & 191 \\
\hline Single-Family Detached ......... & 8 & 6 & 101 & 9 & 6 & 76 \\
\hline Townhouse ................ & 42 & 23 & 655 & 66 & 16 & 191 \\
\hline Other $\ldots \ldots \ldots \ldots \ldots \ldots \ldots \ldots$ & 23 & 14 & 225 & 32 & 12 & 148 \\
\hline \multicolumn{7}{|l|}{ Transportation Type Most Often } \\
\hline Used - & & & & & & \\
\hline Public Transportation ........... & 76 & 25 & NC & 43 & 24 & 555 \\
\hline Personal Vehicles . . . . . . . . . . . & 8 & 6 & 105 & 10 & 5 & 69 \\
\hline Both $\ldots \ldots \ldots \ldots \ldots \ldots \ldots \ldots$ & 42 & 16 & 195 & 50 & 13 & 296 \\
\hline Neither $\ldots \ldots \ldots \ldots \ldots \ldots \ldots \ldots, \ldots$ & 0. & NC & NC & 143 & 89 & NC \\
\hline Don't Know $\ldots \ldots \ldots \ldots \ldots \ldots$ & 60 & 53 & NC & 55 & 54 & 218 \\
\hline
\end{tabular}


Table 4.5.9. Relative Standard Errors for Vehicle Choice When Consumer Must Refuel the Modified Vehicle Twice as Often as a Regular Vehicle, 1994 (Continued) (Percent)

\begin{tabular}{|c|c|c|c|c|c|c|}
\hline \multirow[b]{3}{*}{ Consumer Characteristic } & \multicolumn{6}{|c|}{ Modified Vehicle Must be Fueled Twice as Often } \\
\hline & \multicolumn{3}{|c|}{$\begin{array}{c}\text { Modified Vehicle Pollutes Half as Much } \\
\text { as Regular Vehicle }\end{array}$} & \multicolumn{3}{|c|}{ Modified Vehicle Does Not Pollute } \\
\hline & $\begin{array}{l}\text { Regular } \\
\text { Vehicle }\end{array}$ & $\begin{array}{l}\text { Modified } \\
\text { Vehicle }\end{array}$ & $\begin{array}{l}\text { Don't } \\
\text { Know }\end{array}$ & $\begin{array}{l}\text { Regular } \\
\text { Vehicle }\end{array}$ & $\begin{array}{c}\text { Modified } \\
\text { Vehicle }\end{array}$ & $\begin{array}{l}\text { Don't } \\
\text { Know }\end{array}$ \\
\hline $\begin{array}{l}\text { All Consumers ................ } \\
\text { Respondent Concern for the } \\
\text { Environment }\end{array}$ & 7 & 5 & 85 & 8 & 5 & 61 \\
\hline Extremely Concemed..$\ldots \ldots \ldots$. & 42 & 10 & 249 & 51 & 7 & 1,205 \\
\hline Very Concerned..$\ldots \ldots \ldots \ldots \ldots$ & 19 & 7 & 157 & 24 & 6 & 126 \\
\hline Somewhat Concemed .......... & 14 & 8 & 179 & 13 & 9 & 95 \\
\hline Not Too Concemed ............. & 26 & 38 & 205 & 24 & 41 & 738 \\
\hline Frequency of Gas Purchase & & & & & & . \\
\hline Less than Once a Week .......... & 11 & 7 & 107 & 11 & 8 & 82 \\
\hline Once a Week ................ & 11 & 8 & 124 & 15 & 6 & 96 \\
\hline More than Once a Week ........... & 16 & 14 & 1,007 & 20 & 13 & 231 \\
\hline Amount of Gas Purchase & & & & & & \\
\hline Does not Fill Tank . . . . . . . . . . . & 15 & 17 & 249 & 24 & 13 & 165 \\
\hline Does Fill Tank . . . . . . . . . . . . . & 8 & 5 & 90 & 9 & 5 & 66 \\
\hline
\end{tabular}

NC $=$ No cases in responding sample.

Source: Energy Information Administration, Office of Energy Markets and End Use, Joint Program in Survey Methodology Consumer Vehicle Preference Survey. 
Table 4.5.10. Relative Standard Errors for Vehicle Choice When Consumer Must Refuel the Modified Vehicle Twice as often as a Regular Vehicle and the Modified Vehicle Costs $\$ 1,000$ More, 1994

(Percent)

\begin{tabular}{|c|c|c|c|c|c|c|}
\hline \multirow[b]{3}{*}{ Consumer Characteristic } & \multicolumn{6}{|c|}{ Must Refuel Twice as Often and Vehicle Cost $\$ 1,000$ More } \\
\hline & \multicolumn{3}{|c|}{$\begin{array}{c}\text { Modified Vehicle Pollutes Half as Much } \\
\text { as Regular Vehicle }\end{array}$} & \multicolumn{3}{|c|}{ Modified Vehicle Does Not Pollute } \\
\hline & $\begin{array}{l}\text { Regular } \\
\text { Vehicle }\end{array}$ & $\begin{array}{c}\text { Modified } \\
\text { Vehicle }\end{array}$ & $\begin{array}{l}\text { Don't } \\
\text { Know }\end{array}$ & $\begin{array}{l}\text { Regular } \\
\text { Vehicle }\end{array}$ & $\begin{array}{c}\text { Modified } \\
\text { Vehicle }\end{array}$ & $\begin{array}{l}\text { Don't } \\
\text { Know }\end{array}$ \\
\hline $\begin{array}{l}\text { All Consumers. } \ldots \ldots \ldots \ldots \ldots \ldots \\
\text { Region }\end{array}$ & 11 & $6^{\circ}$ & 62 & 14 & 5 & 78 \\
\hline Northeast $\ldots \ldots \ldots \ldots \ldots \ldots \ldots$. & 35 & 12 & 149 & 40 & 9 & 197 \\
\hline Midwest $\ldots \ldots \ldots \ldots \ldots \ldots \ldots \ldots$ & 20 & 14 & 67 & 28 & 10 & 159 \\
\hline South $\ldots \ldots \ldots \ldots \ldots \ldots \ldots \ldots$ & 16 & 12 & 177 & 20 & 9 & 121 \\
\hline West.$\ldots \ldots \ldots \ldots \ldots \ldots \ldots$ & 32 & 12 & 192 & 34 & 12 & 176 \\
\hline \multicolumn{7}{|l|}{ Number of Vehicles } \\
\hline One ............ & 21 & 12 & 76 & 25 & 8 & 99 \\
\hline Two $\ldots \ldots \ldots \ldots \ldots \ldots \ldots \ldots$ & 16 & 9 & 117 & 19 & 9 & 104 \\
\hline Three $\ldots \ldots \ldots \ldots \ldots \ldots \ldots$. & 37 & 16 & 158 & 44 & 10 & 1074 \\
\hline Four or More.$\ldots \ldots \ldots \ldots \ldots$ & 35 & 22 & 631 & 65 & 14 & NC \\
\hline \multicolumn{7}{|l|}{ Sex of Respondent } \\
\hline Male $\ldots \ldots \ldots \ldots \ldots \ldots \ldots \ldots$ & 15 & 10 & 113 & 17 & 8 & 142 \\
\hline Female $\ldots \ldots \ldots \ldots \ldots \ldots \ldots$ & 17 & 8 & 73 & 23 & 6 & 91 \\
\hline \multicolumn{7}{|l|}{ Age of Main Driver } \\
\hline 16 to $24 \ldots \ldots \ldots$ & 36 & 14 & NC & 43 & 20 & 243 \\
\hline 25 to $34 \ldots \ldots \ldots$ & 23 & 13 & 165 & 30 & 9 & 554 \\
\hline 35 to $44 \ldots \ldots \ldots$ & 20 & 12 & 163 & 37 & 7 & 285 \\
\hline 45 to $54 \ldots \ldots \ldots \ldots \ldots \ldots \ldots$ & 27 & 16 & 126 & 26 & 13 & 254 \\
\hline 55 or Older...$\ldots \ldots \ldots \ldots \ldots$ & 27 & 17 & 66 & 26 & 16 & 61 \\
\hline \multicolumn{7}{|l|}{ Education of Respondent } \\
\hline Elementary $\ldots \ldots \ldots \ldots \ldots \ldots$ & 77 & 34 & NC & 24 & 157 & NC \\
\hline High School $\ldots \ldots \ldots \ldots \ldots \ldots \ldots$ & 20 & 9 & 134 & 25 & 9 & 82 \\
\hline College..$\ldots \ldots \ldots \ldots \ldots \ldots$. & 16 & 10 & 73 & 20 & 7 & 169 \\
\hline Graduate School .............. & 30 & 22 & 75 & 44 & 10 & 277 \\
\hline \multicolumn{7}{|l|}{ Race of Respondent } \\
\hline White $\ldots \ldots \ldots \ldots \ldots \ldots \ldots \ldots$ & 11 & 7 & 59 & 14 & 6 & 86 \\
\hline Black.$\ldots \ldots \ldots \ldots \ldots \ldots \ldots$ & 59 & 20 & 395 & 56 & 15 & 642 \\
\hline Asian .................... & 96 & 27 & NC & 354 & 17 & 385 \\
\hline 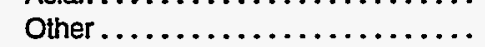 & 94 & 13 & NC & NC & 10 . & 168 \\
\hline \multicolumn{7}{|l|}{ Household Income } \\
\hline$\$ 30,000$ or Less . . . . . . . . . . . . & 18 & 15 & 90 & 26 & 9 & 143 \\
\hline More than $\$ 30,000 \ldots \ldots \ldots \ldots \ldots$ & 14 & 7 & 84 & 17 & 6 & 93 \\
\hline \multicolumn{7}{|l|}{ Type of Housing Unit } \\
\hline Apartment $\ldots \ldots \ldots \ldots \ldots \ldots \ldots$ & 28 & 17 & 139 & 29 & 15 & 243 \\
\hline Single-Family Detached.$\ldots \ldots \ldots$ & 14 & 8 & 69 & 17 & 6 & 97 \\
\hline Townhouse..$\ldots \ldots \ldots \ldots \ldots \ldots$ & 60 & 28 & NC & 62 & 21 & 345 \\
\hline Other $[\ldots \ldots \ldots \ldots, \ldots, \ldots, \cdots$ & 29 & 21 & 251 & 63 & 12 & 160 \\
\hline \multirow{2}{*}{\multicolumn{7}{|c|}{$\begin{array}{l}\text { Transportation Type Most Often } \\
\text { Used }\end{array}$}} \\
\hline & & & & & & \\
\hline Public Transportation ............ & 195 & 44 & 127 & 81 & 22 & NC \\
\hline Personal Vehicles.$\ldots \ldots \ldots \ldots \ldots \ldots$ & 13 & 7 & 88 & 16 & 6 & 88 \\
\hline Both,$\ldots \ldots \ldots \ldots \ldots \ldots \ldots \ldots$ & 51 & 23 & 155 & 51 & 18 & 333 \\
\hline Neither..... & NC & NC & NC & NC & 0 & NC \\
\hline Don't know... & 189 & 219 & 76 & 331 & 34 & 256 \\
\hline
\end{tabular}

\section{See footnotes at end of table.}


Table 4.5.10. Relative Standard Errors for Vehicle Choice When Consumer Must Refuel the Modified Vehicle Twice as often as a Regular Vehicle and the Modified Vehicle Costs \$1,000 More, 1994 (Continued) (Percent)

\begin{tabular}{|c|c|c|c|c|c|c|}
\hline \multirow[b]{3}{*}{ Consumer Characteristic } & \multicolumn{6}{|c|}{ Must Refuel Twice as Often and Vehicle Cost $\$ 1,000$ More } \\
\hline & \multicolumn{3}{|c|}{$\begin{array}{c}\text { Modified Vehicle Pollutes Half as Much } \\
\text { as Regular Vehicle }\end{array}$} & \multicolumn{3}{|c|}{ Modified Vehicle Does Not Pollute } \\
\hline & $\begin{array}{l}\text { Regular } \\
\text { Vehicle } \\
\end{array}$ & $\begin{array}{l}\text { Modified } \\
\text { Vehicle }\end{array}$ & $\begin{array}{l}\text { Don't } \\
\text { Know }\end{array}$ & $\begin{array}{l}\text { Regular } \\
\text { Vehicle }\end{array}$ & $\begin{array}{c}\text { Modified } \\
\text { Vehicle }\end{array}$ & $\begin{array}{l}\text { Don't } \\
\text { Know }\end{array}$ \\
\hline $\begin{array}{l}\text { All Consumers } \ldots \ldots \ldots \ldots \ldots \ldots \\
\text { Respondent Concern for the } \\
\text { Environment }\end{array}$ & 11 & 6 & 62 & 14 & 5 & 78 \\
\hline Extremely Concemed ........... & 111 & 9 & 137 & 78 & 8 & 236 \\
\hline Very Concemed $\ldots \ldots \ldots \ldots \ldots$ & 28 & 8 & 139 & 33 & 7 & 123 \\
\hline Somewhat Concerned...$\ldots \ldots \ldots$ & 12 & 16 & 110 & 19 & 12 & 228 \\
\hline $\begin{array}{l}\text { Not Too Concerned ............. } \\
\text { Frequency of Gas Purchase }\end{array}$ & 31 & 95 & 319 & 40 & 84 & 368 \\
\hline Less than Once a Week .......... & 18 & 9 & 89 & 18 & 9 & 146 \\
\hline Once a Week ............... & 17 & 10 & 106 & 26 & 6 & 118 \\
\hline $\begin{array}{l}\text { More than Once a Week.......... } \\
\text { Amount of Gas Purchase }\end{array}$ & 26 & 21 & 149 & 36 & 16 & 135 \\
\hline Does not Fill Tank . . . . . . . . . . . & 28 & 21 & 235 & 39 & 13 & NC \\
\hline Does Fill Tank . . . . . . . . . . . . . & 12 & 7 & 64 & 15 & 5 & 73 \\
\hline
\end{tabular}

$\mathrm{NC}=$ No cases in responding sample.

Source: Energy Information Administration, Office of Energy Markets and End Use, Joint Program in Survey Methodology Consumer Vehicle Preference Survey. 
Table 4.5.11. Relative Standard Errors for Vehicle Choice When Consumer Must Refuel the Modified Vehicle Twice as Often as a Regular Vehicle and the Modified Vehicle Costs $\$ 1,000$ Less, 1994 (Percent)

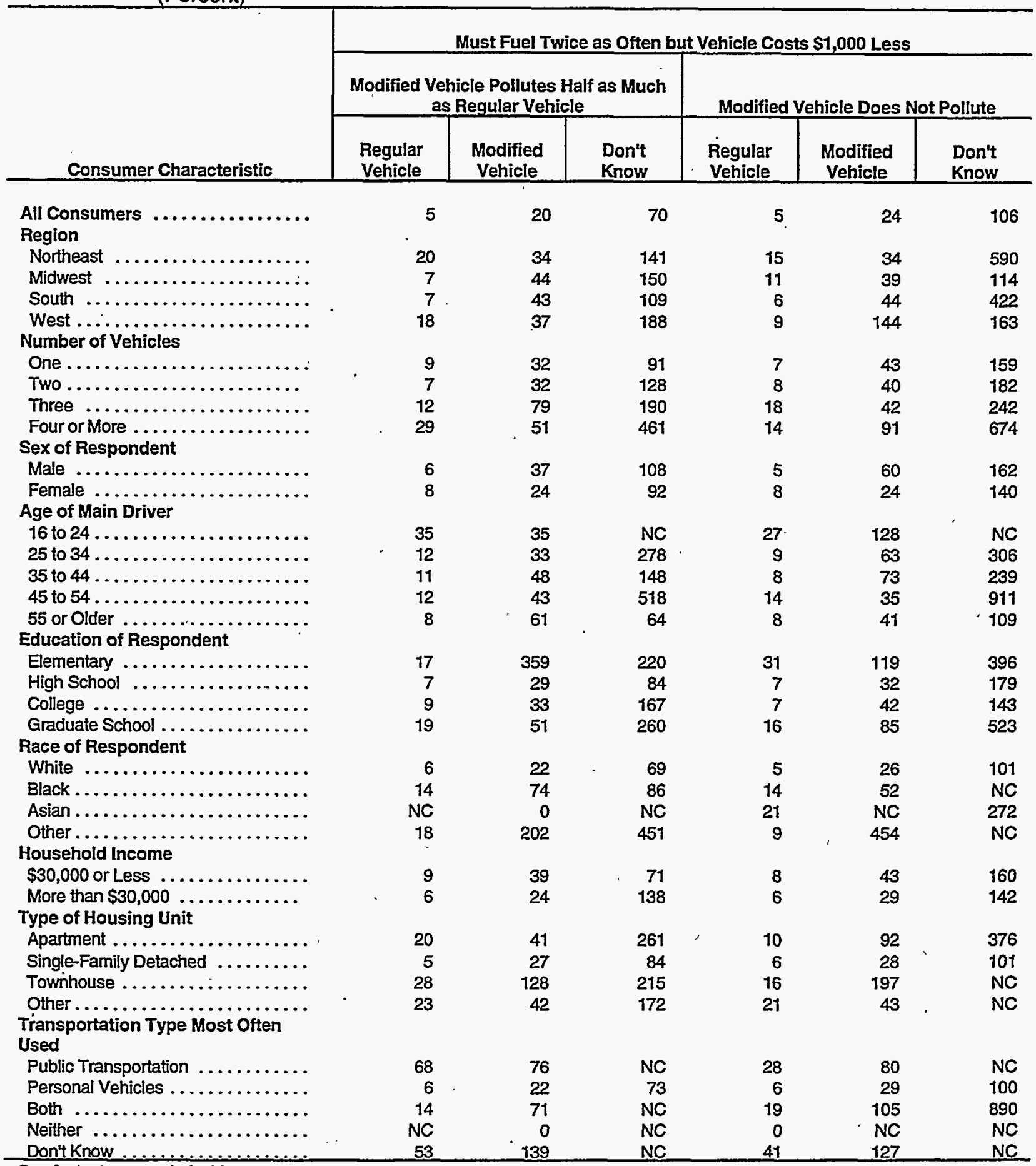

See footnotes at end of table. 
Table 4.5.11. Relative Standard Errors for Vehicle Choice When Consumer Must Refuel the Modified Vehicle Twice as Often as a Regular Vehicle and the Modified Vehicle Costs $\$ 1,000$ Less, 1994 (Continued) (Percent)

\begin{tabular}{|c|c|c|c|c|c|c|}
\hline \multirow[b]{3}{*}{ Consumer Characteristic } & \multicolumn{6}{|c|}{ Must Fuel Twice as Often but Vehicle Costs $\$ 1,000$ Less } \\
\hline & \multicolumn{3}{|c|}{$\begin{array}{c}\text { Modified Vehicle Pollutes Half as Much } \\
\text { as Regular Vehicle }\end{array}$} & \multicolumn{3}{|c|}{ Modified Vehicle Does Not Pollute } \\
\hline & $\begin{array}{l}\text { Regular } \\
\text { Vehicle }\end{array}$ & $\begin{array}{c}\text { Modified } \\
\text { Vehicle }\end{array}$ & $\begin{array}{l}\text { Don't } \\
\text { Know }\end{array}$ & $\begin{array}{l}\text { Regular } \\
\text { Vehicle }\end{array}$ & $\begin{array}{c}\text { Modified } \\
\text { Vehicle }\end{array}$ & $\begin{array}{l}\text { Don't } \\
\text { Know }\end{array}$ \\
\hline $\begin{array}{l}\text { All Consumers ................ } \\
\text { Respondent Concern for the } \\
\text { Environment }\end{array}$ & 5 & 20 & 70 & 5 & 24 & 106 \\
\hline Extremely Concerned $\ldots \ldots \ldots \ldots \ldots$ & 36 & 38 & 343 & 13 & 120 & NC \\
\hline Very Concemed .............. & 11 & 46 & 156 & 8 & 66 & 439 \\
\hline Somewhat Concemed .......... & 10 & 38 & 87 & 7 & 50 & 203 \\
\hline $\begin{array}{l}\text { Not Too Concerned .............. } \\
\text { Frequency of Gas Purchase }\end{array}$ & 9 & 246 & NC & 34 & 72 & 176 \\
\hline Less than Once a Week .......... & 8 & 32 & 85 & 8 & 35 & 87 \\
\hline Once a Week ............... & 8 & 31 & 120 & 7 & 38 & 432 \\
\hline $\begin{array}{l}\text { More than Once a Week .......... } \\
\text { Amount of Gas Purchase }\end{array}$ & 12 & 51 & 299 & 10 & 65 & 1048 \\
\hline $\begin{array}{l}\text { Does not Fill Tank . . . . . . . . . . . . . . . . . . . } \\
\text { Does Fill Tank . . }\end{array}$ & $\begin{array}{r}16 \\
5\end{array}$ & $\begin{array}{l}39 \\
24\end{array}$ & $\begin{array}{r}184 \\
75\end{array}$ & $\begin{array}{r}11 \\
5\end{array}$ & $\begin{array}{l}73 \\
26\end{array}$ & $\begin{array}{r}\text { NC } \\
99\end{array}$ \\
\hline
\end{tabular}

$\mathrm{NC}=$ No cases in responding sample.

Source: Energy Information Administration, Office of Energy Markets and End Use, Joint Program in Survey Methodology Consumer Vehicle Preference Survey. 
Table 4.5.12. Relative Standard Errors for Vehicle Choice When Consumer Must Drive 15 Minutes Out of the Way to Refuel the Modified Vehicle and the Modified Vehicle Has Half the Trunk/Cargo Space of a Regular Vehicle, 1994 (Percent)

\begin{tabular}{|c|c|c|c|c|c|c|}
\hline \multirow[b]{3}{*}{ Consumer Characteristic } & \multicolumn{6}{|c|}{ Consumer Must Drive 15 Minutes Out of the Way and Half Trunk/Cargo Space } \\
\hline & \multicolumn{3}{|c|}{$\begin{array}{l}\text { Modified Vehicle Pollutes Half as Much } \\
\text { as Regular Vehicle }\end{array}$} & \multicolumn{3}{|c|}{ Modified Vehicle Does Not Pollute } \\
\hline & $\begin{array}{l}\text { Regular } \\
\text { Vehicle }\end{array}$ & $\begin{array}{l}\text { Modified } \\
\text { Vehicle }\end{array}$ & $\begin{array}{l}\text { Don't } \\
\text { Know }\end{array}$ & $\begin{array}{l}\text { Regular } \\
\text { Vehicle }\end{array}$ & $\begin{array}{c}\text { Modified } \\
\text { Vehicle }\end{array}$ & $\begin{array}{l}\text { Don't } \\
\text { Know }\end{array}$ \\
\hline $\begin{array}{l}\text { All Consumers } \ldots \ldots \ldots \ldots \ldots \ldots . . \\
\text { Region }\end{array}$ & 14 & 15 & 425 & 12 & 15 & 306 \\
\hline Northeast $\ldots \ldots \ldots \ldots \ldots \ldots \ldots$ & 23 & .68 & NC & 23 & 36 & 428 \\
\hline Midwest $\ldots \ldots \ldots \ldots \ldots \ldots \ldots$ & 36 & 21 & NC & 30 & 32 & 601 \\
\hline South $\ldots \ldots \ldots \ldots \ldots \ldots \ldots$ & 18 & 26 & 908 & 20 & 26 & 915 \\
\hline West $\ldots \ldots \ldots \ldots \ldots \ldots \ldots \ldots$ & 45 & 27 & 276 & 27 & 30 & 754 \\
\hline \multicolumn{7}{|l|}{ Number of Vehicles } \\
\hline One ............. & 29 & 19 & 853 & 19 & 21 & 543 \\
\hline Two $\ldots \ldots \ldots \ldots \ldots \ldots \ldots \ldots$ & 20 & 27 & 380 & 19 & 29 & 303 \\
\hline Three...$\ldots \ldots \ldots \ldots \ldots \ldots$ & 30 & 47 & NC & 34 & 45 & NC \\
\hline Four or More ................ & 38 & 51 & NC & 41 & 58 & NC \\
\hline \multicolumn{7}{|l|}{ Sex of Respondent } \\
\hline Male $\ldots \ldots \ldots \ldots \ldots \ldots \ldots \ldots$ & 18 & 22 & 977 & 19 & 21 & 273 \\
\hline Female..$\ldots \ldots \ldots \ldots \ldots \ldots$ & 21 & 20 & 435 & 16 & 22 & 1,048 \\
\hline \multicolumn{7}{|l|}{ Age of Main Driver } \\
\hline 16 to $24 \ldots \ldots \ldots \ldots \ldots \ldots \ldots$ & 32 & 70 & NC & 173 & 23 & NC \\
\hline 25 to $34 \ldots \ldots \ldots \ldots \ldots \ldots \ldots$ & 21 & 31 & 812 & 26 & 38 & 658 \\
\hline 35 to $44 \ldots \ldots \ldots \ldots \ldots \ldots \ldots$ & 45 & 20 & NC & 19 & 39 & NC \\
\hline 45 to $54 \ldots \ldots \ldots \ldots \ldots \ldots \ldots$ & 26 & 57 & NC & 24 & 37 & NC \\
\hline 55 or Older $\ldots \ldots \ldots \ldots \ldots \ldots \ldots$ & 35 & 27 & 279 & 25 & 25 & 219 \\
\hline \multicolumn{7}{|l|}{ Education of Respondent } \\
\hline 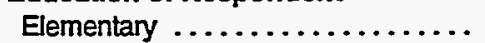 & 71 & 128 & NC & 105 & 61 & NC \\
\hline High School...$\ldots \ldots \ldots \ldots \ldots$ & 19 & 21 & 508 & 24 & 18 & 474 \\
\hline College $\ldots \ldots \ldots \ldots \ldots \ldots \ldots$ & 22 & 25 & NC & 16 & 29 & 343 \\
\hline Graduate School . . . . . . . . . . . . . & 59 & 41 & 351 & 26 & 50 & NC \\
\hline \multicolumn{7}{|l|}{ Race of Respondent } \\
\hline White $\ldots \ldots \ldots \ldots \ldots \ldots \ldots$ & 15 & 17 & 388 & 14 & 17 & 270 \\
\hline Black $\ldots \ldots \ldots \ldots \ldots \ldots \ldots \ldots$ & 54 & 34 & NC & 25 & 54 & NC \\
\hline 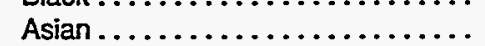 & 103 & 124 & NC & 132 & 97 & NC \\
\hline Other $, \ldots, \ldots, \ldots, \cdots, \ldots$ & 106 & 49 & NC & 56 & 51 & NC \\
\hline \multicolumn{7}{|l|}{ Household Income } \\
\hline$\$ 30,000$ or Less . . . . . . . . . . . . . & 46 & 14 & 827 & 32 & 18 & 291 \\
\hline More than $\$ 30,000 \ldots \ldots \ldots \ldots \ldots$ & 13 & 26 & 487 & 12 & 23 & 693 \\
\hline \multicolumn{7}{|l|}{ Type of Housing Unit } \\
\hline Apartment $\ldots \ldots \ldots \ldots \ldots \ldots$ & 58 & 29 & 521 & 36 & 28 & 374 \\
\hline Single-Family Detached ......... & 15 & 19 & 883 & 15 & 20 & 394 \\
\hline Townhouse $\ldots \ldots \ldots \ldots \ldots \ldots \ldots$ & 54 & 117 & NC & 47 & 86 & NC \\
\hline Other $. \ldots \ldots \ldots \ldots \ldots \ldots \ldots, \ldots$ & 41 & 28 & 534 & 28 & 47 & NC \\
\hline \multicolumn{7}{|l|}{ Transportation Type Most Often } \\
\hline \multicolumn{7}{|l|}{$\begin{array}{l}\text { Iransportation Iype Most Unten } \\
\text { Used }\end{array}$} \\
\hline Public Transportation ............ & 0 & NC & NC & 150 & 27 & NC \\
\hline Personal Vehicles $\ldots \ldots \ldots \ldots \ldots \ldots$ & 15 & 18 & 372 & 14 & 20 & 251 \\
\hline Both,$\ldots \ldots \ldots \ldots \ldots \ldots$ & 72 & 51 & NC & 38 & 68 & NC \\
\hline Neither $\ldots \ldots \ldots \ldots \ldots \ldots \ldots \ldots$ & NC & NC & NC & NC & NC & NC \\
\hline Don't know & 72 & 0 & NC & 76 & 169 & NC \\
\hline
\end{tabular}

See footrotes at end of table. 
Table 4.5.12. Relative Standard Errors for Vehicle Choice When Consumer Must Drive 15 Minutes Out of the Way to Refuel the Modified Vehicle and the Modified Vehicle Has Half the Trunk/Cargo Space of a Regular Vehicle, 1994 (Continued) (Percent)

\begin{tabular}{|c|c|c|c|c|c|c|}
\hline \multirow[b]{3}{*}{ Consumer Characteristic } & \multicolumn{6}{|c|}{ Consumer Must Drive 15 Minutes Out of the Way and Half Trunk/Cargo Space } \\
\hline & \multicolumn{3}{|c|}{$\begin{array}{c}\text { Modified Vehicle Pollutes Half as Much } \\
\text { as Regular Vehicle }\end{array}$} & \multicolumn{3}{|c|}{ Modified Vehicle Does Not Pollute } \\
\hline & $\begin{array}{l}\text { Regular } \\
\text { Vehicle }\end{array}$ & $\begin{array}{c}\text { Modified } \\
\text { Vehicle }\end{array}$ & $\begin{array}{l}\text { Don't } \\
\text { Know }\end{array}$ & $\begin{array}{l}\text { Regular } \\
\text { Vehicle } \\
\end{array}$ & $\begin{array}{c}\text { Modified } \\
\text { Vehicle }\end{array}$ & $\begin{array}{l}\text { Don't } \\
\text { Know }\end{array}$ \\
\hline $\begin{array}{l}\text { All Consumers } \ldots \ldots \ldots \ldots \ldots \ldots \ldots \\
\text { Respondent Concern for the } \\
\text { Environment }\end{array}$ & 14 & 15 & 425 & 12 & 15 & 306 \\
\hline Extremely Concemed ........... & 61 & 38 & 435 & 55 & $34^{\circ}$ & NC \\
\hline Very Concemed...$\ldots \ldots \ldots \ldots$ & 27 & 25 & NC & 30 & 21 & 490 \\
\hline Somewhat Concerned .......... & 25 & 26 & NC & 14 & 40 & 293 \\
\hline $\begin{array}{l}\text { Not Too Concemed } \ldots \ldots \ldots \ldots \ldots \\
\text { Trunk Size }\end{array}$ & 57 & 125 & 276 & 36 & 104 & NC \\
\hline Large Trunk ............... & 24 & 22 & 644 & 22 & 21 & 919 \\
\hline Meḍium Trunk . ............ & 56 & 52 & 431 & 28 & 49 & 335 \\
\hline Small Trunk ............... & 60 & 39 & NC & 38 & 57 & 508 \\
\hline No Trunk $\ldots \ldots \ldots \ldots \ldots \ldots$ & 20 & 30 & 845 & 19 & 32 & 802 \\
\hline \multicolumn{7}{|l|}{$\begin{array}{l}\text { More Than Half the Trunk Space } \\
\text { Used }\end{array}$} \\
\hline Yes......$\ldots \ldots \ldots \ldots \ldots \ldots \ldots$ & 21 & -22 & 289 & 14 & 26 & 1,042 \\
\hline All the Time...$\ldots \ldots \ldots \ldots \ldots$ & 66 & 64 & NC & 54 & 69 & NC \\
\hline Most of the Time ............ & 27 & 102 & NC & 25 & 80 & NC \\
\hline Some of the Time ............ & 23 & 37 & 724 & 20 & 39 & NC \\
\hline 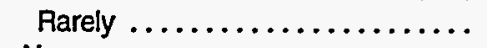 & 142 & 25 & 184 & 32 & 43 & 534 \\
\hline $\begin{array}{l}\text { No } \ldots \ldots \ldots \ldots \ldots \ldots \ldots \ldots \ldots \\
\text { Things Stored or Left in Trunk }\end{array}$ & . 21 & 21 & NC & 21 & 21 & 249 \\
\hline Yes....$\ldots \ldots \ldots \ldots \ldots \ldots \ldots$ & 30 & 46 & 553 & 24 & 41 & NC \\
\hline No $\ldots \ldots \ldots \ldots \ldots \ldots \ldots \ldots \ldots$ & 22 & 42 & NC & 20 & 48 & NC \\
\hline \multicolumn{7}{|l|}{ Frequency of Gas Purchase } \\
\hline Less than Once a Week ......... & 18 & 28 & 834 & 17 & 25 & 1,099 \\
\hline Once a Week ................ & 26 & 19 & 711 & 22 & 21 & 245 \\
\hline More than Once a Week .......... & 31 & 36 & 640 & 24 & 46 & NC \\
\hline \multicolumn{7}{|l|}{ Amount of Gas Purchase } \\
\hline Does not Fill Tank . . . . . . . . . . . . & 47 & 29 & 565 & 47 & 27 & NC \\
\hline Does Fill Tank . ................. & 14 & 17 & 551 & 12 & 18 & 283 \\
\hline
\end{tabular}


Table 4.5.13. Relative Standard Errors for Vehicle Choice When Consumer Must Refuel Modified Vehicle Twice as Often as a Regular Vehicle and the Modified Vehicle Has Half the Trunk/Cargo Space of a Regular Vehicle, 1994 (Percent)

\begin{tabular}{|c|c|c|c|c|c|c|}
\hline \multirow[b]{3}{*}{ Consumer Characteristic } & \multicolumn{6}{|c|}{ Must Fuel Twice as Often and Half TrunkCargo Space } \\
\hline & \multicolumn{3}{|c|}{$\begin{array}{l}\text { Modified Vehicle Pollutes Half as Much } \\
\text { as Regular Vehicle }\end{array}$} & \multicolumn{3}{|c|}{ Modified Vehicle Does Not Pollute } \\
\hline & $\begin{array}{l}\text { Regular } \\
\text { Vehicle }\end{array}$ & $\begin{array}{l}\text { Modified } \\
\text { Vehicle }\end{array}$ & $\begin{array}{l}\text { Don't } \\
\text { Know }\end{array}$ & $\begin{array}{l}\text { Regular } \\
\text { Vehicle }\end{array}$ & $\begin{array}{l}\text { Modified } \\
\text { Vehicle }\end{array}$ & $\begin{array}{l}\text { Don't } \\
\text { Know }\end{array}$ \\
\hline \multicolumn{6}{|l|}{ Region } & 360 \\
\hline Northeast $\ldots \ldots \ldots \ldots \ldots \ldots \ldots$. & 25 & 26 & 819 & 28 & 23 & 641 \\
\hline Midwest $\ldots \ldots \ldots \ldots \ldots \ldots \ldots$ & 32 & 13 & 241 & 22 & 24 & 393 \\
\hline South $\ldots \ldots \ldots \ldots \ldots \ldots \ldots$ & 18 & 21 & 540 & $\overline{23}$ & 16 & 764 \\
\hline West $\ldots \ldots \ldots \ldots \ldots \ldots \ldots \ldots$ & 13 & 42 & NC & 32 & 23 & NC \\
\hline \multicolumn{7}{|l|}{ Number of Vehicles } \\
\hline One $\ldots \ldots \ldots \ldots$ & 19 & 18 & 282 & 19 & 20 & 751 \\
\hline Two $\ldots \ldots \ldots \ldots \ldots \ldots \ldots$ & 15 & 16 & 674 & 20 & 15 & 340 \\
\hline Three $\ldots \ldots \ldots \ldots \ldots \ldots \ldots \ldots$ & 38 & 33 & 571 & 33 & 31 & NC \\
\hline Four or More $\ldots \ldots \ldots \ldots \ldots \ldots$ & 21 & 75 & NC & 71 & 24 & NC \\
\hline \multicolumn{7}{|l|}{ Sex of Respondent } \\
\hline Male..$\ldots \ldots \ldots \ldots \ldots \ldots \ldots$ & 15 & 17 & 317 & 15 & 19 & 1,158 \\
\hline \multicolumn{7}{|l|}{ Age of Main Driver } \\
\hline 16 to $24 \ldots \ldots \ldots$ & 63 & 23. & NC & 33 & 46 & NC \\
\hline 25 to $34 \ldots \ldots \ldots \ldots \ldots \ldots \ldots$ & 26 & 18 & 986 & 25 & 22 & 705 \\
\hline 35 to $44 \ldots \ldots \ldots \ldots \ldots \ldots \ldots$ & 18 & 20 & NC & 24 & 23 & 391 \\
\hline 45 to $54 \ldots \ldots \ldots \ldots \ldots \ldots \ldots$ & 18. & 49 & 237 & 32 & 18 & NC \\
\hline 55 or Older $\ldots \ldots \ldots \ldots \ldots \ldots \ldots$ & 20 & 27 & 321 & 30 & 22 & 565 \\
\hline \multicolumn{7}{|l|}{ Education of Respondent } \\
\hline Elementary ................. & 64 & 115 & NC & 62 & 103 & NC \\
\hline High School $\ldots \ldots \ldots \ldots \ldots \ldots$ & 16 & 19 & 1,235 & 21 & 16 & 308 \\
\hline College $\ldots \ldots \ldots \ldots \ldots \ldots \ldots \ldots$ & 16 & 15 & 265 & 17 & 17 & 1,010 \\
\hline Graduate School $\ldots \ldots \ldots \ldots \ldots \ldots$ & 25 & 36 & 676 & 39 & 25 & NC \\
\hline \multicolumn{7}{|l|}{ Race of Respondent } \\
\hline White $\ldots \ldots \ldots \ldots \ldots \ldots \ldots$ & 10 & 13 & 294 & 13 & 12 & 322 \\
\hline Black $\ldots \ldots \ldots \ldots \ldots \ldots \ldots \ldots$ & 400 & 10 & NC & 43 & 29 & NC \\
\hline Asian..$\ldots \ldots \ldots \ldots \ldots \ldots \ldots$ & 19 & 299 & NC & 166. & 44 & NC \\
\hline Other $\ldots \ldots \ldots \ldots \ldots \ldots \ldots \ldots$ & 74 & 30 & 560 & 57 & 30 & NC \\
\hline \multicolumn{7}{|l|}{ Household Income } \\
\hline$\$ 30,000$ or Less $\ldots \ldots \ldots \ldots \ldots \ldots$ & 21 & 22 & 365 & 31 & 17 & 382 \\
\hline More than $\$ 30,000 \ldots \ldots \ldots \ldots$ & 12 & 13 & 387 & 13 & 13 & 620 \\
\hline \multicolumn{7}{|l|}{ Type of Housing Unit } \\
\hline Apartment $\ldots . \ldots \ldots \ldots \ldots \ldots$ & 26 & 31 & NC & 53 & 24. & 447 \\
\hline Single-Family Detached..$\ldots \ldots \ldots$ & 12 & 13 & 272 & 14 & 13 & 623 \\
\hline Townhouse $\ldots \ldots \ldots \ldots \ldots \ldots$ & 42 & 102 . & NC & 35 & 57 & NC \\
\hline Other.$\ldots \ldots \ldots \ldots \ldots \ldots \ldots \ldots$ & 53 & 24 & 643 & 61 & 25 & 497 \\
\hline \multicolumn{7}{|l|}{ Transportation Type Most Often } \\
\hline Used & & & & & & \\
\hline Public Transportation ........... & 54 & 135 & NC & 42 & 124 & NC \\
\hline Personal Vehicles . . . . . . . . . . . & 12 & 13 & 286 & 14 & 12 & 631 \\
\hline Both $\ldots \ldots \ldots \ldots \ldots \ldots \ldots \ldots$ & 44 & 39 & NC & 49 & 36 & 531 \\
\hline Neither.$\ldots \ldots \ldots \ldots \ldots \ldots$. & NC & NC & NC & NC & 0 & NC \\
\hline Don'4 Know ................ & 0 & NC & NC & 0 & NC & NC \\
\hline
\end{tabular}


Table 4.5.13. Relative Standard Errors for Vehicle Choice When Consumer Must Refuel Modified Vehicle Twice as Often as a Regular Vehicle and the Modified Vehicle Has Half the Trunk/Cargo Space of a Regular Vehicle, 1994 (Continued) (Percent)

\begin{tabular}{|c|c|c|c|c|c|c|}
\hline \multirow[b]{3}{*}{ Consumer Characteristic } & \multicolumn{6}{|c|}{ Must Fuel Twice as Often and Half Trunk/Cargo Space } \\
\hline & \multicolumn{3}{|c|}{$\begin{array}{c}\text { Modified Vehicle Pollutes Half as Much } \\
\text { as Regular Vehicle }\end{array}$} & \multicolumn{3}{|c|}{ Modified Vehicle Does Not Pollute } \\
\hline & $\begin{array}{l}\text { Regular } \\
\text { Vehicle }\end{array}$ & $\begin{array}{l}\text { Modified } \\
\text { Vehicle }\end{array}$ & $\begin{array}{l}\text { Don't } \\
\text { Know } \\
\end{array}$ & $\begin{array}{l}\text { Regular } \\
\text { Vehicle }\end{array}$ & $\begin{array}{c}\text { Modified } \\
\text { Vehicle }\end{array}$ & $\begin{array}{l}\text { Don't } \\
\text { Know }\end{array}$ \\
\hline \multicolumn{7}{|l|}{$\begin{array}{l}\text { Respondent Concern for the } \\
\text { Environment }\end{array}$} \\
\hline Extremely Concemed ........... & 44 & 27 & 687 & 41 & 36 & 245 \\
\hline Very Concerned..$\ldots \ldots \ldots \ldots \ldots$ & 16 & 25 & 968 & 23 & 14 & NC \\
\hline Somewhat Concemed .......... & 14 & 22 & 670 & . 21 & 20 & 845 \\
\hline Not Too Concerned $\ldots . . . \ldots \ldots$ & 107 & 51 & 371 & 73 & 58 & NC \\
\hline \multicolumn{7}{|l|}{ Trunk Size } \\
\hline Large Trunk .............. & 37 & 11 & 988 & 36 & 10 & 465 \\
\hline Medium Trunk .............. & 32 & 31 & 366 & 25 & 53 & 139 \\
\hline Small Trunk ................ & 34 & 19 & NC & 34 & 24 & NC \\
\hline No Trunk $\ldots \ldots \ldots \ldots \ldots \ldots \ldots$ & 9 & 47 & 369 & 13 & 32 & NC \\
\hline \multicolumn{7}{|l|}{$\begin{array}{l}\text { More Than Half the Trunk Space } \\
\text { Used }\end{array}$} \\
\hline Yes...$\ldots \ldots \ldots \ldots \ldots \ldots \ldots \ldots$ & 13 & 17 & 481 & 14 & 17 & 551 \\
\hline All the Time...$\ldots \ldots \ldots \ldots \ldots$ & 33 & 81 & 496 & 48 & 41 & NC \\
\hline Most of the Time ............ & 24 & 77 & 283 & 26 & 43 & NC \\
\hline Some of the Time...$\ldots \ldots \ldots$ & 17 & 25 & NC & 16 & 36 & 855 \\
\hline Rarely ................. & 34 & 21 & NC & 41 & 20 & 493 \\
\hline No $\ldots \ldots \ldots \ldots \ldots \ldots \ldots \ldots \ldots$ & 18 & 16 & 401 & 28 & 13 & 907 \\
\hline \multicolumn{7}{|l|}{ Things Stored or Left in Trunk } \\
\hline Yes $\ldots \ldots \ldots \ldots \ldots \ldots \ldots \ldots \ldots$ & 22 & 39 & 257 & 19 & 30 & NC \\
\hline No $\ldots \ldots \ldots \ldots \ldots \ldots \ldots \ldots \ldots$ & 16 & 31 & NC & 19 & 38 & 738 \\
\hline \multicolumn{7}{|l|}{ Frequency of Gas Purchase } \\
\hline Less than Once a Week .......... & 13 & 19 & 250 & 21 & 17 & 297 \\
\hline Once a Week..$\ldots \ldots \ldots \ldots \ldots$. & 17 & 16 & 1,634 & 18 & 15 & 938 \\
\hline More than Once a Week .......... & 38 & 24 & 724 & 32 & 24 & NC \\
\hline \multicolumn{7}{|l|}{ Amount of Gas Purchase } \\
\hline Does not Fill Tank .............. & 27 & 29 & NC & 35 & 31 & NC \\
\hline Does Fill Tank . . . . . . . . . . . . . . . . & 11 & 12 & 256 & 13 & 11 & 342 \\
\hline
\end{tabular}

NC $=$ No case in responding sample.

Source: Energy Information Administration, Office of Energy Markets and End Use, Joint Program in Survey Methodology Consumer Vehicle Preference Survey. 
Table 4.5.14. Relative Standard Errors for Vehicle Choice When Consumer Must Drive 15 Minutes Out of the Way to Refuel Modified Vehicle and Modified Vehicle Must be Refueled Twice as Often as a Regular Vehicle, 1994 (Percent)

\begin{tabular}{|c|c|c|c|c|c|c|}
\hline \multirow{3}{*}{ Consumer Characteristic } & \multicolumn{6}{|c|}{ Consumer Must Drive 15 Minutes Out of the Way and Fuel Twice as Often } \\
\hline & \multicolumn{3}{|c|}{$\begin{array}{c}\text { Modified Vehicle Pollutes Half as Much } \\
\text { as Regular Vehicle }\end{array}$} & \multicolumn{3}{|c|}{ Modified Vehicle Does Not Pollute } \\
\hline & $\begin{array}{l}\text { Regular } \\
\text { Vehicle }\end{array}$ & $\begin{array}{l}\text { Modified } \\
\text { Vehicle }\end{array}$ & $\begin{array}{l}\text { Don't } \\
\text { Know }\end{array}$ & $\begin{array}{l}\text { Regular } \\
\text { Vehicle }\end{array}$ & $\begin{array}{c}\text { Modified } \\
\text { Vehicle }\end{array}$ & $\begin{array}{l}\text { Don't } \\
\text { Know }\end{array}$ \\
\hline All Consumers...$\ldots \ldots \ldots \ldots$. & 25 & 5 & 410 & 28 & 4 & 213 \\
\hline \multicolumn{7}{|l|}{ Region } \\
\hline Northeast $\ldots \ldots \ldots \ldots \ldots \ldots \ldots$ & 44 & 14 & 861 & 56 & 11 & 217 \\
\hline Midwest $\ldots \ldots \ldots \ldots \ldots \ldots \ldots$ & 75 & 7 & 363 & 68 & 7 & NC \\
\hline South $: \ldots \ldots \ldots \ldots \ldots \ldots \ldots$ & 41 & 8 & 1,131 & 56 & 6 & 408 \\
\hline West.$\ldots \ldots \ldots \ldots \ldots \ldots \ldots \ldots$ & 50 & 13 & NC & 51 & 11 & 444 \\
\hline \multicolumn{7}{|l|}{ Number of Vehicles } \\
\hline One ... :................... & 50 & 8 & 414 & 40 & 8 & 207 \\
\hline Two $\ldots \ldots \ldots \ldots \ldots \ldots \ldots \ldots$ & 33 & 8 & 1,264 & 50 & 6 & 581 \\
\hline Three $\ldots \ldots \ldots \ldots \ldots \ldots \ldots$ & 89 & 10 & 745 & 107 & 9 & 667 \\
\hline Four or More...$\ldots \ldots \ldots \ldots \ldots$ & 69 & 19 & NC & 71 & 20 & NC \\
\hline \multicolumn{7}{|l|}{ Sex of Respondent } \\
\hline Male $\ldots \ldots \ldots \ldots$ & 36 & 7 & 668 & 37 & 7 & 236 \\
\hline Female $\ldots \ldots \ldots \ldots \ldots \ldots \ldots$ & 35 & 6 & 521 & 44 & 5 & 405 \\
\hline \multicolumn{7}{|l|}{ Age of Main Driver } \\
\hline 16 to $24 \ldots \ldots \ldots$ & 70 & 12 & NC & 45 & 22 & NC \\
\hline 25 to $34 \ldots \ldots \ldots \ldots \ldots \ldots$ & 43 & 12 & NC & 46 & 11 & 546 \\
\hline 35 to $44 \ldots \ldots \ldots \ldots \ldots \ldots \ldots$ & 34 & 11 & NC & 56 & 6 & NC \\
\hline 45 to $54 \ldots \ldots \ldots \ldots \ldots \ldots \ldots$ & 131 & 7 & 841 & 127 & 8 & 241 \\
\hline 55 or Older $\ldots \ldots \ldots \ldots \ldots \ldots$ & 84 & 10 & 219 & 78 & 9 & 214 \\
\hline \multicolumn{7}{|l|}{ Education of Respondent } \\
\hline Elementary...$\ldots \ldots \ldots \ldots \ldots$ & 284 & 20 & NC & NC & $0^{\circ}$ & NC \\
\hline High School ................ & 42 & 9 & 578 & 49 & 7 & 465 \\
\hline College $\ldots \ldots \ldots \ldots \ldots \ldots \ldots$ & 42 & 6 & 508 & 45 & 6 & 457 \\
\hline Graduate School ............. & 39 & 24 & NC & 54 & 13 & 217 \\
\hline \multicolumn{7}{|l|}{ Race of Respondent } \\
\hline White $\ldots \ldots \ldots \ldots \ldots \ldots \ldots \ldots$ & 28 & 5 & 371 & 31 & 4 & 350 \\
\hline Black ................ & 132 & 13 & NC & 70 & 21 & NC \\
\hline Asian.$\ldots \ldots \ldots \ldots \ldots \ldots$ & 83 & 63 & NC & 364 & 30 & 244 \\
\hline 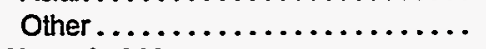 & 73 & 25 & NC & 364 & 50 & 96 \\
\hline \multicolumn{7}{|l|}{ Household Income } \\
\hline$\$ 30,000$ or Less $\ldots \ldots \ldots \ldots \ldots$ & 52 & 9 & 234 & 53 & 7 & 580 \\
\hline More than $\$ 30,000 \ldots \ldots \ldots \ldots$ & 29 & 6 & NC & 34 & 5 & 221 \\
\hline \multicolumn{7}{|l|}{ Type of Housing Unit } \\
\hline Apartment $\ldots \ldots \ldots \ldots \ldots \ldots \ldots$ & 69 & 9 & NC & 63 & 14 & 213 \\
\hline Single-Family Detached...$\ldots \ldots$ & 32 & 6 & 413 & 37 & 5 & 342 \\
\hline Townhouse ................ & 104 & 25 & NC & 356 & 13 & 505 \\
\hline Other $\ldots \ldots \ldots \ldots \ldots \ldots \ldots \ldots$ & 55 & 16 & 705 & 54 & 13 & NC \\
\hline \multicolumn{7}{|l|}{ Transportation Type Most Often } \\
\hline Used & & & & & & \\
\hline Public Transportation ........... & NO & 0 & NC & 182 & 18 & NC \\
\hline Personal Vehicles .............. & 27 & 6 & 423 & 31 & 5 & 270 \\
\hline Both $\ldots \ldots \ldots \ldots \ldots \ldots \ldots$ & 144 & 11 & NC & 400 & 12 & 259 \\
\hline Don't Know & 101 & 126 & NC & NC & 37 & 200 \\
\hline
\end{tabular}

See footnotes at end of table. 
Table 4.5.14. Relative Standard Errors for Vehicle Choice When Consumer Must Drive 15 Minutes Out of the Way to Refuel Modified Vehicle and Modified Vehicle Must be Refueled Twice as Often as a Regular Vehicle, 1994 (Continued) (Percent)

\begin{tabular}{|c|c|c|c|c|c|c|}
\hline \multirow[b]{3}{*}{ Consumer Characteristic } & \multicolumn{6}{|c|}{ Consumer Must Drive 15 Minutes Out of the Way and Fuel Twice as Often } \\
\hline & \multicolumn{3}{|c|}{$\begin{array}{l}\text { Modified Vehicle Pollutes Half as Much } \\
\text { as Regular Vehicle }\end{array}$} & \multicolumn{3}{|c|}{ Modified Vehicle Does Not Pollute } \\
\hline & $\begin{array}{l}\text { Regular } \\
\text { Vehicle }\end{array}$ & $\begin{array}{l}\text { Modified } \\
\text { Vehicle }\end{array}$ & $\begin{array}{l}\text { Don't } \\
\text { Know }\end{array}$ & $\begin{array}{l}\text { Regular } \\
\text { Vehicle }\end{array}$ & $\begin{array}{l}\text { Modified } \\
\text { Vehicle }\end{array}$ & $\begin{array}{l}\text { Don't } \\
\text { Know }\end{array}$ \\
\hline $\begin{array}{l}\text { All Consumers } \ldots \ldots \ldots \ldots \ldots \ldots \\
\text { Respondent Concern for the } \\
\text { Environment }\end{array}$ & 25 & 5 & 410 & 28 & 4 & 213 \\
\hline Extremely Concerned ............ & 120 & 10 & 269 & 95 & 7 & 907 \\
\hline Very Concemed .............. & 53 & 7 & NC & 45 & 7 & 882 \\
\hline Somewhat Concemed . . . . . . . . & 34 & 10 & NC & 43 & 10 & 342 \\
\hline Not Too Concemed ............. & 124 & 51 & 259 & 129 & 98 & 95 \\
\hline Frequency of Gas Purchase & & & & & & \\
\hline Less than Once a Week .......... & 53 & 6 & 326 & 42 & 7 & 212 \\
\hline Once a Week ................... & 37 & 7 & NC & 45 & 6 & 789 \\
\hline More than Once a Week . . . . . . . . . & 38 & 20 & 779 & 71 & 14 & 503 \\
\hline Amount of Gas Purchase & & & & & & \\
\hline Does not Fill Tank . . . . . . . . . . . . . & 64 & 17 & NC & 54 & 14 & NC \\
\hline Does Fill Tank $\ldots \ldots \ldots \ldots \ldots \ldots$ & 27 & 5 & 387 & 32 & 4 & 198 \\
\hline
\end{tabular}

NC $=$ No cases in responding sample.

Source: Energy Information Administration, Office of Energy Markets and End'Use, Joint Program in Survey Methodology Consumer Vehicle Preference Survey. 
Table 4.5.15. Relative Standard Errors for Vehicle Choice When Consumer Must Drive 15 Minutes Out of the Way to Refuel the Modified Vehicle, the Modified Vehicle Must be Refueled Twice as Often as a Regular Vehicle, and the Modified Vehicle Costs $\$ 1,000$ Less, 1994 (Percent)

\begin{tabular}{|c|c|c|c|c|c|c|}
\hline \multirow{3}{*}{ Consumer Characteristic } & \multicolumn{6}{|c|}{15 Minutes Out of the Way to Fuel, Fuel Twice as Often, Vehicle $\$ 1,000$ Less } \\
\hline & \multicolumn{3}{|c|}{$\begin{array}{c}\text { Modified Vehicle Pollutes Half as Much } \\
\text { as Regular Vehicle }\end{array}$} & \multicolumn{3}{|c|}{ Modified Vehicle Does Not Pollute } \\
\hline & $\begin{array}{l}\text { Regular } \\
\text { Vehicle }\end{array}$ & $\begin{array}{l}\text { Modified } \\
\text { Vehicle }\end{array}$ & $\begin{array}{l}\text { Don't } \\
\text { Know }\end{array}$ & $\begin{array}{l}\text { Regular } \\
\text { Vehicle }\end{array}$ & $\begin{array}{l}\text { Modified } \\
\text { Vehicle }\end{array}$ & $\begin{array}{l}\text { Don't } \\
\text { Know }\end{array}$ \\
\hline All Consumers $\ldots \ldots \ldots \ldots \ldots \ldots$ & 26 & 17 & 249 & 37 & 13 & 179 \\
\hline Region & - & & & & & \\
\hline Northeast $\ldots \ldots \ldots \ldots \ldots \ldots \ldots$ & 45 & 42 & 482 & 84 & 37 & 103 \\
\hline Midwest $\ldots \ldots \ldots \ldots \ldots \ldots \ldots$ & 57 & 43 & 215 & 89 & 25 & NC \\
\hline South $\ldots \ldots \ldots \ldots \ldots \ldots \ldots$ & 66 & 19 & 565 & 50 & 26 & 588 \\
\hline West $\ldots \ldots \ldots \ldots \ldots \ldots \ldots \ldots$ & 40 & 45 & NC & 91 & 19 & NC \\
\hline \multicolumn{7}{|l|}{ Number of Vehicles } \\
\hline One $\ldots \ldots \ldots \ldots \ldots \ldots \ldots \ldots$ & 79 & 22 & 185. & 85 . & 19 & 152 \\
\hline Two $\ldots \ldots \ldots \ldots \ldots \ldots \ldots \ldots$ & 35 & 27 & 330 & 46 & 23 & 595 \\
\hline Three $\ldots \ldots \ldots \ldots \ldots \ldots \ldots \ldots \ldots$. & 90 & 37 & NC & 33 & 121 & NC \\
\hline Four or More ............... & 28 & 142 & NC & NC & 0 & NC \\
\hline \multicolumn{7}{|l|}{ Sex of Respondent } \\
\hline Male $\ldots \ldots \ldots \ldots \ldots \ldots \ldots \ldots$ & 28 & 34 & 332 & 45 & 20 & 258 \\
\hline Female...$\ldots \ldots \ldots \ldots \ldots$ & 46 & 18 & 369 & 63 & 18 & 254 \\
\hline \multicolumn{7}{|l|}{ Age of Main Driver } \\
\hline 16 to $24 \ldots \ldots \ldots \ldots \ldots \ldots \ldots \ldots$ & 34 & 84 & NC & 71 & 40 & NC \\
\hline 25 to $34 \ldots \ldots \ldots \ldots \ldots \ldots \ldots \ldots$ & 59 & 26 & NC & 56 & 26 & NC \\
\hline 35 to $44 \ldots \ldots \ldots \ldots \ldots \ldots \ldots \ldots$ & 26 & 41 & NC & 71 & 26 & 520 \\
\hline 45 to $54 \ldots \ldots \ldots \ldots \ldots \ldots \ldots \ldots$ & NC & 19 & 282 & 105 & 43 & 232 \\
\hline 55 or Older $\ldots \ldots \ldots \ldots \ldots \ldots$ & 204 & 29 & 125 & 210 & 25 & 131 \\
\hline \multicolumn{7}{|l|}{ Education of Respondent } \\
\hline Elementary $\ldots \ldots \ldots \ldots \ldots \ldots \ldots$. & NC & NC & NC & NC & NC & NC \\
\hline High School $\ldots \ldots \ldots \ldots \ldots \ldots \ldots$ & 34 & 35 & 576 & 41 & 40 & 216 \\
\hline College $\ldots \ldots \ldots \ldots \ldots \ldots \ldots \ldots$ & 42 & 24 & 219 & 62 & 18 & 332 \\
\hline Graduate School $\ldots \ldots \ldots \ldots \ldots \ldots$ & 96 & 23 & NC & 150 & 16 & 536 \\
\hline \multicolumn{7}{|l|}{ Race of Respondent } \\
\hline White $\ldots \ldots \ldots \ldots \ldots \ldots \ldots \ldots \ldots$ & 33 & 16 & 222 & 42 & 15 & 161 \\
\hline Black $\ldots \ldots \ldots \ldots \ldots \ldots \ldots \ldots$ & 116 & 55 & NC & 54 & 79 & NC \\
\hline Asian...$\ldots \ldots \ldots \ldots \ldots \ldots$ & 0 & NC & NC & NC & 0 & NC \\
\hline Other $\ldots \ldots \ldots \ldots \ldots \ldots \ldots \ldots \ldots$ & 50 & 104 & NC & 244 & 37 & NC \\
\hline \multicolumn{7}{|l|}{ Household Income } \\
\hline$\$ 30,000$ or Less & 66 & 28 & 188 & 61 & 29 & 264 \\
\hline More than $\$ 30,000 \ldots \ldots$ & 27 & 21 & 831 & 47 & 15 & 239 \\
\hline \multicolumn{7}{|l|}{ Type of Housing Unit } \\
\hline Apartment ............. & 96 & 35 & 372 & 68 & 35 & 531 \\
\hline Single-Family Detached ......... & 23 & 28 & 398 & 48 & 15 & 536 \\
\hline Townhouse ................. & NC & 0 & NC & 82 & 156 & NC \\
\hline Other...$\ldots \ldots \ldots \ldots \ldots \ldots \ldots$ & 257 & 25 & 390 & 188 & 37 & 106 \\
\hline \multirow{2}{*}{\multicolumn{7}{|c|}{$\begin{array}{l}\text { Transportation Type Most Often } \\
\text { Used }\end{array}$}} \\
\hline & & & & & & \\
\hline Public Transportation ........... & NC & NC & NC & 99 & 129 & NC \\
\hline Personal Vehicles...$\ldots \ldots \ldots \ldots$. . & 22 & 27 & 214 & 46 & 15 & 189 \\
\hline Both $\ldots \ldots \ldots \ldots \ldots \ldots \ldots \ldots \ldots$ & NC & 0 & NC & 189 & 48 & NC \\
\hline Don't know. & NC & 0 & NC & NC & 0 & NC \\
\hline
\end{tabular}


Table 4.5.15. Relative Standard Errors for Vehicle Choice When Consumer Must Drive 15 Minutes Out of the Way to Refuel the Modified Vehicle, the Modified Vehicle Must be Refueled Twice as Often as a Regular Vehicle, and the Modified Vehicle Costs $\$ 1,000$ Less, 1994 (Continued) (Percent)

\begin{tabular}{|c|c|c|c|c|c|c|}
\hline \multirow[b]{3}{*}{ Consumer Characteristic } & \multicolumn{6}{|c|}{15 Minutes Out of the Way to Fuel, Fuel Twice as Otten, Vehicle $\$ 1,000$ Less } \\
\hline & \multicolumn{3}{|c|}{$\begin{array}{l}\text { Modified Vehicle Pollutes Half as Much } \\
\text { as Regular Vehicle }\end{array}$} & \multicolumn{3}{|c|}{ Modified Vehicle Does Not Pollute } \\
\hline & $\begin{array}{l}\text { Regular } \\
\text { Vehicle }\end{array}$ & $\begin{array}{l}\text { Modified } \\
\text { Vehicle }\end{array}$ & $\begin{array}{l}\text { Don't } \\
\text { Know }\end{array}$ & $\begin{array}{l}\text { Regular } \\
\text { Vehicle }\end{array}$ & $\begin{array}{c}\text { Modified } \\
\text { Vehicle }\end{array}$ & $\begin{array}{l}\text { Don't } \\
\text { Know }\end{array}$ \\
\hline $\begin{array}{l}\text { All Consumers } \ldots \ldots \ldots \ldots \ldots \ldots \\
\text { Respondent Concern for the } \\
\text { Environment }\end{array}$ & 26 & 17 & 249 & 37 & 13 & 179 \\
\hline Extremely Concemed ........... & 95 & 60 & 154 & 98 & 28 & NC \\
\hline Very Concemed ............... & 35 & 41 & NC & 61 & 24 & 227 \\
\hline Somewhat Concemed .......... & 44 & 22 & NC & 58 & 26 & 288 \\
\hline $\begin{array}{l}\text { Not Too Concemed ............. } \\
\text { Frequency of Gas Purchase }\end{array}$ & 161 & 166 & 153 & 279 & 26 & NC \\
\hline Less than Once a Week .......... & 32 & 38 & 277 & 53 & 20 & 225 \\
\hline Once a Week ................ & 50 & 20 & 674 & 60 & 18 & 616 \\
\hline More than Once a Week . . . . . . . . & 62 & 34 & 488 & 102 & 46 & 254 \\
\hline Amount of Gas Purchase & & & & & & \\
\hline Does not Fill Tank .............. & 24 & 137 & NC & 78 & 33 & NC \\
\hline Does Fill Tank . . . . . . . . . . . & 33 & 16 & 231 & 42 & 15 & 165 \\
\hline
\end{tabular}


Table 4.5.16. Relative Standard Errors for Vehicle Choice When Consumer Mụst Drive 15 Minutes Out of the Way to Refuel the Modified Vehicle, the Modified Vehicle Must be Refueled Twice as Often as a Regular Vehicle, and the Modified Vehicle Has Half the Trunk/Cargo Space of a Regular Vehicle, 1994 (Percent)

\begin{tabular}{|c|c|c|c|c|c|c|}
\hline \multirow[b]{3}{*}{ Consumer Characteristic } & \multicolumn{6}{|c|}{ Drive 15 minutes out of the Way, Fuel Twice as Often, Half Trunk/Cargo Space } \\
\hline & \multicolumn{3}{|c|}{$\begin{array}{c}\text { Modified Vehicle Pollutes Half as Much } \\
\text { as Regular Vehicle }\end{array}$} & \multicolumn{3}{|c|}{ Modified Vehicle Does Not Pollute } \\
\hline & $\begin{array}{l}\text { Regular } \\
\text { Vehicle }\end{array}$ & $\begin{array}{c}\text { Modified } \\
\text { Vehicle }\end{array}$ & $\begin{array}{l}\text { Don't } \\
\text { Know }\end{array}$ & $\begin{array}{l}\text { Regular } \\
\text { Vehicle }\end{array}$ & $\begin{array}{l}\text { Modified } \\
\text { Vehicle }\end{array}$ & $\begin{array}{l}\text { Don't } \\
\text { Know }\end{array}$ \\
\hline \multicolumn{6}{|l|}{ Region } & 196 \\
\hline Northeast $\ldots \ldots \ldots \ldots \ldots \ldots \ldots$ & 25 & 35 & 1,230 & 47 & 15 & 878 \\
\hline Midwest $\ldots \ldots \ldots \ldots \ldots \ldots \ldots$ & 31 & 15 & 572 & 32 & 16 & 1,059 \\
\hline South $\ldots \ldots \ldots \ldots \ldots \ldots \ldots$ & 33 & 13 & 792 & 30 & 12 & 312 \\
\hline West . . . . . . . . . . . . . & 52 & 18 & NC & 41 & 19 & 213 \\
\hline \multicolumn{7}{|l|}{ Number of Vehicles } \\
\hline One $\ldots \ldots \ldots \ldots \ldots$ & 43 & 11 & 831 & 42 & 10 & 262 \\
\hline Two $\ldots \ldots \ldots \ldots \ldots \ldots \ldots$ & 22 & 15 & . 1,137 & 22 & 15 & 404 \\
\hline Three...$\ldots \ldots \ldots \ldots \ldots \ldots$ & 36 & 25 & 532 & 38 & 22 & 354 \\
\hline 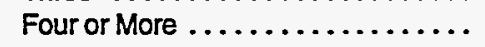 & 47 & 39 & NC & 97 & 21 & NC \\
\hline \multicolumn{7}{|l|}{ Sex of Respondent } \\
\hline Male...$\ldots \ldots \ldots \ldots \ldots \ldots$ & 24 & 14 & 496 & 26 & 11 & 285 \\
\hline Female $\ldots \ldots \ldots \ldots \ldots \ldots \ldots$ & 24 & 11 & 1,097 & 25 & 10 & 272 \\
\hline \multicolumn{4}{|l|}{ Age of Main Driver } & 68 & 22 & NC \\
\hline 25 to $34 \ldots \ldots \ldots \ldots \ldots \ldots \ldots \ldots \ldots$ & 36 & 19 & NC & 44 & 15 & 1,018 \\
\hline 35 to $44 \ldots \ldots \ldots \ldots \ldots \ldots \ldots$ & 25 & 22 & 915 & 33 & 13 & 445 \\
\hline 45 to $54 \ldots \ldots \ldots \ldots \ldots \ldots \ldots$ & 55 & 15 & 631 & 46 & 17 & 285 \\
\hline 55 or Older $\ldots \ldots \ldots \ldots \ldots \ldots$ & 41 & 20 & 606 & 30 & 21 & 248 \\
\hline \multicolumn{7}{|l|}{ Education of Respondent } \\
\hline Elementary ................. & 274 & 23 & NC & 229 & 32 & NC \\
\hline High School ................. & 35 & 14 & 331 & 46 & 10 & 337 \\
\hline College $\ldots \ldots \ldots \ldots \ldots \ldots \ldots$ & 20 & 13 & 2,273 & 22 & 13 & 244 \\
\hline Graduate School .............. & 55 & 29 & NC & $\overline{33}$ & 23 & 1,005 \\
\hline \multicolumn{7}{|l|}{ Race } \\
\hline$\ldots \ldots \ldots \ldots \ldots$ & 16 & 10 & 701 & 18 & 8 & 204 \\
\hline Black ................... & 101 & 25 & 414 & 140 & 20 & 566 \\
\hline$A \operatorname{sian} . \ldots \ldots \ldots \ldots \ldots \ldots, \ldots$, & NC & 0 & NC & 52 & 100 & NC \\
\hline Other.$\ldots \ldots \ldots \ldots \ldots \ldots \ldots \ldots$ & 215 & 15 & NC & 201 & 32 & NC \\
\hline \multicolumn{7}{|l|}{ Household Income } \\
\hline$\$ 30,000$ or Less $\ldots \ldots \ldots \ldots \ldots \ldots$ & 39 & 12 & 1,565 & 44 & 9 & NC \\
\hline More than $\$ 30,000 \ldots \ldots \ldots \ldots \ldots$ & 18 & 12 & 485 & 19 & 11 & 159 \\
\hline \multicolumn{7}{|l|}{ Type of Housing Unit } \\
\hline Apartment $\ldots \ldots \ldots \ldots \ldots \ldots \ldots$ & 48 & 16 & NC & 108 & 9 & NC \\
\hline Single-Family Detached ......... & 20 & 11 & 381 & 17 & 11 & 251 \\
\hline Townhouse ................ & 41 & 81 & NC & 467 & 18 & 199 \\
\hline Other $\ldots \ldots \ldots \ldots \ldots \ldots \ldots$ & 63 & 19 & NC & 52 & 20 & 661 \\
\hline \multirow{2}{*}{\multicolumn{7}{|c|}{$\begin{array}{l}\text { Transportation Type Most Ofte } \\
\text { Used }\end{array}$}} \\
\hline & & & & & & \\
\hline Public Transportation ........... & 115 & 45 & NC & 47 & 68 & NC \\
\hline Personal Vehicles ............. & 19 & 11 & 1,163 & 21 & 10 & 181 \\
\hline Both $\ldots \ldots \ldots \ldots \ldots \ldots \ldots \ldots$ & 91 & 19 & NC & 86 & 20 & NC \\
\hline Don't know ................... & NC & 0 & NC & NC & 0 & NC \\
\hline
\end{tabular}

See footnotes at end of table. 
Table 4.5.16. Relative Standard Errors for Vehicle Choice When Consumer Must Drive 15 Minutes Out of the Way to Refuel the Modified Vehicle, the Modified Vehicle Must be Refueled Twice as Often as a Regular Vehicle, and the Modified Vehicle Has Half the Trunk/Cargo Space of a Regular Vehicle, 1994 (Continued) (Percent)

\begin{tabular}{|c|c|c|c|c|c|c|}
\hline \multirow[b]{3}{*}{ Consumer Characteristic } & \multicolumn{6}{|c|}{ Drive 15 minutes out of the Way, Fuel Twice as Often, Half Trunk/Cargo Space } \\
\hline & \multicolumn{3}{|c|}{$\begin{array}{c}\text { Modified Vehicle Pollutes Half as Much } \\
\text { as Regular Vehicle }\end{array}$} & \multicolumn{3}{|c|}{ Modified Vehicle Does Not Pollute } \\
\hline & $\begin{array}{l}\text { Regular } \\
\text { Vehicle }\end{array}$ & $\begin{array}{l}\text { Modified } \\
\text { Vehicle }\end{array}$ & $\begin{array}{l}\text { Don't } \\
\text { Know }\end{array}$ & $\begin{array}{l}\text { Regular } \\
\text { Vehicle }\end{array}$ & $\begin{array}{l}\text { Modified } \\
\text { Vehicle }\end{array}$ & $\begin{array}{l}\text { Don't } \\
\text { Know }\end{array}$ \\
\hline $\begin{array}{l}\text { All Consumers } \ldots \ldots \ldots \ldots \ldots \ldots \\
\text { Respondent Concern for the } \\
\text { Environment }\end{array}$ & 17 & 9 & 474 & 18 & 8 & 196 \\
\hline Extremely Concerned ........... & 46 & 21 & NC & 63 & 15 & 196 \\
\hline Very Concemed .............. & 27 & 14 & 878 & 29 & 12 & 982 \\
\hline Somewhat Concemed .......... & 28 & 17 & 431 & 29 & 18 & 333 \\
\hline \multicolumn{7}{|l|}{ Trunk Size } \\
\hline Large Trunk ................ & 45 & 13 & 264 & 36 & 11 & 396 \\
\hline Medium Trunk..$\ldots \ldots \ldots \ldots \ldots$ & 62 & 22 & NC & 75 & 16 & 671 \\
\hline Small Trunk $\ldots \ldots \ldots \ldots \ldots \ldots$ & 72 & 12 & NC & 56 & 15 & 350 \\
\hline \multicolumn{7}{|l|}{$\begin{array}{l}\text { More Than Half the Trunk Space } \\
\text { Used }\end{array}$} \\
\hline Yes...$\ldots \ldots \ldots \ldots \ldots \ldots \ldots$ & 21 & 13 & 364 & 20 & 14 & 251 \\
\hline All the Time $\ldots \ldots \ldots \ldots \ldots \ldots$ & 50 & 66 & NC & 177 & 17 & NC \\
\hline Most of the Time ............. & 51 & 28 & NC & 72 & 39 & 150 \\
\hline Some of the Time ............ & 33 & 22 & 278 & 24 & 21 & 1,155 \\
\hline Rarely.$\ldots \ldots \ldots \ldots \ldots \ldots \ldots$ & 41 & 19 & 1,367 & 34 & 30 & 566 \\
\hline $\begin{array}{l}\text { No } \ldots \ldots \ldots \ldots \ldots \ldots \ldots \ldots \ldots \\
\text { Things Stored or Left in Trunk }\end{array}$ & 36 & 11 & NC & 44 & 8 & 293 \\
\hline Yes $\ldots . . . \ldots \ldots \ldots \ldots \ldots \ldots \ldots$ & 41 & 21 & 554 & 31 & 26 & 247 \\
\hline No $\ldots \ldots \ldots \ldots \ldots \ldots \ldots \ldots \ldots$ & 30 & 26 & 482 & 36 & 18 & 868 \\
\hline \multicolumn{7}{|l|}{ Frequency of Gas Purchase } \\
\hline Less than Once a Week ......... & 21 & 15 & 943 & 25 & 12 & 411 \\
\hline Once a Week ............... & 28 & 13 & 515 & 26 & 12 & 231 \\
\hline More than Once a Week .......... & 79 & 17 & NC & 75 & 16 & 632 \\
\hline \multicolumn{7}{|l|}{ Amount of Gas Purchase } \\
\hline Does not Fill Tank .............. & 118 & 15 & NC & 38 & 28 & NC \\
\hline Does Fill Tank . . . . . . . . . . . . . . & 17 & 10 & 453 & 20 & 8 & 186 \\
\hline
\end{tabular}

$\mathrm{NC}=$ No cases in responding sample.

Source: Energy Information Administration, Office of Energy Markets and End Use, Joint Program in Survey Methodology Consumer Vehicle Preference Survey. 



\subsection{Data Quality}

Most of the information concerning the sample selection and sample weights found in the following pages is excerpted from "Methods Report for Joint Program in Survey Methodology Study of Public Attitudes About Alternative Fuel Vehicles" provided to EIA by the University of Maryland.

\section{Sample Selection}

The eligible population for the study consisted of telephone households in the continental United States that owned or leased one or more motor vehicles driven on a regular basis. The respondent was the adult in the household most knowledgeable about the use of the household's vehicles.

The sample was selected using the Brick-Waksberg (1991)' modification of the Mitofsky-Waksberg (Waksberg 1978) Random Digit dialing two-stage cluster design. A frame of all possible clusters, defined as banks of 100 telephone numbers, was generated (stratified by Census Region) from the January 1994 Bellcore Master Data File, a listing of all area code exchange combinations in the United States. A systematic selection of clusters was then made from this frame. One telephone number was randomly generated in each selected cluster and called. If it was a household, the cluster was retained; if not, the cluster was excluded.

A total of 543 clusters was retained and eight telephone numbers sampled within each. Since clusters are selected with probabilities proportionate to size and the number of second-stage households (households contained within the retained clusters) can vary by cluster, the Brick-Waksberg design does not produce an equal probability sample. The design requires weighting to adjust for these unequal probabilities.

Although the method does not achieve an equal probability sample, it has operational advantages. Unlike the MitofskyWaksberg design, the Brick-Waksberg method does not require sequential replacement of nonresidential telephone numbers. Instead, the total sample is generated and released based on estimates of nonresidential telephone numbers and the anticipated response rate. In this way, the cluster size is achieved without the cost of replacing non-households and nonworking numbers as they are identified.

\section{Response Rate}

A total of 4,344 telephone numbers was selected from the 543 clusters. The disposition of these numbers is summarized in Table 4.6.1.

\footnotetext{
${ }^{1}$ Michael J. Brick and Joseph Waksberg, “Avoiding Sequential Sampling with Random Digit Dialing," Survey Methodology (1991), pp. 17, $27-41$.

2 Joseph Waksberg, "Sampling Methods for Random Digit Dialing," Journal of the American Statistical Association (1978), pp. 73, 40-46.
} 
Table 4.6.1. Disposition of Selected Telephone Numbers

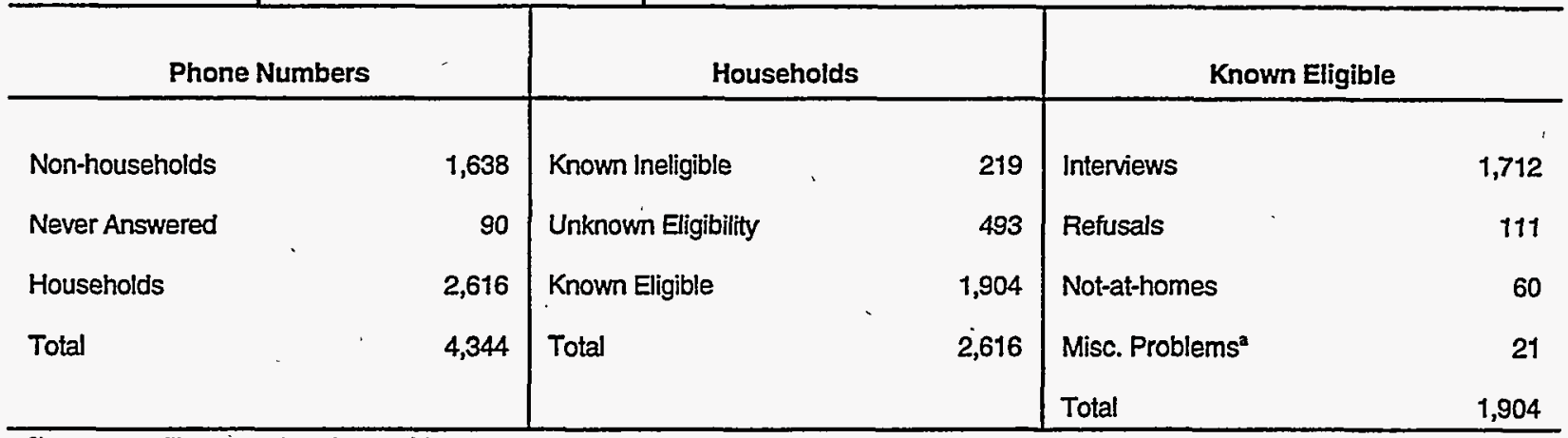

"Language, illness, or hearing problems.

Of the 4,344 numbers, 1,638 were non-households (businesses and non-working numbers). In addition, 90 numbers were never answered after at least 20 dialings and were assumed to be non-households.

Of the 2,616 identified households, eligibility (whether the household owned or leased a vehicle) was determined for 2,123, of which 1,904 were eligible and 219 were ineligible. For 493 cases, eligibility could not be determined mainly because of refusals. The response rate is the total number of interviews divided by the number of eligible cases. The unknown eligibility category can be treated in various ways. The most conservative approach, treating 100 percent of such cases as eligible, gives a response rate of 71.4 percent. A more realistic response rate can be calculated by assuming the same proportion of these households had a vehicle ( 89.7 percent) as for the 2,123 households for which eligibility was determined. This response rate is 73.0 percent.

\section{Sample Weights}

Two design weights were used to adjust for unequal probabilities of selection: (1) the inverse of the number of telephone numbers in the household and (2) the ratio of the mean number of households per cluster to the number of households in the particular cluster. (In eight cases, this weight was trimmed so that it did not exceed three times the mean weight.)

There are also two post-stratification weights: (1) a geographic weight to adjust the sample distribution by major Census region to the distribution of all households with cars and (2) a cluster weight that is the ratio of households with cars (in the cluster) to households with cars that meet the regular use screening criterion. (Most often, this weight equals 1.)

Finally, an additional factor sets the weighted sample size equal to the unweighted sample size. All weights and the adjustment factor are combined into one variable (variable name = WEIGHT) and attached to the record for each case in the data set.

\section{Nonsampling and Sampling Error}

The statistics in this report are estimates of population values. These estimates are based upon a randomly chosen subset of the entire population of households with vehicles in the contiguous United States. As a result, estimates always differ from the true population values. The differences between estimated values and the actual population values are of two types, nonsampling errors and sampling errors. Nonsampling errors are errors of the survey process that can result from difficulties such as unit nonresponse or item nonresponse, inaccuracies in data collection, or incomplete coverage in the design of the sampling frame. Sampling error is a result of the survey design, due to the fact that data are obtained from a subset of the population of interest, rather than all members. 


\section{Nonsampling Errors / Adjustment for Item Nonresponse}

Item nonresponse occurs when an item (or several items) is missing in an otherwise completed questionnaire, possibly because the respondent does not know or, less frequently, refuses to give the answer to a particular question. Item nonresponse is also recorded when the interviewer does not ask the question or does not record the answer during the interview. For eight respondent demographic characteristics and 15 vehicle characteristic variables, values were imputed for nonresponse. No imputations were made for missing preference or attitudinal items. Imputations were made using a technique known as "hot-deck" imputation. In hot-decking, when a certain response is missing for a given respondent, another respondent, called a "donor," is randomly chosen to furnish its reported value for that missing item. That value is then assigned to the respondent with item nonresponse.

To serve as a donor, the respondent has to be similar to the nonrespondent in characteristics correlated with the missing item. This procedure was used to reduce the bias caused by different nonresponse rates for a particular item among different types of respondents. Characteristics used to define "similar" depended on the nature of the item to be imputed. The most frequently used characteristics were: Census region, State, age of the respondent, household income, type of home, and education of the respondent. This analysis used a vector hot-deck procedure. With this procedure, the respondent that donated a particular item to a receiver also donated certain related items if any of these were missing. Thus, a vector of values, rather than a single value, is copied from the donor to the receiver. This helps to keep the hot-decked values internally consistent, avoiding the generation of implausible combinations of respondent or vehicle characteristics.

\section{Sampling Error}

Sampling error occurs because the selected sample represents only one of the possible samples that could be selected under the same survey specifications. The estimated values are developed from one of the many possible samples that could be drawn and, therefore, will differ from true population values that would be obtained from a complete enumeration. Each possible sample yields its own estimate of the true population values, with the differences attributable to the particular set of cases selected in each sample.

One measure of the variability of a survey estimate due to the sampling process is the average magnitude of the difference between the values of the estimate for individual samples and the average value of the estimate over all samples of the same size based on the same design. In other words, sampling error is a measure of the variability of an estimate over all comparable samples, one of which was drawn. The average magnitude of the sampling error is measured by the standard error of an estimate. The standard error is the root-mean-square measure of average difference over all possible samples.

Most statistical packages assume simple random sampling. This study employed a more complex design. Therefore, in estimating sampling errors, a method is needed to take account of the sample design and the use of weights. SUDAAN (Survey Data Analysis) was used to compute the design effect (the ratio of the variance reflecting design complexities to the variance of a simple random sample of the same size) on 21 variables (five demographic, six attitudinal, and ten behaviorial). The design effect was estimated at 1.13. Standard errors were computed by multiplying the standard error associated with a simple random sample design by the design effect as follows:

$$
D E \times \sqrt{\frac{P C T \times(1-P C T)}{n}}=S_{P C T}
$$

where $\mathrm{DE}$ is the design effect, $\mathrm{PCT}$ is the estimate (in the form of a percent of the total), and $\mathrm{S}_{\mathrm{PCr}}$ is the standard error of the estimate.

In this report, standard errors were expressed as relative standard errors (RSE). The relative standard error (RSE) is the standard error expressed as a percent of the estimate, that is, for an estimate PCT: 


$$
\frac{S_{P C T}}{P C T}=R S E_{P C T}
$$

Estimates with RSE greater than 50 percent were withheld from the published tables due to their lack of precision. Estimates were also withheld if the number of observations was less than 10 .

Using the RSE. To determine the standard error for an estimate, multiply the RSE for the estimate, shown in the tables in this appendix, by the estimate. The standard error can be used to construct confidence intervals and to perform hypothesis tests by using standard statistical methods.

\section{Calculating the Confidence Range}

To calculate the 95-percent confidence range (that range which covers the true value of the estimate with 95 percent confidence):

1. Multiply the standard error by 1.96

2. Subtract the result of Step 1 from the given estimate to determine the bottom of the range

3. Add the result of Step 1 to the given estimate to determine the top of the range.

\section{Measuring Statistical Significance}

To determine if the difference between any two estimates in this report are statistically significant:

1. Calculate the standard error of each estimate

2. Square the standard error of each estimate

3. Add the two values from Step 2

4. Take the square root of the value in Step 3

5. Multiply the value in Step 4 by 1.96

If the value in Step 5 is less than the difference in the estimates, the difference between the estimates is statistically significant. 
Section 5.

U.S. Census Region

Map and Glossary 



\subsection{U.S. Census Region Map}

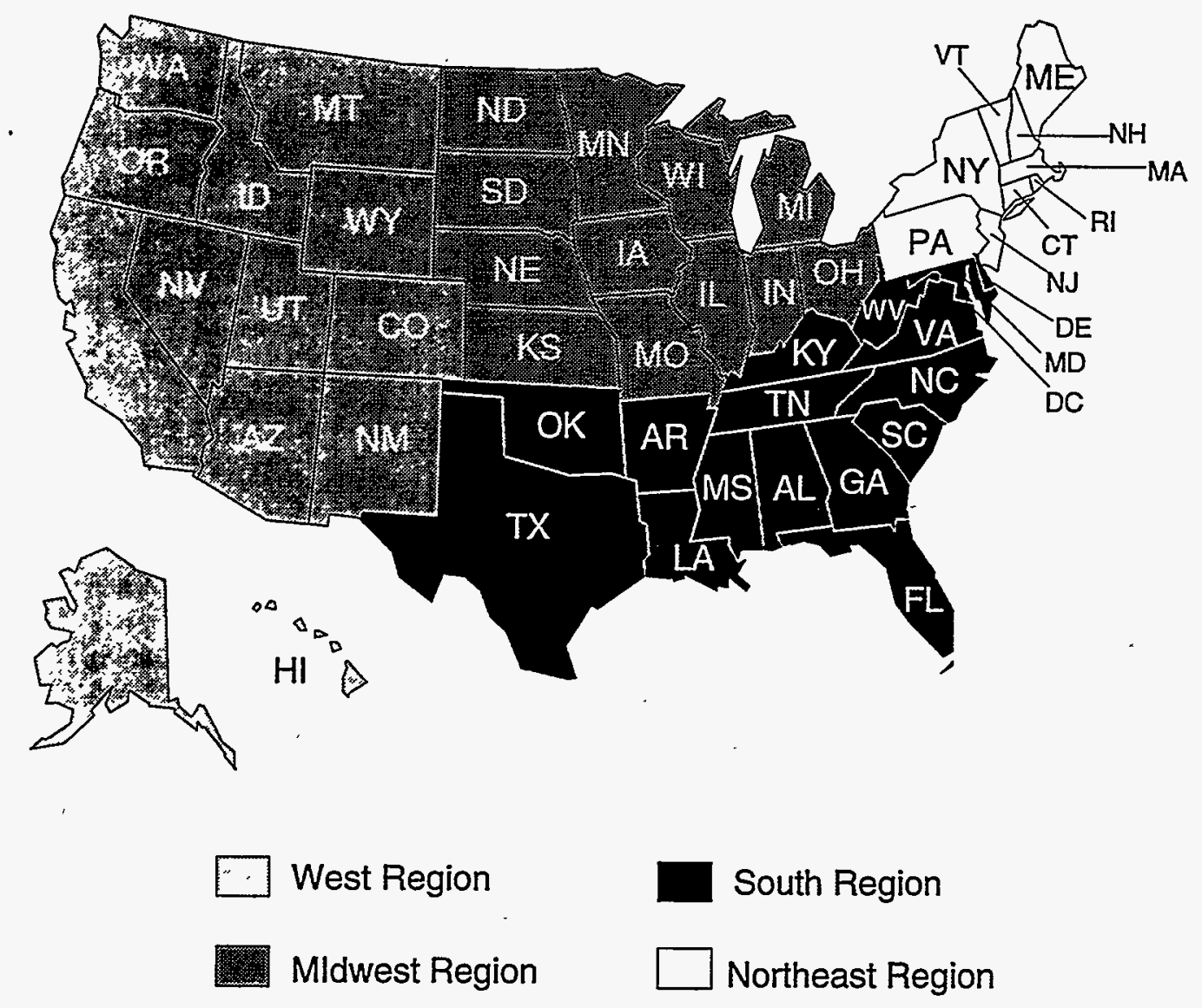





\subsection{Glossary}

Alternative Fuel: As defined pursuant to EPACT: "methanol, denatured ethanol, and other alcohols; mixtures containing 85 percent or more (or such other percentage, but not less than 70 pefcent, as determined by the Secretary, by rule, to provide for requirements relating to cold start, safety, or vehicle functions) by volume of methanol, denatured ethanol, and other alcohols with gasoline or other fuels; natural gas; liquefied petroleum gas; hydrogen; coal-derived liquid fuels; fuels (other than alcohols) derived from biological materials; electricity (including electricity from solar energy); and any other fuel the Secretary determines, by rule, is substantially not petroleum and would yield substantial energy security benefits and substantial environmental benefits."

Alternative-Fuel Vehicle: A vehicle that has the capability of being fueled by an alternative fuel. This category of vehicle includes dual-fuel, bi-fuel and flexible-fuel, as well as dedicated vehicles.

Bi-Fuel Vehicle: A vehicle with the capability of using two separate fuel systems, one that can be operated on a conventional fuel and one that can be operated on an alternative fuel.

Clean Air Act Amendments of 1990 (CAAA): Public Law No. 105-549. The 1990 amendments to the Clean Air Act of 1970 include provisions that require gasoline refiners to reformulate their gasolines to meet more stringent emissions standards. In cities that do not meet Federal air-quality requirements set forth in the 1990 amendments, gasolines must be reformulated during certain months, when air pollution levels are most serious. The regulations also require certain fleet operators in 22 cities nationwide to use clean fuel vehicles.

Compressed Natural Gas (CNG): Natural gas that has been condensed under high pressures, typically between 2,000 and 3,600 psi, and expands when released from a container; used as an alternative fuel for motor vehicles.

Converted Vehicle: A vehicle originally designed to operate on gasoline that has been modified to run on an alternative fuel.

Dedicated Vehicle: A motor vehicle that operates solely on one fuel.

Dual-Fuel Vehicle: Vehicles designed to run on a combination of an alternative fuel such as CNG or LPG, and a conventional fuel, such as gasoline or diesel. Dual-fuel systems are used mostly in heavy-duty or diesel engines. The vehicle generally has two separate fuel tanks, from which both fuels are injected into the combustion chamber simultaneously.

Electric Vehicle: A vehicle powered by electricity. Generally, the electricity is provided by batteries, which store electricity, but may also be provided by photovoltaic cells or a fuel cells, which convert light or chemical energy to electricity.

Energy Policy Act of 1992 (EPACT): Public Law 104-486. A broad energy act with several titles that deal with alternative transportation fuels. EPACT includes provisions for accelerating purchases of alternative-fuel vehicles by Federal fleets, certain urban area State government fleets, the fleets of providers of alternative fuels, and under certain conditions, private and municipal fleets.

Fleet Vehicle: Any on-road motor vehicle owned or operated by the reporting company and used in the normal operations of the company. Fleet vehicles include gasoline and/or diesel-powered vehicles and alternative-fuel vehicles,

Flexible-Fuel Vehicle: A vehicle that has the ability to operate on a mixture of an alternative fuel and gasoline or diesel or to operate exclusively on an alternative fuel or gasoline or diesel.

Gross Vehicle Weight (GVW): The weight of the empty vehicle plus the weight of the maximum load that would be carried on the vehicle. 
Heavy Trucks: A truck weighing more than $26,000 \mathrm{lbs}$. GVW. If the reporting company was unable to estimate the weight of a fleet vehicle, the company's best assessment of the vehicle size classification was acceptable.

Light-Duty Vehicles: Those vehicles (passenger cars, trucks, vans, and sport/utility vehicles) that weigh no more than $8,500 \mathrm{lbs}$. GVW. If the reporting company was unable to estimate the weight of a fleet vehicle, the company's best assessment of the vehicle size classification was acceptable.

Light Trucks: A truck or van weighing between 8,501 and $14,000 \mathrm{lbs}$. GVW.

Liquefied Natural Gas (LNG): Natural gas that has been condensed to a liquid, typically by cryogenically cooling the gas; used as an alternative fuel for motor vehicles.

Liquefied Petroleum Gas (LPG): A hydrocarbon and colorless gas byproduct of natural gas production, produced from crude oil; used as an alternative fuel for motor vehicles.

Medium Trucks: A truck or van weighing between $14,001 \mathrm{lbs}$. GVW and $26,000 \mathrm{lbs}$. GVW. If the reporting company was unable to estimate the weight of a fleet vehicle, the company's best assessment of the vehicle size classification was acceptable.

Metropolitan Area: A metropolitan statistical area or consolidated metropolitan statistical area, as established by the Bureau of the Census, with a 1980 population of more than 250,000 .

Multifuel Vehicle: Any alternative-fuel vehicle capable of operating on more than one fuel. This term is meant to encompass bi-fuel, flexible-fuel; dual-fuel, and hybrid vehicles.

Municipal Fleets: Fleets that are part of local government (i.e., are not part of Federal or State government). These fleets provide services to particular political jurisdictions below the State level of government.

Nonattainment Area: A region determined by population density in accordance with the U.S. Census Bureau that exceeds minimum acceptable national air quality standards for one or more air pollutants regulated under the Clean Air Act.

Private Fleet: Any nonresidential business fleet, i.e., a fleet that is not a unit of government:

Private Fueling Facility: A fueling facility that normally services only fleets and is not open to the general public.

Propane: See Liquefied Petroleum Gas (LPG).

Public Fueling Facility: A fueling facility that is open to the general public. 